JOINT TRANSPORTATION RESEARCH PROGRAM

FHWA/IN/JTRP-2009/27

Final Report

VERIFICATION OF LRFD BRIDGE DESIGN AND

ANALYSIS SOFTWARE FOR INDOT

Amit H. Varma

Jungil Seo

August 2009 


\section{TECHNICAL Summary}

INDOT Research

Technology Transfer and Project Implementation Information

TRB Subject Code: 25-1 Bridges

Publication No.: FHWA/IN/JTRP-2009/27, SPR-3023

August 2009

Final Report

\section{Verification of LRFD Bridge Design and Analysis Software for INDOT}

\section{Introduction}

Bridge design is an elaborate process involving detailed calculations, decisions, and code checks. For this reason, bridge designers rely heavily on bridge analysis and design software to generate values required for their design. It is not safe to adopt the computed values without validating the bridge design software. This validation can be performed using corresponding hand calculations, which can be very time consuming process for even a single bridge. Hence, more efficient and comprehensive validation process is needed.

Baker el al (2003) developed Process 12-50 as part of a TRB research project. The significance of the process is in processing the computational results from the bridge design software. The results are compiled into a unique format so that they can be used to import and filter the results in database management program. The Indiana Department of Transportation (INDOT) has funded this research project to implement Process 12-50 for bridges and software (CONSPAN and MERLIN-DASH) used commonly in Indiana. The INDOT study included both concrete and composite steel I-girder bridges. The evaluation and verification of prestressed concrete bridge design software (CONSPAN) was presented earlier (Choe et al. 2009). This report presents the evaluation and verification of composite steel bridge design software (MERLINDASH).

\section{Findings}

A test-bed of twenty one bridges was developed with the guidance from an Indiana Department of Transportation appointed research advisory panel (RAP). The test-bed included five simplespan and sixteen multi-span bridge superstructures. An indigenous computer program (PURDUE CSBD) was developed to implement the bridge design calculations specified in the AASHTO LRFD specifications, which is currently endorsed by the INDOT bridge design manual. Both MERLIN-DASH and PURDUE CSBD were used to generate design calculation results for the complete testbed of bridges. The output from both computer programs is compared to identify assumptions and discrepancies between MERLIN-DASH and the AASHTO LRFD specifications.
These comparisons indicate excellent agreement between the results from both programs for: (1) moments, (2) shears, (3) stresses, (4) deflections, (5) flexural strength and all relevant parameters, (6) shear strength and all relevant parameters, and (7) shear connector related parameters. The test-bed of bridge structures and the PURDUE CSBD program are recommended for evaluating and verifying other bridge design software. The comparison also shows good agreement between maximum live load deflections computed by MERLIN-DASH and PURDUE CSBD if the correct reduction factor for the force effect $\left(m_{\text {red }}\right)$ is utilized. The factor is determined based on the value of ADTT and it appears that MERLIN-DASH does not utilize ADTT properly. 


\section{Implementation}

This project has implemented NCHRP 12-50 to validate bridge design software: (i) CONSPAN, and (ii) MERLIN-DASH. In the process, we have developed: (i) prestressed concrete bridge database, (ii) prestressed concrete bridge design evaluation program, (iii) steel bridge database, and (iv) steel bridge design evaluation program. Each of these components and the validation of software (CONSPAN and MERLIN-DASH) require annual maintenance and updating based on interim revisions of AASHTO LRFD Bridge Design Standards, and newer versions of the software.

\section{Contacts}

For more information:

Prof. Amit Varma

Principal Investigator

School of Civil Engineering

Purdue University

West Lafayette IN 47907

Phone: (765) 496-3419

E-mail: ahvarma@purdue.edu
This annual maintenance and updating should be implemented through Dr. McCullouch's office at Purdue University. There should be part time funding (1/2 Research Assistantship) for a structures M.S. degree student to work with the PI (Dr. Varma) and Dr. MuCullouch to update the databases, programs, and verifications each year. Thus, the verified databases, programas, and verified versions of bridge design software will be available from Dr. McCullouch's office each year. This will allow INDOT bridge designers and consultants to use the validated software for design without requiring additional verification work.

\author{
Indiana Department of Transportation \\ Office of Research and Development \\ 1205 Montgomery Street \\ P.O. Box 2279 \\ West Lafayette, IN 47906 \\ Phone: (765) 463-1521 \\ Fax: (765) 497-1665

\section{Purdue University} \\ Joint Transportation Research Program \\ School of Civil Engineering \\ West Lafayette, IN 47907-1284 \\ Phone: (765) 494-9310 \\ Fax: (765) 496-7996 \\ E:mail: jtrp@ecn.purdue.edu
}


Final Report

FHWA/IN/JTRP-2009/27

\title{
VERIFICATION OF LRFD BRIDGE DESIGN AND ANALYSIS SOFTWARE FOR INDOT
}

\author{
by \\ Amit H. Varma \\ Principal Investigator \\ Assistant Professor \\ Jungil Seo \\ Graduate Student \\ Research Assistant \\ School of Civil Engineering \\ Purdue University \\ Joint Transportation Research Program \\ Project No. C-36-56GGG \\ File No. 7-4-84 \\ SPR-3023
}

\author{
Prepared in Cooperation with the \\ Indiana Department of Transportation \\ and the U.S. Department of Transportation \\ Federal Highway Administration
}

The contents of this report reflect the views of the authors, who are responsible for the facts and the accuracy of the data presented herein. The contents do not necessarily reflect the official views or policies of the Indiana Department of Transportation or the Federal Highway Administration at the time of publication. The report does not constitute a standard, specification, or regulation.

\author{
Purdue University \\ West Lafayette, IN 47906 \\ August 2009
}


TECHNICAL REPORT STANDARD TITLE PAGE

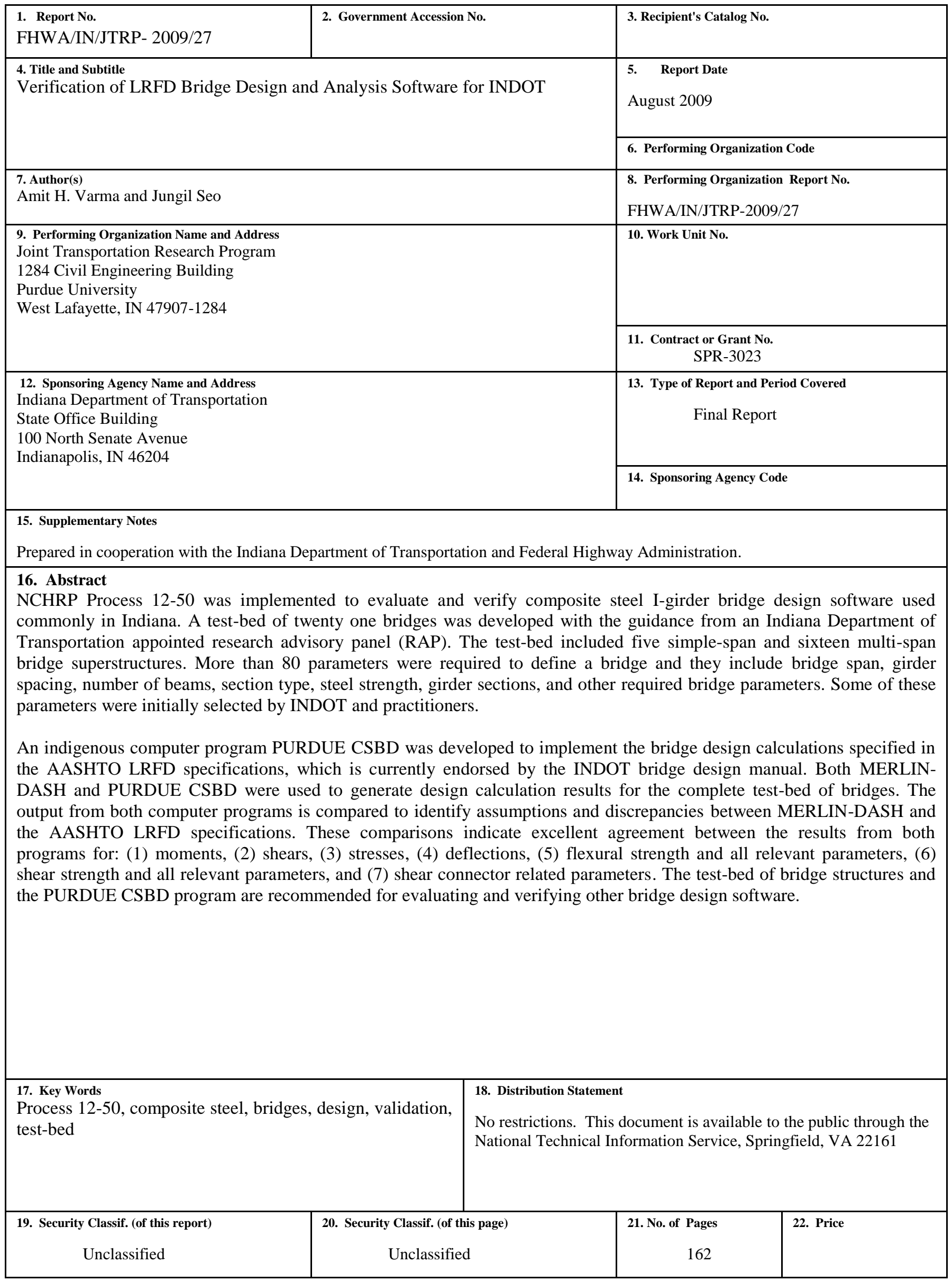




\section{TABLE OF CONTENTS}

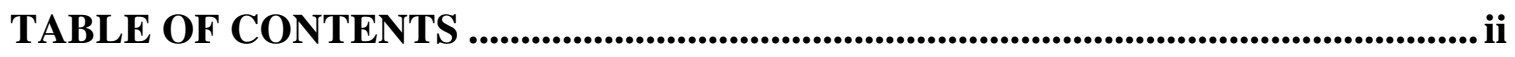

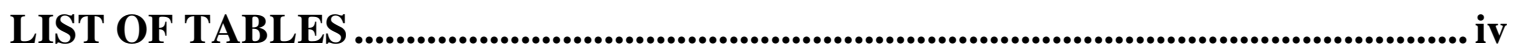

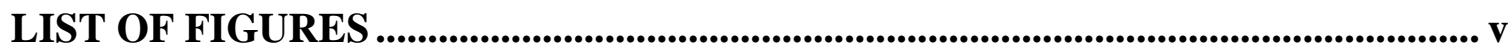

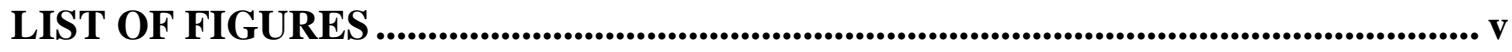

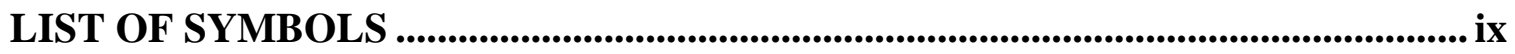

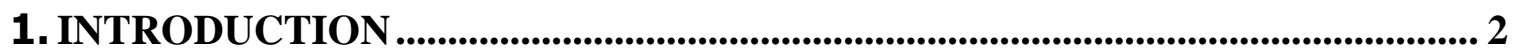

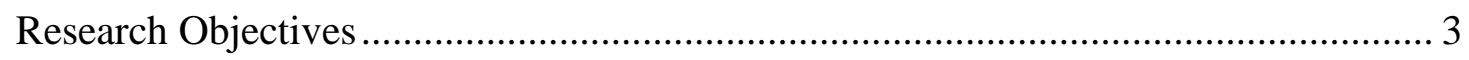

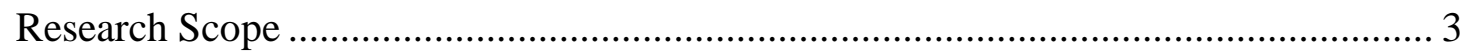

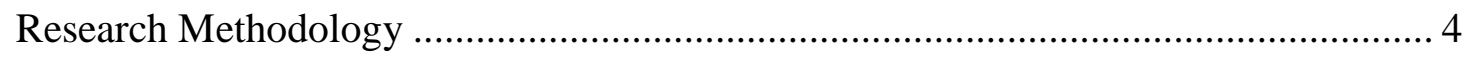

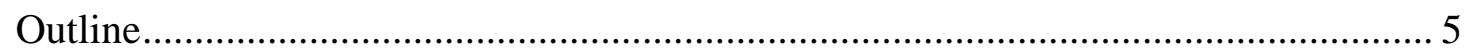

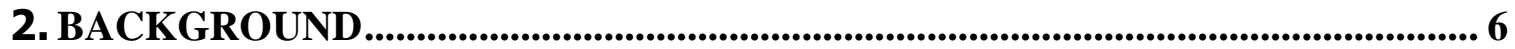

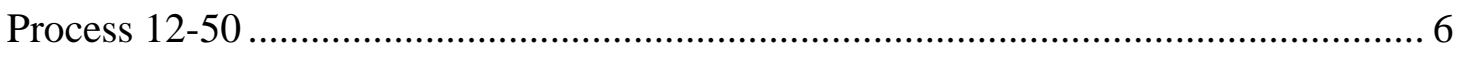

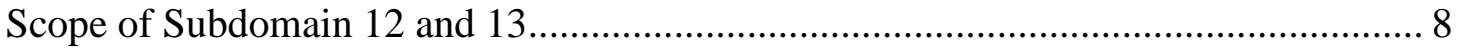

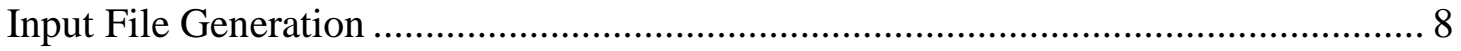

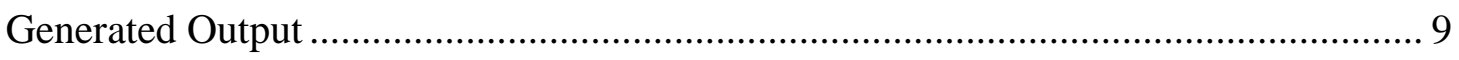

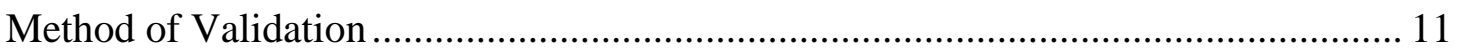

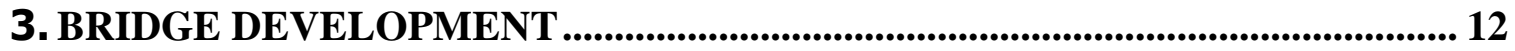

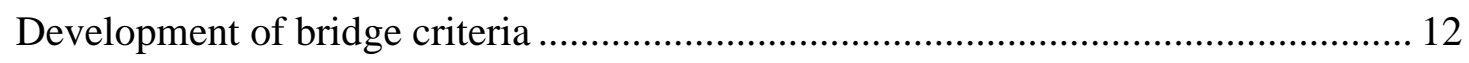

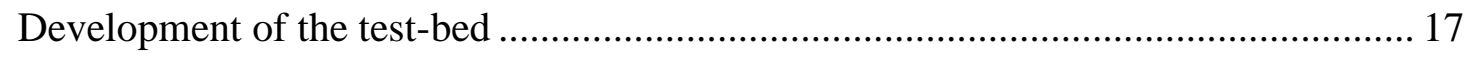

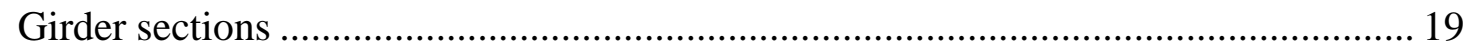

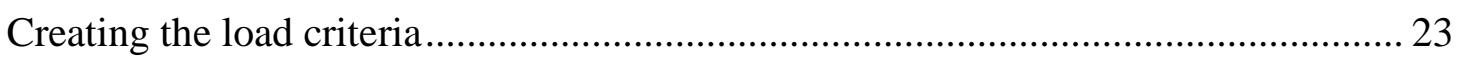

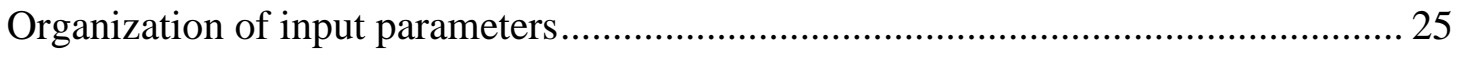

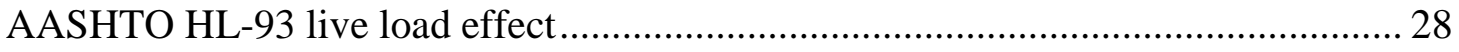

Computer program's process for generation input files........................................ 30

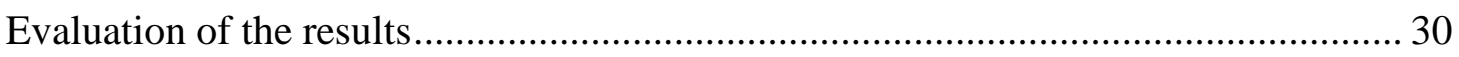

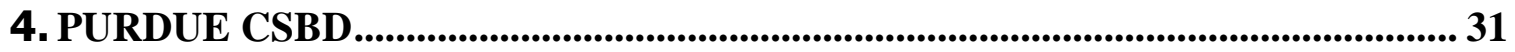

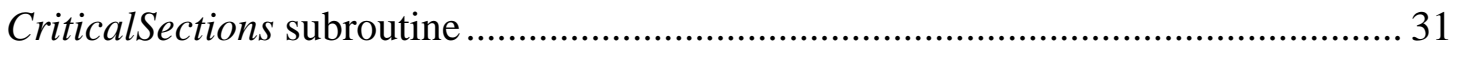

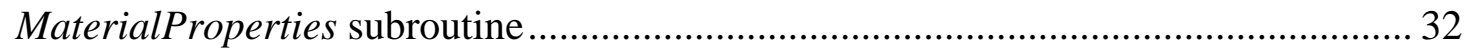




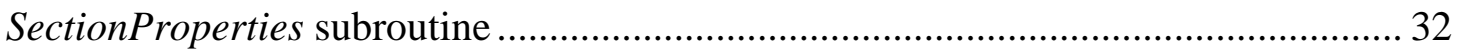

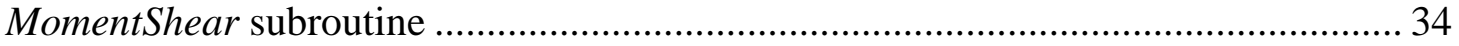

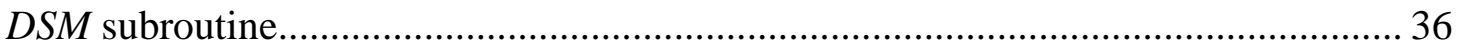

PlasticMomentCapacity subroutine .................................................................. 42

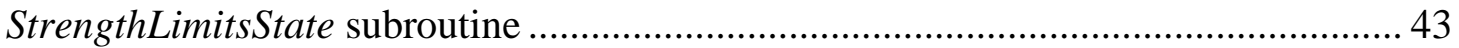

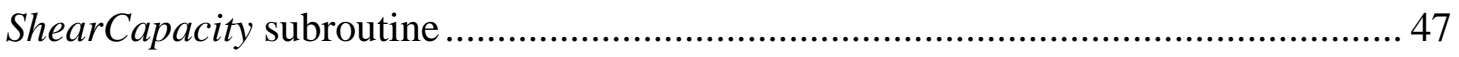

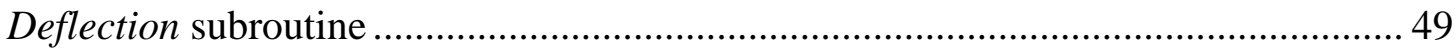

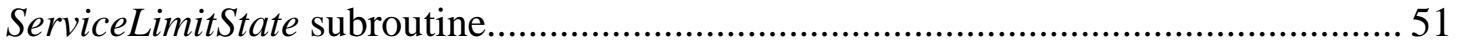

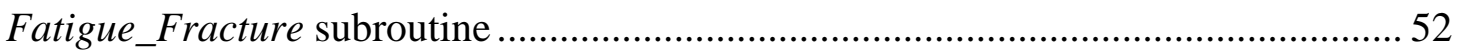

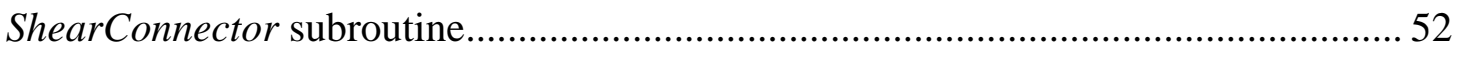

5. ANALYSIS OF RESULTS .................................................................................5 54

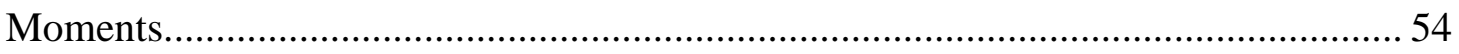

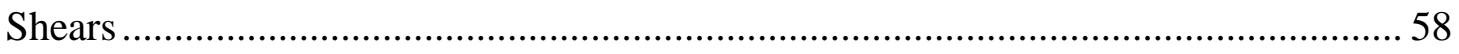

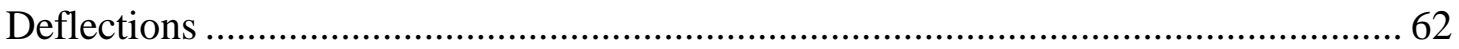

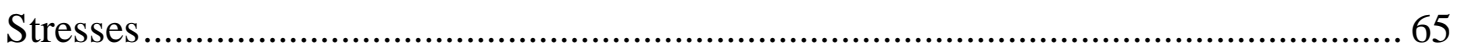

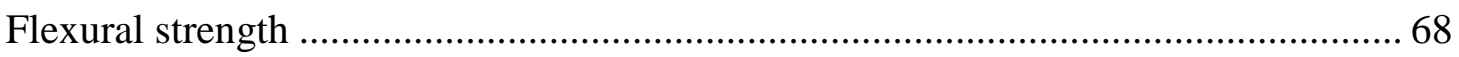

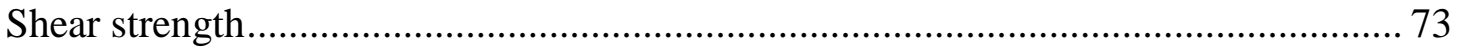

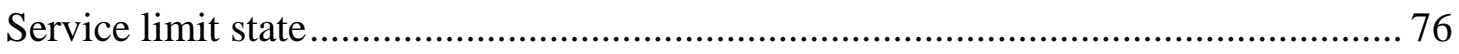

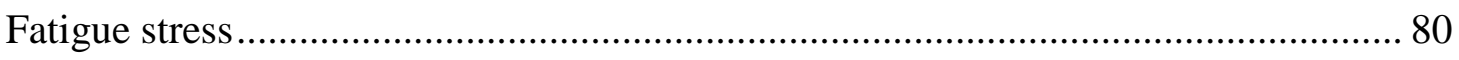

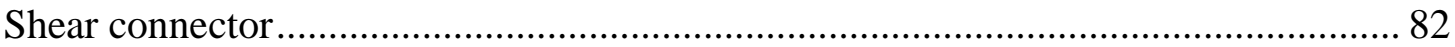

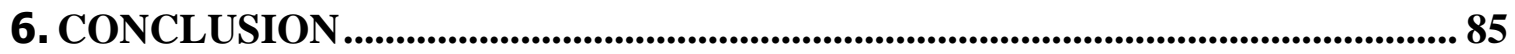

LIST OF REFERENCES .................................................................................. 87

Appendix A

Appendix B .................................................................................................................. 92

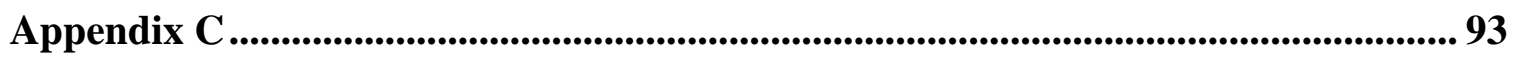

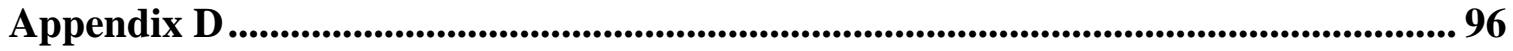




\section{LIST OF TABLES}

Table

Page

Table 2.1 NCHRP 12-50 Report IDs by description (Baker et al., 2003) ................................ 10

Table 2.2 NCHRP 12-50 Report IDs by Subdomain ........................................................ 10

Table 3.1 Input parameters relating to the global geometry of composite steel I-girder bridges . 13

Table 3.2 Input parameters relating to the local geometry of composite steel I-girder bridges ... 13

Table 3.3 Input parameters relating to the steel material properties ........................................ 14

Table 3.4 Input parameters relating to the section properties of the steel reinforcement ............ 14

Table 3.5 Input parameters relating to strength load modifiers ............................................ 14

Table 3.6 Input parameters relating to loads applied to composite steel I-girder bridges ........... 15

Table 3.7 Miscellaneous parameters of composite steel I-girder bridges................................. 15

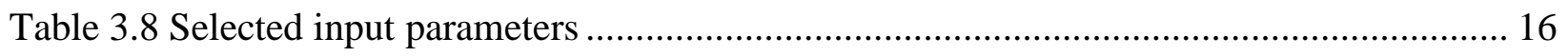

Table 3.9 Finalized bridge cases for the test-bed........................................................ 18

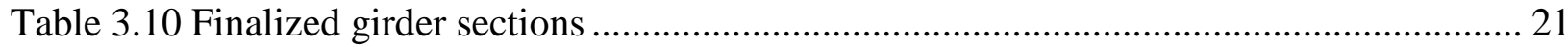

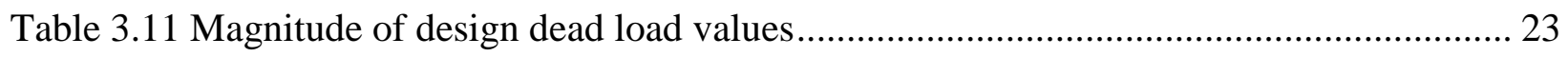

Table 5.1 Comparison of the maximum deflection due to live load computed by MERLIN-

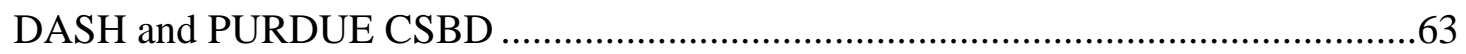

Table 5.2 Comparison of $C_{b}$ and $R_{h}$ computed by MERLIN-DASH and PURDUE CSBD $($ BridgeID $=11)$

Table 5.3 Comparison of $V_{s r}$ and $p_{\text {maxall }}$ computed by MERLIN-DASH and PURDUE CSBD $($ BridgeID $=18)$ 


\section{LIST OF FIGURES}

Figure

Page

Figure 2.1 Sample format of NCHRP 12-50 Output ......................................................... 9

Figure 2.2 Example of Plots for Graphical Comparison......................................................... 11

Figure 3.1 Configuration of plate girder section of simple span bridge .................................... 20

Figure 3.2 Configuration of plate girder section of two span bridge......................................... 20

Figure 3.3 Configuration of plate girder section three span bridge ............................................ 20

Figure 3.4 Configuration of HL-93 design truck ……….................................................... 24

Figure 3.5 SteelBridgeInput worksheet (a) conceptual (b) actual .............................................. 26

Figure 3.6 RSS worksheet (a) conceptual (b) actual................................................................. 27

Figure 3.7 Conceptual process of importing live load effects from the result files of the

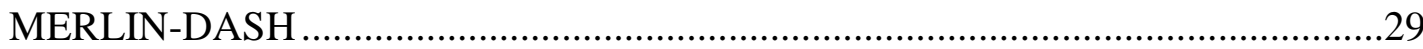

Figure 4.1 Example of numbering of nodes and elements for two span bridges .......................... 39

Figure 4.2 Example of numbering of degree of freedom in the global coordinate system for two

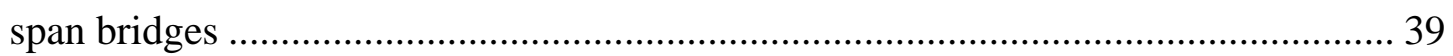

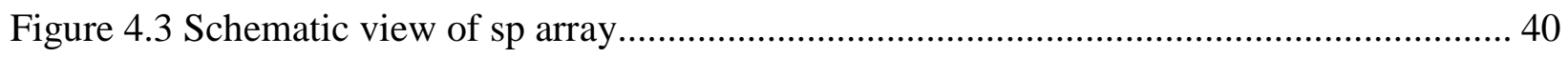

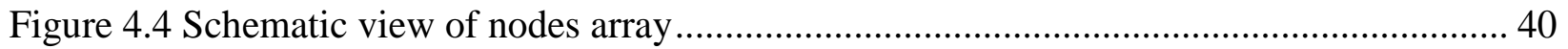

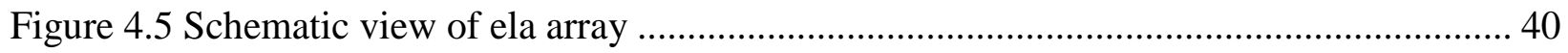

Figure 4.6 The Schur complement of a matrix block ................................................................. 41

Figure 4.7 The inverse of the Schur complement of a matrix block............................................. 41

Figure 5.1 Comparison of Service I Moment (BridgeID = 10) ............................................... 55

Figure 5.2 Comparison of Service II Moment (BridgeID = 10) ……..................................... 55

Figure 5.3 Comparison of Strength I Moment (BridgeID = 10) ................................................... 56

Figure 5.4 Comparison of Strength II Moment (BridgeID = 10) ……….................................. 56

Figure 5.5 Comparison of Strength IV Moment (BridgeID = 10) ………................................. 57

Figure 5.6 Comparison of Fatigue Moment (BridgeID = 10) …………………....................... 57

Figure 5.7 Comparison of Service I Shear (BridgeID = 13) ……........................................... 59

Figure 5.8 Comparison of Service II Shear (BridgeID = 13) ……......................................... 59

Figure 5.9 Comparison of Strength I Shear (BridgeID = 13) …….......................................... 60

Figure 5.10 Comparison of Strength II Shear (BridgeID = 13) .............................................. 60

Figure 5.11 Comparison of Strength IV Shear (BridgeID = 13) ................................................... 61 
Figure 5.12 Comparison of Fatigue Shear (BridgeID = 13)

Figure 5.13 Comparison of deflection due to dead load including DC1, DC2, and DW

$$
(\text { BridgeID }=16)
$$

Figure 5.14 Normalized maximum live load deflections due to live loads .....

Figure 5.15 Comparison of stresses at top of slab under Service I with positive live load

$$
(\text { BridgeID }=19)
$$

Figure 5.16 Comparison of stresses at top flange under Service I with positive live load

$$
(\text { BridgeID }=19)
$$

Figure 5.17 Comparison of stresses at bottom flange under Service I with positive live load

$$
(\text { BridgeID }=19) \text {. }
$$

Figure 5.18 Comparison of moment capacity in positive flexure (BridgeID $=11)$. .70

Figure 5.19 Comparison of the moment gradient factor, $C_{b}$, of the non-composite section

$$
(\text { BridgeID }=11)
$$

Figure 5.20 Comparison of the hybrid factor, $R_{h}$, of the non-composite section (BridgeID $=$ 11).

Figure 5.21 Comparison of load shedding factor, $R_{b}$, of the non-composite section (BridgeID $=11)$. .71

Figure 5.22 Comparison of the nominal compression flange local buckling flexural resistance, $F n c_{F L B}($ BridgeID $=11)$

Figure 5.23 Comparison of the nominal compression lateral torsional buckling flexural resistance, $F n c_{L T B}($ BridgeID $=11)$

Figure 5.24 Comparison of the plastic shear capacity, $V_{p}($ BridgeID $=20)$

Figure 5.25 Comparison of the ratio of the shear buckling resistance to the shear yield strength for unstiffened web, $C_{\text {unstiffened }}($ BridgeID $=20)$

Figure 5.26 Comparison of the nominal shear resistance of stiffened section, $V_{n}$ (BridgeID = 20)

Figure 5.27 Comparison of flange at the top flange stress due to Service II load (BridgeID = 21)

Figure 5.28 Comparison of flange stress at the bottom flange due to Service II load $($ BridgeID $=21)$ 
Figure

Figure 5.29 Comparison of compression flange stress due to Service II load (BridgeID = 21)....78

Figure 5.30 Comparison of the limiting flange stress for the top flange (BridgeID $=21)$...........78

Figure 5.31 Comparison of the limiting flange stress for the bottom flange (BridgeID = 21) ......79

Figure 5.32 Comparison of the nominal bend buckling resistance for webs for compression flange stress check (BridgeID $=21)$ .79

Figure 5.33 Comparison of the fatigue stress range of the top flange (BridgeID = 9) $\ldots \ldots \ldots \ldots \ldots \ldots . . . . . .11$

Figure 5.34 Comparison of the fatigue stress range of the bottom flange (BridgeID = 9) ...........81

Figure 5.35 Comparison of horizontal fatigue shear range per unit length (BridgeID = 18) $\ldots \ldots . . .84$

Figure 5.36 Comparison of maximum allowable pitch (BridgeID = 18) .............................. 84

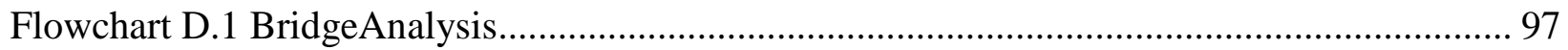

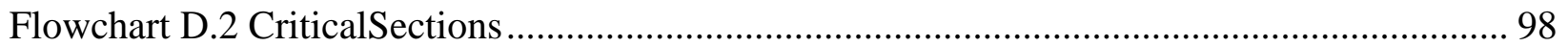

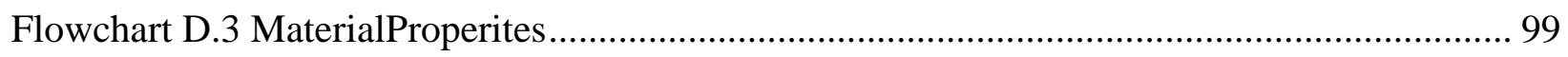

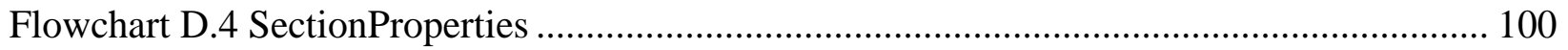

Flowchart D.5 SectionProperties - PGsectionProperties -............................................... 101

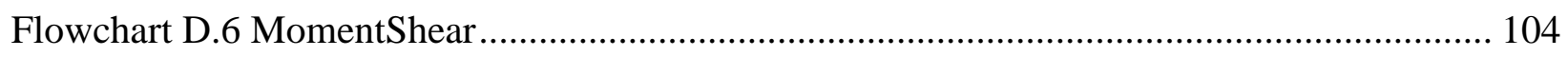

Flowchart D.7 MomentShear - MomentArray.................................................................. 105

Flowchart D.8 MomentShear - SumMomentShear ........................................................ 106

Flowchart D.9 MomentShear - ShearArray ............................................................... 107

Flowchart D.10 MomentShear - Loadcombination......................................................... 108

Flowchart D.11 MomentShear - Stresscombination .................................................... 110

Flowchart D.12 PlasticMomentCapacity ................................................................... 112

Flowchart D.13 PlasticMomentCapacity - Madfunct ....................................................... 114

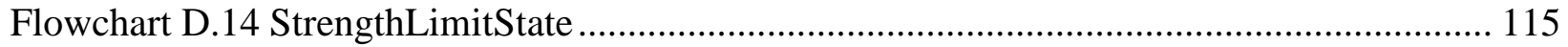

Flowchart D.15 StrengthLimitState - SectionProportionCheck ....................................... 117

Flowchart D.16 StrengthLimitState - FLBLTBCategory ............................................... 118

Flowchart D.17 StrengthLimitState - FLBandLTBResistance ............................................. 119

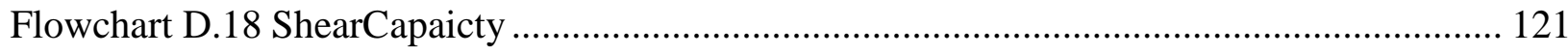

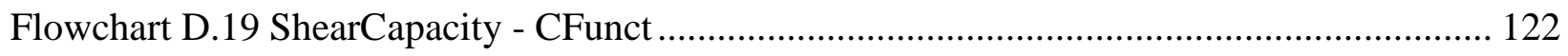

Flowchart D.20 ShearCapacity - VnIntPanel................................................................. 123

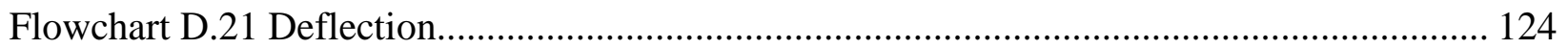


Figure Page

Flowchart D.22 Deflection - DeltaArray ....................................................................... 125

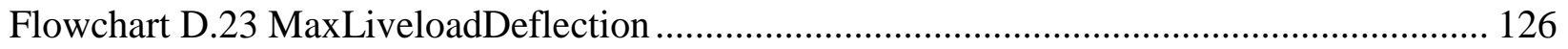

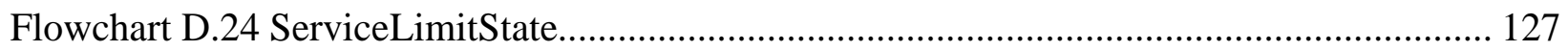

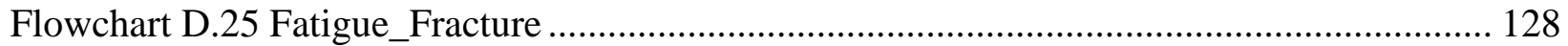

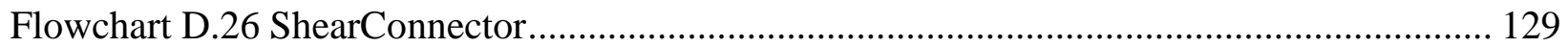

Flowchart D.27 ShearConnector_QFunct................................................................... 130

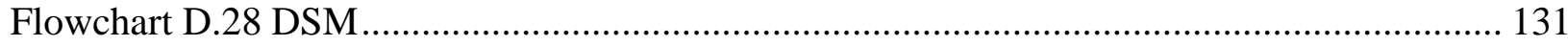

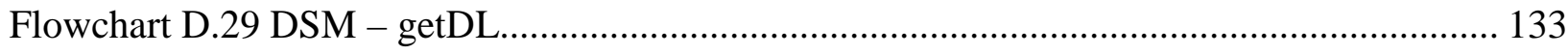

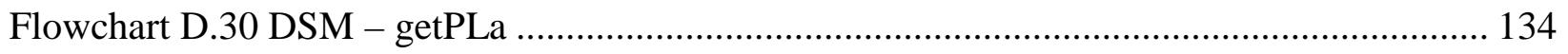

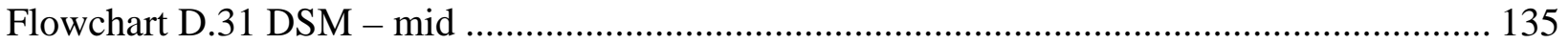

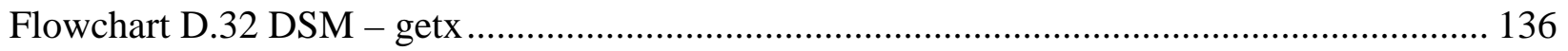

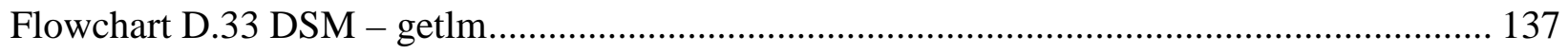

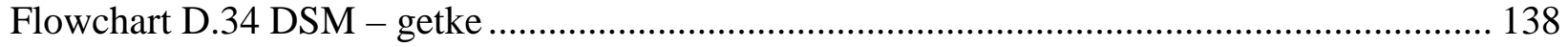

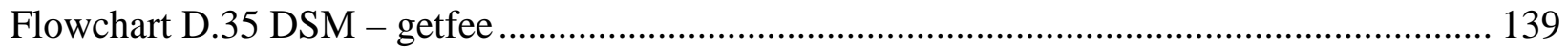

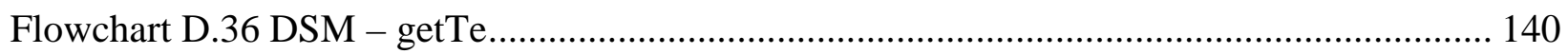

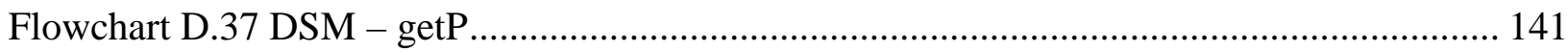

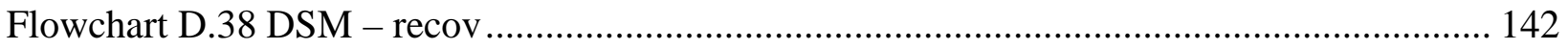




\section{LIST OF SYMBOLS}

\section{Symbol Description}

ADTT Average daily truck traffic over the design life

$A D T T_{S L} \quad$ Single-lane ADTT

$A_{f n} \quad$ Sum of the flange area and the area of any cover plates on the side of the neutral axis corresponding to $D_{n}$ in a hybrid section $\left(\mathrm{in}^{2}\right)$

$A_{g} \quad$ Gross cross-section area of the non-composite section (in ${ }^{2}$ )

$A_{L T} \quad$ Cross-section area of the long term-composite section (in $\left.{ }^{2}\right)$

$A_{r t} \quad$ Area of the top layer of longitudinal reinforcement within the effective concrete deck width $\left(\mathrm{in}^{2}\right)$

$A_{s c} \quad$ Cross-sectional area of a stud shear connector $\left(\right.$ in $\left.^{2}\right)$

$A_{S T} \quad$ Cross-section area of the short-term composite section (in $\left.{ }^{2}\right)$

$A_{\text {STfat }} \quad$ Cross-section area of the short-term composite section for fatigue analysis $\left(\mathrm{in}^{2}\right)$

$a_{w c} \quad$ Ratio of two times the web area in compression to the area of the compression flange

$b_{\text {barrier }} \quad$ Width of traffic barrier (ft.)

$b_{\text {bridge }} \quad$ Bridge width (ft.)

$b_{e} \quad$ Effective width of the concrete deck (in.)

$b_{f b o t} \quad$ Width of bottom flange (in.)

$b_{f t o p} \quad$ Width of top flange (in.)

baunch Width of haunch (in.)

$b_{\text {overhang }} \quad$ Width of overhang (ft.)

$b_{\text {roadway }} \quad$ Width of clear roadway (ft.)

$C \quad$ Ratio of the shear-buckling resistance to the shear specified minimum yield strength

$C_{b} \quad$ Moment gradient modifier

D Total depth of the steel section (in.) 


\section{Symbol Description}

$D_{c} \quad$ Depth of the web in compression in the elastic range (in.)

$d_{c} \quad$ Distance from the plastic neutral axis to the mid-thickness of the compression flange used to compute the plastic moment (in.)

DCl Permanent load acting on the non-composite section

DC2 Permanent load acting on the long-term composite section

$D_{c p} \quad$ Depth of the web in compression at the plastic moment (in.)

$D_{n} \quad$ Larger of the distances from the elastic neutral axis of the cross-section to the inside face of either flange in a hybrid section, or the distance from the neutral axis to the inside face of the flange on the side of the neutral axis where yielding occurs first when the neutral axis is at the mid-depth of the web (in.)

$d_{o} \quad$ Transverse stiffener spacing in interior panels(in.)

$d_{\text {oend }} \quad$ Transverse stiffener spacing in end panels (in.)

$D_{p} \quad$ Distance from the top of the concrete deck to the neutral axis of the composite section at the plastic moment (in.)

$d_{r b} \quad$ Distance from the plastic neutral axis to the centerline of the bottom layer of longitudinal concrete deck reinforcement used to compute the plastic moment (in.)

$d_{r t} \quad$ Distance from the plastic neutral axis to the centerline of the top layer of longitudinal concrete deck reinforcement used to compute the plastic moment (in.)

$d_{s c} \quad$ Diameter of a shear connector (in.)

$D_{t} \quad$ Total depth of the composite section (in.)

$d_{t} \quad$ Distance from the plastic neutral axis to the midthickness of the tension flange used to compute the plastic moment (in.)

DW Wearing surface dead load acting on the long-term composite section

$d_{w} \quad$ Distance from the plastic neutral axis to the middepth of the web used to compute the plastic moment (in.)

$d_{\text {web }} \quad$ Web depth (in.)

del $l_{g} \quad$ Deflection due to the self weight of a girder (in.)

$d e l_{\text {slab }} \quad$ Deflection due to the slab deck weight (in.)

del haunch Deflection due to the concete haunch weight (in.) 


\section{Symbol Description}

$\begin{array}{ll}d e l_{f o r m} & \text { Deflection due to the form work weight (in.) } \\ d e l_{D C 1} & \text { Deflection due to DC1 load (in.) } \\ d e l_{D C 2} & \text { Deflection due to DC2 load (in.) } \\ d e l_{D W} & \text { Deflection due to DW load (in.) } \\ d e l_{D L} & \text { Deflection due to dead load only (in.) } \\ d e l_{\text {maxTruck }} & \text { The maximum live load deflection due to truck loading only(in.) } \\ d e l_{\text {maxLane }} & \text { The maximum live load deflection due to lane load only (in.) } \\ d e l_{L L m a x} & \text { The maximum live load deflection (in.) } \\ E_{c} & \text { Modulus of elasticity of concrete (ksi) } \\ E_{s} & \text { Modulus of elasticity of steel (ksi) }\end{array}$

$f_{0} \quad$ Stress due to the factored loads without consideration of flange lateral bending at a brace point opposite to the one corresponding to $f_{2}$, calculated from the moment envelope value that produces the largest compression at this point in the flange under consideration, or the smallest tension if this point is never in compression; positive for compression and negative for tension (ksi)

$f_{1} \quad$ Stress at the opposite end of an unbraced length from $f_{2}$ representing the intercept of the most critical assumed linear stress distribution through either $f_{2}$ and $f_{\text {mid }}$, or through $f_{2}$ and $f_{0}$, taken as $2 f_{\text {mid }^{-}} f_{2} \geq f_{0}$ (ksi)

$f_{2} \quad$ Largest compressive stress due to the factored loads without consideration of lateral bending at either end of an unbraced length calculated from the critical moment envelope value; always taken as positive unless stress is zero or tensile at both ends of the unbraced length in which case $f_{l}$ is taken as zero (ksi)

$f_{\text {bfserII }} \quad$ Bottom-flange stress due to Service II load calculated without consideration of flange lateral bending (ksi)

$f_{b u} \quad$ Largest value of the compressive stress throughout the unbraced length in the flange under consideration, calculated without consideration of flange lateral bending (ksi)

$f^{\prime}{ }_{c} \quad$ Minimum specified 28-day compressive strength of concrete (ksi)

$f_{\text {cserII }} \quad$ Compression-flange stress due to Service II load calculated without consideration of flange lateral bending (ksi) 


\section{Symbol Description}

$f_{D C 1} \quad$ Compression-flange stress caused by the factored permanent load applied before the concrete deck has hardened or is made composite, calculated without consideration of flange lateral bending (ksi)

$f_{D C 2} \quad$ Compression-flange stress caused by the factored permanent load acting on the long-term composite section, calculated without consideration of flange lateral bending (ksi)

$f_{f} \quad$ Flange stress due to Service II load calculated without consideration of flange lateral bending (ksi)

$f_{\text {fat } T} \quad$ Fatigue flange stress at the top flange $(\mathrm{ksi})$

$f_{\text {fat } B} \quad$ Fatigue flange stress at the bottom flange (ksi)

$f_{l} \quad$ Flange lateral bending stress (ksi)

FLB flange local buckling

$f_{L L+I M} \quad$ Compression-flange stress caused by the factored vehicular live load plus impact acting on the short-term composite section, calculated without consideration of flange lateral bending (ksi)

$f_{\text {mid }} \quad$ Stress due to the factored loads without consideration of flange lateral bending at the middle of the unbraced length of the flange under consideration, calculated from the moment envelope value that produces the largest compression at this point, or the smallest tension if this point is never in compression (ksi)

$F_{n} \quad$ Nominal flexural resistance of a flange (ksi)

$f_{n} \quad$ Largest of the specified minimum yield strengths of each component included in the calculation of $\mathrm{A}_{\mathrm{fn}}$ for a hybrid section when yielding occurs first in one of the components, or the largest of the elastic stresses in each component on the side of the neutral axis corresponding to $\mathrm{D}$, at first yield on the opposite side of the neutral axis (ksi)

$F_{n c} \quad$ Nominal flexural resistance of a compression flange (ksi)

$F_{n c F L B} \quad$ Nominal compression-flange local buckling flexural resistance (ksi)

$F_{n c L T B} \quad$ Nominal compression-flange lateral torsional buckling resistance (ksi)

$F_{n t} \quad$ Nominal flexural resistance of a tension flange (ksi)

$f_{t} \quad$ Stress due to the factored loads on the gross area of a tension flange calculated without consideration of flange lateral bending (ksi); sum of the various tensionflange flexural stresses caused by the different loads, i.e., DCI, DC2, DW and LL+IM, acting on their respective sections (ksi) 


\section{Symbol Description}

$f_{t \text { fserII }} \quad$ Top-flange stress due to Service I1 load calculated without consideration of flange lateral bending (ksi)

$F_{u} \quad$ Specified minimum tensile strength of steel (ksi)

$F_{y c} \quad$ Specified minimum yield strength of a compression flange (ksi)

$F_{y f} \quad$ Specified minimum yield strength of a flange (ksi)

$F_{y g} \quad$ Specified minimum yield strength of steel for additional elements(ksi)

$F_{y r} \quad$ Compression-flange stress at the onset of nominal yielding within the crosssection, including residual stress effects but not including compression-flange lateral bending, taken as the smaller of $0.7 \mathrm{~F}_{\mathrm{yc}}$ and $\mathrm{F}_{\mathrm{yw}}$, but not less than $0.5 \mathrm{~F}_{\mathrm{yc}}(\mathrm{ksi})$

$F_{y r e} \quad$ Specified minimum yield strength of a reinforcement steel bar (ksi)

$F_{y t} \quad$ Specified minimum yield strength of a tension flange (ksi)

$F_{y w} \quad$ Specified minimum yield strength of a web (ksi)

$h_{\text {beam }} \quad$ Height of the composite section (in.)

$h_{\text {beamNC }} \quad$ Height of the non-composite section (in.)

I haunch $\quad$ Moment of inertia of the haunch (in4)

IM Dynamic load allowance

$I M_{f a t} \quad$ Dynamic load allowance for fatigue analysis

$I_{\text {slab }} \quad$ Moment of inertia of the slab deck (in4)

$I_{\text {web }} \quad$ Moment of inertia of the web of a steel section about the vertical axis in the plane of the web (in4)

$I_{x g} \quad$ Moment of inertia of the non-composite section about x-axis $\left(\mathrm{in}^{4}\right)$

$I_{x g f a t} \quad$ Moment of inertia of the non-composite section about x-axis for fatigue analysis $\left(\right.$ in $\left.^{4}\right)$

$I_{x L T} \quad$ Moment of inertia of the long term-composite section about $\mathrm{x}$-axis $\left(\mathrm{in}^{4}\right)$

$I_{x S T} \quad$ Moment of inertia of the short-term composite section about x-axis $\left(\right.$ in $\left.^{4}\right)$

IxSTfat Moment of inertia of the short-term composite section about $\mathrm{x}$-axis for fatigue analysis $\left(\mathrm{in}^{4}\right)$ 


\section{Symbol Description}

$I_{y c} \quad$ Moment of inertia of the compression flange of a steel section about the vertical axis in the plane of the web (in.4)

$I_{y t} \quad$ Moment of inertia of the tension flange of a steel section about the vertical axis in the plane of the web (in4)

$k \quad$ Shear-buckling coefficient for webs

$L \quad$ Effective span length (ft.)

$L_{b} \quad$ Unbraced length (ft.)

LL $\quad$ Vehicular live load

$L_{p} \quad$ Limiting unbraced length to achieve the nominal flexural resistance of $\mathrm{R}_{\mathrm{b}} \mathrm{R}_{\mathrm{h}} \mathrm{F}_{\mathrm{yc}}$ under uniform bending $(\mathrm{ft})$

$L_{r} \quad$ Limiting unbraced length to achieve the onset of nominal yielding in either flange under uniform bending with consideration of compression-flange residual stress effects (in.)

$L_{S I} \quad$ Length increment(ft.)

LTB Lateral torsional buckling

$m \quad$ Number of POI or multiple presence factor

$M \quad$ Bending moment about the major-axis of the cross-section (k-ft.)

$M_{A D} \quad$ Additional bending moment that must be applied to the short-term composite section to cause nominal yielding in either steel flange ( $\mathrm{k}-\mathrm{ft}$.)

$M_{D C 1} \quad$ Bending moment caused by the factored permanent load DC1 (k-ft.)

$M_{D C 2} \quad$ Bending moment caused by the factored permanent load DC2 (k-ft.)

$M_{D W} \quad$ Bending moment caused by the factored permanent load DW (k-ft.)

$M_{\text {flive }} \quad$ The bending moment range due to live load for the fatigue analysis (kip-ft.)

$M_{l} \quad$ Lateral bending moment in the flanges k-ft.)

$M_{n} \quad$ Nominal flexural resistance of a section (k-ft.)

$M_{\text {negliveenv }} \quad$ The negative moment envelope due to vehicular load (kip-ft.)

$M_{\text {negliveenvT }}$ The negative moment envelope due to truck only for the fatigue analysis (kip-ft.) 


\section{Symbol Description}

$M_{p} \quad$ Plastic moment (k-ft.)

$M_{\text {posliveenv }} \quad$ The positive moment envelope due to vehicular load (kip-ft.)

$M_{\text {posiveenvT }}$ The positive moment envelope due to truck only for the fatigue analysis (kip-ft.)

$m_{\text {red }} \quad$ Reduction factor for the force effect determined based on ADTT

$M_{u} \quad$ Moment due to the factored loads (k-ft)

$M_{y} \quad$ Yield moment (k-ft.)

$M_{y c} \quad$ Yield moment with respect to the compression flange (k-ft.)

$M_{y t} \quad$ Yield moment with respect to the tension flange (k-ft.)

$N \quad$ Number of cycles of stress range

$n \quad$ Number of cycles per truck passage

$N_{G} \quad$ Number of girder lines

$N_{L} \quad$ Number of traffic lanes

$n_{L T} \quad$ Modular ratio of the long term-composite section

$N_{S} \quad$ Number of spans

$n_{s c} \quad$ Number of shear connector in a cross section

$n_{S T} \quad$ Modular ratio of the short-term composite section

$P_{c} \quad$ Plastic force in the compression flange used to compute the plastic moment (kip)

$p_{\text {maxall }} \quad$ Maximum allowable pitch of shear connectors along the longitudinal axis (in.)

$P_{r b} \quad$ Plastic force in the bottom layer of longitudinal deck reinforcement used to compute the plastic moment (kip)

$P_{r t} \quad$ Plastic force in the top layer of longitudinal deck reinforcement used to compute the plastic moment (kip)

$P_{t} \quad$ Plastic force in the tension flange used to compute the plastic moment (kip)

$P_{w} \quad$ Plastic force in the web used to compute the plastic moment (kip) 


\section{Symbol Description}

$Q \quad$ First moment of the transformed short-term area of the concrete deck about the neutral axis of the short-term composite section, or optionally in regions of negative flexure of straight girders only, the first moment of the longitudinal reinforcement about the neutral axis of the composite section if the concrete is not considered to be effective in tension in computing the range of longitudinal stress (in.3)

$q_{c} \quad$ Unit weight of concrete $\left(\mathrm{lbs} / \mathrm{ft}^{3}\right)$

$q_{s} \quad$ Unit weight of steel $\left(\mathrm{lbs} / \mathrm{ft}^{3}\right)$

$R_{b} \quad$ Web load-shedding factor

$R_{h} \quad$ Hybrid factor

$S \quad$ Elastic section modulus $\left(\mathrm{in}^{3}\right)$

$S_{b} \quad$ Elastic section modulus of the non-composite section at the bottom of the bottom flange $\left(\right.$ in $\left.^{3}\right)$

$S_{b L T} \quad$ Elastic section modulus of the long term-composite section at the bottom of the bottom flange(in $\left.{ }^{3}\right)$

$S_{b S T} \quad$ Elastic section modulus of the short-term composite section at the bottom of the bottom flange $\left(\mathrm{in}^{3}\right)$

$S_{\text {bSTat }} \quad$ Elastic section modulus of the short-term composite section at the bottom of the bottom flange for fatigue analysis $\left(\mathrm{in}^{3}\right)$

$S_{G} \quad$ Girder spacing (ft.)

$S_{t} \quad$ Elastic section modulus of the non-composite section at the top of the top flange $\left(\mathrm{in}^{3}\right)$

$S_{t L T} \quad$ Elastic section modulus of the long term -composite section at the top of the top flange $\left(\mathrm{in}^{3}\right)$

$S_{\text {tslabLT }} \quad$ Elastic section modulus of the long term -composite section at the top of the slab $\operatorname{deck}\left(\right.$ in $\left.^{3}\right)$

$S_{\text {tslabst }} \quad$ Elastic section modulus of the short-term composite section at the top of the slab $\operatorname{deck}\left(\mathrm{in}^{3}\right)$

$S_{\text {tslabSTfat }}$ Elastic section modulus of the short-term composite section at the top of the slab deck for fatigue analysis $\left(\mathrm{in}^{3}\right)$

$S_{t S T} \quad$ Elastic section modulus of the short-term composite section at the top of the top flange $\left(\right.$ in $\left.^{3}\right)$

$S_{\text {tSTfat }} \quad$ Elastic section modulus of the short-term composite section at the top of the top flange for fatigue analysis $\left(\mathrm{in}^{3}\right)$ 


\section{Symbol Description}

\begin{tabular}{|c|c|}
\hline$t_{f b b o t}$ & Thickness of bottom flange (in.) \\
\hline$t_{f c}$ & Thickness of the compression flange (in.) \\
\hline$t_{f t}$ & Thickness of the tension flange (in.) \\
\hline$t_{\text {ftop }}$ & Thickness of top flange (in.) \\
\hline$t_{\text {haunch }}$ & Thickness of haunch (in.) \\
\hline$t_{s}$ & Thickness of a concrete deck (in.) \\
\hline$t_{s e}$ & Effective thickness of a concrete deck (in.) \\
\hline$t_{w e b}$ & Web thickness (in.) \\
\hline$V_{c r}$ & Shear-buckling resistance (kip) \\
\hline$V_{f}$ & Vertical shear force range under the Fatigue Load Combination (kip) \\
\hline$V_{\text {flive }}$ & Vertical shear force range due to live load for the fatigue analysis (kip) \\
\hline$V_{n}$ & Nominal shear resistance (kip) \\
\hline$V_{\text {negliveenv }}$ & The negative shear envelope due to the vehicular load (kip) \\
\hline$V_{p}$ & Plastic shear force (kip) \\
\hline$V_{\text {posliveenv }}$ & The positive shear envelope due to the vehicular load (kip) \\
\hline$V_{s r}$ & Horizontal fatigue shear range per unit length (kip/in.) \\
\hline$V_{u}$ & Shear due to the factored loads (kip) \\
\hline$w_{\text {barrier }}$ & Line load contributed by traffic barrier (kip/ft) \\
\hline$w_{\text {form }}$ & Line load contributed by form work dead load (kip/ft) \\
\hline$w_{g}$ & Line load contributed by steel girder (kip/ft) \\
\hline$w_{\text {haunch }}$ & Line load contributed by haunch dead load (kip/ft) \\
\hline$w_{s l a b}$ & Line load contributed by slab dead load (kip/ft) \\
\hline$y_{b f}$ & $\begin{array}{l}\text { Distance from the bottom of the bottom flange to the center of the bottom flange } \\
\text { (in.) }\end{array}$ \\
\hline
\end{tabular}




\section{Symbol Description}

$y_{b L T} \quad$ Distance from the elastic neutral axis of the long-term composite section to the bottom of the bottom flange(in.)

$y_{b S T} \quad$ Distance from the elastic neutral axis of the short-term composite section to the bottom of the bottom flange(in.)

$y_{\text {bSTfat }} \quad$ Distance from the elastic neutral axis of the short-term composite section to the bottom of the bottom flange for fatigue analysis (in.)

$y_{g b} \quad$ Distance from the elastic neutral axis of non-composite section to the bottom of the bottom flange(in.)

$y_{g t} \quad$ Distance from the elastic neutral axis of non-composite section to the top of the top flange(in.)

$y_{\text {haunch }} \quad$ Distance from the bottom of the bottom flange to the center of the haunch (in.)

$y_{\text {slab }} \quad$ Distance from the bottom of the bottom flange to the center of the slab deck (in.)

$y_{t f} \quad$ Distance from the bottom of the bottom flange to the center of the top flange (in.)

$y_{t L T} \quad$ Distance from the elastic neutral axis of the long-term composite section to the top of the top flange(in.)

$y_{t S T} \quad$ Distance from the elastic neutral axis of the short-term composite section to the top of the top flange(in.)

$y_{t S T f a t} \quad$ Distance from the elastic neutral axis of the short-term composite section to the top of the top flange for fatigue analysis (in.)

$y_{w e b} \quad$ Distance from the bottom of the bottom flange to the center of the web (in.)

$Y_{b a r} \quad$ Distance from the plastic neutral axis to the top of the element where the plastic neutral axis is located (in.)

$Z_{r} \quad$ Shear fatigue resistance of an individual shear connector (kip)

$\beta \quad$ Factor equal to two times the area of the web based on D, divided by $A_{f n}$ used in computing the hybrid factor

$\eta_{D} \quad$ Ductility factor

$\eta_{I} \quad$ Importance factor

$\eta_{R} \quad$ Redundancy factor

$\lambda_{f} \quad$ Slenderness ratio for the compression flange; slenderness ratio for the flange

$\lambda_{p f} \quad$ Limiting slenderness ratio for a compact flange 


\section{Symbol Description}

$\lambda_{r f} \quad$ Limiting slenderness ratio for a noncompact flange

$\lambda_{r w} \quad$ Limiting slenderness ratio for a noncompact web

$\rho \quad$ Limiting slenderness ratio for a noncompact web

$\square_{f} \quad$ Resistance factor for flexure

$\square_{v} \quad$ Resistance factor for shear

$\square y \quad$ Resistance factor for yielding on the gross section of tension members 


\section{INTRODUCTION}

Bridge design is an elaborate process which involves detailed calculations, decisions, and code checks. Due to these reasons, the designer heavily relies on bridge analysis and design software to generate values required for the design. Bridge design software is also evolving constantly to include better design options and improved calculations. However, it is important to evaluate and verify software through its various design options and flows. This validation can be performed using corresponding hand calculations. However, it can be time consuming to perform thousands of computations for a single bridge as software does. Hence, this limits the number of bridges for the verification. Furthermore, hand calculations become obsolete and needs to be modified upon the release of new version of design specifications and design software.

Process 12-50 (Baker et al., 2003) was developed by the Transportation Research Board (TRB) in 2003. The process presents a reasonable approach for verifying bridge design software. The significance of the process is in processing the computational results from the bridge design software. The results are compiled into a unique format so that they can be used to import and filter the results in database management program. Process 12-50 was developed as part of a TRB research project that focused on validating software. The Indiana Department of Transportation (INDOT) has funded a research project (2006-08) to implement Process 12-50 for bridges and software in Indiana. The INDOT study included both concrete and composite steel Igirder bridges. The evaluation and verification of prestressed concrete bridge design software were presented earlier (Choe et al. 2009).

This report presents the implementation of NCHRP Process 12-50 to evaluate and verify composite steel bridge software used commonly in Indiana, namely, MERLIN-DASH. The report is limited to slab-on-girder bridges with geometric and material parameters typical in the state of Indiana. An indigenous computer program, PURDUE CSBD, was developed to verify the results generated by MERLIN-DASH. This program was written in Visual Basic for Applications (VBA) code, and its computational processes were in accordance with the AASHTO LRFD specifications, which are endorsed by the current Indiana Department of Transportation (INDOT) Bridge Design Manual. The results from both programs are compared to verify design calculations for the complete test-bed of bridges. The comparisons focus on moments and shears, stresses, deflections, flexural strength, and shear strength. 


\section{$\underline{\text { Research Objectives }}$}

The purpose of this research is to validate composite steel I-girder bridge design software. To achieve the purpose followings are required to be performed:

1. Develop a test-bed of single and multi-span steel I-girder composite bridges that may be considered reasonable for design in the state of Indiana

2. Develop a computer program to perform relevant computations for the test-bed of bridges based on the AASHTO LRFD specifications (2008)

3. Implement Process 12-50 output file format to compile the output data from the design software and the computer program into database.

4. Compare output from the software and computer program to validate the software.

5. Identify discrepancies and causes of them from the comparisons, if any.

\section{$\underline{\text { Research Scope }}$}

An INDOT research advisory panel (RAP) was appointed for this study. The panel consists of DOT engineers, researchers, practitioners, and consultants and they are to guide this study and its scope. Based on the suggestions by the panel, the scope of this research was determined and they are verifying structural analysis calculations to develop moment and shear envelopes, concrete and steel stresses, dead load deflections and maximum instantaneous deflection, design calculations associated with flexural strength, vertical shear strength, and calculations associated with the fatigue limit state. Only interior girders were considered and all calculations are based on the current (as of Jan, 2009) AASHTO LRFD Bridge Design Specifications (2008). 


\section{Research Methodology}

The research objectives were achieved by conducting the project as follows:

1. Identifying parameters. Bridge design parameters associated with composite steel I-girder bridge design such as the bridge geometric, material, and girder size were determined with the guidance of Research Advisory Panel (RAP). These parameters were determined based on engineering practice in Indiana. The focus is on MERLIN-DASH, commercial composite steel I-girder design software, developed by University of Maryland, since it is commonly used for steel I-girder bridge design in Indiana.

2. Generating Test-bed and Input Pre-processor. Typical bridge parameters were decided after a series of discussions with the RAP members. They are used to generate a realistic and practical test-bed of steel I-girder bridges that may be considered in the state of Indiana. The details of bridges of the test-bed were entered manually into the MERLIN-DASH using its graphical user interface for analysis.

3. Indigenous Program. An indigenous program, namely PURDUE CSBD, was developed by Purdue. It was written in Visual Basic for Applications (VBA) of Microsoft Excel workbook. The program imports the input details of bridges from the test-bed for analysis. The program was developed based on the design procedures and equations from the 2008 AASHTO LRFD Bridge Design Specifications.

4. Analyze and organize output. Both the MERLIN-DASH and PURDUE CSBD program were executed to analyze to obtain results for each bridge of the test-bed. The results included section properties, moment and shear envelopes, deflections under dead loads and the maximum live load deflection, and concrete slab and steel flange stresses. Other results associated with design code check such as strength limit state, serviceability state, and fatigue state. An additional VBA code was developed to extract and compile results into the Process 12-50 output file format.

5. Compare and evaluate results. The results from MERLIN-DASH and PURDUE CSBD program were stored in the Process 12-50 output file format for comparison and evaluation. They were compared numerically and graphically. These comparisons were conducted for all the bridges in the test-bed to examine discrepancies, if any. Causes of these discrepancies were determined by using 2008 AASHTO LRFD Bridge Design Specifications. 


\section{Outline}

This report mainly presents the implementation of Process 12-50 for validating steel Igirder bridge design software. The details are followed in next chapters.

- Chapter 2 describes the scope of subdomain 12 and 13. The summary of the implementation of NCHRP Process 12-50 for steel I-girder bridge design software is discussed.

- Chapter 3 discusses the methodology used in determining the bridge test-bed, input parameters, and reviewing results for two programs.

- Chapter 4 presents the description of subroutines which take the most part of the PURDUE CSBD program. The chapter also identifies the theory, assumptions, and AASHTO LRFD Bridge Design Specifications used in the PURDUE CSBD program.

- $\quad$ Chapter 5 summarizes comparisons of results for MERLIN-DASH and PURDUE CSBD. The chapter identifies limitations of the software.

- Chapter 6 presents the conclusions of the research.

Appendices A, B, and C contain supplemental tables for the Report IDs and Appendix D contains the flowcharts for most of the subroutines used in PURDUE CSBD. 


\section{BACKGROUND}

A comprehensive test-bed of bridges for subdomain 12 and 13 were developed by Baker el al (2003). More than 50 bridges were considered for subdomain 12 (Composite Rolled Steel Sections) and nearly 170 bridges were considered for subdomain 13 (Composite Steel plate sections). These test structures were designed according to the 1994 AASHTO LRFD with 1997 interim revisions. Two independently developed computer programs compiled output from the bridge software. Macros were written in Microsoft Excel to create the comparison charts and tables and to review the data. Process 12-50 (Baker et al., 2003) was developed by the Transportation Research Board (TRB) in 2003. The process presents a reasonable approach for verifying bridge design software. The significance of the process is in processing the computational results from the bridge design software. The results are compiled into a unique format so that they can be used to import and filter the results in database management program. Process 12-50 was developed as part of a TRB research project that focused on validating software. The Indiana Department of Transportation (INDOT) has funded a research project (2006-08). Two types of bridges were considered and they are prestressed concrete I-girders and steel I-girders. This research project focus on the implementation of Process 12-50 to verify bridge design software for steel I -girders used commonly in the state of Indiana. The bridge design software is in accordance with the 4th edition of the AASHTO LRFD Bridge Design Specifications (2008).

\section{Process 12-50}

Baker et al. (2003) developed NCHRP process 12-50 as a roadmap for validating bridge design and analysis software. The procedure consists of six steps:

1. Understand the Problem Domain. It is critical that the user fully understands the problem domain. This is to ensure successful implementation of process 12-50. It is also important to identify the limitations of numerical comparisons when the user compares the set of values produced by the computational processes.

2. Divide the Large Problem Domain into Smaller Subdomains. For relatively large computations, dividing the bridge analyses and design processes into several subdomains are required. Sample of the subdomains for the design of slab-on-girder bridge superstructures is 
presented in Table 1. 30 subdomains were identified by Baker et al. (3) and process 12-50 was implemented for 18 of them.

3. Define Parameters for Subdomains. The description of each subdomain, the purpose, scope, and limitations of the computation are presented in this step. Numbers of parameters required by individual computational process are also defined.

4. Generate Problems Using Parametric Form. For each computational subdomain, relevant test problems are designed. A set of input values are required to address the associated issues for a specific subdomain. File generation software (text editors, Microsoft excel, or FORTRAN code) are used to generate the input files.

5. Perform Computations for Problems within the Subdomain. Computer programs are used to perform computations after a set of input files are generated. They are executed automatically to generate output using batch files.

6. Evaluate the Results from the Computations. The output generated by computer programs includes bridge analysis results, design calculations, and final design details. They are exported in ascii text, comma-delimited text, or tab-delimited text formats. The computer program output is acquired by using a macro or batch file and the output was saved into Microsoft Access. After the database software acquires the results, queries are developed to display, compare, and evaluate the results from the different computational processes. The results are queried and studied manually or exported to spreadsheet (Microsoft Excel) for graphical study. Methods of study include comparing values from a test suite for computational process validation, comparing results from different computational processes, and developing plots that illustrate trends in various output parameters.

Baker et al. (2003) created a unique output file format to facilitate the use of database management or spreadsheet program to query and sort through the results. Figure 2.1 shows the output file format. The format consists of seven fields: Bridge ID, Process ID, Report ID, Location, Value, Subdomain, and Location ID. Bridge ID represents an identification number for each test bed or problem and Process ID indicates a unique number representing each computational process. Report Id contains the designation for each result. In the Location field, the physical location of a result along the span is presented. The Value field contains the output value that corresponds to the Report ID. The Subdomain ID field contains the subdomain 
number. The Location ID identifies a point along the bridge span; it corresponds to the Location field.

\section{Scope of Subdomain 12 and 13}

A subset of the entire test suite was developed by Baker et al (1). The subset contains a set of data representing a specific area of the AASHTO LRFD specifications (2). Subdomain 12 was assigned to composite rolled steel sections and more than 50 bridge cases were produced. For composite steel plate girders, subdomain 13 was assigned and nearly 170 bridge cases were developed. Five different computational processes $(C P s)$ were used to generate problems and associated results for both Subdomain 12 and 13 and they are Girder(LRFD) (Version 1, Release 02, Level 01), PennDOT STLRFD(1.1A), Girder(LRFD) (Version 1, Release 04, Level 00, Beta), Girder(LRFD) (Version 1, Release 05, Level 00), and PennDOT STLRFD (1.2E). Some assumptions were made to reduce the number of variables in each analysis as shown below.

- HL-93 live load configuration

- Constant girder web depth

- Roadway width (curb-to-curb) equal to 34 or $44 \mathrm{ft}$

- Constant dynamic load allowance factors of 1.15 for fatigue and 1.13 for others

- Constant load modification factors: Importance $(\eta \mathrm{I})=1.05$, Ductility $(\eta \mathrm{D})=1.0$, and Redundancy $(\eta \mathrm{R})=1.0$

- Constant live load distribution factor equal to 0.85 lanes/girder

- Stiffened or unstiffened plate girders with variable stiffener spacing while unstiffened rolled beams

\section{Input File Generation}

A procedure for developing the input files known as the Input Vector method was developed by Baker et al. (2003). Input files were generated automatically using an Input Vector. The Input Vector is a large table containing the data defining each bridge case. It, also, facilitates input file creation. The geometry of the steel I-shapes was contained in an additional worksheet, referred to as BeamData. The Input Vector wrote the input files for both computational processes by using a macro and Microsoft Excel formulas. Additional worksheets were required to contain 
the input file templates. Each worksheet corresponded to a specific program. As the macro worked through the bridges, data in the Input Vector and the BeamData worksheets was entered into each template worksheet and the input files were created.

A batch file was also created as the macro generated the input files. The file contains a series of commands. The commands instructed the operating system to execute the input files through each computational process. In addition, the location of output files to be saved was instructed by the commands.

\section{Generated Output}

The code of computer programs was modified to write the output file in a database readable format. The modified code assigned ReportIDs, a unique identifier, to the output and generated the output files. The significance of the Report ID became evident in the postprocessing stage; it relates the output from two or more computational processes for comparison. Tables 2.1 through 2.2 presented the set of Report IDs developed by Baker et al., where Report IDs $40000-49999$ pertained to Steel I-girder bridges.

Descriptions for 95 Report IDs associated with simply-supported steel bridge design results were presented. Appendix A of this report contains the Report IDs along with their descriptions. Appendix B of this report contains the Report IDs corresponding to the effects of dead and live loads (moment, shear, and deflection).

\begin{tabular}{|ccccccc|}
\hline Bridge ID & Process ID & Report ID & Location & Value & Subdomain & Location ID \\
1 & 1 & 50002 & 10.00 & 401.1355 & 18 & 1 \\
1 & 1 & 50003 & 10.00 & 1266950 & 18 & 1 \\
1 & 1 & 50004 & 10.00 & 354.6180 & 18 & 1 \\
1 & 1 & 50005 & 10.00 & 1120025. & 18 & 1 \\
\hline
\end{tabular}

Figure 2.1 Sample format of NCHRP 12-50 Output 


\begin{tabular}{|c|l|}
\hline Report IDs & Description \\
\hline Range & \\
\hline $10000-11999$ & Dead Load Distribution \\
\hline $12000-19999$ & Live Load Distribution Factors \\
\hline $20000-24999$ & Steel Cross-section \\
\hline $25000-29999$ & Prestressed Concrete Cross-section \\
\hline $30000-31999$ & Dead Load Actions \\
\hline $32000-33999$ & Live Load Actions \\
\hline $34000-39999$ & Combined Actions \\
\hline $40000-49999$ & Steel (Non-composite/Composite) \\
\hline $50000-59999$ & Prestressed Concrete (Non-composite/Composite) \\
\hline $60000-69999$ & Substructure - Columns \\
\hline $70000-79999$ & Substructure - Footings \\
\hline
\end{tabular}

Table 2.1 NCHRP 12-50 Report IDs by description (Baker et al., 2003)

\begin{tabular}{|c|l|}
\hline Report IDs & Subdomains \\
\hline Range & \\
\hline $10000-11999$ & 1 \\
\hline $12000-19999$ & 2 \\
\hline $20000-24999$ & 5 \\
\hline $25000-29999$ & 4 \\
\hline $30000-31999$ & 6 \\
\hline $32000-33999$ & 7 \\
\hline $34000-39999$ & 8 \\
\hline $40000-49999$ & $9,10,12,13$ \\
\hline $50000-59999$ & $15-20$ \\
\hline
\end{tabular}

Table 2.2 NCHRP 12-50 Report IDs by Subdomain 


\section{Method of Validation}

Baker et al. (2003) developed graphs for each Report ID to compare results from the computational processes. A macro imported the output into a database, where a query filtered the computational results by Report ID into tables. Once exported into a spreadsheet application, a macro created graphs according to Report ID for graphical comparison of the data. Figure 2.2 shows an example of a graphical comparison developed by Baker et al. (2003). The graph presents the factored minimum strength I moment versus span length for two computational processes: Girder (LRFD) and STLRFD. Girder (LRFD) generates results $(+)$ at the tenth points of the span length and STLRFD $(\Delta)$ produces output at the span length's twentieth points. The comparisons indicate that both applications generate reasonable results may be inferred from the chart.

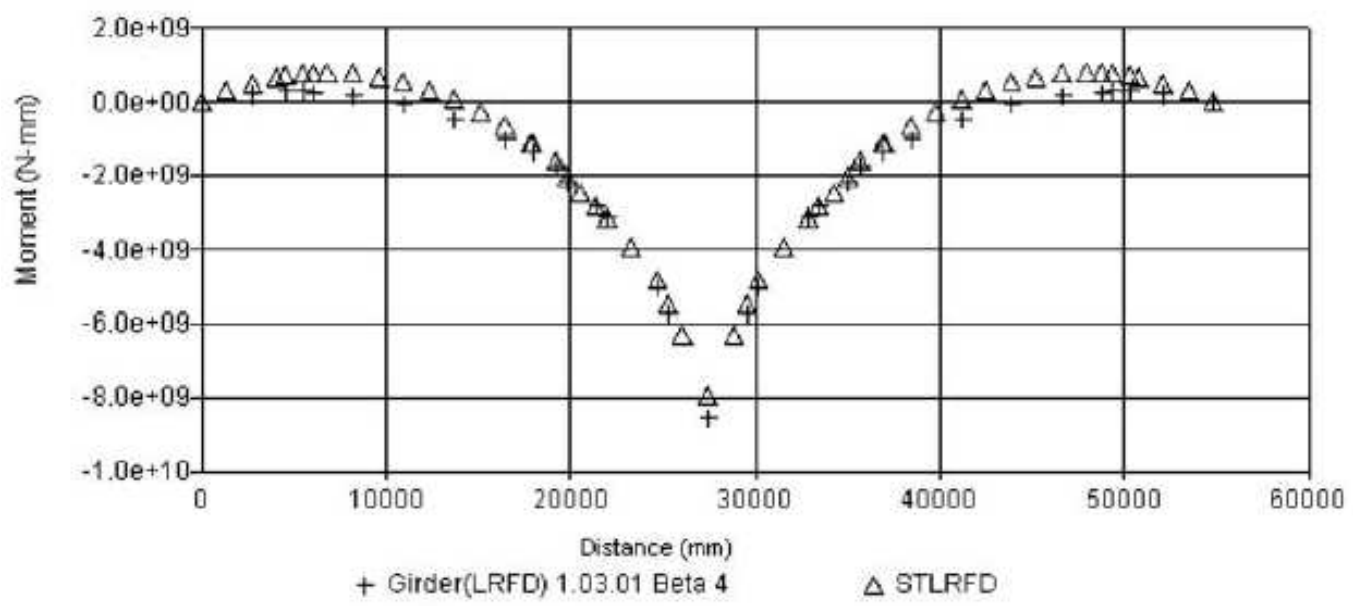

Figure 2.2 Example of Plots for Graphical Comparison 


\section{BRIDGE DEVELOPMENT}

This chapter presents the development of the test-bed of both simple-span and multi-span composite steel bridges for validating the bridge design software used by INDOT. The Process 12-50 was used to validate the bridge design software and the test-bed of bridges. Baker et al. (2003) developed a test-bed of almost 200 bridges by varying several design parameters in small increments. However, the software analysis results from these numerous bridges were overwhelming and time intensive to post-process. As a result, Baker et al. could not develop an indigenous program to verify the design calculations reported by the software programs.

In this research, a different approach was used to develop the test bed of bridges. The test bed of bridges was limited to practical ranges and values of span lengths, numbers of spans, girder sections, and material properties. The test-bed of composite steel bridges was developed with guidance from the research advisory panel (RAP). The test-bed included both simple and multi-span bridges with composite RSS I-girder. The values of about 80 parameters were required to define each bridge in the test-bed. The values and ranges for the parameters were selected by the consensus of the authors and the RAP members. This approach significantly reduced the number of bridges in the test bed. All bridges in the test bed were practical and eligible for design and construction in the state of Indiana. The reduced number of bridges allowed for more detailed post-processing and evaluation of the software results, which is the focus of this research.

\section{Development of bridge criteria}

Numbers of design parameters are required to define a composite steel I-girder bridge.

The categorization of the parameters is presented in Tables 3.1 to 3.7. These parameters were categorized into primary and secondary parameters. The values and ranges for the parameters were selected after a series of meetings and teleconferences between the authors and the RAP members and are shown in Tables 3.8. The parameters included: (1) span length, $L$, (2) span ratio, (3) number of spans, $N_{S}$, (4) skew, $\theta_{s k}$, (5) girder spacing, $S_{G}$, (6) overhang width, $b_{\text {overhang, }}$, (7) slab thickness, $t_{s}$, (8) section type, (9) barrier width, $b_{\text {overhang }}$, (10) material properties, (11) load modifiers, and (12) average daily truck traffic, ADTT. As shown in the tables, some parameters were held constant and practical ranges and increments were defined for some of the 
parameters to reduce the total number of bridges in the test-bed to be more manageable value and allowed for more detailed post-processing and evaluation of the design software results. The remaining parameters and section sizes are discussed together in the following sub-sections.

\begin{tabular}{|c|c|c|}
\hline \multirow{2}{*}{ Parameter } & \multicolumn{2}{|c|}{ Type } \\
\hline & Primary & Secondary \\
\hline Span length, L & $\checkmark$ & \\
\hline Span ratio & $\checkmark$ & \\
\hline Bridge width, $w_{\text {bridge }}$ & $\checkmark$ & \\
\hline Traffic lane width & & $\checkmark$ \\
\hline Number of beams, $N_{G}$ & $\checkmark$ & \\
\hline Number of lanes, $N_{L}$ & & $\checkmark$ \\
\hline Number of spans, $N_{S}$ & & $\checkmark$ \\
\hline Skew, $\theta_{s k}$ & & $\checkmark$ \\
\hline
\end{tabular}

Table 3.1 Input parameters relating to the global geometry of composite steel I-girder bridges

\begin{tabular}{|c|c|c|}
\hline \multirow{2}{*}{ Parameter } & \multicolumn{2}{|c|}{ Type } \\
\hline & Primary & Secondary \\
\hline Girder spacing, $S_{G}$ & $\checkmark$ & \\
\hline Overhang width, $b_{\text {overhang }}$ & & $\checkmark$ \\
\hline Slab thickness, $t_{s}$ & $\checkmark$ & \\
\hline Effective slab thickness, $t_{\text {se }}$ & $\checkmark$ & \\
\hline Haunch thickness, $t_{\text {haunch }}$ & $\checkmark$ & \\
\hline Haunch width, $b_{\text {haunch }}$ & $\checkmark$ & \\
\hline Section type & $\checkmark$ & \\
\hline Barrier width, $b_{\text {barrier }}$ & & $\checkmark$ \\
\hline
\end{tabular}

Table 3.2 Input parameters relating to the local geometry of composite steel I-girder bridges 


\begin{tabular}{|c|c|c|}
\hline \multirow{2}{*}{ Parameter } & \multicolumn{2}{|c|}{ Type } \\
\hline & Primary & Secondary \\
\hline Steel modulus of elasticity, $E_{s}$ & & $\checkmark$ \\
\hline Unit weight of steel, $q_{s}$ & & $\checkmark$ \\
\hline Compression flange yield stress, $F_{y c}$ & $\checkmark$ & \\
\hline Tension flange yield stress, $F_{y t}$ & $\checkmark$ & \\
\hline Web yield stress, $F_{y w}$ & & $\checkmark$ \\
\hline Mild reinforcement yield strength, $F_{y r e}$ & & $\checkmark$ \\
\hline Shear studs yield strength, $F_{y g}$ & & $\checkmark$ \\
\hline Slab concrete modulus of elasticity, $E_{c}$ & & $\checkmark$ \\
\hline Unit weight of concrete, $q_{c}$ & & $\checkmark$ \\
\hline Slab concrete strength at 28 days, $f_{c}^{\prime}$ & & $\checkmark$ \\
\hline
\end{tabular}

Table 3.3 Input parameters relating to the steel material properties

\begin{tabular}{|c|c|c|}
\hline \multirow{2}{*}{ Parameter } & \multicolumn{2}{|c|}{ Type } \\
\hline & Primary & Secondary \\
\hline Transverse reinforcement bar size & & $\checkmark$ \\
\hline Quantity of transverse reinforcement & & $\checkmark$ \\
\hline Area of Transverse reinforcement bar, $A_{s r}$ & & $\checkmark$ \\
\hline
\end{tabular}

Table 3.4 Input parameters relating to the section properties of the steel reinforcement

\begin{tabular}{|c|c|c|}
\hline \multirow{2}{*}{ Parameter } & \multicolumn{2}{|c|}{ Type } \\
\hline & Primary & Secondary \\
\hline Ductility, $\eta_{D}$ & & $\checkmark$ \\
\hline Operational Importance, $\eta_{I}$ & & $\checkmark$ \\
\hline Redundancy, $\eta_{R}$ & & $\checkmark$ \\
\hline
\end{tabular}

Table 3.5 Input parameters relating to strength load modifiers 


\begin{tabular}{|c|c|c|}
\hline \multirow{2}{*}{ Parameter } & \multicolumn{2}{|c|}{ Type } \\
\hline & Primary & Secondary \\
\hline $\begin{array}{c}\text { Dead load applied to non-composite section } \\
\text { (interior girders), } D C 1\end{array}$ & & $\checkmark$ \\
\hline Dead load of barriers, $D C 2$ & & $\checkmark$ \\
\hline Dead load of future wearing surface, $D W$ & & $\checkmark$ \\
\hline Live Load & & $\checkmark$ \\
\hline
\end{tabular}

Table 3.6 Input parameters relating to loads applied to composite steel I-girder bridges

\begin{tabular}{|c|c|c|}
\hline \multirow{2}{*}{ Parameter } & \multicolumn{2}{|c|}{ Type } \\
\cline { 2 - 3 } & Primary & Secondary \\
\hline Dynamic Load Allowance, $I M$ & & $\checkmark$ \\
\hline Dynamic Load Allowance, $I M_{f a t}$ & & $\checkmark$ \\
\hline Single Lane Average Daily Truck Traffic, $A D T T_{S L}$ & & $\checkmark$ \\
\hline
\end{tabular}

Table 3.7 Miscellaneous parameters of composite steel I-girder bridges 


\begin{tabular}{|c|c|}
\hline Span length, $\mathrm{L}$ & $60 \mathrm{ft}, 80 \mathrm{ft}, 110 \mathrm{ft}, 160 \mathrm{ft}$ \\
\hline Span ratio & $\begin{array}{c}1: 1-2 \text { span } \\
1: 1.25: 1-3 \text { span }\end{array}$ \\
\hline Number of beams, $N_{G}$ & $\begin{array}{c}5-60 \mathrm{ft}, 80 \mathrm{ft}, 110 \mathrm{ft} \\
4-160 \mathrm{ft}\end{array}$ \\
\hline Number of lanes, $N_{L}$ & 3 \\
\hline Number of spans, $N_{S}$ & Simple, 2span, 3span \\
\hline Skew, $\theta_{s k}$ & $0^{\circ}$ \\
\hline Girder spacing, $S_{G}$ & $\begin{array}{c}9 \mathrm{ft}-60 \mathrm{ft} \text { span } \\
10 \mathrm{ft}-80 \mathrm{ft}, 110 \mathrm{ft} \text { span } \\
12 \mathrm{ft}-160 \mathrm{ft} \text { span }\end{array}$ \\
\hline Overhang width, $b_{\text {overhang }}$ & $2.5 \mathrm{ft}$ \\
\hline Slab thickness, $t_{s}$ & $\begin{array}{c}\text { 8.0in - 60ft, 80ft, } 110 \mathrm{ft} \text { span } \\
9.0 \mathrm{in}-160 \mathrm{ft} \text { span }\end{array}$ \\
\hline Effective slab thickness, $t_{s e}$ & $\begin{array}{c}7.5 \mathrm{in}-60 \mathrm{ft}, 80 \mathrm{ft}, 110 \mathrm{ft} \text { span } \\
8.5 \mathrm{in}-160 \mathrm{ft} \text { span }\end{array}$ \\
\hline Section type & $\begin{array}{c}\text { RSS }-60 \mathrm{ft}, 80 \mathrm{ft} \text { span } \\
\text { Plate }-110 \mathrm{ft}, 160 \mathrm{ft}\end{array}$ \\
\hline Barrier width, $b_{\text {barrier }}$ & $1.5 \mathrm{ft}$ \\
\hline Steel modulus of elasticity, $E_{s}$ & $29000 \mathrm{ksi}$ \\
\hline Unit weight of steel, $q_{s}$ & $490 \mathrm{pcf}$ \\
\hline Compression flange yield stress, $F_{y c}$ & 50ksi, 70ksi \\
\hline Tension flange yield stress, $F_{y t}$ & 50ksi, 70ksi \\
\hline Web yield stress, $F_{y w}$ & $50 \mathrm{ksi}$ \\
\hline Mild reinforcement yield strength, $F_{y r e}$ & $60 \mathrm{ksi}$ \\
\hline Shear studs yield strength, $F_{y g}$ & $60 \mathrm{ksi}$ \\
\hline Slab concrete modulus of elasticity, $E_{c}$ & $3625 \mathrm{ksi}$ \\
\hline Unit weight of concrete, $q_{c}$ & $150 \mathrm{pcf}$ \\
\hline Slab concrete strength at 28 days, $f_{c}^{\prime}$ & $4 \mathrm{ksi}$ \\
\hline Ductility, $\eta_{D}$ & 1.0 \\
\hline Operational Importance, $\eta_{I}$ & 1.0 \\
\hline Redundancy, $\eta_{R}$ & 1.0 \\
\hline Average Daily Truck Traffic, $A D T T_{S L}$ & 1500 \\
\hline
\end{tabular}

Table 3.8 Selected input parameters 


\section{Development of the test-bed}

Ninety six bridges were determined initially by varying five major bridge design parameters including span lengths (60 ft., $80 \mathrm{ft}$., $110 \mathrm{ft}$., and $160 \mathrm{ft}$.), numbers of spans (simple span, two spans, and three spans), presence of transverse stiffeners, presence of shear studs in the negative flexure region, and use of hybrid sections in negative flexure. For the efficient postprocessing and evaluation, the number of bridge was reduced by further refining and recategorizing the bridge design parameters. The total number of bridges was finally reduced to twenty one. These are listed in Table 3.9. Transverse stiffeners are not used commonly due to economic reasons (costs related to fabrication are too high). They are considered for only a few of the long-span bridges in Table 3.9. The behavior of hybrid sections with shear studs in negative flexure region is not expected to be much different from uniform sections with shear studs in terms of the flexural strength and shear strength. Hence, only a few bridges in Table 3.9 have hybrid sections with shear studs in the negative flexure region. 


\begin{tabular}{|c|c|c|c|c|c|c|}
\hline $\begin{array}{l}\text { Number } \\
\text { of Span }\end{array}$ & $\begin{array}{c}\text { Span } \\
\text { Length(ft) }\end{array}$ & $\begin{array}{c}\text { Section } \\
\text { Type }\end{array}$ & Stiffeners & $\begin{array}{c}\text { Shear studs } \\
\text { in negative flexure }\end{array}$ & $\begin{array}{l}\text { Hybrid sections } \\
\text { in negative flexure }\end{array}$ & $\begin{array}{c}\text { Bridge } \\
\text { Number }\end{array}$ \\
\hline \multirow{5}{*}{$\begin{array}{l}\text { Simple } \\
\text { Span }\end{array}$} & 60 & Rss & - & - & - & 1 \\
\hline & 80 & Rss & - & - & - & 2 \\
\hline & 110 & Plate & Yes & - & - & 3 \\
\hline & \multirow{2}{*}{160} & \multirow{2}{*}{ Plate } & Yes & - & - & 4 \\
\hline & & & - & - & - & 5 \\
\hline \multirow{8}{*}{2 Span } & 60 & Rss & - & - & - & 6 \\
\hline & 80 & Rss & - & - & - & 7 \\
\hline & \multirow{3}{*}{110} & \multirow{3}{*}{ Plate } & Yes & - & - & 8 \\
\hline & & & \multirow{2}{*}{ - } & Yes & Yes & 9 \\
\hline & & & & - & Yes & 10 \\
\hline & \multirow{3}{*}{160} & \multirow{3}{*}{ Plate } & Yes & - & - & 11 \\
\hline & & & \multirow{2}{*}{ 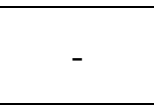 } & Yes & Yes & 12 \\
\hline & & & & - & Yes & 13 \\
\hline \multirow{8}{*}{3 Span } & 60 & Rss & - & - & - & 14 \\
\hline & 80 & Rss & - & - & - & 15 \\
\hline & \multirow{3}{*}{110} & \multirow{3}{*}{ Plate } & Yes & - & - & 16 \\
\hline & & & \multirow{2}{*}{-} & Yes & Yes & 17 \\
\hline & & & & - & Yes & 18 \\
\hline & \multirow{3}{*}{160} & \multirow{3}{*}{ Plate } & Yes & - & - & 19 \\
\hline & & & \multirow{2}{*}{ 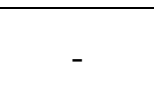 } & Yes & Yes & 20 \\
\hline & & & & - & Yes & 21 \\
\hline
\end{tabular}

Table 3.9 Finalized bridge cases for the test-bed 


\section{$\underline{\text { Girder sections }}$}

Selecting trial girder sections for steel bridges is not trivial because there are no catalogs, standard sections, or table to select from. For prestressed concrete bridges, the INDOT design manual provides a prestressed concrete I-beam selection chart which provides acceptable span length and girder spacing for standard section. Similar information for steel bridges is not available in the INDOT bridge design manual or elsewhere. The initial trial girder sections for bridges in the test-bed were selected by a series of meetings with local engineers and INDOT specialists. The selected sections were entered into MERLIN-DASH to determine their validity using the code check option which is based on the AASHTO LRFD specifications. This code check includes comparisons of moments, shears, stresses, and other required values to the allowable values specified by the AASHTO LRFD specifications. The initial trial sections were modified by increasing or decreasing the element (flanges and webs) of girder sections until they satisfied all required fields such as strength limit state check, and shear capacity check. The girder sections for the test-bed bridges were finalized and they are shown in Table 3.10. The girder sections were finalized using the following details:

- Different girder sections were selected depending on the location of the point of interest (POI). That is, the girder sections for positive and negative flexure are different each other. For example, top flange thickness in the positive flexure region was designed to be thinner than the corresponding bottom flange thickness. In the negative flexure region, the top flange thickness was the same as bottom flange thickness.

- The web depth for both plate girders and RSS was assumed to be continuous along the span, whereas the flange width was assumed to be continuous for only plate girders.

- Two different top flange thicknesses were selected for simple span bridges. The top flange in the center of simple span bridges (where the bending moments are larger), was designed to be thicker. This is common practice in Indiana for economic reasons. Figures 3.1 through 3.3 show layout and configuration of girder sections used for bridges in the test-bed.

The bridge width and haunch dimensions were determined based on Indiana practice and the values for girder spacing, $S_{G}$, overhang width, $b_{\text {overhang, }}$, barrier width, $b_{\text {barrier }}$, and girder section. 


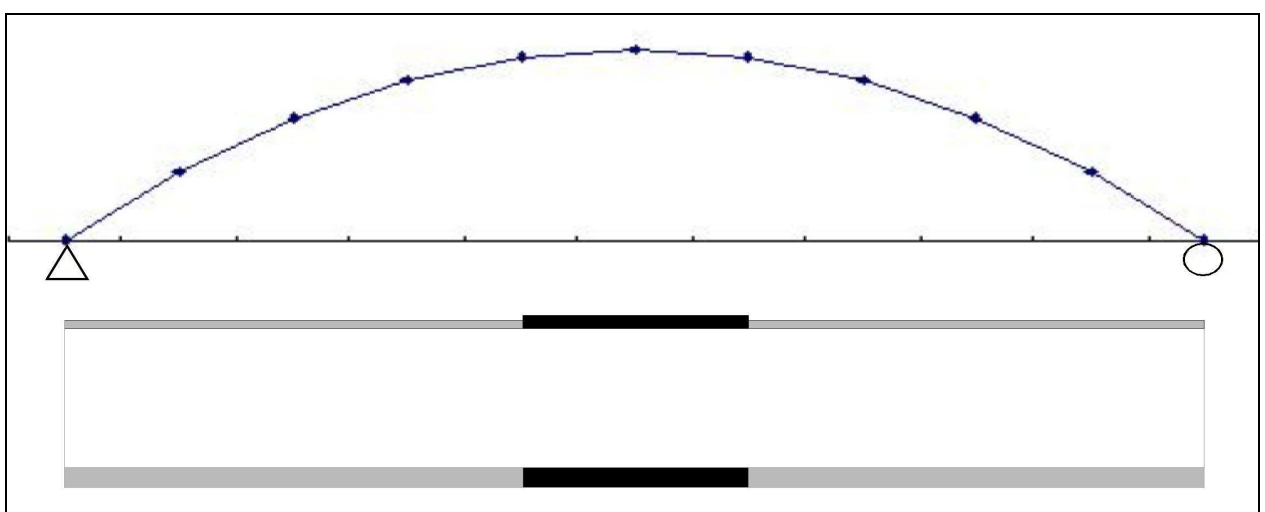

Figure 3.1 Configuration of plate girder section of simple span bridge

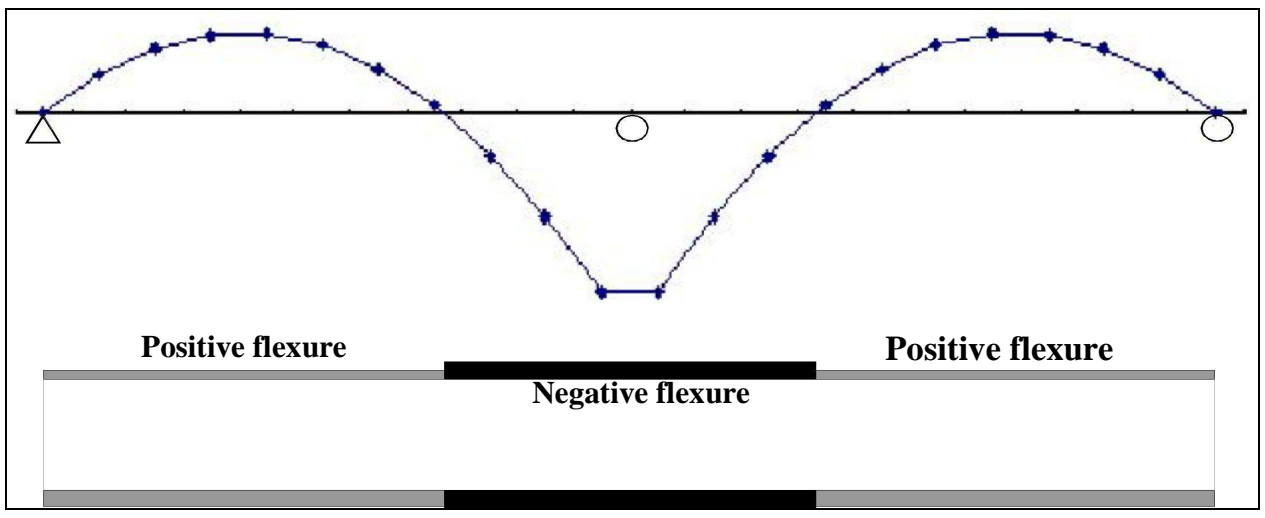

Figure 3.2 Configuration of plate girder section of two span bridge

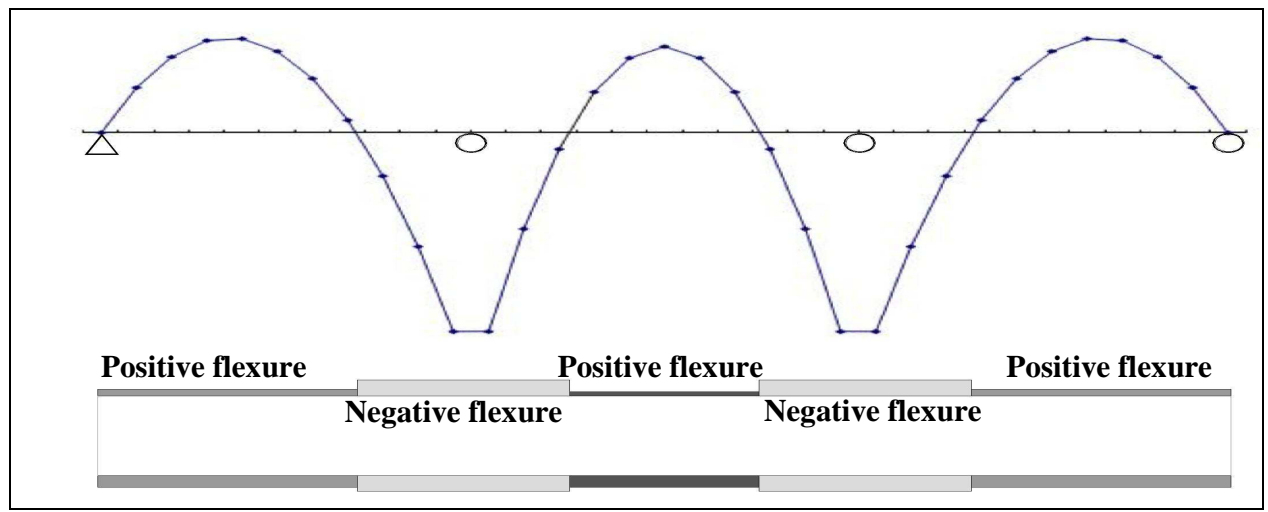

Figure 3.3 Configuration of plate girder section three span bridge 


\begin{tabular}{|c|c|c|c|c|c|c|c|c|c|c|c|}
\hline BridgeID & 1 & 2 & 3 & 4 & 5 & 6 & 7 & 8 & 9 & 10 & 11 \\
\hline Number of beams, $N_{G}$ & 5 & 5 & 5 & 4 & 4 & 5 & 5 & 5 & 5 & 5 & 4 \\
\hline Number of spans, $N_{S}$ & 1 & 1 & 1 & 1 & 1 & 2 & 2 & 2 & 2 & 2 & 2 \\
\hline Bridge width, $w_{\text {bridge }}(\mathrm{ft})$ & 41 & 45 & 45 & 42 & 42 & 41 & 45 & 45 & 45 & 45 & 42 \\
\hline Span length, L (ft) & 60 & 80 & 110 & 160 & 160 & 60 & 80 & 110 & 110 & 110 & 160 \\
\hline Eff. slab thickness, $t_{s e}$ (in) & 7.5 & 7.5 & 7.5 & 8.5 & 8.5 & 7.5 & 7.5 & 7.5 & 7.5 & 7.5 & 8.5 \\
\hline Haunch thickness, $t_{\text {haunch }}$ (in.) & 1.855 & 2.86 & 2.5 & 3.12 & 3.125 & 1.93 & 2.76 & 2.5 & 2.625 & 2.625 & 3.625 \\
\hline Haunch width, $b_{\text {haunch }}$ (in.) & 11.5 & 12.2 & 16 & 22 & 22 & 15 & 16.6 & 14 & 16 & 16 & 22 \\
\hline Barrier width, $b_{\text {barrier }}(\mathrm{ft})$ & 1.5 & 1.5 & 1.5 & 1.5 & 1.5 & 1.5 & 1.5 & 1.5 & 1.5 & 1.5 & 1.5 \\
\hline Girder spacing, $S_{G}(\mathrm{ft})$ & 9 & 10 & 10 & 12 & 12 & 9 & 10 & 10 & 10 & 10 & 12 \\
\hline \multicolumn{12}{|l|}{ Girder Section } \\
\hline Section Type (PG or RSS) & RSS & RSS & $\mathrm{PG}$ & PG & $\mathrm{PG}$ & RSS & RSS & $\mathrm{PG}$ & $\mathrm{PG}$ & $\mathrm{PG}$ & PG \\
\hline RSS, Pos 1 & W33X130 & W36X210 & & & & W30X124 & W36X194 & & & & \\
\hline Top Flange Width, $b_{t f}$ (in) & & & 16 & 22 & 22 & & & 14 & 16 & 16 & 22 \\
\hline Top FlangeThickness, $f_{t f}$ (in) & & & 1.25 & 1.625 & 1.375 & & & 1 & 1.125 & 1.125 & 1.625 \\
\hline Web Depth, $d_{\text {web }}($ in $)$ & & & 42 & 66 & 69 & & & 45 & 51 & 51 & 57 \\
\hline Web Thickness, $t_{\text {web }}$ (in) & & & 0.5 & 0.5 & 0.625 & & & 0.5 & 0.5 & 0.625 & 0.5 \\
\hline Bot. Flange Width, $b_{b f}($ in $)$ & & & 16 & 22 & 22 & & & 14 & 16 & 16 & 22 \\
\hline Bot. Flange Thickness, $t_{b f}$ (in) & & & 1.5 & 1.75 & 1.625 & & & 1.125 & 1.25 & 1.25 & 1.75 \\
\hline RSS, Pos 2 & W33X130 & W36X210 & & & & & & & & & \\
\hline Top Flange Width, $b_{t f}$ (in) & & & 16 & 22 & 22 & & & & & & \\
\hline Top FlangeThickness, $f_{t f}$ (in) & & & 1.25 & 1.625 & 1.375 & & & & & & \\
\hline Web Depth, $d_{w e b}($ in $)$ & & & 42 & 66 & 69 & & & & & & \\
\hline Web Thickness, $t_{\text {web }}($ in $)$ & & & 0.5 & 0.5 & 0.625 & & & & & & \\
\hline Bot. Flange Width, $b_{b f}($ in $)$ & & & 16 & 22 & 22 & & & & & & \\
\hline Bot. Flange Thickness, $t_{b f}$ (in) & & & 1.875 & 2.125 & 2 & & & & & & \\
\hline RSS, Neg 1 & & & & & & W30X173 & W36X260 & & & & \\
\hline Top Flange Width, $b_{t f}$ (in) & & & & & & & & 14 & 16 & 16 & 22 \\
\hline Top FlangeThickness, $f_{t f}$ (in) & & & & & & & & 1.5 & 1.875 & 1.875 & 2 \\
\hline Web Depth, $d_{w e b}($ in $)$ & & & & & & & & 45 & 51 & 51 & 57 \\
\hline Web Thickness, $t_{w e b}($ in $)$ & & & & & & & & 0.5 & 0.5 & 0.625 & 0.5 \\
\hline Bot. Flange Width, $b_{b f}$ (in) & & & & & & & & 14 & 16 & 16 & 22 \\
\hline Bot. Flange Thickness, $t_{b f}$ (in) & & & & & & & & 1.625 & 1.875 & 1.875 & 2 \\
\hline
\end{tabular}

Table 3.10 Finalized girder sections 


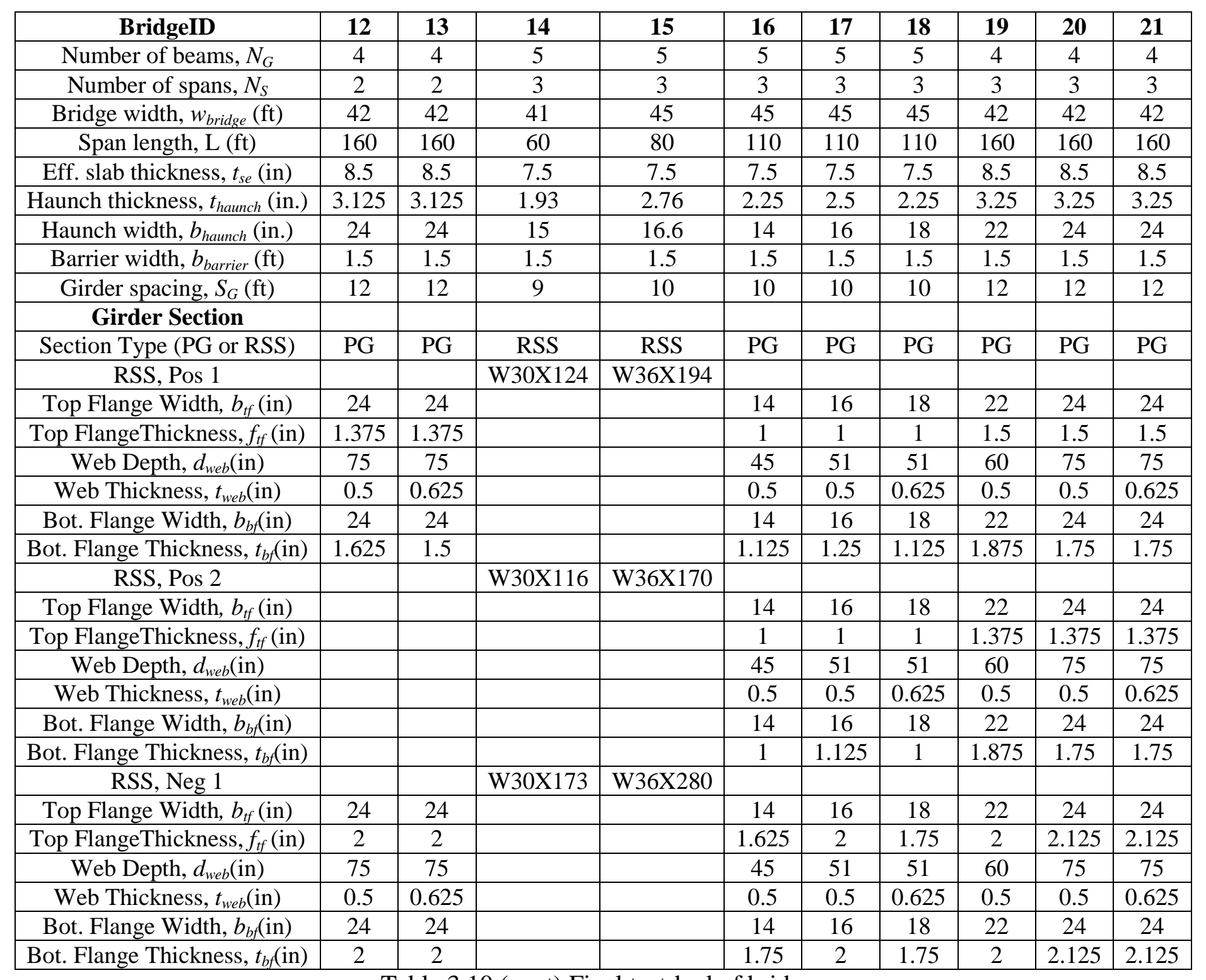

Table 3.10 (cont) Final test-bed of bridges 


\section{Creating the load criteria}

The permanent load for analysis consists of DC1, DC2, and DW. DC1 includes the selfweight of the steel girder, concrete slab deck, permanent deck forms, and haunch on noncomposite section. DC2 consists of traffic barriers and DW consists of future wearing surface. Both DC2 and DW are on the long-term composite section. The design load values are shown in Table 3.11. Most of the unit weights and load per unit area (except the future wearing surface and barriers) were converted into line loads based on either the cross-sectional area or tributary width of the interior girder since the bridges were modeled as girder-lines. The future wearing surface was determined by taking its unit weight times the clear roadway width and dividing that value by the number of girder lines. For the traffic barriers, the load was doubled since traffic barriers are along two coping lines. Doubled load was divided by the number of girder lines.

The AASHTO HL-93 design truck and lane load were used for the transient load. Figure 3.4 shows the schematic placement of truck axles. For the strength analysis the distance between two 30 kips axles was assumed to be $14 \mathrm{ft}$. and $30 \mathrm{ft}$. was assumed for the fatigue analysis. For the maximum negative live load moment, $90 \%$ of the moment by two design trucks (IM=33\%) spaced a minimum of $50.0 \mathrm{ft}$. between the lead axle of one truck and the rear axle of the other truck, combined with $90 \%$ of the moment by the design lane load.

\begin{tabular}{|c|c|}
\hline Load Type & Value \\
\hline Unit weight of steel, $q_{s}(\mathrm{kip} / \mathrm{ft} 3)$ & 0.49 \\
\hline Unit weight of concrete, $q_{c}(\mathrm{kip} / \mathrm{ft} 3)$ & 0.150 \\
\hline Deck forms $(\mathrm{kip} / \mathrm{ft} 2)$ & 0.015 \\
\hline Barrier $(\mathrm{kip} / \mathrm{ft})$ & 0.405 \\
\hline Future wearing surface $(\mathrm{kip} / \mathrm{ft} 2)$ & 0.035 \\
\hline
\end{tabular}

Table 3.11 Magnitude of design dead load values 


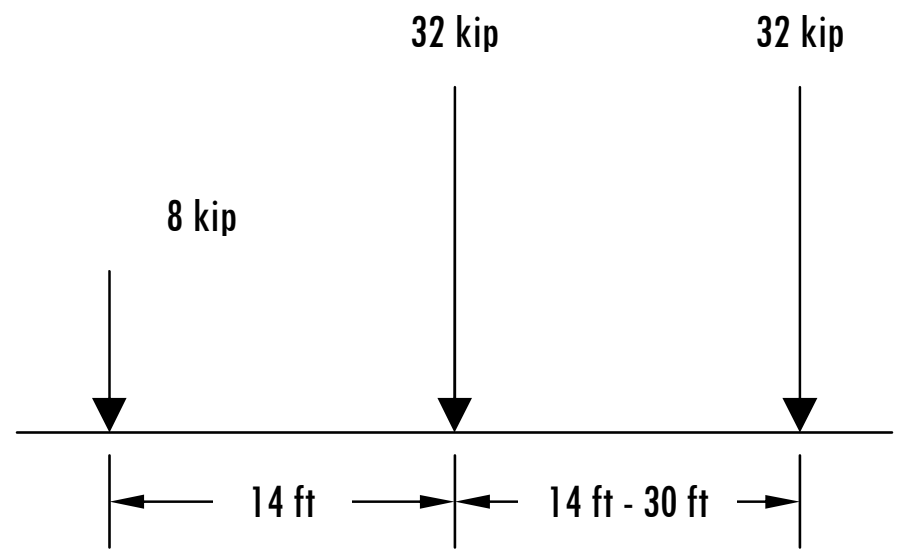

Figure 3.4 Configuration of HL-93 design truck 


\section{Organization of input parameters}

This sub-section describes the organization of the bridge parameters for input file creation. The input parameters were stored in two worksheets of an Excel workbook: SteelBridgeInput and RSS. In the SteelBridgeInput worksheet, the data is formatted similar to the Input Vector described in Chapter 2 to produce input files as suggested by Baker et al. (2003). The RSS worksheet contains the section properties of the Rolled Steel Sections. The section properties include the geometry of RSS sections, elastic and plastic moment of inertia, and other properties. This worksheet is shown in Figure 3.6.

The Input Vector consists of three parts: (1) the input parameter descriptions, (2) input parameter values, and (3) the current bridge values as shown in Figure 3.5. Part 1 consists of the two left columns, which contain the input identification number, or Input ID, and the descriptions of the input parameters, respectively. Each row corresponds to a specific input parameter and the Input ID only serves to track the amount of input parameters. The input parameter values for bridge of the test-bed are located in Part 2 of the Input Vector. Each column within the part corresponds to each bridge. An identification numbers were assigned to each bridge located under the "Input Vector" heading. The number is referred to Bridge ID. PURDUE CSBD uses this number to enter the parameters for a specific bridge into the program. A column located between Part 1 and Part 2 contains the input parameter values of the current bridge. That is, this range of cells contains the values of the current bridge under analysis. 


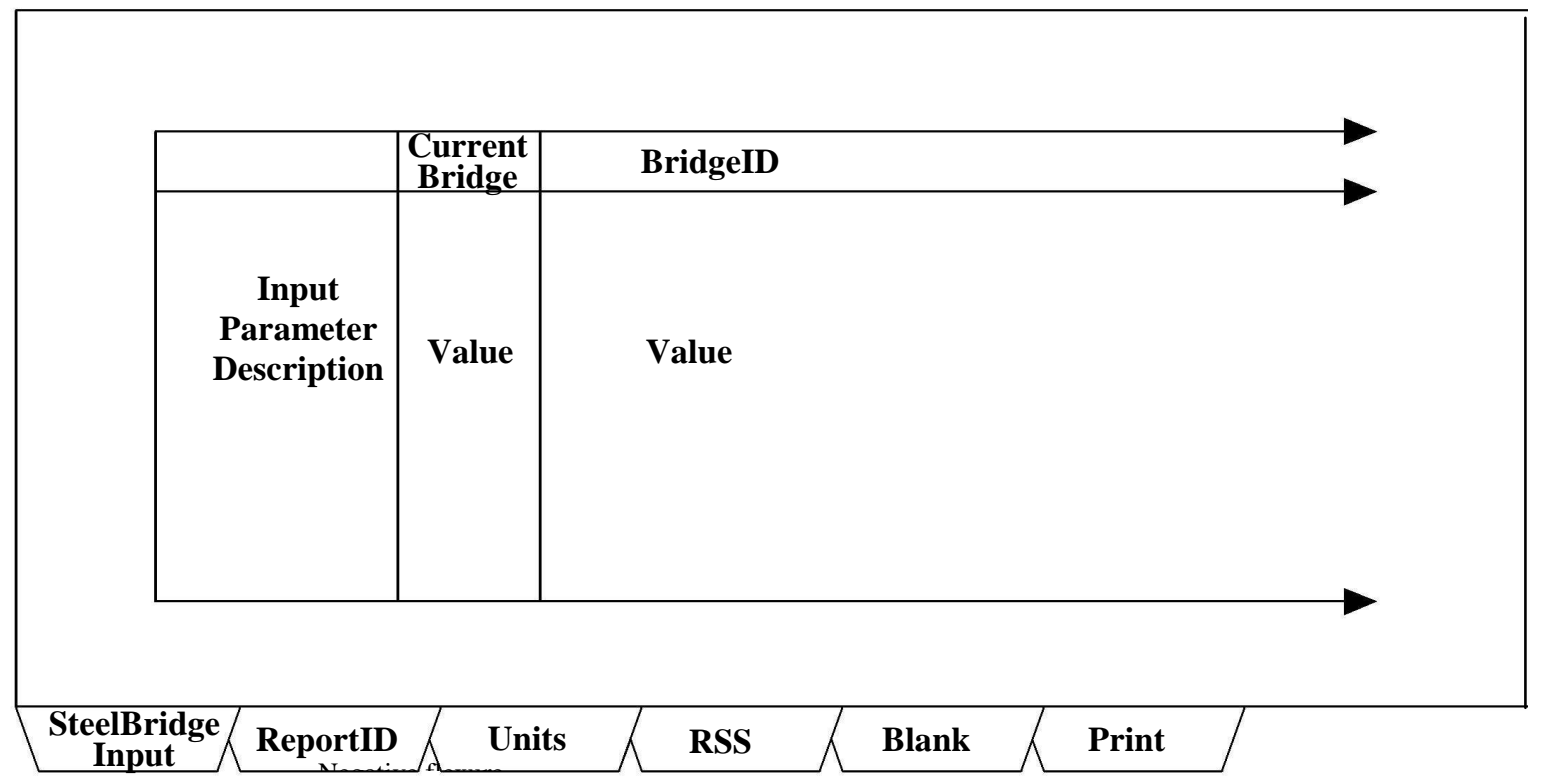

(a)

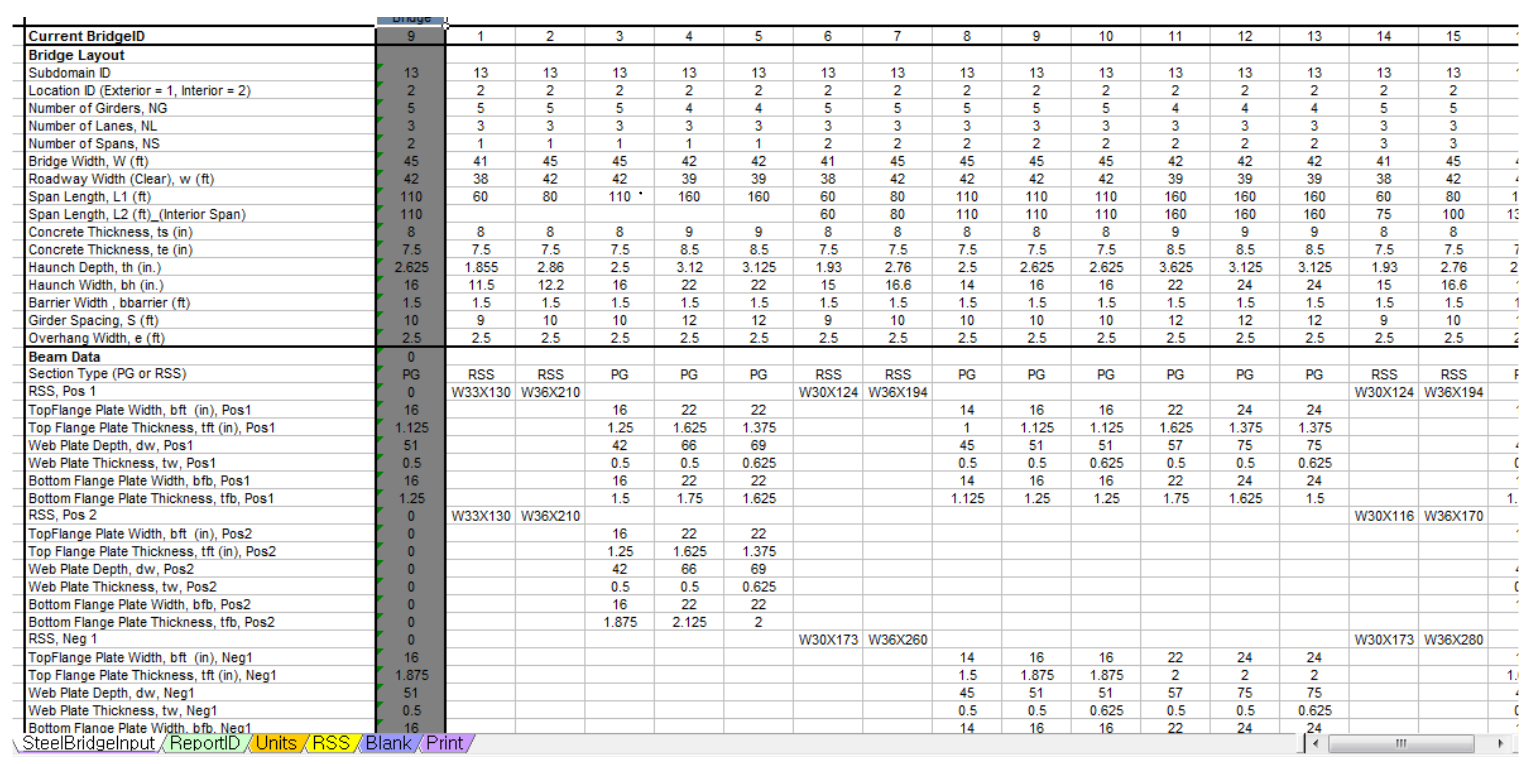

(b)

Figure 3.5 SteelBridgeInput worksheet (a) conceptual (b) actual 


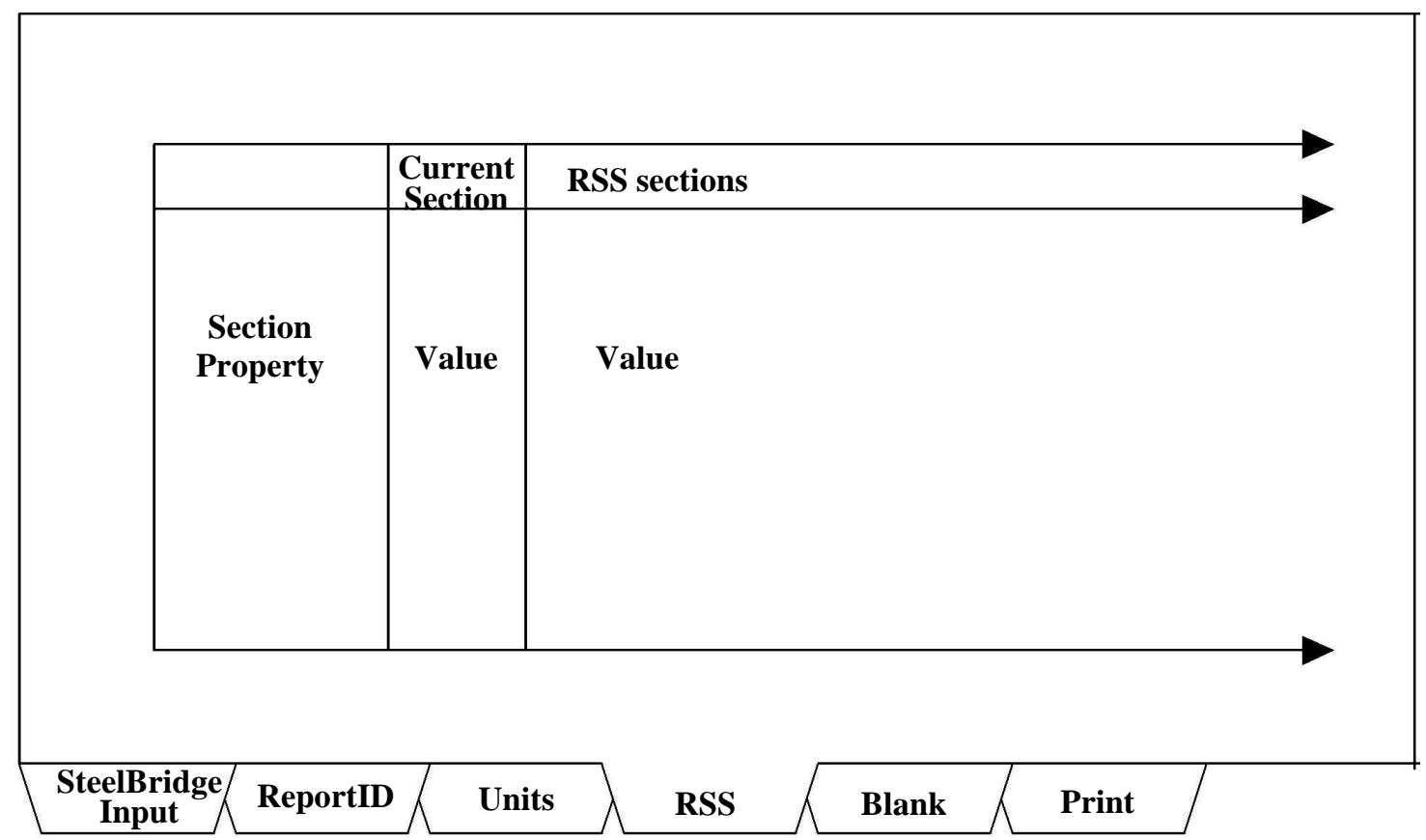

(a)

\begin{tabular}{|c|c|c|c|c|c|c|c|c|c|c|c|c|c|c|c|c|c|}
\hline & A & B & C & D & $\mathrm{E}$ & $\mathrm{F}$ & G & $\mathrm{H}$ & 1 & $\mathrm{~J}$ & $\mathrm{~K}$ & $\mathrm{~L}$ & M & $\mathrm{N}$ & 0 & $\mathrm{P}$ & Q \\
\hline 1 & Start Bridge ID & 9 & & & & & & & & & & & & & & & \\
\hline 2 & End Bridge ID & 9 & & & & & & & & & & & & & & & \\
\hline 3 & & Current & & & & & & & & & & & & & & & \\
\hline 4 & & Bridge & & & & & & & & & & & & & & & \\
\hline 5 & Section & w36X210 & W30X116 & W30X124 & W30X132 & \begin{tabular}{|l|} 
W30X148 \\
\end{tabular} & W30X173 & W30X191 & w30X211 & W30X235 & W30X261 & W30X292 & w30X326 & W30X391 & W33X118 & W33X130 & W33X14 \\
\hline 6 & W & 210 & 116 & 124 & 132 & 148 & 173 & 191 & 211 & 235 & 261 & 292 & 326 & 391 & 118 & 130 & 141 \\
\hline 7 & A & 61.8 & 34.200 & 36.500 & 38.900 & 43.500 & 50.800 & 56.100 & 62.000 & 69.000 & \begin{tabular}{|l|l|}
76.700 \\
\end{tabular} & 85.700 & 95.700 & 114.000 & 34.700 & 38.300 & 41.600 \\
\hline 8 & d & 36.69 & 30.000 & 30.200 & 30.310 & 30.670 & 30.440 & 30.680 & 30.940 & 31.300 & 31.610 & 32.010 & 32.400 & 33.190 & 32.860 & 33.090 & 33.300 \\
\hline 9 & tw & 0.83 & 0.565 & 0.585 & 0.615 & 0.650 & 0.655 & 0.710 & 0.775 & 0.830 & 0.930 & 1.020 & 1.140 & 1.360 & 0.550 & 0.580 & 0.605 \\
\hline 10 & bf & 12.18 & 10.500 & 10.500 & 10.545 & 10.480 & 14.985 & 15.040 & 15.015 & 15.055 & 15.155 & 15.255 & 15.370 & 15.590 & 11.480 & 11.510 & 11.535 \\
\hline 11 & tf & 1.36 & 0.850 & 0.930 & 1.000 & 1.180 & 1.065 & 1.185 & 1.315 & 1.500 & 1.650 & 1.850 & 2.050 & 2.440 & 0.740 & 0.855 & 0.960 \\
\hline 12 & k & 2.3125 & 1.500 & 1.580 & 1.750 & 2.000 & 1.875 & 1.938 & 2.125 & 2.250 & 2.438 & 2.625 & 2.813 & 3.250 & 1.563 & 1.688 & 1.750 \\
\hline 13 & $b f / 2 t f$ & 4.5 & 6.170 & 5.650 & 5.300 & 4.400 & 7.000 & 6.300 & 5.700 & 5.000 & 4.600 & 4.100 & 3.700 & 3.200 & 7.800 & 6.700 & 6.000 \\
\hline 14 & h/tw & 39.1 & 47.800 & 46.200 & 43.900 & 41.500 & 41.200 & 38.000 & 34.900 & 32.500 & 29.000 & 26.500 & 23.700 & 19.900 & 54.500 & 51.700 & 49.600 \\
\hline 15 & Ix & 13200 & 4930 & 5360 & 5770 & 6680 & 8200 & 9170 & 10300 & 11700 & 13100 & 14900 & 16800 & 20700 & 5900 & 6710 & 7450 \\
\hline 16 & $Z x$ & 833 & 378 & 408 & 437 & 500 & 605 & 673 & 749 & 845 & 941 & 1060 & 1190 & 1430 & 415 & 467 & 514 \\
\hline 17 & Sx & 719 & 329 & 355 & 380 & 436 & 539 & 598 & 663 & 746 & 827 & 928 & 1030 & 1250 & 359 & 406 & 448 \\
\hline 18 & $\mathrm{rx}$ & 14.6 & 12.000 & 12.100 & 12.200 & 12.400 & 12.700 & 12.800 & 12.900 & 13.000 & 13.100 & 13.200 & 13.200 & 13.500 & 13.000 & 13.200 & 13.400 \\
\hline 19 & & & & & & & & & & & & & & & & & \\
\hline 20 & & & & & & & & & & & & & & & & & \\
\hline 21 & & & & & & & & & & & & & & & & & \\
\hline 22 & & & & & & & & & & & & & & & & & \\
\hline 23 & & & & & & & & & & & & & & & & & \\
\hline
\end{tabular}

(b)

Figure 3.6 RSS worksheet (a) conceptual (b) actual 


\section{AASHTO HL-93 live load effect}

Live load effects generated by MERLIN-DASH were imported and stored in the Blank worksheet of PURDUE CSBD. Live load effects included the bending moment and shear due to AASHTO HL-93 live load acting on the short-term composite section. The load dynamic factor, IM, of 1.33 was applied to the bending moment and shear. Evaluation for the bending moment and shear due to live load was performed as developing PURDUE CSBD for analyzing for AASHTO HL-93 live load effects. The imported live load effects were further processed for design code check with various load combinations.

The conceptual process of importing live load effects from the MERLIN-DASH output file is shown in Figure 3.7. A macro was developed to import live load effects from output files generated by the MERLIN-DASH. The result file of the current bridge is opened in the Blank worksheet of PURDUE CSBD. The analysis results generated by MERLIN-DASH are presented in tabular format and each table has a unique number. The macro imports an interesting live load effect upon the corresponding table number. Then, the imported live load effect is stored internally to be used later. After importing live load effects, data in the Blank worksheet is deleted for next bridge 


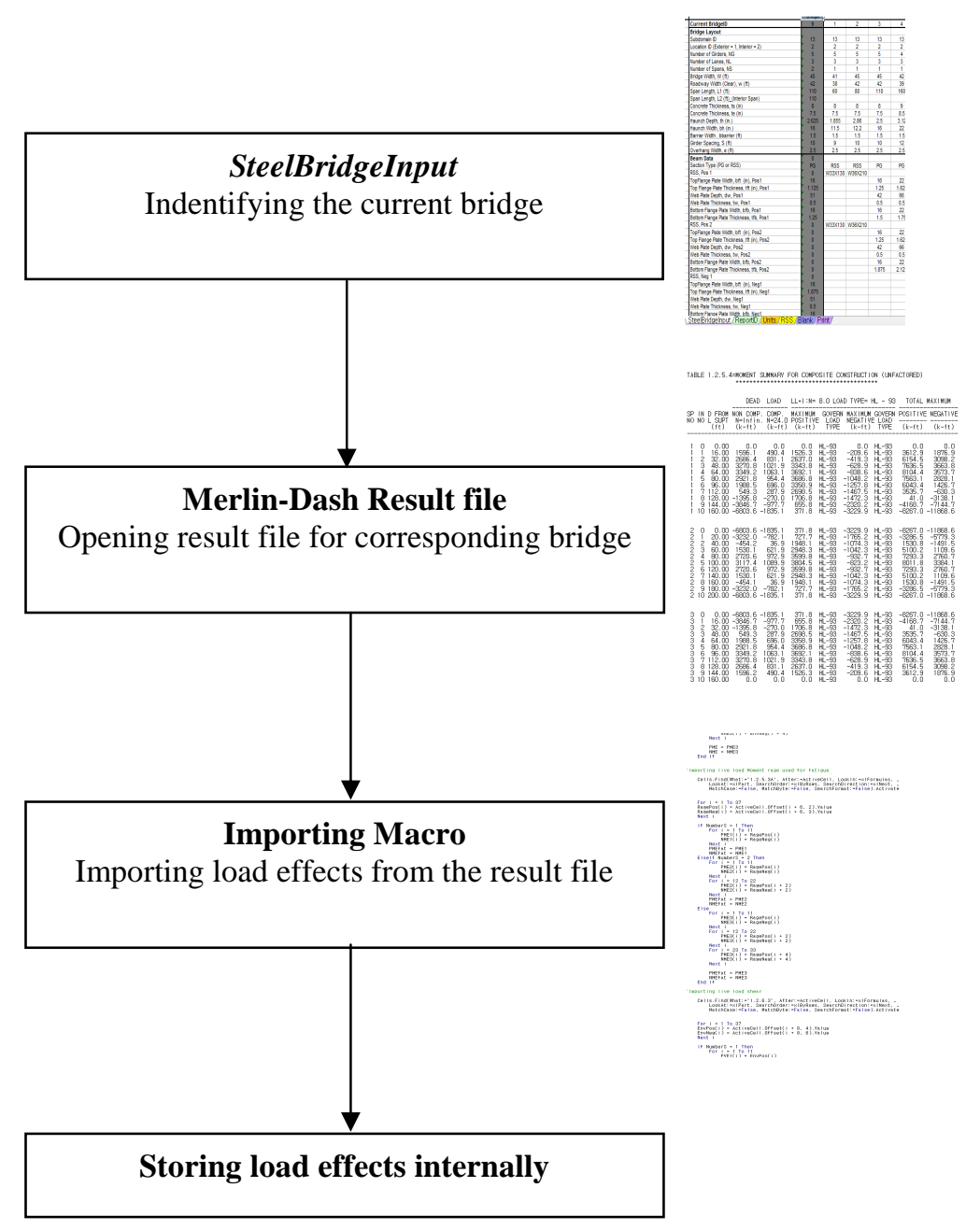

Figure 3.7 Conceptual process of importing live load effects from the result files of the MERLIN-DASH 


\section{Computer program's process for generation input files}

The SteelBridgeInput worksheet of PURDUE CSBD contains a control button, the "Start." The control button initiates the PURDUE CSBD program to execute the analysis. A designation number (Bridge ID) is assigned to each bridge of the test-bed. The PURDUE CSBD program performs the computation based upon this designation number. As PURDUE CSBD executes through each Bridge ID within the loop, the computer program obtains values of bridge input parameters for each bridge. Most of input parameters of composite steel I-girder are stored in the SteelBridgeInput and RSS worksheet. The PURDUE CSBD reads the input parameters directly from the two worksheets to eliminate the need for input files. This task is performed automatically by the PURDUE CSBD program.

\section{Evaluation of the results}

The output data produced by MERLIN-DASH needs to be formatted since MERLINDASH does not automatically generate the output data with the database readable format suggested by Baker et al. (2003). Hence, an additional macro was developed to rewrite the MERLIN-DASH output into the proposed format. The output data from two computational processes is filtered according to ReportID and stored into an Access database. Additional ninety two Report IDs were added for better comparisons into the list of ReportID developed by Baker et al. (2003). They are presented in Appendix C.

A query filters the data by Report ID into tables within the database. The filtered data are exported into Excel for the evaluation. Another macro that creates graphs for each ReportID was developed. Each graph created by the macro contains a filtering feature allowing the evaluation of a single or a set of bridges. The graphical feature is used for the nominal capacity results since they are given along the span length. Numerical comparisons are used for ReportID of single number. 


\section{PURDUE CSBD}

An indigenous computer program, PURDUE CSBD, was developed to conduct structural analysis and perform design calculations for all the simple and multi-span bridges in the test-bed. The program was written in Visual Basic for Applications (VBA) code using the appropriate AASHTO LRFD specifications to perform the design calculations for composite steel bridges. The PURDUE CSBD program reads the input parameters from the BridgeInput and RSS, worksheets. PURDUE CSBD computes section properties, moments, shears, stresses, deflections. The program also performs design calculations associated with flexural strength, shear strength, fatigue limit state, and shear connectors. The general process of PURDUE CSBD is shown in Flowchart D.1 of Appendix D. As shown in the flowchart, various steps and numbers of subroutines were included in the process. The program generates the output for each bridge in a database readable file format. This output is accessed by a separate module in PURDUE CSBD and used to generate numerical and graphical comparisons of the bridge design and analysis results generated by MERLIN-DASH and PURDUE CSBD. Flowcharts for all relevant design computation algorithms in the PURDUE CSBD program are provided in Appendix D and the WriteOutput subroutine is not included.

\section{CriticalSections subroutine}

The CriticalSections subroutine calculates the physical location of each tenth point along the span length. The subroutine is inevitable since most of results generated by MERLIN-DASH are shown with tenth points and their physical locations. Additionally, PURDUE CSBD uses the location of each tenth point as a coordinate system when the program is executed. A flowchart of the CriticalSections subroutine is shown in Flowchart D.2 of Appendix D. As shown in the flowchart, following steps are included in the subroutine.

1. Find values for number of span, $N_{S}$, and span Length, $L$, from the SteelBridgeInput worksheet.

2. Divide span Length, $L$, by 10 to compute the length increments, $L_{S I}$.

3. Compute the location of each tenth point along the span length, $x(\mathrm{i})$, as given in Equation 4.1

$$
\mathrm{x}(\mathrm{i})=(\mathrm{i}-1) L_{S I} \quad \text { Eq. } 4.1
$$




\section{MaterialProperties subroutine}

The MaterialProperties subroutine finds values for material properties of steel and concrete from the SteelBridgeInput worksheet. The values are stored in constants and arrays and used in other subroutines later. The SteelBridgeInput worksheet contains values for the elastic modulus of steel, $E_{s}$, elastic modulus of concrete, $E_{c}$, unit weight of steel, $q_{s}$, unit weight of concrete, $q_{c}$, minimum yield stress of reinforcement steel bars, $F_{y r e}$, and minimum yield stress of steel girder. A flowchart of the MaterialProperties subroutine is shown in Flowchart D.3 of Appendix D.

\section{SectionProperties subroutine}

This subroutine computes the cross sectional area, centroid, elastic section modulus, and moment of inertia of the non-composite and composite sections. The subroutine identifies the presence of shear studs in negative flexure. When shear studs are presented in negative flexure, the reinforcement steel is added into section properties. Concrete slab deck and haunch in positive flexure are transformed to an equivalent steel area. However, concrete slab deck and haunch in negative flexure are not taken into composite section properties except the fatigue analysis. They are assumed to be effective in both positive and negative flexure for the fatigue analysis as specified in Article 6.6.1.2.1 of AASHTO LRFD specifications (2008). The algorithm of the subroutine is presented in Flowchart D.4 of Appendix D.

Two different subroutines were developed to perform the computation of section properties and they are RSSsectionProperties and PGsectionProperties. One of these two subroutines is called upon the type of steel girder section. The flowchart of the PGsectionProperties subroutine is shown in Flowchart D.5 of Appendix D. The flowchart of the RSSsectionProperties subroutine is not shown since the algorithm of RSSsectionProperties is the same as that of PGsectionProperties. The only difference is the non-composite section properties which are stored in the RSS worksheet. The algorithm of the SectionProperties subroutine consists of several steps described below.

1. Compute the gross area of the non-composite section at the first tenth point $\left(\mathrm{A}_{\mathrm{g}}\right)$

2. Compute the first moment of area of each element (flanges and webs) of the non-composite girder sections, $\mathrm{y}(\mathrm{i}) \mathrm{A}(\mathrm{i})$, about the bottom face of the non-composite girder sections. Take 
their sum, $\Sigma$ y(i)A(i), and divide it by the gross area, $\mathrm{A}_{\mathrm{g}}$, to determine the centroid of the non-composite section with respect to the extreme bottom fiber, $\mathrm{y}_{\mathrm{gb}}$.

3. Compute the centroid of the non-composite section with respect to the extreme top fiber, $\mathrm{y}_{\mathrm{gt}}$ by subtracting $\mathrm{y}_{\mathrm{gb}}$ from the depth of the non-composite section, $\mathrm{h}_{\text {beamNC. }}$

4. Compute the moment of inertia of each part I(i) about its own centroid as shown in Equation 4.2 .

$$
\begin{array}{ll}
I(i)=b h^{3} / 12 & \text { Eq. } 4.2
\end{array}
$$

5. Compute the distance from the $\mathrm{y}_{\mathrm{gb}}$ to the centroid of each part, $\mathrm{y}(\mathrm{i})$, to compute the moment of inertia of the gross section, $I_{g}$, at the first tenth point as shown in Equation 4.3.

$$
\begin{array}{ll}
I_{g}=\Sigma I(i)+A(i)\left(y_{g b}-y(i)\right)^{2} & \text { Eq. } 4.3
\end{array}
$$

6. Compute the elastic section modulus with respect to the bottom and top, $S_{b}$, $S_{t}$ by dividing $I_{g}$ by $y_{g b}$ and $y_{g t}$.

7. Divide the modulus of elasticity of steel section, Es, by the modulus of elasticity of concrete slab, $E c$, to obtain the modular ratio of the short-term composite section, $n_{S T}$. Equation 4.4 is used.

$$
n_{S T}=E_{S} / E_{C} \quad \text { Eq. } 4.4
$$

8. Compute the effective width of the deck slab, $b_{e}$, according to AASHTO (2008) Article 4.6.2.6.1. For interior girders, the width is taken as one-half the distance to the adjacent girder on each side of girder.

9. Compute the area of concrete slab and haunch given by Equations 4.5 and 4.6. For section properties in negative flexure, concrete slab and haunch area are not taken into section properties. However, when shear studs are presented in negative flexure, longitudinal steel reinforcements are taken into section properties.

$$
\begin{array}{ll}
A_{\text {slab }}=\left(b_{e} t_{e s}\right) & \text { Eq. } 4.5 \\
A_{\text {haunch }}=\left(b_{e} t_{e s}\right) & \text { Eq. } 4.6
\end{array}
$$

10. Repeat step 2 to compute the centroid of the short-term composite sections with respect to the extreme bottom fiber, $y_{b S T}$, given by Equation 4.7.

$$
y_{b S T}=\frac{\sum(y(i) A(i))+y_{\text {slabST }} A_{\text {slab }} / n_{S T}+y_{\text {haunch }} A_{\text {haunch }} / n_{S T}}{\sum A(i)+A_{\text {slab }} / n_{S T}+A_{\text {haunch }} / n_{S T}} \quad \text { Eq. } 4.7
$$


11. Repeat step 3 to calculate the centroid of the short-term composite sections with respect to the extreme top fiber, $y_{t S T}$.

12. Repeat step 4 and 5 to compute the moment of inertia of the short-term composite section, $I_{x S T}$. Equation 4.8 is used to compute $I_{x S T}$.

$$
\begin{aligned}
& I_{x S T}=I_{x g}+A_{g}\left(y_{b S T}-y_{g b}\right)^{2} I_{\text {slabsT }}+A_{\text {slab }}\left(y_{b S T}-y_{\text {slab }}\right)^{2} \\
& +I_{\text {haunchST }}+A_{\text {haunch }}\left(y_{b S T}-y_{\text {hauch }}\right)^{2}
\end{aligned}
$$

13. Repeat Step 6 to compute the elastic section modulus at the short-term composite with respect to the bottom and top.

14. Repeat step 7 to compute the modular ratio of the long-term composite section, $n_{L T} . n_{S T}$ is multiplied by 3 to determine $n_{L T}$.

15. Repeat step $11 \sim 13$ to compute the long-term composite section properties.

16. Repeat step $9 \sim 12$ to compute the section properties of the short-term composite sections required for the fatigue analysis.

17. Repeat step $1 \sim 16$ for the rest of tenth points

\section{MomentShear subroutine}

The load effects (including moment, shear, deflection, and stress) due to dead load and live load are computed in this subroutine. Additional subroutines (MomentArray and ShearArray) were developed to write the computed data to a readable format. The MomentArray subroutine is called to generate the bending moment and the ShearArray subroutine is called to generate shear. The general process of the MomentArray subroutine and ShearArray subroutine are presented in Flowchart D.7 and D.9, respectively. The direct stiffness matrix approach is used to perform the actual computation and the matrix approach is built in the DSM subroutine. The details of the DSM subroutine are discussed later.

For prestressed concrete bridges, tables of normalized influence function for various span configurations and span ratio published by the American Institute for Steel Construction (AISC) were used to generate the bending moment and shear due to live load. The tables were not used in this study since they are only applicable to bridges with homogeneous stiffness along the span length. Instead, the MomentShear subroutine was modified to develop tables of influence ordinates internally. The subroutine placed unit gravitational load, 1 kip, to every tenth point. 
The DSM subroutine performed the calculation and the computed load effects due to the unit load at each tenth point are stored. Load effects of the unit load at all tenth points were used to determine the maximum load effect using the Muller-Breslau principle. However, developing the tables took additional time for the computation and live load effects generated by MERLINDASH have been checked with other commercially available software and by hundreds of endusers. Eventually, it was decided to import live load effects generated by MERLIN-DASH.

The flowchart of MomentShear subroutine is shown in Flowchart D.6 of Appendix D and the algorithm of the subroutine consists of the following steps:

1. Compute the dead loads in kip/ft.

2. Determine unfactored moment due to the self weight of the non-composite girder, slab weight, haunch, and form by calling the MomentArray subroutine.

3. Compute unfactored moment due to DC1 by calling the SumMomentShear subroutine.

4. Determine unfactored shear due to each dead load element by calling the ShearArray subroutine.

5. Compute unfactored shear due to DC1 by calling the SumMomentShear subroutine.

6. Determine contra-flexure points where the direction of bending moment changes.

7. Compute unfactored moment and shear due to DC2 and DW by calling the MomentArray subroutine and ShearArray subroutine, respectively. Section properties of the long-term composite sections and contra-flexure points are applied.

8. Compute distribution factor for live load moment, DFM, and shear, DFV, according to AASHTIO LRFD Article 4.6.2.2 by calling the DistributionFactor public function. Equation 4.9 and 4.10 were used to compute distribution factor for live load moment, DFM, and shear, DFV.

$$
\begin{aligned}
& D F M=\max (D F M 1, D F M 2) \\
& D F M 1=0.06+\left(\frac{S_{G}}{14}\right)^{0.4}\left(\frac{S_{G}}{L}\right)^{0.3}\left(\frac{K_{g}}{12.0 L t_{s}^{3}}\right)^{0.1} \\
& D F M 2=0.075+\left(\frac{S_{G}}{9.5}\right)^{0.6}\left(\frac{S_{G}}{L}\right)^{0.2}\left(\frac{K_{g}}{12.0 L t_{s}^{3}}\right)^{0.1}
\end{aligned}
$$




$$
\begin{aligned}
& D F M=\max (D F V 1, D F V 2) \\
& D F V 1=0.36+\frac{S_{G}}{25} \\
& D F V 2=0.36+\frac{S_{G}}{12}-\left(\frac{S_{G}}{35}\right)^{2}
\end{aligned}
$$

9. Import Live load effects generated by MERLIN-DASH

10. Compute factored moment and factored shear with various load combinations by calling the Loadcombination public function as shown in Flowchart D.10 of Appendix D.

11. Determine stresses at both the top and bottom of flanges and the top of the concrete slab with various load combinations by calling the StressCombination public function as shown in Flowchart D.11 of Appendix D.

\section{$\underline{D S M}$ subroutine}

The DSM subroutine takes a huge role in PURDUE CSBD. The bending moment and shear due to dead load are actually computed by the subroutine. The direct stiffness matrix approach is used in the subroutine. Each tenth point is identified as a node and an element is defined by between two adjacent tenth points. The physical location of each node is entered to the subroutine using $x$ (i) generated by the CriticalSections subroutine. Section properties including section area and moment of inertia computed by the SectionProperties subroutine are assigned into each element. Figure 4.1 presents an example of numbering of nodes and elements for two span bridges. Numbers inside the circle are identification numbers of nodes and numbers inside the rectangular indicate identification numbers of elements. Each node has one to three degrees of freedom depending on its constrain and they are numbered as shown in Figure 4.2.

Flowchart D.28 of Appendix D shows the algorithm of the subroutine which consists of several steps as below.

1. Compute the number of nodes $\left(n_{n}\right)$ and elements $\left(n_{e}\right)$ based on the number of spans.

2. Assign section properties of each element into $s p$ array by calling the sectionarray public function. Figure 4.3 shows the schematic view of the array. The first column contains cross sectional areas of elements and the second column stores moment of inertias.

3. Assign node information of each node into nodes array by calling the getnodes public function. Nodal information is entered as shown in Figure 4.4. The first three columns of the 
array define active or restrained degree of freedom (DOF) of nodes. 1 is assigned to restrained DOFs and 0 is assigned to active DOFs. The fourth and fifth column defines $\mathrm{x}$ and y locations of each node.

4. Assign element information into ela array by calling the getela public function. Figue 4.5 shows the schematic view of the array. The first two columns contain the elastic modulus of steel, $\mathrm{E}_{\mathrm{s}}$ and the identification number of an element from the $s p$ array. For example, section properties of the second element stored in the $2_{\text {nd }}$ row of the $s p$ array, hence, 2 is entered into the second row on the second column of the ela array. The third column contains the type of loading case. 1 is assigned for the uniformly distributed load case and 2 is entered for the point load acting on an element. The last two columns contain the starting and end node number which defines an element.

5. Obtain element load case by calling the getDL. Element load case of each span is stored in $D L$ array as shown in Flowchart D.29 of Appendix D. The first column indicates the load case number. Only one load case is assumed, hence, 1 is assigned. The second column contains the type of element load. Load type 1 is a distributed load of value w1 stored in column3. Load type 2 is a point load (P) at position (a) and these values are stored in columns 3 and 4 respectively.

6. Obtain the value of the point load acting on a node and the location of the point load by calling the getPLa. The flowchart of getPLa is shown in Flowchart D.30 of Appendix D. The first column corresponds to the node that is being loaded and the second column is the corresponding dof. That is, 1 is assigned for translation and 2 is assigned for rotation. The load case number is stored in the third column and the fourth column contains the value of the point load.

7. Assign the identification number to each degree of freedom and determine the total number of degree of freedoms, ndof, by calling the mid public function. The flowchart of the function is shown in Flowchart D.31 of Appendix D.

8. Obtain the location of each node in the Cartesian coordinate system by calling the getx public function. The location is written as (x,y). The far left point of bridges (Location 100) is assumed to be $(0,0)$. The flowchart of the function is shown in Flowchart D.32 of Appendix D. 
9. Assign the global identification numbers to degree of freedoms within the first element by calling the getlm public function. This identifies global degree of freedoms corresponding to local degree of freedom within the element. The flowchart of the function is shown in Flowchart D.33 of Appendix D.

10. Compute the element stiffness matrix of the first element by calling the getke public function. The element number (ie) of the first element, ela array, $x$ array, and $s p$ array obtained earlier are used. Information of the first element including nodal information is processed to compute the 6 by 6 element stiffness matrix of the first element. The flowchart of the function is shown in Flowchart D.34 of Appendix D.

11. Compute the fixed end force of the first element by calling the getfee public function. The value of uniform load $(w)$ and the length of the first element are computed and the 1 by 6 element fixed end force array of the first element is obtained. The flowchart of the function is shown in Flowchart D.35 of Appendix D.

12. Compute the transformation matrix for the first element by calling the getTe public function. The flowchart of the function is shown in Flowchart D.36 of Appendix D.

13. Transform the computed element stiffness matrix (ke) into the global element stiffness matrix (Ke) using Equation 4.11.

$$
K e=T e^{T} \cdot k e \cdot T e
$$

14. Transform the computed element fixed end force array (fee) into the global fixed end force array (Fe) using Equation 4.12

$$
F e=T e^{T} \cdot f e e \quad \text { Eq. } 4.12
$$

15. Compute the global stiffness matrix $(\mathrm{K})$ by assembling the global element stiffness matrix $(\mathrm{Ke})$.

16. Compute the global fixed end force array $(\mathrm{Fe})$ by assembly the global element fixed end force array (fee) as given in Equation 4.13.

$$
F=P-F e \quad \text { Eq. } 4.13
$$

17. Compute the global displacement matrix (delta) using Equation 4.14.

$$
\begin{array}{ll}
\text { delta }=K^{-1} \cdot F & \text { Eq. } 4.14
\end{array}
$$

18. Compute element forces by calling the recov public function. The flowchart of the function is shown in Flowchart D.38 of Appendix D. 
A series of arrays are created internally as described above to enter material property, section property, and loading condition. Since each span has more than 10 elements (including 2 elements at each contra flexure points) and three degrees of freedom are assumed at each node, the subroutine produces a huge size of the global stiffness matrix that PURDUE CSBD can not calculate the inverse of the matrix. Hence, a special linear algebra technique, the Schur complement, is used. The detail of the Schur complement is presented in Figure 4.6. The global stiffness matrix is divided into four different matrix blocks which are $\boldsymbol{A}, \boldsymbol{B}, \boldsymbol{C}$, and $\boldsymbol{D}$. Then, the inverse of the matrix is computed using algebra as shown in Figure 4.7.

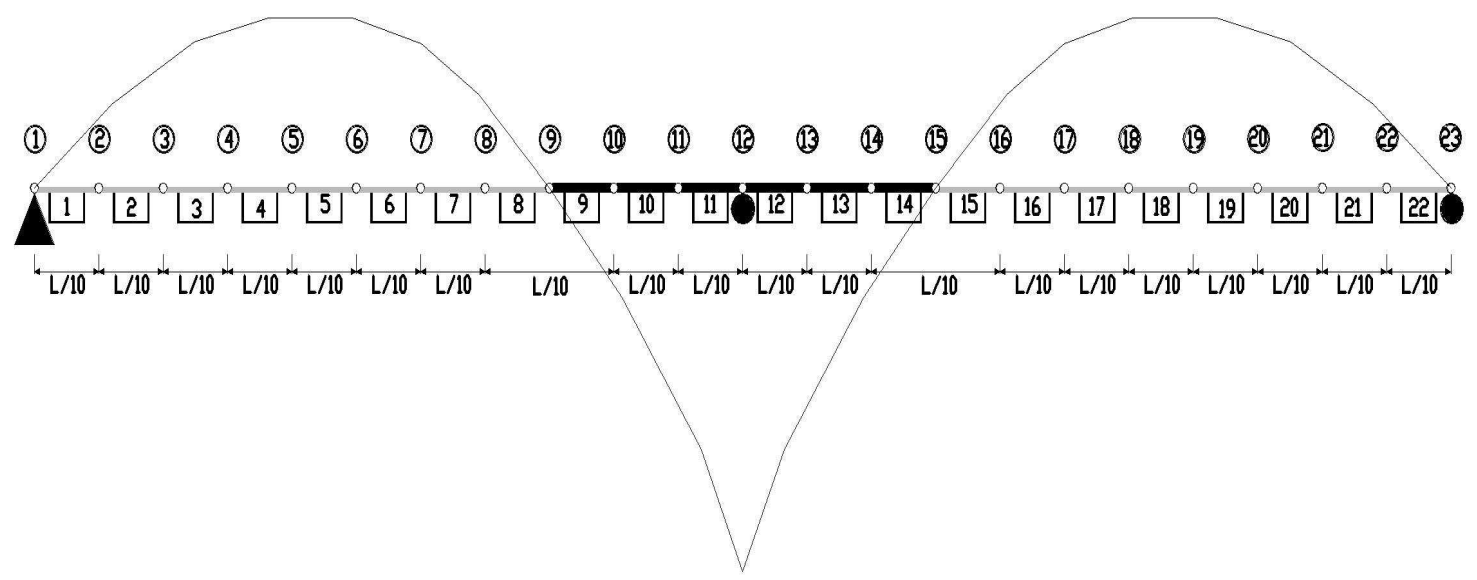

Figure 4.1 Example of numbering of nodes and elements for two span bridges

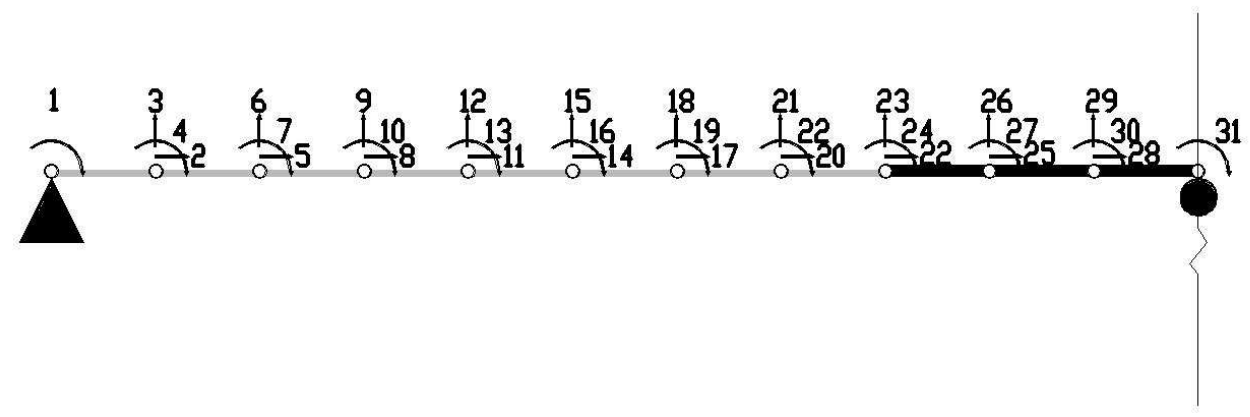

Figure 4.2 Example of numbering of degree of freedom in the global coordinate system for two span bridges 


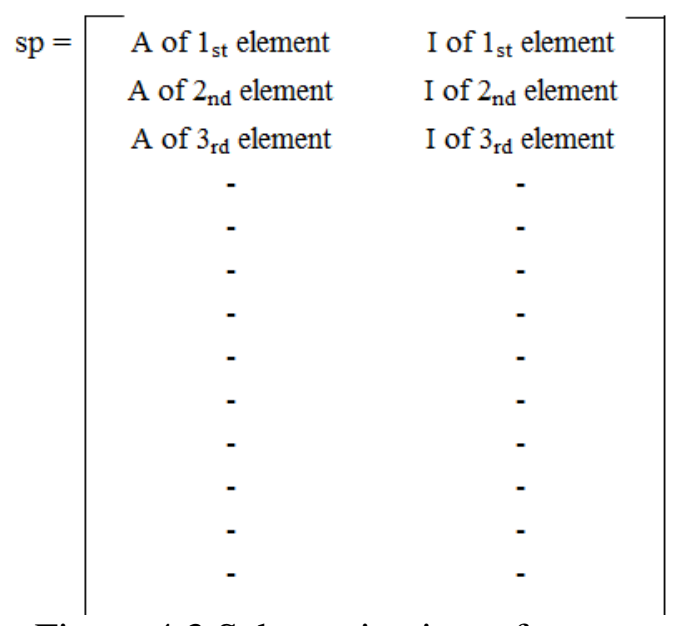

Figure 4.3 Schematic view of $s p$ array

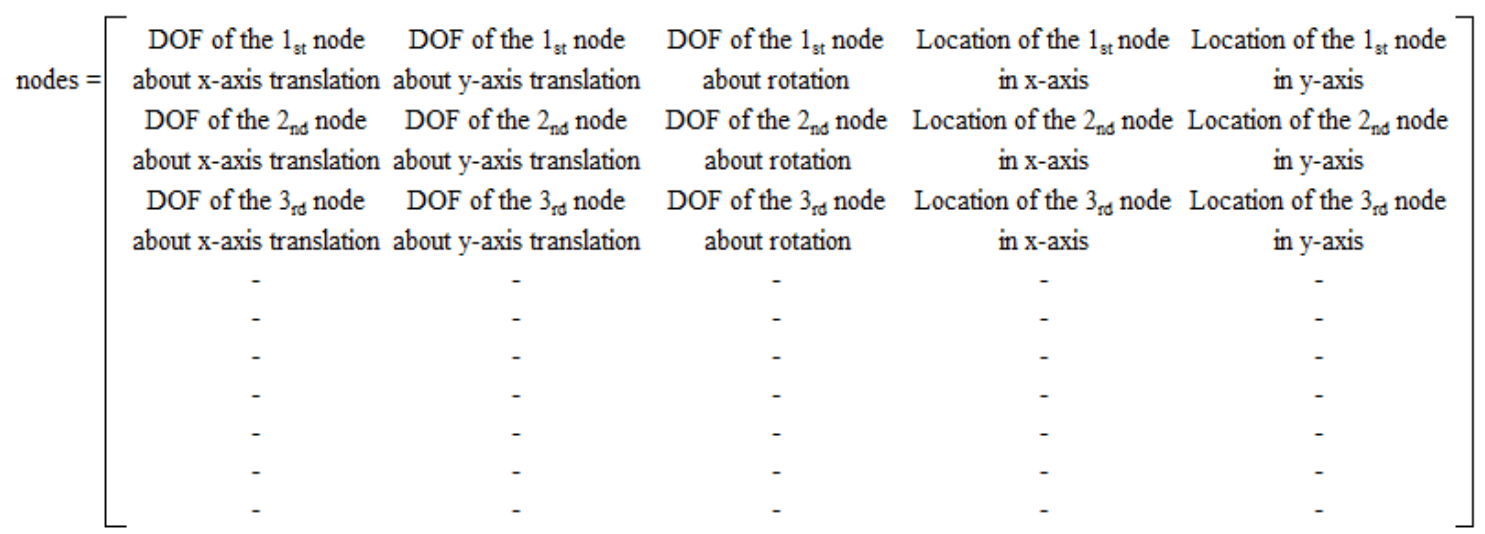

Figure 4.4 Schematic view of nodes array

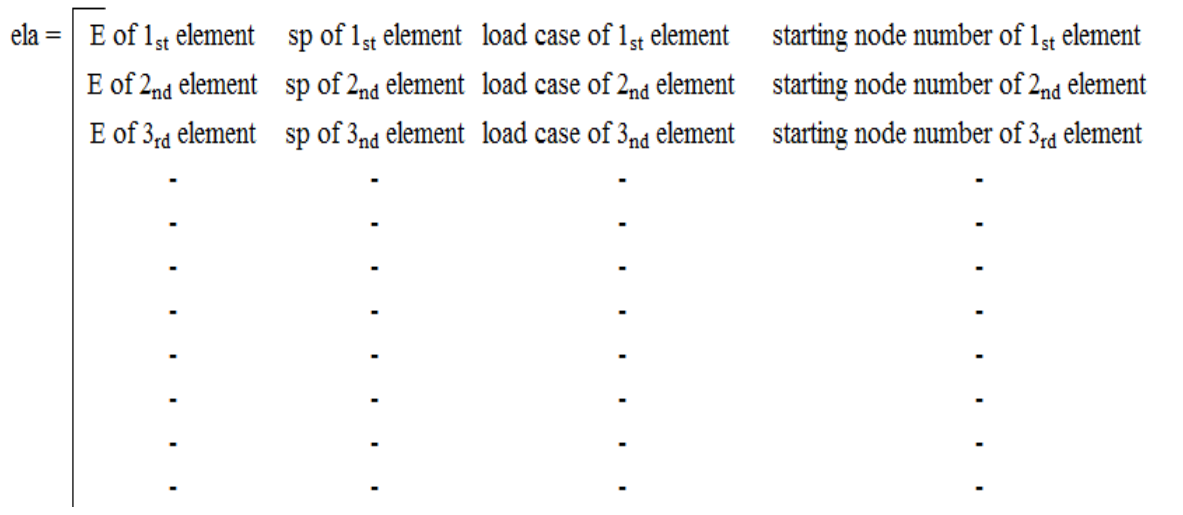

ending node number of $1_{\text {st }}$ element

ending node number of $2_{\text {nd }}$ element

ending node number of $3_{\text {rd }}$ element

Figure 4.5 Schematic view of ela array 


$$
K=\left[\begin{array}{ll}
A & B \\
C & D
\end{array}\right]
$$

Figure 4.6 The Schur complement of a matrix block

$$
K^{-1}=\frac{1}{A D-B C}\left[\begin{array}{cc}
D & -B \\
-C & A
\end{array}\right]
$$

Figure 4.7 The inverse of the Schur complement of a matrix block 


\section{PlasticMomentCapacity subroutine}

This subroutine calculates the plastic moment capacity, $M_{p}$, of composite sections along the span length. The plastic moment capacity is used later to determine the nominal flexural resistance, $M_{n}$. The subroutine computes the plastic moment capacity according to AASHTO LRFD Article D6.1. As stated in the article, the plastic neutral axis is determined with no net axial force assumed. To determine plastic neutral axis, plastic forces in steel and concrete portions of composite sections are calculated using the yield strengths of each part of steel section and a rectangular stress block on concrete portion with the magnitude of the compressive stress equal to $0.85 \mathrm{fc}$ '.

By computing the plastic neutral axis, the location of the axis can be determined whether it is located in the web or top flange or concrete deck. After determining the location of the axis, the plastic moment capacity, $M_{p}$, is calculated easily by using equations for the various potential locations of the plastic neutral axis given in Table 1 and 2 of Article D6.1. As specified in the article, the plastic force in the longitudinal reinforcement in positive flexure is conservatively neglected. The plastic moment capacity in positive flexure is computed using Table 1 and the capacity in negative flexure is calculated using Table 2.

A flowchart of the PlasticMomentCapacity subroutine is shown in Flowchart D.12 of Appendix D. The algorithm of the subroutine consists of the following steps:

1. Find values of distances of the top longitudinal reinforcement from the top of the concrete slab and the distances of the bottom longitudinal reinforcement from the bottom of the concrete slab.

2. Compute plastic forces of each component of cross-section summarized in Equation 4.15.

$$
\begin{aligned}
& P_{s}=0.85 f^{\prime}{ }_{c} b_{e} t_{e s} \\
& P_{c}=F_{y c} A_{f c} \\
& P_{w}=F_{y w} A_{w} \\
& P_{t}=F_{y t} A_{f t} \\
& P_{r t}=F_{y r e} A_{r t} \\
& P_{r b}=0
\end{aligned}
$$

3. Check the condition among plastic forces as specified in Table 1 and 2 and determine case number to use. 
4. Compute the distance from the plastic neutral axis to the top of the element where the plastic neutral axis is located, $Y_{b a r}$, using the equation given for each case number.

5. Compute the plastic moment capacity, $M_{p}$, using the equation given for each case number.

6. Compute the distance from the top of the concrete deck to the neutral axis of the composite section at the plastic moment, $D_{p}$.

7. Compute the additional moment required to cause yielding in bottom flanges, $M_{a d}$, and Yield moment, $M_{y}$. The additional moment required to cause yielding in bottom flanges, $M_{a d}$, is determined using Equation 4.17 and Equation 4.18 is used to compute Yield moment, $M_{y}$. The additional moment required to cause yielding in bottom flanges, $M_{a d}$, and yield moment, $M_{y}$, are used later to check strength limit state, service limit state. Equation 4.16 and 4.17 are given in AASHTO LRFD Article D6.2.2. The PlasticMomentCapacity subroutine calls a public function, Madfunct, to perform the computation and the algorithm of the function is shown in Flowchart D.13 of Appendix D.

$$
M_{a d}=\left(F_{y b f}-\left(\frac{M_{D C 1}}{S_{b}}+\frac{M_{D C 2}}{S_{b L T}}+\frac{M_{D W}}{S_{b L T}}\right)\right) S_{b S T}
$$

where :

Eq. 4.16

$F_{y b f}=$ The minimum yield stress of the bottom flange

$$
\begin{array}{ll}
M_{y}=M_{D C 1}+M_{D C 2}+M_{D W}+M_{a d} \quad \text { Eq. } 4.17
\end{array}
$$

\section{StrengthLimitsState subroutine}

This subroutine computes the flexural strength as specified in Article 6.10 of the AASHTO LRFD specifications (2008). The subroutine determines the compactness of composite section first. According to the Article, the nominal flexural resistance of the section, $M_{n}$, is used for composite compact sections in positive flexure, whereas the nominal flexural resistance of the compression flange, $F_{n c}$, is used for non-compact sections. For composite section in negative flexure, the nominal flexural resistance of the compression flange, $F_{n c}$, is used for discretely braced flanges in compression, and the nominal flexural resistance of the tension flange, $F_{n t}$, is used for discretely braced flanges in tension. $F_{n c}$ is determined as the smaller between the local buckling resistance of the compression flange, $F_{n c F L B}$, and the lateral torsional buckling 
resistance of the compression flange, $F_{n c L T B}$. Additional parameters are required to compute the flexural strength and they include the web-load shedding factor, $R_{b}$, hybrid factor, $R_{h}$, moment gradient modifier, $C_{\mathrm{b}}$, slenderness ratio for the compression flange, $\lambda_{f}$, limiting slenderness ratios, $\lambda_{p f}, \lambda_{r f}$, unbraced length, $L_{b}$, limiting unbraced lengths, $L_{p}, L_{r}$, and other parameters.

A flowchart of the StrengthLimitState subroutine is shown in Flowchart D.14 of Appendix D. The algorithm of the subroutine consists of the following steps:

1. Compute the depth of web in compression, $D_{c}$, at both the non-composite stage and composite stage by calling the DepthThicknessRatio public function. The public function was developed according to AASHTO LRFD Article D6.3.1. The function computes $D_{c}$ as given in Equation 4.18. For composite sections in negative flexure, depth of web in compression is computed for the section consisting of the steel girder and longitudinal reinforcement.

$$
D_{c}=\left(\frac{-f_{c}}{\left|f_{c}\right|+f_{t}}\right) d-t_{f c} \geq 0
$$

where:

$d=$ depth of the steel section

$f c=$ sum of the compression-flange stresses

Eq. 4. 18

caused by the different loads.

$f t=$ sum of the tension-flange stresses

caused by the different loads.

2. Determine the web category.

3. Check section proportions by calling the SectionProportionCheck public function. The section proportion is checked according to AASHTO LRFD Article 6.10.2 and the algorithm of the function is shown in Flowchart D.15 of Appendix D.

4. Compute the effective radius of gyration for lateral torsional buckling as shown in Equation 4.19.

$$
r_{t}=\frac{b_{f_{c}}}{\sqrt{12\left(1+\frac{D_{c} t_{w}}{3 b_{f_{c}} t_{f c}}\right)}}
$$

5. Calculate the slenderness ratio for the compression flange, $\lambda_{f}$, and limiting slenderness ratios, $\lambda_{p f}$ and $\lambda_{r f}$, as shown in Equation 4.20 to 4.22 . 


$$
\begin{aligned}
& \lambda_{f}=\frac{b_{f c}}{2 t_{f c}} \\
& \lambda_{p f}=0.38 \sqrt{\frac{E}{F_{y c}}} \\
& \lambda_{r f}=0.56 \sqrt{\frac{E}{F_{y r}}}
\end{aligned}
$$

Eq. 4. 22

6. Determine the flange local buckling category.

7. Determine the unbraced length, $L_{b}$.

8. Compute other limiting unbraced lengths, $L_{p}$ and $L_{r}$ as shown in Equations 4.23 to 4.24.

$$
\begin{aligned}
& L_{p}=1.0 r_{t} \sqrt{\frac{E}{F_{y c}}} \\
& L_{r}=\pi r_{t} \sqrt{\frac{E}{F_{y r}}}
\end{aligned}
$$

9. Determine the lateral torsional buckling category. Step 5 to 9 is performed by calling the FLBLTBCategory public function and the algorithm of the function is presented in Flowchart D.16 of Appendix D.

10. Compute the hybrid factor, $R_{h}$, using Equation 4.25.

$R_{h}=1$ for RSS, homogenous built-up sections and built-up sections with a higher-strength steel in the web than in both flanges.

Otherwise,

$$
R_{h}=\frac{12+\beta\left(3 \rho-\rho^{3}\right)}{12+2 \beta}
$$

Where:

$$
\begin{aligned}
\beta= & \frac{2 D_{n} t_{w}}{A_{f n}} \\
\rho= & \min \left(F_{y w} / f_{n}, 1.0\right) \\
D_{n}= & \text { larger of the distances from the elastic neutral axis } \\
& \text { of the cross-section to the inside face of either } \\
& \text { flange. }
\end{aligned}
$$


11. Compute the web load-shedding factor, $R_{b}$, using Equation 4.26.

$R_{b}=1$ for the composite section in positive flexure or the section satisfying the proportion limit or the web satisfying $2 D_{c} / t_{w} \leq \lambda_{w}$.

Otherwise,

$$
\begin{gathered}
R_{b}=1-\left(\frac{a_{w c}}{1200+300 a_{w c}}\right)\left(\frac{2 D_{c}}{t_{w}}-\lambda_{r w}\right) \leq 1.0 \\
\text { where } \lambda_{r w}=5.7 \sqrt{\frac{E}{F_{y c}}} \\
a_{w c}=\frac{2 D_{c} t_{w}}{b_{f c} t_{f c}}
\end{gathered}
$$

12. Compute the moment gradient modifier, $C_{b}$, as shown in Figure 4.27.

$C_{b}=1$ for unbraced cantilevers and members

$$
\text { where } f_{\text {mid }} / f_{2}>1 \text { or } f_{2}=0
$$

Otherwise,

Eq. 4.27

$$
C_{b}=1.75-1.05\left(\frac{f_{1}}{f_{2}}\right)+0.3\left(\frac{f_{1}}{f_{2}}\right)^{2} \leq 2.3
$$

13. Compute the nominal flexural resistance of compact section in positive flexure using Equation 4.28.

$$
M_{n}=M_{p} \text { for } D_{p} \leq 0.1 D_{t}
$$

Otherwise:

$$
\begin{array}{lll}
M_{n}=M_{p}\left(1.07-0.7 \frac{D_{p}}{D_{t}}\right) & \text { for simple span } & \text { Eq. } 4.28 \\
M_{n}=M_{p}\left(1.07-0.7 \frac{D_{p}}{D_{t}}\right) \leq 1.3 R_{h} M_{y} & \text { for continuous span } &
\end{array}
$$

14. Determine the nominal flexural resistance of a compression flange based on the flange local buckling category and the lateral torsional buckling category. Equations 4.29 and 4.30 are used for this calculation. Step 14 is performed by the FLBandLTBResistance subroutine and the algorithm of the subroutine is shown in Flowchart D.17 of Appendix D. 


$$
F_{n c F L B}=R_{h} R_{b} F_{y c} \quad \text { for } \lambda_{f} \leq \lambda_{p f}
$$

Otherwise:

$$
\begin{aligned}
& F_{n c F L B}=\left(1-\left(1-\frac{F_{y r}}{R_{h} F_{y c}}\right)\right)\left(\frac{\lambda_{f}-\lambda_{p f}}{\lambda_{r f}-\lambda_{p f}}\right) R_{h} R_{b} F_{y c} \\
& F_{n c L T B}=R_{h} R_{b} F_{y c} \text { for } L_{b} \leq L_{p} \\
& F_{n c L T B}=\left(1-\left(1-\frac{F_{y r}}{R_{h} F_{y c}}\right)\right)\left(\frac{L_{b}-L_{p}}{L_{r}-L_{p}}\right) R_{h} R_{b} F_{y c} \leq R_{h} R_{b} F_{y c} \\
& \quad \text { for } L_{p}<L_{b} \leq L_{r} \\
& F_{n c L T B}=F_{c r} \leq R_{h} R_{b} F_{y c} \text { for } L_{b r}<L_{b}
\end{aligned}
$$

Eq. 4. 30

15. Check the strength limit state of the section in positive flexure according to the web category as shown in Equation 4.31.

$$
\begin{array}{ll}
M_{u} \leq \phi_{f} M_{n} & \text { for compact sections } \\
f_{b u} \leq \phi_{f} F_{n c} & \text { for non-compact sections }
\end{array}
$$

Eq. 4.31

\section{ShearCapacity subroutine}

The ShearCapacity subroutine computes the shear strength of a girder at specific tenth points along the span length. The subroutine was developed in accordance with AASHTO LRFD Article 6.10.9. The general process of the subroutine is shown in Flowchart D.18 of Appendix D. The computation flow heavily depends on the presence of transverse stiffeners. For this reason, the subroutine identifies the presence of transverse stiffeners from the test-bed first. For unstiffened girder sections, AASHTO LRFD Article 6.10.9.2 is used to compute the nominal resistance of unstiffened webs. For stiffened sections, AASHTO LRFD Article 6.10.9.3 is used to calculate the nominal resistance of stiffened webs. The tension field action is taken into consideration for the computation of the shear strength. The algorithm of the subroutine consists of the following steps:

1. Identify the presence of transverse stiffeners

2. Obtain values for interior panels spacing $\left(d_{o}\right)$ and end panels spacing $\left(d_{o e n d}\right)$ from the testbed. 
3. Determine tenth points located within end panels.

4. Compute the plastic shear force, $V_{p}$, using Equation 4.32 .

$$
V_{p}=0.58 F_{y w} D t_{w}
$$

Eq. 4. 32

5. Compute the shear-buckling coefficient for webs, $k$, using Equation 4.33.

$$
\begin{array}{lll}
k=5+\frac{5}{d_{0} / d_{\text {web }}} & \text { for stiffened sections } & \text { Eq. } 4.33 \\
k=5 & \text { for unstiffened sections } &
\end{array}
$$

6. Compute the ratio of the shear-buckling resistance to the shear yield strength, $C$, for sections that can reach to post-buckling shear resistance as shown in Equation 4.34. In the subroutine, the CFunct is called to perform the calculation. The general flow of the function is given in Flowchart D.19 of Appendix D.

$$
\begin{array}{ll}
C=1.0 & \text { for } \frac{D}{t_{w}} \leq 1.12 \sqrt{\frac{E k}{F_{y w}}} \\
C=\frac{1.12}{D / t_{w}} \sqrt{\frac{E k}{F_{y w}}} \quad \text { for } 1.12 \sqrt{\frac{E k}{F_{y w}}}<\frac{D}{t_{w}} \leq 1.4 \sqrt{\frac{E k}{F_{y w}}} \\
C=\frac{1.57}{\left(D / t_{w}\right)^{2}} \sqrt{\frac{E k}{F_{y w}}} \quad \text { for } \frac{D}{t_{w}}>1.4 \sqrt{\frac{E k}{F_{y w}}}
\end{array}
$$

Where:

$$
k=5+\frac{5}{\left(d_{0} / D\right)^{2}}
$$

7. Compute the nominal shear resistance of interior web panels by calling the VnIntPanel public function.4.38 as shown in Flowchart D.20. Equation 4.35 is used in the function.

$$
V_{n}=V_{p}\left[C+\frac{0.87(1-C)}{\sqrt{1+\left(d_{0} / D\right)^{2}}}\right] \text { for } \frac{2 D t_{w}}{\left(b_{f c} t_{f c}+b_{f t} t_{f t}\right)} \leq 2.5
$$

Otherwise:

Eq. 4. 35

$$
V_{n}=V_{p}\left[C+\frac{0.87(1-C)}{\sqrt{1+\left(d_{0} / D\right)^{2}}+d_{0} / D}\right]
$$

8. Compute the nominal shear resistance of end panels using Equation 4.36. 


$$
V_{n}=C V_{p}
$$

Eq. 4.36

9. Compute the nominal shear resistance of unstiffened sections using Equation 4.37.

$$
\begin{aligned}
& V_{n}=C V_{p} \\
& \text { where } \\
& \qquad \mathrm{C}=\text { ratio of the shear buckling resistance to the shear yield } \\
& \quad \text { strength with the shear buckling coefficient, k. taken } \\
& \quad \text { equal to 5.0. }
\end{aligned}
$$

\section{Deflection subroutine}

The Deflection subroutine computes deflections due to dead loads and maximum live load deflection. A flowchart of the subroutine is shown in Flowchart D.21 of Appendix D. Deflections of concern include those due to dead load (including girder self-weight, haunch, form work, traffic barriers, and future wearing surface) and live load. Like the calculation of load effects in the MomentShear subroutine, the direct stiffness matrix is used for the computation. The Deltaarray subroutine was developed for the computation of deflections. The DSM subroutine is called to perform the actual computation and the computed values are processed in the Deltaarray and return to the Deflection subroutine.

For the maximum live load deflection, PURDUE CSBD calls the MaxLiveloadDeflection public function to perform the computation. The program uses the ASSHTO HL-93 truck loading as live load. Since the truck loading is a transient moving load, PURDUE CSBD calculated the live load deflections due to a unit gravitational load by placing it at each tenth point along the span. The calculated deflection results were stored in a tabulated format. The maximum live load deflection was computed using the tabulated values and the Muller-Breslau Principle. The maximum live load deflection due to lane load was also computed. The maximum live load deflection is taken as the larger of live load deflection resulting from the design truck alone or that resulting from 25 percent of the design truck taken together with the design lane load. The distribution factor for live load deflection (DFD) was applied since both MERLINDASH and PURDUE CSBD use the approximate DFD method for analysis. The multiple presence factor $(\mathrm{m})$ is multiplied by the number of lanes (NL) and divided by the number of girders (NG). The distribution factor for live load deflection is further factored with the reduction 
factor $\left(m_{r e d}\right)$ for the force effect when the value of average daily truck traffic (ADTT) is less than 1000 as specified in the AASHTO LRFD Commentary 3.6.1.1.2. The factor of 0.95 is applied if ADTT is greater than 100 and less than 1000 and 0.9 is multiplied to DFD if ADTT is less than 100.

The general algorithm of the Deflection subroutine consists of the following steps:

1. Compute deflections due to DC1 (self weight, concrete slab, haunch, and form) at all tenth points by calling the Deltaarray subroutine.

2. Compute deflections due to DC2 (traffic barrier) at all tenth points by calling the Deltaarray subroutine.

3. Compute deflections due to DW (wearing surface) at all tenth points by calling the Deltaarray subroutine.

4. Call the MaxLiveloadDeflection public function to compute the maximum live load deflection.

5. Develop tables of deflection influence ordinates by placing a unit gravitational load, $1 \mathrm{kip}$, to each tenth point.

6. Compute deflection due to truck loading only using the Muller-Breslau Principle.

7. Compute deflection due to lane load only by calling the DeltaArray.

8. Select the multiple presence factor, $m$, based on the number of lanes.

9. Obtain value for the average daily truck traffic, ADTT, from the test-bed.

10. Select the reduction factor, $m_{\text {red }}$, for the multiple presence factor based on the average daily truck traffic, $A D T T$.

11. Compute the distribution factor for the live load deflection, $D F D$, using Equation 4.38.

$$
D F D=m_{r e d} m \frac{N_{L}}{N_{G}}
$$

12. Determine the maximum live load deflection using Equation 4.39 as given below.

$$
\begin{aligned}
& d e l_{L L \max }=\max [ D F D\left(d e l_{\max \text { Truck }} I M\right), \\
&\left.D F D\left(\frac{1}{4} d e l_{\max T r u c k} I M+d e l_{\max L a n e}\right)\right]
\end{aligned}
$$




\section{ServiceLimitState subroutine}

This subroutine compares flange stresses due to Service II load to the allowable values specified in AASHTO LRFD Article 6.10.4.2. As stated in the article, the purpose of the article is to prevent unacceptable permanent deflections caused by dead load and live load. Flange stresses computed by the MomentShear subroutine and the hybrid factor, $R_{h}$, computed by the StrengthLimitState subroutine are used for the comparison. When shear studs are not presented in negative flexure, the concrete slab is not taken in to the consideration and the girder section is treated as the non-composite section. The algorithm of the subroutine consists of the following steps:

1. Determine stresses at the top of the top flange due to Service II load at all tenth points.

2. Determine stresses at the bottom of the bottom flange due to Service II load at all tenth points.

3. Compute the allowable stress for the top flange as given in Equation 4.40.

$$
\begin{array}{ll}
f_{f} \leq 0.95 R_{h} F_{y f} & \text { for composite sections } \\
f_{f}+\frac{f_{f}}{2} \leq 0.8 R_{h} F_{y f} & \text { for non-composite sections }
\end{array}
$$

4. Compute the allowable stress for the bottom flange as given in Equation 4.41.

$$
\begin{array}{ll}
f_{f}+\frac{f_{f}}{2} & \leq 0.95 R_{h} F_{y f} \quad \text { for composite sections } \\
f_{f}+\frac{f_{f}}{2} & \leq 0.8 R_{h} F_{y f} \quad \text { for non-composite sections }
\end{array}
$$

5. Determine compression flange stresses due to Service II load without consideration of flange lateral bending.

6. Compute the nominal bend-buckling resistance for webs without longitudinal stiffeners using Equation 4.42 .

$$
F_{c r w}=\frac{0.9 E k}{\left(D / t_{w}\right)^{2}}
$$

7. Check if the girder section satisfies the service limit state. 


\section{Fatigue Fracture subroutine}

This subroutine performs calculation related to the load-induced fatigue. Live load stress range due to the passage of the fatigue load is imported from the MERLIN-DASH result. Since MERLIN-DASH does not provide fatigue results, only fatigue stresses at the top and bottom flange are computed in this subroutine. The short-term composite section properties for the fatigue analysis are computed by the SectionProperties subroutine and used in this subroutine. The algorithm of the subroutine is presented in Flowchart D.25 of Appendix D and it consists of the following steps:

1. Call the positive and negative live load moment envelope due to truck load only.

2. Compute the fatigue live load moment range using Equation 4.43.

$$
M_{\text {flive }}=\gamma\left(M_{\text {posliveenvT }}-M_{\text {negliveenvT }}\right) \quad \text { Eq. } 4.43
$$

3. Compute the top and bottom fatigue stress as given in Equation 4.44.

$$
\begin{aligned}
& f_{\text {fat } T}=M_{\text {flive }} / S_{\text {tSTfat }} \\
& f_{\text {fatB }}=M_{\text {flive }} / S_{b S T f a t}
\end{aligned}
$$

\section{ShearConnector subroutine}

The ShearConnector subroutine computes values for parameters related to shear connectors as specified in AASHTO LRFD Article 6.10.10. These parameters include the range of shear due to live loads and impact, $V_{f}$, statical moment about the neutral axis of the composite section of the transformed compressive concrete area, $Q$, range of horizontal shear , $V_{s r}$, longitudinal fatigue range per unit length, $V_{f a t}$, and maximum allowable pitch, $p_{\text {maxall }}$. Two shear connectors per transverse section area were assumed in this study. For the computation of the statical moment about the neutral axis of the composite section, $Q$, and moment of inertia of the short-term composite section, I, the concrete deck is taken into consideration if shear studs are applied in negative flexure. Allowable range of horizontal shear, $Z_{r}$, was assumed to be 2.9 kips per connector during the development of the test-bed.

The MERLIN-DASH provides the recommended number of shear connectors per transverse section area based on the strength limit state given in AASHTO LRFD Article 6.10.10.4. However, the comparison of the value is out of the scope of this project. Thus, the recommended number of shear connectors is not computed in this subroutine. The flowchart of 
the subroutine is shown in Flowchart D.26 of Appendix D. The algorithm for the ShearConnector subroutine consists of the following steps:

1. Obtain pre-assumed values from the test-bed. They include diameter of a shear connector, $d_{s c}$, number of shear connector in a cross section, $n_{s c}$, and shear fatigue resistance of an individual shear connector, $Z_{r}$.

2. Determine the vertical shear force range under the fatigue load combination using Equation 4.45 .

$$
V_{f}=\gamma\left(V_{\text {posliveenv }}-V_{\text {negliveenv }}\right)
$$

3. Compute statical moment about the neutral axis of the composite section of the transformed compressive concrete area, $Q$, by calling the QFunct public function. The function follows several steps and they are shown in the Flowchart D.27 of Appendix D.

4. Compute longitudinal fatigue range per unit length, $V_{\text {fat }}$, using Equation 4.46.

$$
V_{f a t}=\frac{V_{f} \mathrm{Q}}{I_{x S T f a t}}
$$

5. Compute horizontal fatigue range per unit length, $V_{s r}$, using Equation 4.47.

$$
V_{s r}=\sqrt{\left(V_{f a t}\right)^{2}+\left(F_{f a t}\right)^{2}}
$$

where

Eq. 4.47

$$
F_{\text {fatt }}=0 \text { for straight bridges }
$$

6. Determine the maximum allowable pitch, $p_{\text {maxall }}$, using Equation 4.48.

$$
p_{\max \text { all }}=\min \left(\frac{N_{s c} Z_{r}}{V_{s r}}, 24\right)
$$




\section{ANALYSIS OF RESULTS}

The complete test-bed of steel I-girder bridges was analyzed using both PURDUE CSBD and the commercial program, MERLIN-DASH. This section focuses on the comparisons of (1) moments and shears, (2) stresses, (3) deflections, (4) flexural strength, and (5) shear strength. The comparisons are used to identify numerical discrepancies between two computer programs and the underlying causes or assumptions leading to these discrepancies. These comparisons of the design calculation results generated a vast amount of numerical data for the complete test-bed of composite steel bridges. This section summarizes the typical comparisons between MERLINDASH and PURDUE CSBD design calculation results. In most cases, only the MERLIN-DASH values and curves are visible in the graphical comparisons because the results from both programs overlap each other completely.

The comparison of those two results produced a tremendous amount of numerical data for the complete test-bed of bridges. Hence, this chapter summarizes the general comparison and talks about the findings from it. The remaining comparison plots and numerical results are reported in the accompanying $\mathrm{CD}$ and can be reviewed separately.

\section{Moments}

The typical comparisons of moment envelopes computed by MERLIN-DASH and PURDUE CSBD are shown in Figures 5.1-5.6. Figure 5.1 shows the comparison of Service I Moment and Figure 5.2 presents the comparison of Service II Moment. Figure 5.3 shows the comparison of Strength I Moment and Figure 5.4 presents the comparison of Strength II Moment. Figure 5.5 shows the comparison of Strength IV Moment and Figure 5.6 presents the comparison of Fatigue Moment. Note that the bending moment at each tenth point is computed by summing moments due to dead loads (DC1, DC2, and DW) and live load (maximum positive and maximum negative). The MERLIN-DASH results in figures are top on the PURDUE CSBD program. The figures show good agreement at all tenth point locations along the span length. Comparisons for the remaining test bed of bridges are reported in the accompanying $\mathrm{CD}$, and also show good agreement. 


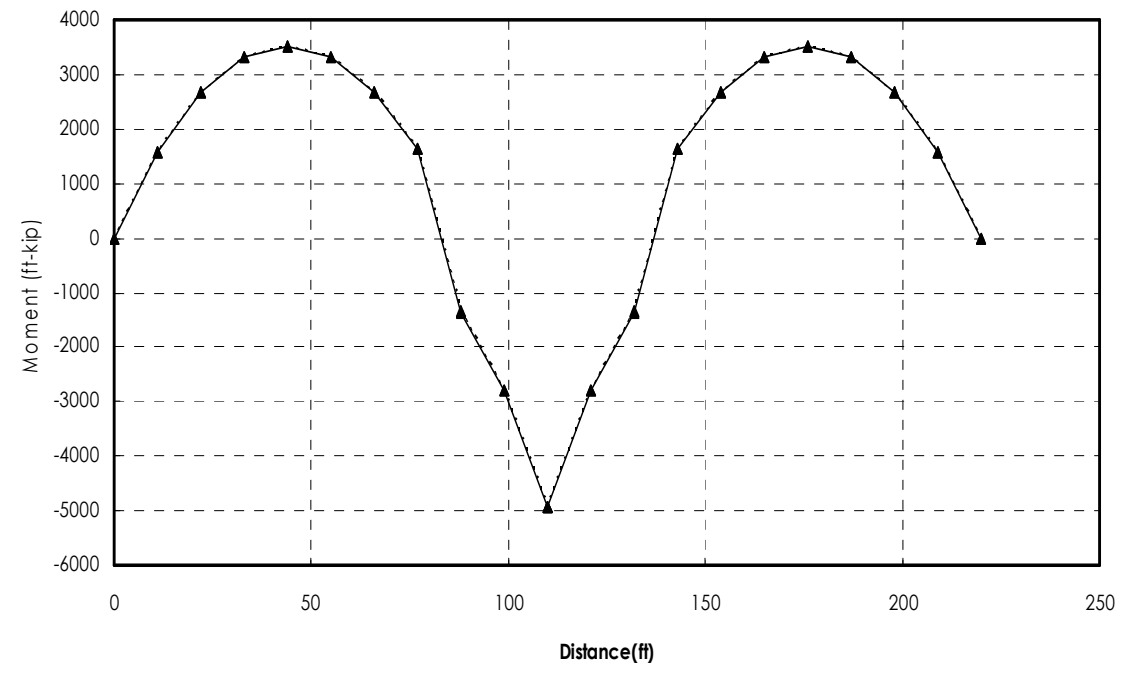

$\cdots \Delta \cdots$ PURDUE CSBD $\longrightarrow$ MERLIN-DASH

Figure 5.1 Comparison of Service I Moment $($ BridgeID $=10)$

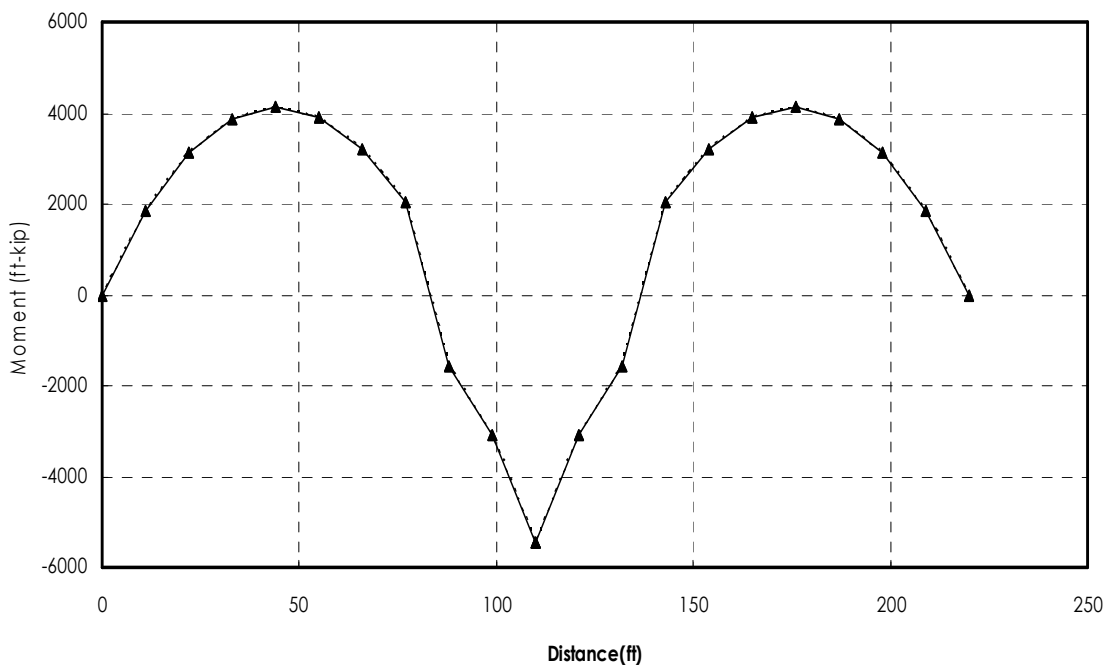

$\cdots \triangle \cdots$ PURDUE CSBD $\longrightarrow$ MERLIN-DASH

Figure 5.2 Comparison of Service II Moment (BridgeID = 10) 


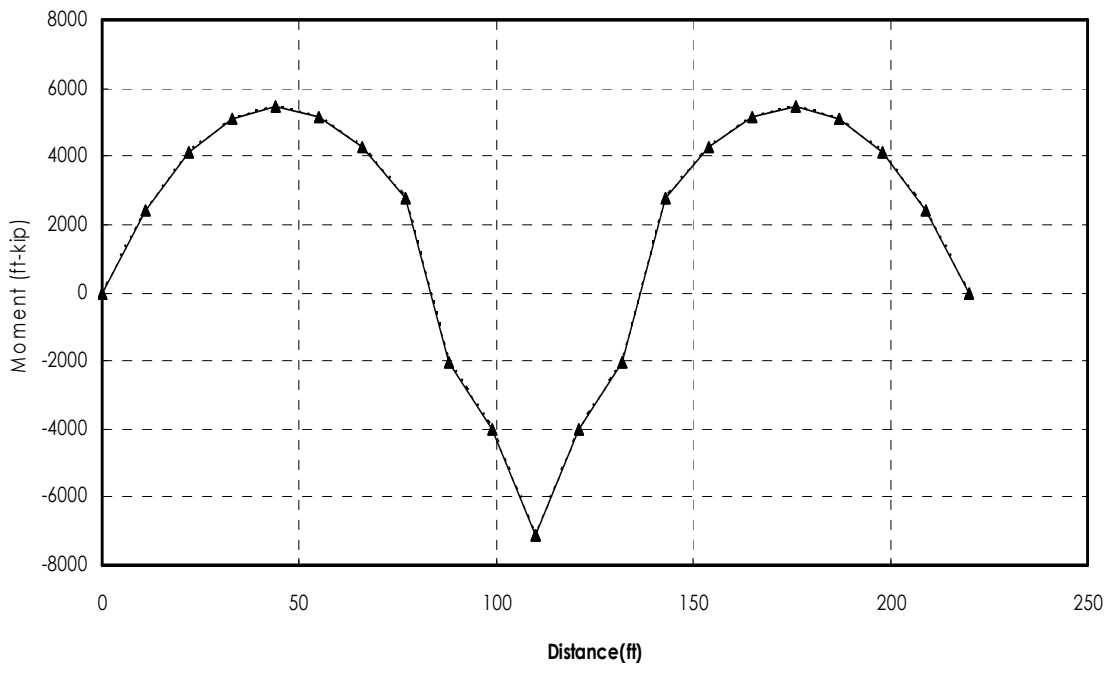

$\cdots \triangle \cdots$ PURDUE CSBD $\multimap$ MERLIN-DASH

Figure 5.3 Comparison of Strength I Moment $($ BridgeID = 10)

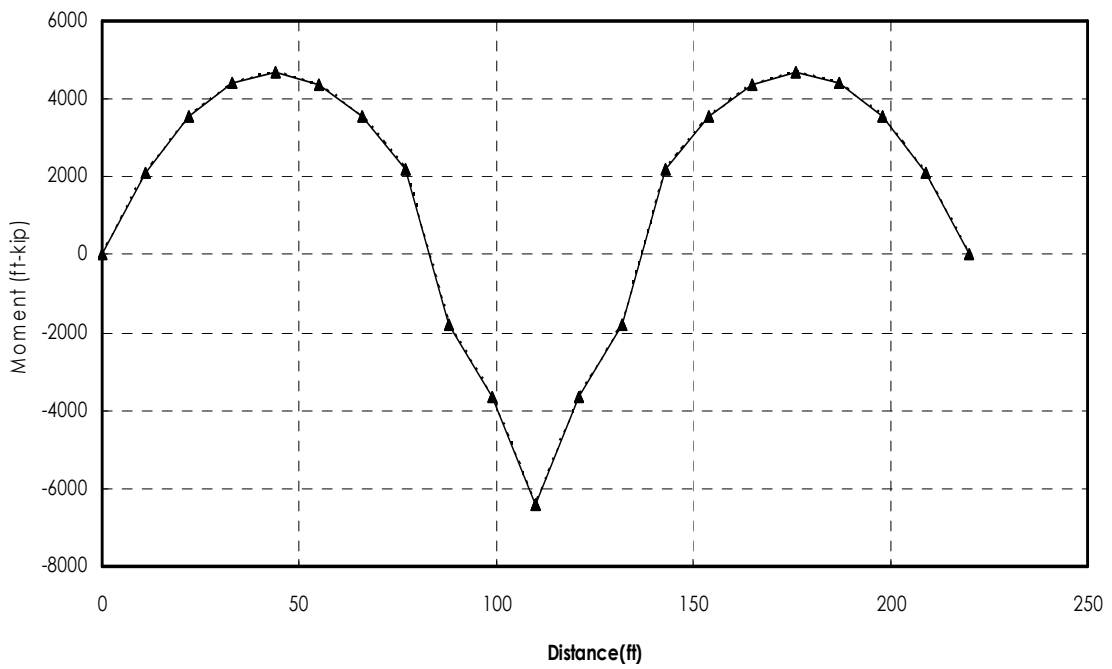

$\cdots \Delta \cdots$ PURDUE CSBD $\longrightarrow$ MERLIN-DASH

Figure 5.4 Comparison of Strength II Moment $($ BridgeID = 10) 


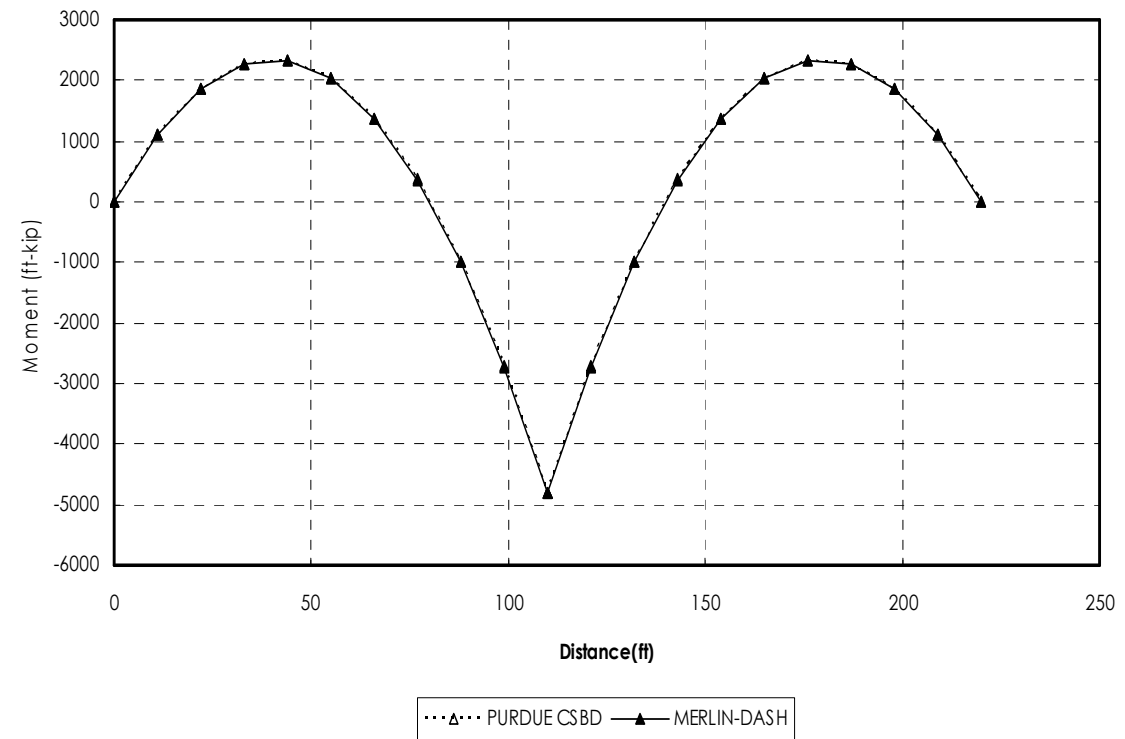

Figure 5.5 Comparison of Strength IV Moment (BridgeID = 10)

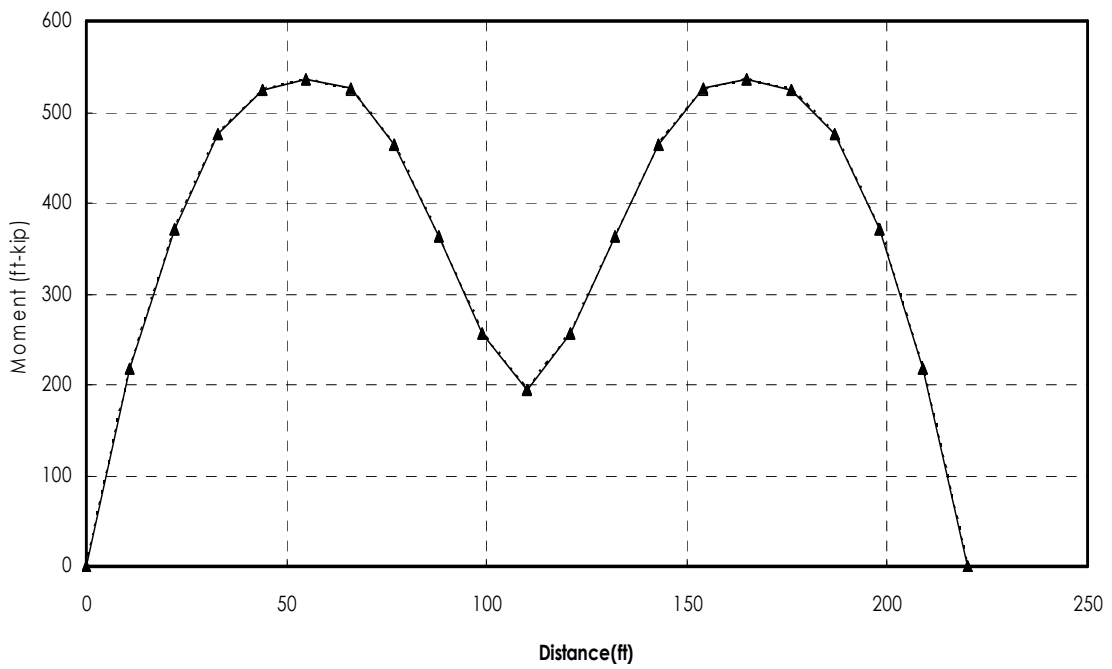

$\cdots \Delta \cdots$ PURDUE CSBD $\longleftarrow$ MERLIN-DASH

Figure 5.6 Comparison of Fatigue Moment $($ BridgeID = 10) 


\section{Shears}

Shear envelopes for each steel I-girder bridge computed by MERLIN-DASH and PURDUE CSBD were compared. The comparisons showed good agreement between MERLINDASH and PURDUE CSBD calculations for different load combinations. Figure 5.7 to 5.12 present the typical comparisons of shear envelopes computed by MERLIN-DASH and PURDUE CSBD. Figure 5.7 shows the comparison of Service I Shear and Figure 5.8 presents the comparison of Service II Shear. Figure 5.9 shows the comparison of Strength I Shear and Figure 5.10 presents the comparison of Strength II Shear. Figure 5.11 shows the comparison of Strength IV Shear and Figure 5.12 presents the comparison of Fatigue Shear. Shear at each tenth point is computed by summing shears due to dead loads (DC1, DC2, and DW) and live load (maximum positive and maximum negative). The figures show good agreement at all tenth point locations along the span length. The remaining comparison is reported in the accompanying $\mathrm{CD}$, and also show good agreement. 


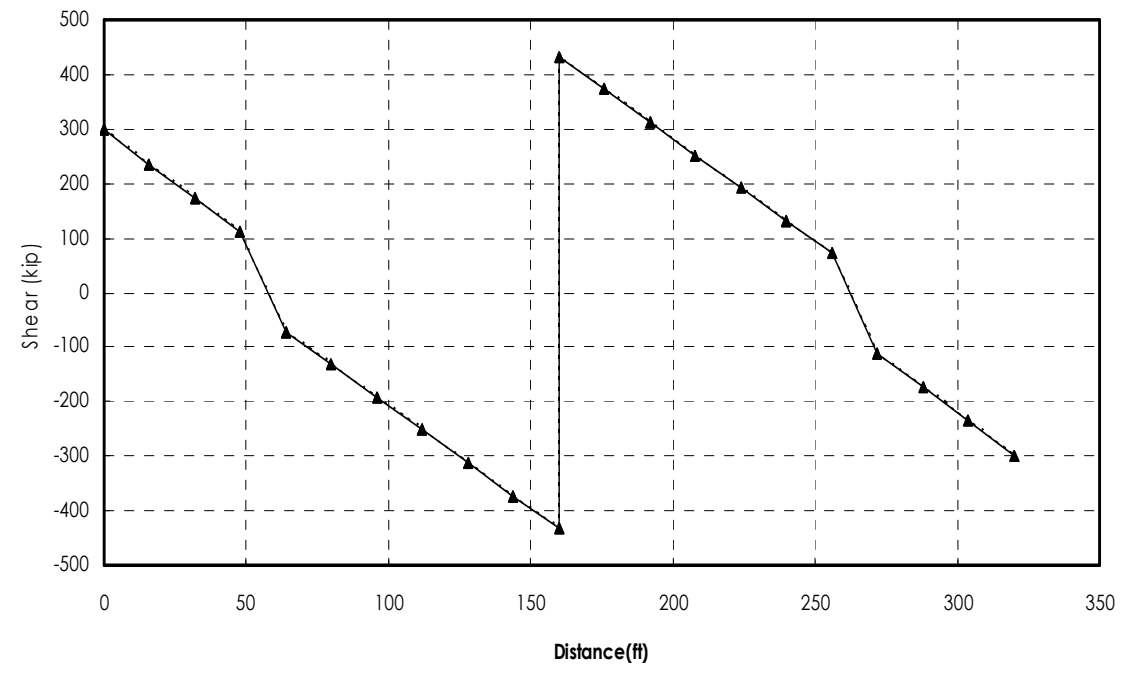

$\cdots \Delta \cdots$ PURDUE CSBD $\longrightarrow$ MERLIN-DASH

Figure 5.7 Comparison of Service I Shear $($ BridgeID = 13)

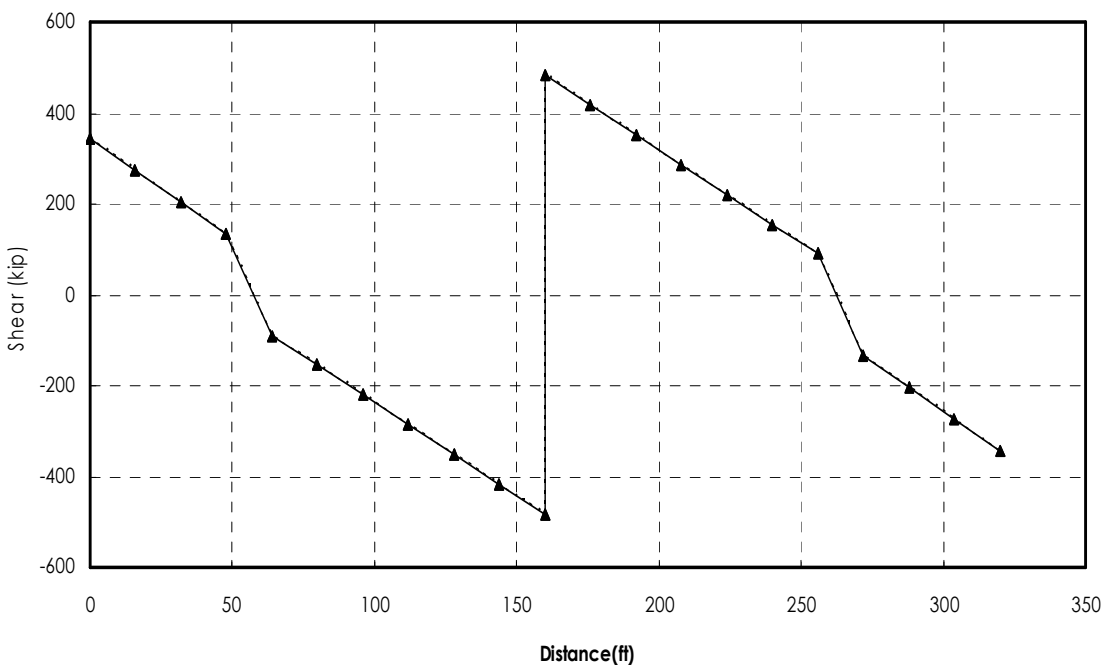

$\cdots \Delta \cdots$ PURDUE CSBD —MERLIN-DASH

Figure 5.8 Comparison of Service II Shear (BridgeID = 13) 


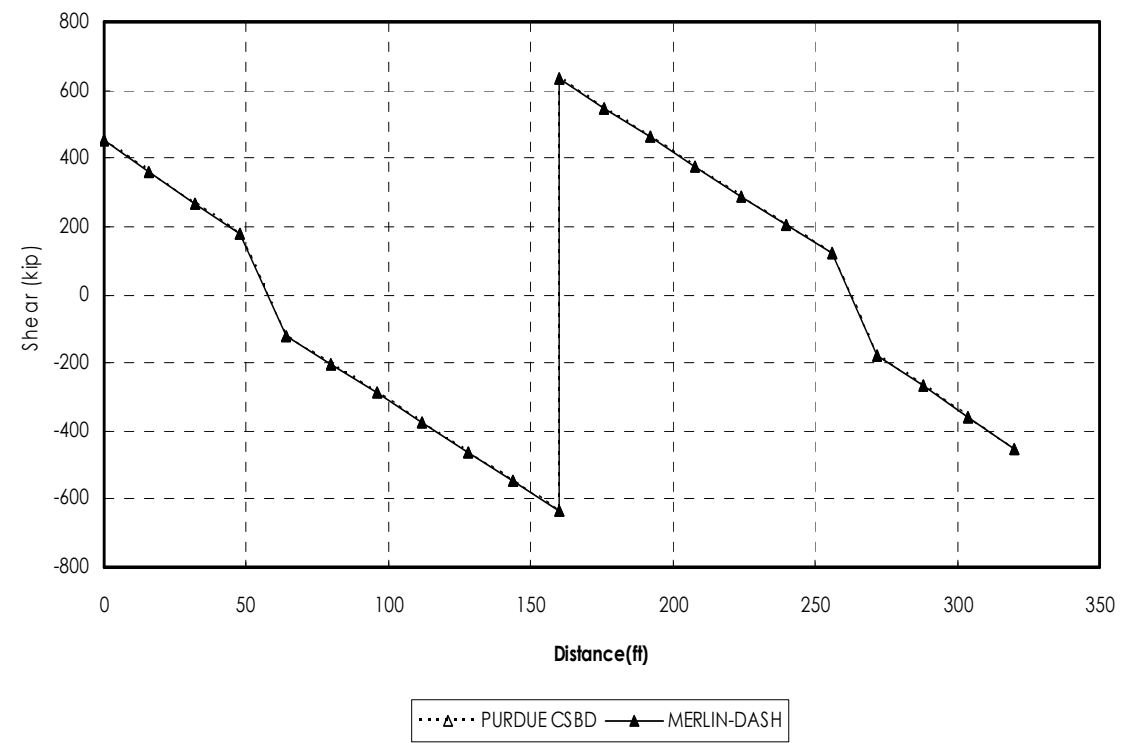

Figure 5.9 Comparison of Strength I Shear (BridgeID = 13)

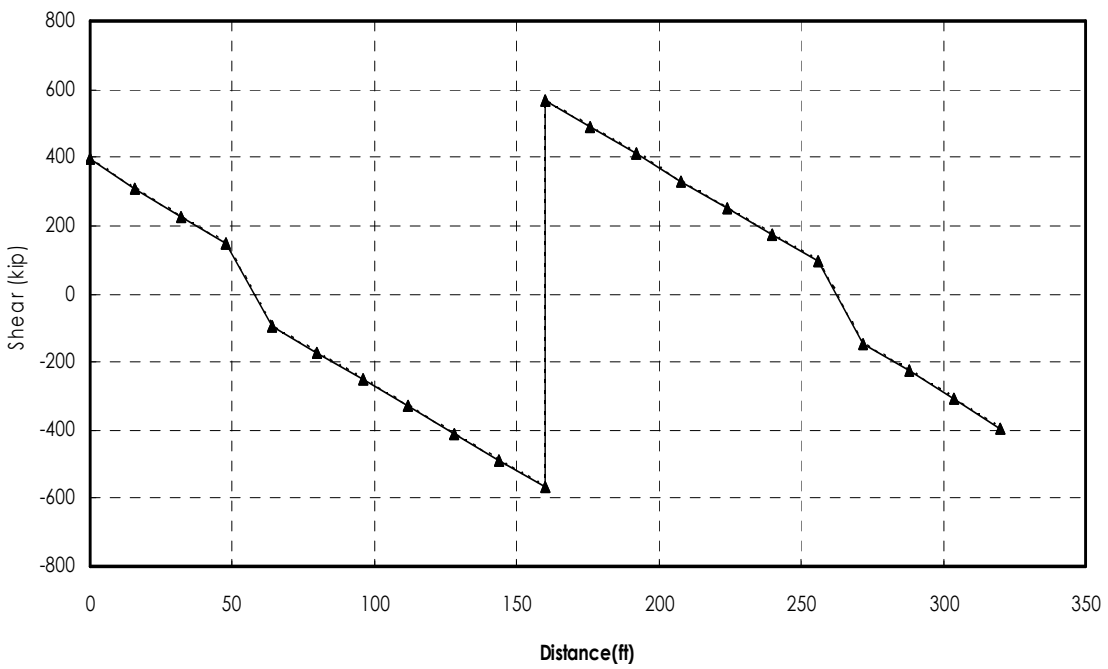

$\cdots \Delta \cdots$ PURDUE CSBD $\longrightarrow$ MERLIN-DASH

Figure 5.10 Comparison of Strength II Shear $($ BridgeID = 13) 


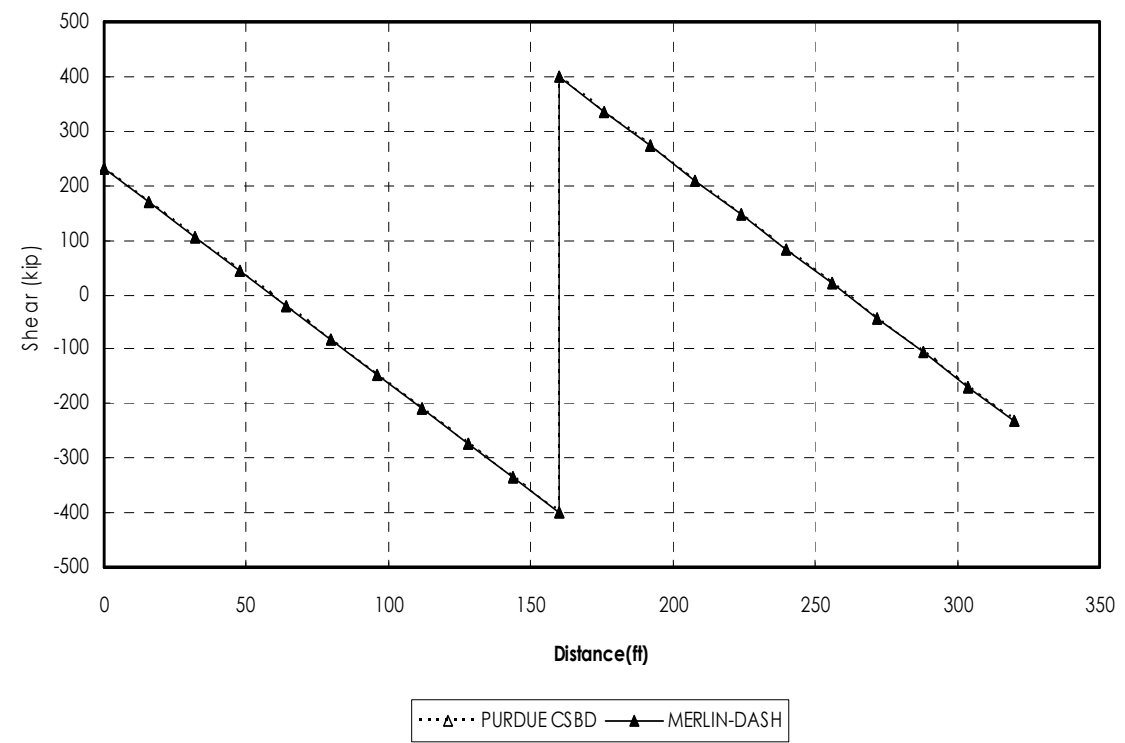

Figure 5.11 Comparison of Strength IV Shear (BridgeID = 13)

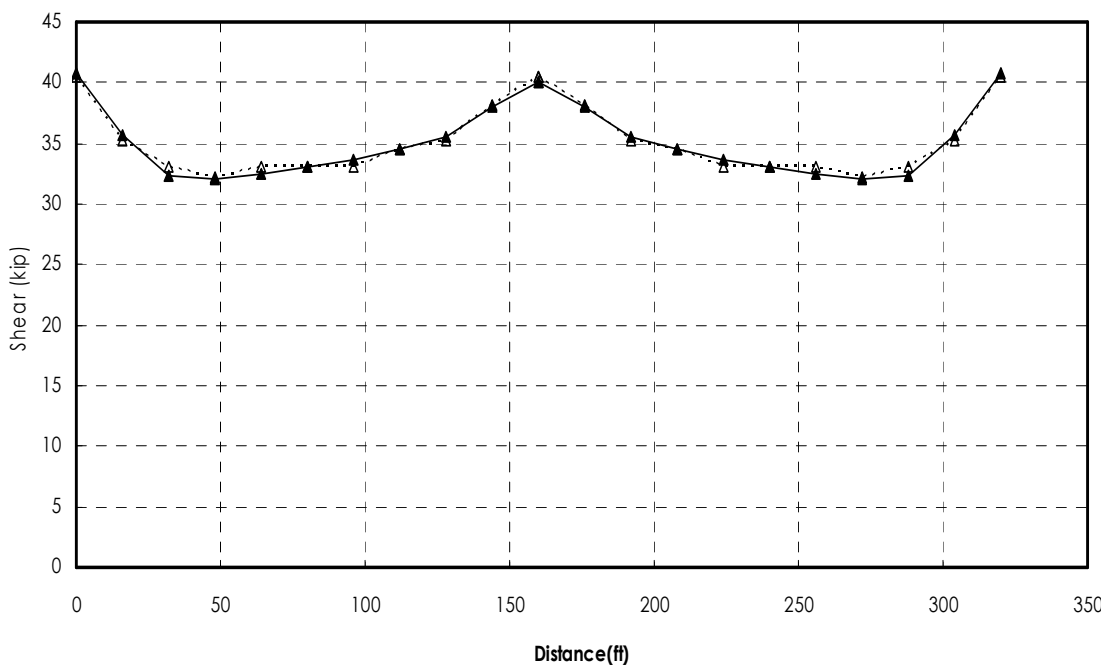

$\cdots \Delta \cdots$ PURDUE CSBD $\multimap$ MERLIN-DASH

Figure 5.12 Comparison of Fatigue Shear (BridgeID = 13) 


\section{Deflections}

MERLIN-DASH and PURDUE CSBD calculated deflections due to DC1 (the selfweight of the steel girder, concrete deck, and haunch), DC2 (traffic barriers), and DW (future wearing surface). The summation of deflections due to DC1, DC2, and DW generated by both MERLIN-DASH and PURDUE CSBD were compared and they showed excellent agreement between two programs. In this report, the typical comparison of the summation of dead load deflections is presented in Figure 5.13. The values of deflections calculated by two programs completely overlap each other.

The maximum live load deflection computed by MERLIN-DASH and PURDUE CSBD was compared and they are shown in table 5.1. It appears that there was 5 to $10 \%$ discrepancy between the maximum live load computed by two programs. To identify the cause of the discrepancy, the distribution factor for live load deflection (DFD) computed by MERLIN-DASH and PURDUE CSBD was compared. MERLIN-DASH applied the reduction factor 0.9 to DFD, which is applicable only when ADTT is less than 100 as described earlier. However, 1500 was assumed for ADTT in this was assumed for all bridges in the test-bed. It appears that MERLINDASH does not utilize ADTT properly. The maximum live load deflection computed by MERLIN-DASH was calibrated by dividing DFD by 0.9 for the comparison purpose. Figure 5.14 shows the normalized maximum live load deflection of bridges in the test bed. Both the table and the figure show good agreement between two programs. The ratio of the maximum live load deflection computed by MERLIN-DASH to PURDUE CSBD varies from 1.00 to 1.06 . 


\begin{tabular}{|c|c|c|c|c|}
\hline \multirow{3}{*}{ BridgeID } & \multicolumn{4}{|c|}{ Maximum live load deflection } \\
\hline & \multicolumn{2}{|c|}{ Merlin Dash } & \multirow{2}{*}{$\begin{array}{l}\text { PURDUE } \\
\text { CSBD } \\
\text { (in.) }\end{array}$} & \multirow{2}{*}{$\frac{\text { MERLIN-DASH }}{\text { PURDUE CSBD }}$} \\
\hline & $\begin{array}{c}\text { DFD } \\
\left(\mathrm{m}_{\mathrm{red}}=\mathbf{0 . 9}\right)\end{array}$ & $\operatorname{del}_{L L \max }(\mathrm{in})$. & & \\
\hline 1 & 0.459 & -0.5210 & -0.5578 & 0.93 \\
\hline 2 & 0.459 & -0.7200 & -0.7815 & 0.92 \\
\hline 3 & 0.459 & -1.0870 & -1.1924 & 0.91 \\
\hline 4 & 0.574 & -1.2160 & -1.3474 & 0.90 \\
\hline 5 & 0.574 & -1.1290 & -1.2502 & 0.90 \\
\hline 6 & 0.459 & -0.5240 & -0.5518 & 0.95 \\
\hline 7 & 0.459 & -0.6330 & -0.6809 & 0.93 \\
\hline 8 & 0.459 & -1.0550 & -1.1480 & 0.92 \\
\hline 9 & 0.459 & -0.7340 & -0.7926 & 0.93 \\
\hline 10 & 0.459 & -0.7000 & -0.7565 & 0.93 \\
\hline 11 & 0.574 & -1.3490 & -1.4850 & 0.91 \\
\hline 12 & 0.574 & -0.8150 & -0.8946 & 0.91 \\
\hline 13 & 0.574 & -0.8180 & -0.8964 & 0.91 \\
\hline 14 & 0.459 & -0.8340 & -0.8983 & 0.93 \\
\hline 15 & 0.459 & -1.0040 & -1.0826 & 0.93 \\
\hline 16 & 0.459 & -1.5770 & -1.7417 & 0.91 \\
\hline 17 & 0.459 & -1.1010 & -1.2088 & 0.91 \\
\hline 18 & 0.459 & -1.0570 & -1.1631 & 0.91 \\
\hline 19 & 0.574 & -1.8740 & -2.0515 & 0.91 \\
\hline 20 & 0.574 & -1.2183 & -1.3313 & 0.92 \\
\hline 21 & 0.574 & -1.1798 & -1.2887 & 0.92 \\
\hline
\end{tabular}

Table 5.1 Comparison of the maximum deflection due to live load computed by MERLINDASH and PURDUE CSBD 


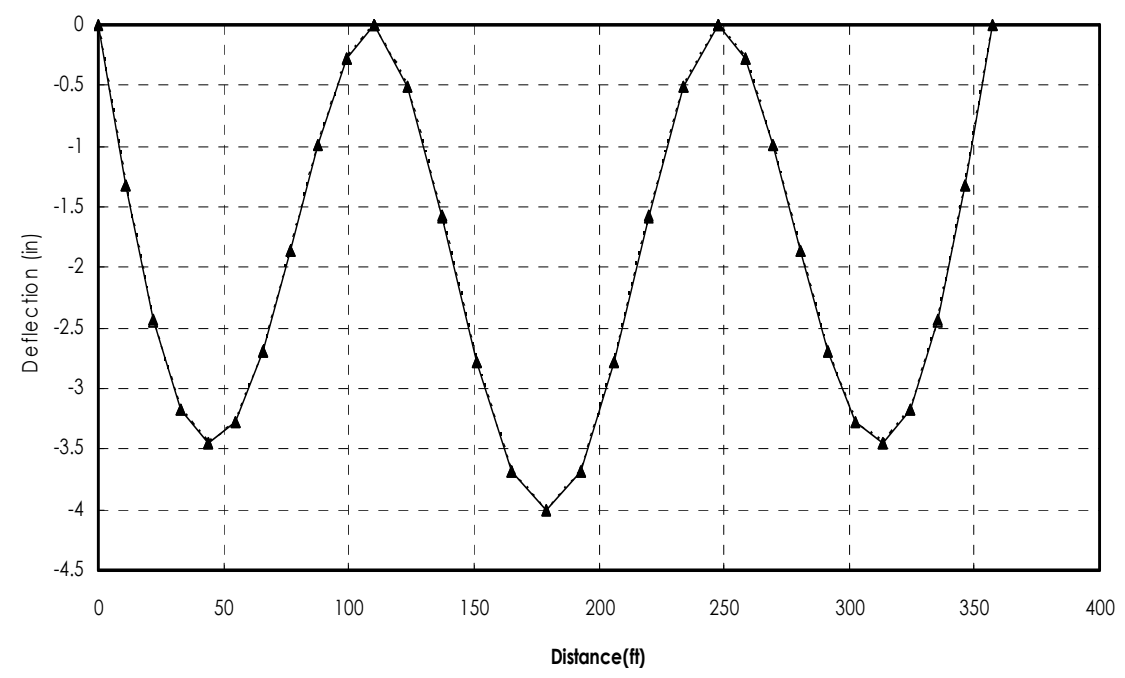

$\cdots \Delta \cdots$ PURDUECSBD $\longrightarrow$ MERLIN-DASH

Figure 5.13 Comparison of deflection due to dead load including DC1, DC2, and DW (BridgeID =16)

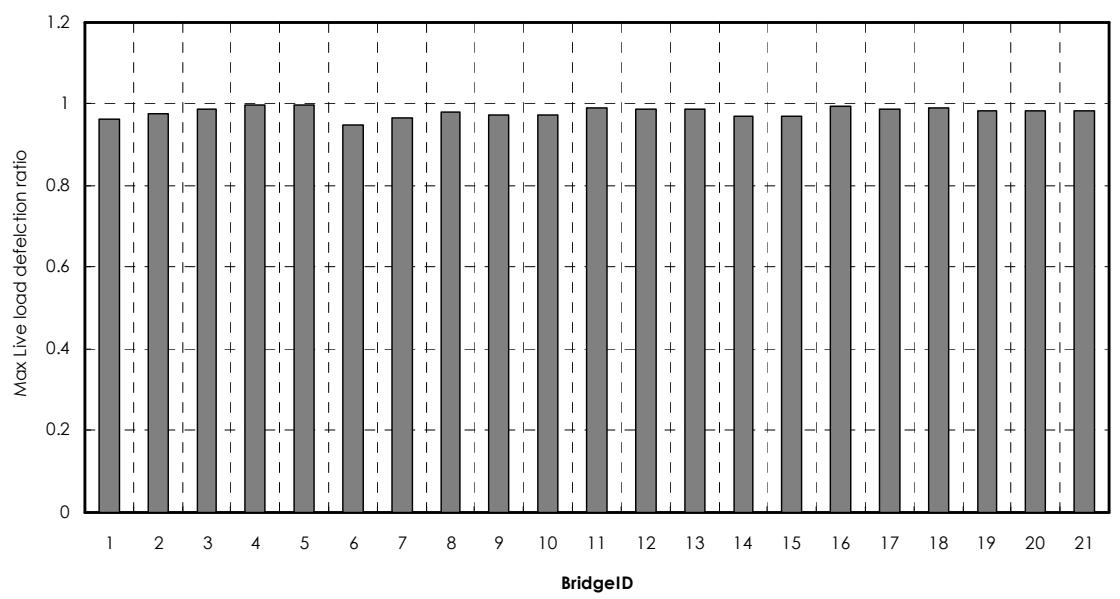

Figure 5.14 Normalized maximum live load deflections due to live loads 


\section{Stresses}

The stresses in the concrete and the steel flanges were computed by both MERLINDASH and PURDUE CSBD. Both computer programs calculated the girder section modulus at three loading stages, which include non-composite, short term composite and long term composite. The computed section moduli were used to determine concrete stress, top flange stress, and bottom flange stress. The stresses due to external load were computed separately and load factors were applied to determine stresses with different load combinations. The stresses computed by MERLIN-DASH and PURDUE CSBD for two loading combinations were compared graphically and show excellent agreement. For example, Figures $5.15-5.17$ show the typical comparisons. Figure 5.15 shows comparison of stresses at the top of the concrete slab in the positive flexure region. Figure 5.16 presents the comparison of stresses at the top of the top flange with maximum positive live load stresses. Figure 5.17 shows the comparison of stresses at the bottom of the bottom flange with maximum positive live load stresses. These figures are typical and show excellent agreement at the tenth point locations along the span. The remaining comparison is reported in the accompanying $\mathrm{CD}$, and also show good agreement. 


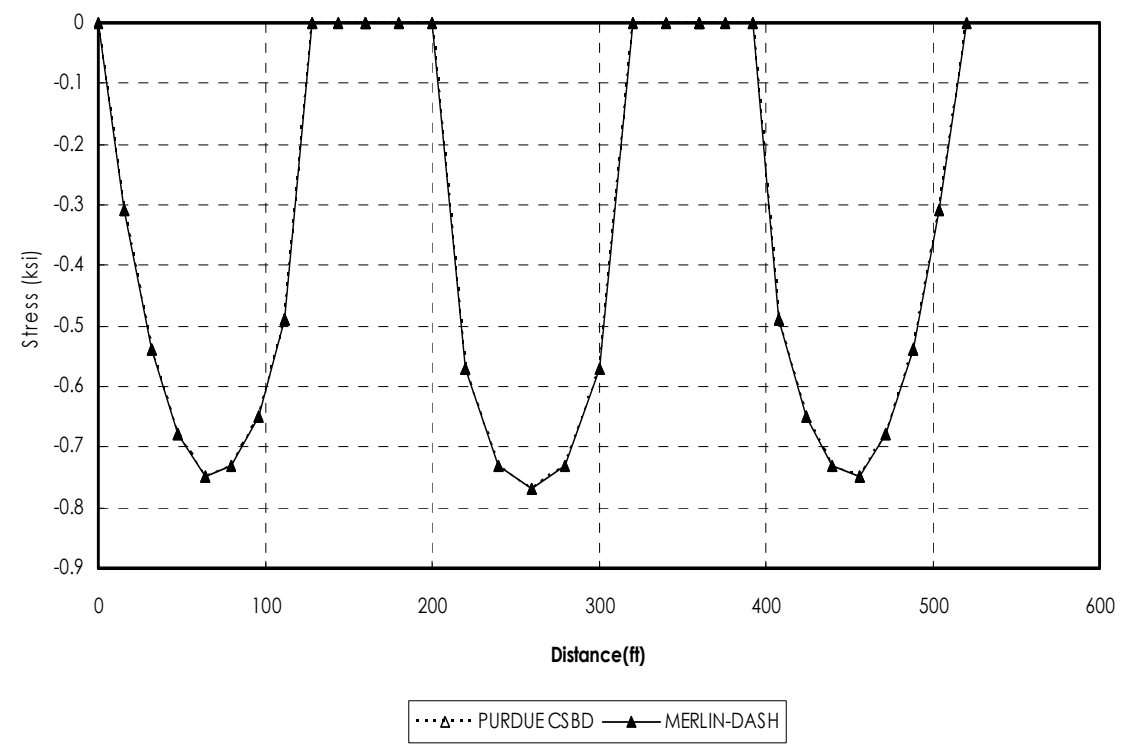

Figure 5.15 Comparison of stresses at top of slab under Service I with positive live load $($ BridgeID $=19)$

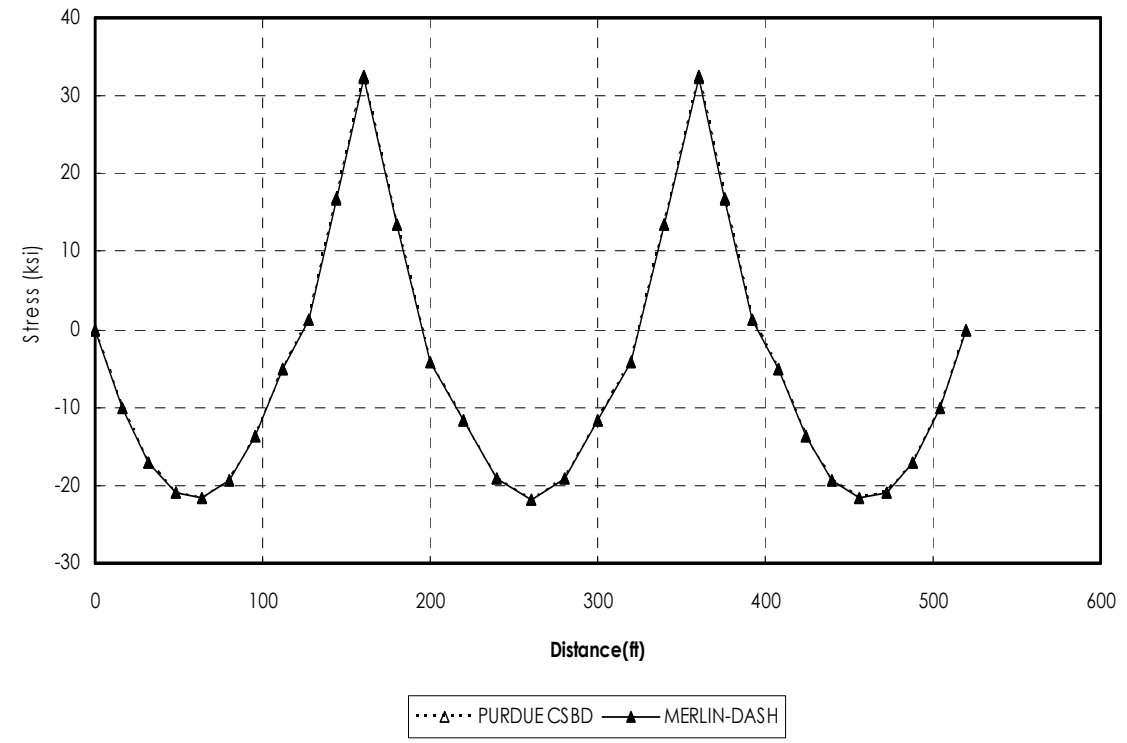

Figure 5.16 Comparison of stresses at top flange under Service I with positive live load $($ BridgeID $=19)$ 


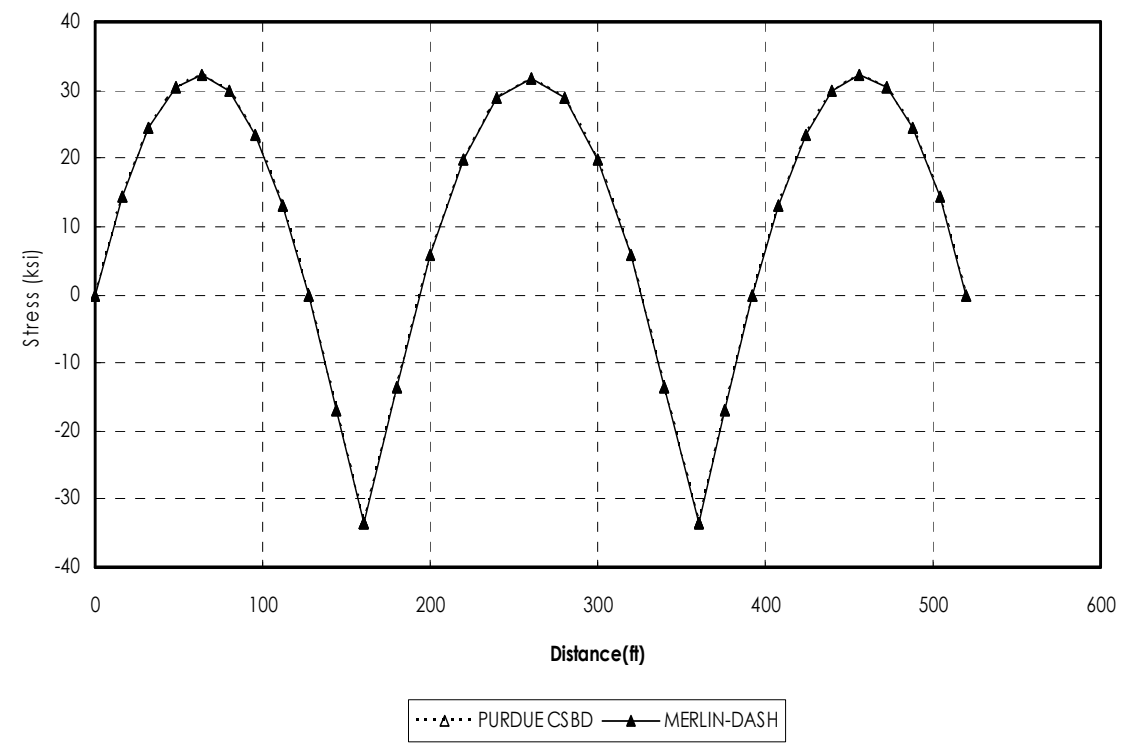

Figure 5.17 Comparison of stresses at bottom flange under Service I with positive live load $($ BridgeID $=19)$ 


\section{Flexural strength}

Design parameters related to the flexural strength of the girder section are described in the previous chapter. Both MERLIN-DASH and PURDUE CSBD computed the values for them and their comparisons showed excellent agreement between the two programs. For example, Figures 5.18 - 5.23 show the typical comparisons of design parameters related to the flexural strength of the girder section calculated by both programs. The nominal flexural resistance of the section $\left(M_{n}\right)$ computed by two programs is presented in Figure 5.18. The figure shows excellent agreement between two programs. Figure 5.19 shows the comparison of the moment gradient factor, $C_{\mathrm{b}}$, of the non-composite sections computed by both programs. Figure 5.20 and Figure 5.21 show the comparison of the hybrid factor, $R_{h}$, and the load shedding factor, $R_{b}$, of the noncomposite sections, respectively. The comparison of the nominal compression flange local buckling flexural resistance $\left(F_{n c F L B}\right)$ is shown in Figure 5.22 and the comparison of the nominal compression lateral torsional buckling flexural resistance, $F_{n c L T B}$, is presented in Figure 5.23. It appears that there are some minor discrepancies in the moment gradient factor, $C_{b}$, and hybrid factor, $R_{h}$, as shown in Table 5.2. These discrepancies in the moment gradient factor, $C_{b}$, and hybrid factor, $R_{h}$, are examined. They are negligible and do not have significant effects to the values of the nominal flexural resistance, $F_{n c}$. The comparison for the remaining bridges in the test-bed are compared and reported in the accompanying CD. 


\begin{tabular}{|c|c|c|c|c|c|c|}
\hline \multirow{2}{*}{ BridgeID } & \multirow{2}{*}{$\begin{array}{c}\text { Location } \\
\text { ID }\end{array}$} & \multirow{2}{*}{ Location } & \multicolumn{2}{|c|}{ Cb } & \multicolumn{2}{c|}{ Rh } \\
\cline { 4 - 7 } & & & PURDUE & MERLIN- & PURDUE & MERLIN- \\
CSBD & DASH & CSBD & DASH \\
\hline 11 & 1 & 0 & 1.68 & 1.68 & 0.98 & 0.978 \\
\hline 11 & 2 & 16 & 1.68 & 1.68 & 0.98 & 0.985 \\
\hline 11 & 3 & 32 & 1.16 & 1.16 & 0.98 & 0.985 \\
\hline 11 & 4 & 48 & 1.02 & 1.02 & 0.98 & 0.985 \\
\hline 11 & 5 & 64 & 1.04 & 1.04 & 0.98 & 0.985 \\
\hline 11 & 6 & 80 & 1.04 & 1.04 & 0.98 & 0.984 \\
\hline 11 & 7 & 96 & 1.21 & 1.22 & 0.98 & 0.984 \\
\hline 11 & 8 & 112 & 1.63 & 1.62 & 0.98 & 0.983 \\
\hline 11 & 9 & 128 & 1.68 & 1.66 & 0.99 & 0.988 \\
\hline 11 & 10 & 144 & 1.33 & 1.33 & 0.99 & 0.988 \\
\hline 11 & 11 & 160 & 1.33 & 1.33 & 0.99 & 0.988 \\
\hline 11 & 12 & 160 & 1.33 & 1.33 & 0.99 & 0.988 \\
\hline 11 & 13 & 176 & 1.33 & 1.33 & 0.99 & 0.988 \\
\hline 11 & 14 & 192 & 1.68 & 1.66 & 0.99 & 0.988 \\
\hline 11 & 15 & 208 & 1.63 & 1.62 & 0.98 & 0.983 \\
\hline 11 & 16 & 224 & 1.21 & 1.22 & 0.98 & 0.984 \\
\hline 11 & 17 & 240 & 1.04 & 1.04 & 0.98 & 0.984 \\
\hline 11 & 18 & 256 & 1.04 & 1.04 & 0.98 & 0.985 \\
\hline 11 & 19 & 272 & 1.02 & 1.02 & 0.98 & 0.985 \\
\hline 11 & 20 & 288 & 1.16 & 1.16 & 0.98 & 0.985 \\
\hline 11 & 21 & 304 & 1.68 & 1.68 & 0.98 & 0.985 \\
\hline 11 & 22 & 320 & 1.68 & 1.68 & 0.98 & 0.978 \\
\hline
\end{tabular}

Table 5.2 Comparison of $C_{b}$ and $R_{h}$ computed by MERLIN-DASH and PURDUE CSBD $($ BridgeID $=11)$ 


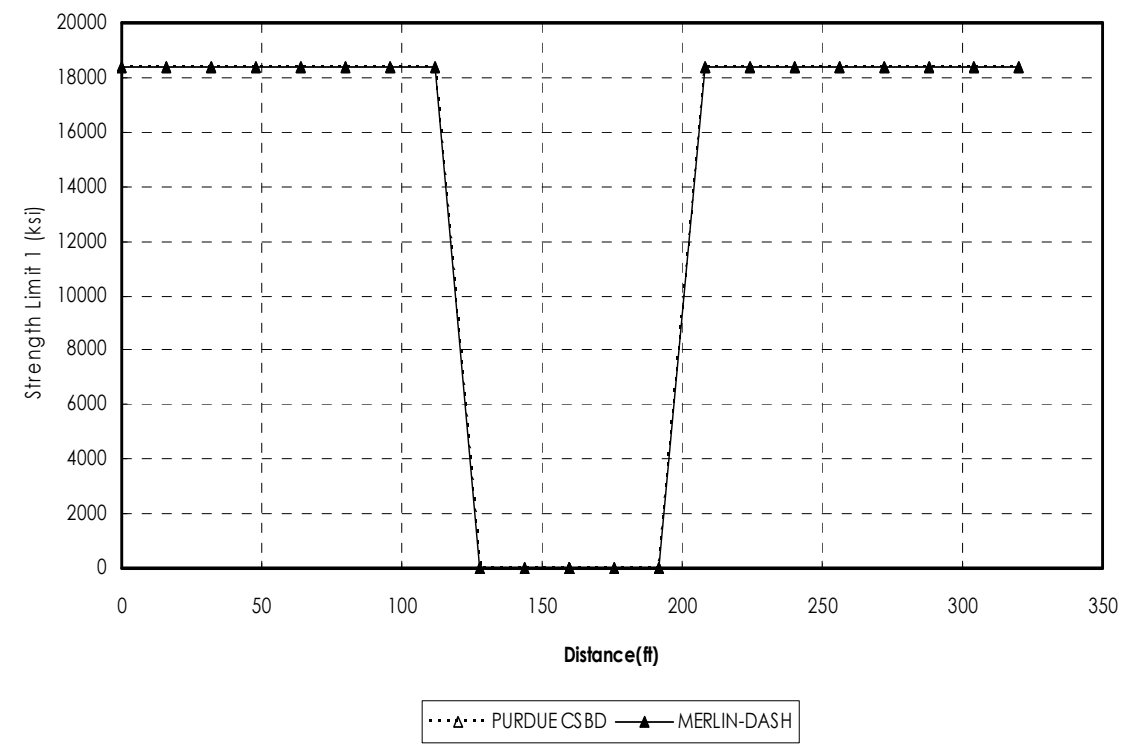

Figure 5.18 Comparison of moment capacity in positive flexure (BridgeID = 11)

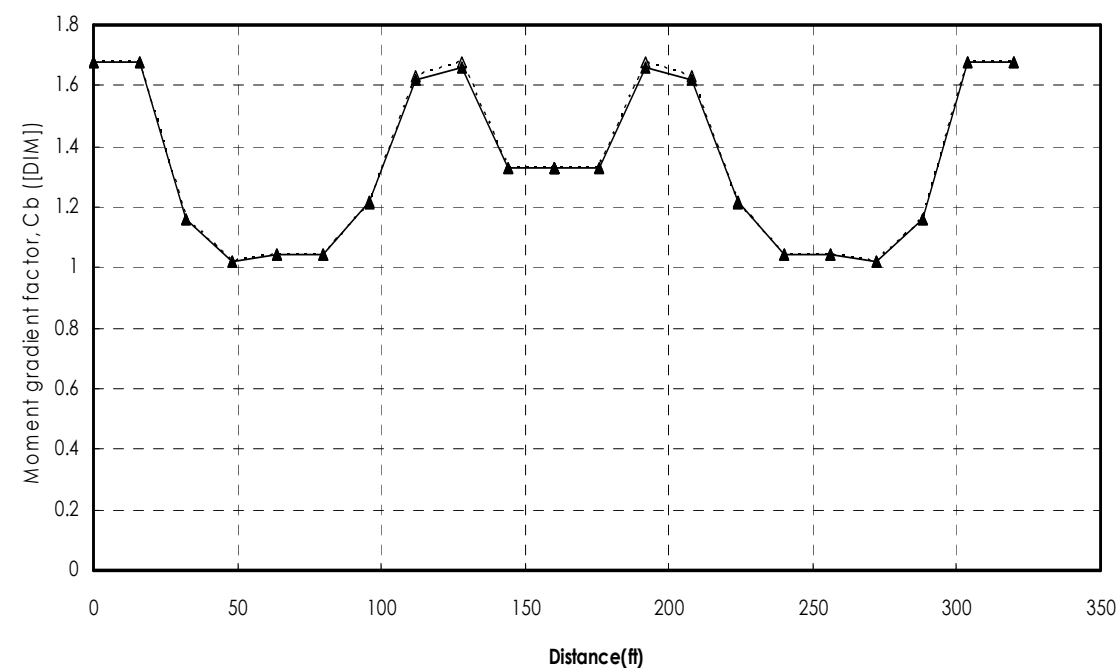

$\cdots \Delta \cdots$ PURDUE CSBD —MERLIN-DASH

Figure 5.19 Comparison of the moment gradient factor, $C_{b}$, of the non-composite section (BridgeID = 11) 


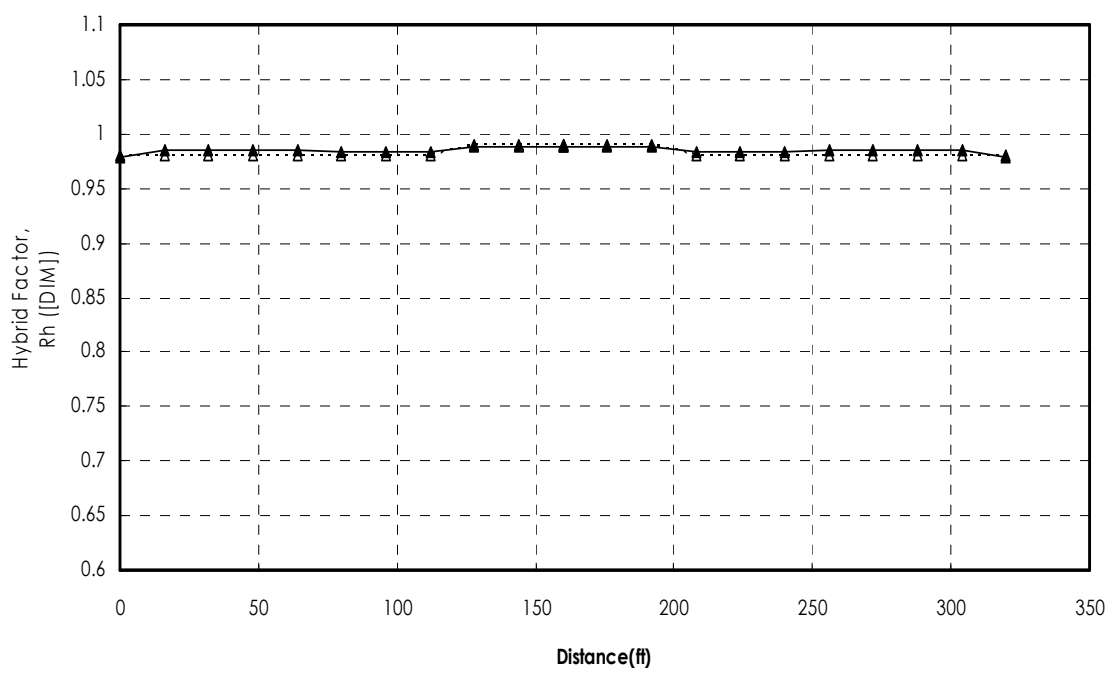

$\cdots \Delta \cdots$ PURDUE CSBD $\longrightarrow$ MERLIN-DASH

Figure 5.20 Comparison of the hybrid factor, $R_{h}$, of the non-composite section (BridgeID = 11)

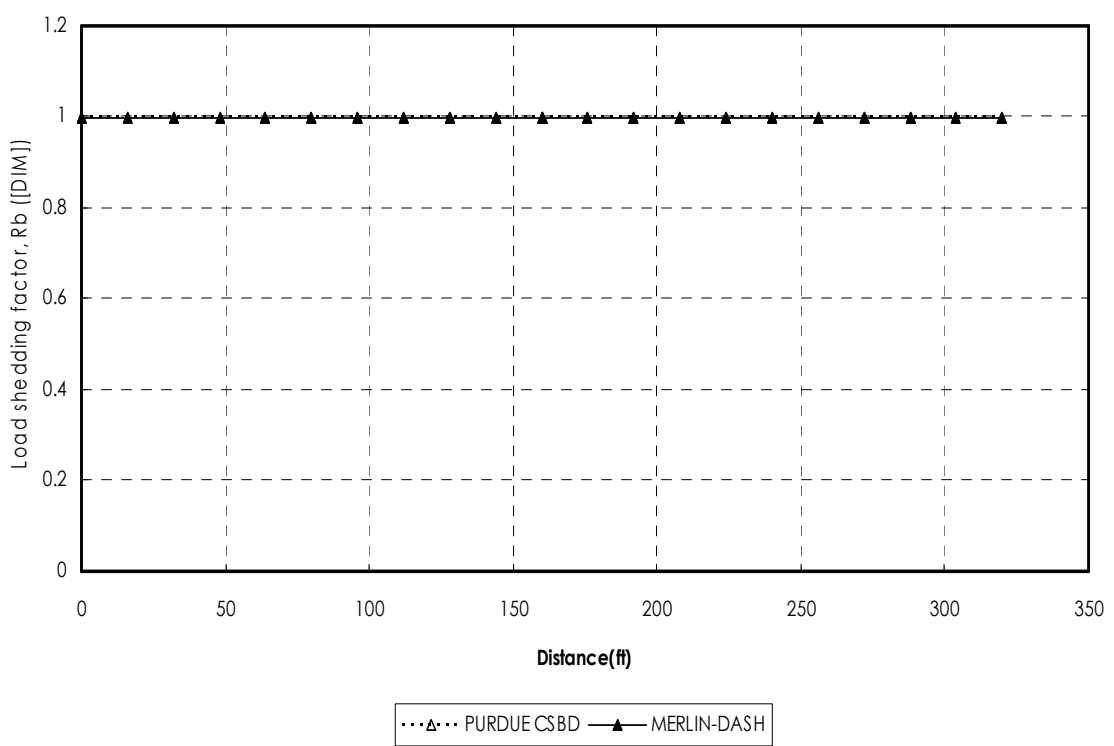

Figure 5.21 Comparison of load shedding factor, $R_{b}$, of the non-composite section (BridgeID = 11) 


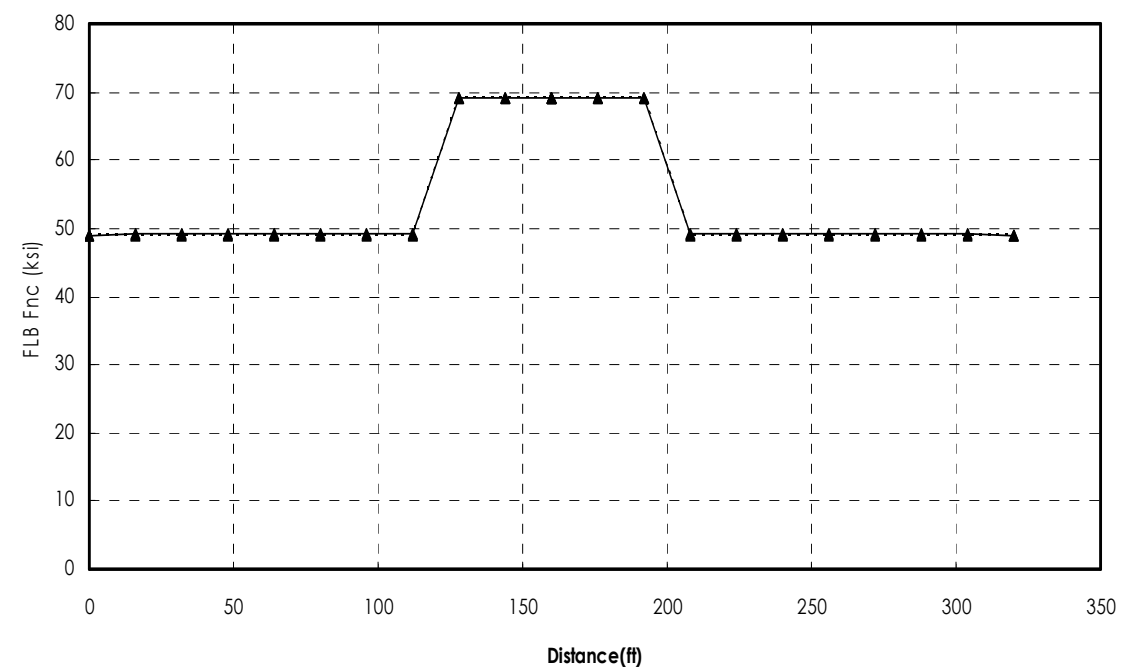

$\cdots \Delta \cdots$ PURDUE CSBD $\longleftarrow$ MERLIN-DASH

Figure 5.22 Comparison of the nominal compression flange local buckling flexural resistance, $F c_{F L B}($ BridgeID $=11)$

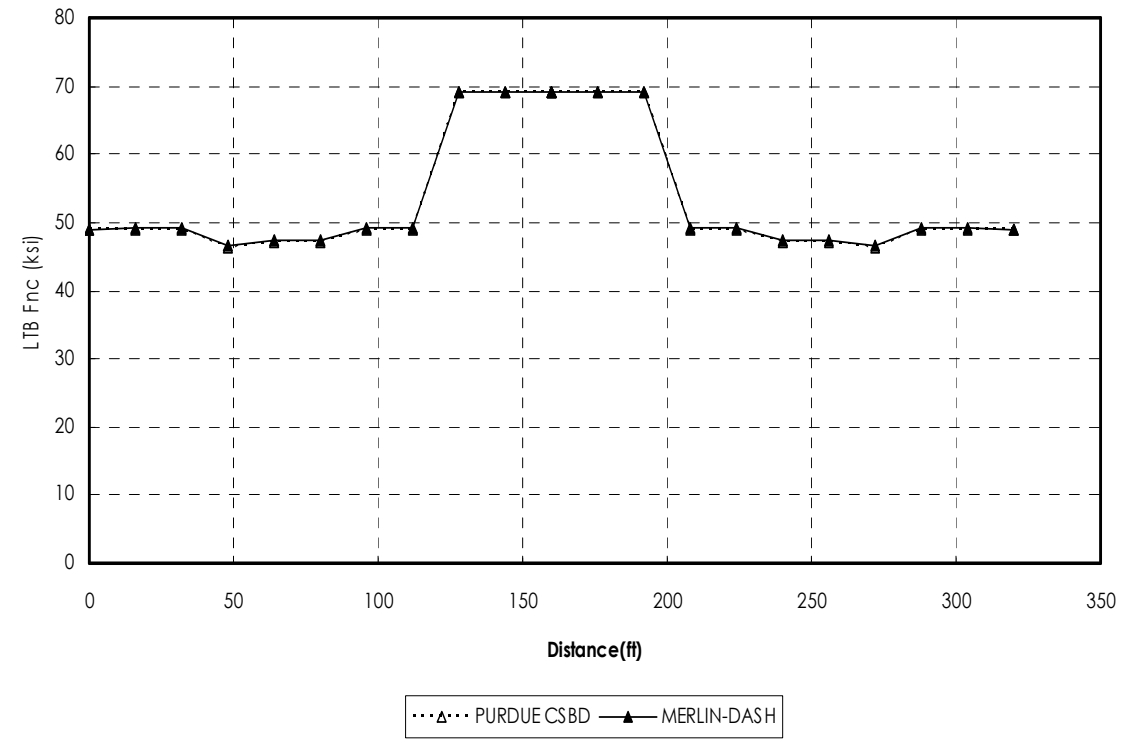

Figure 5.23 Comparison of the nominal compression lateral torsional buckling flexural resistance, $F n c_{L T B}($ BridgeID $=11)$ 


\section{Shear strength}

The shear strength of steel composite sections depends partially on the web portion of girder sections and transverse stiffeners. MERLIN-DASH provides two output tables related to the shear strength. One table shows the unstiffened section shear strength, $V_{\text {nunistiffened }}$. This table also presents shear buckling coefficient, $k$, the ratio of the shear buckling resistance to the shear yield strength, $C$, the plastic shear capacity, $V_{p}$, and the nominal shear resistance, $V_{n}$. The second table presents shear capacity check. In this table the nominal shear resistance, $V_{n}$, is compared with LRFD maximum shear envelope due to external loads.

PURDUE CSBD also calculated the shear strength and related variables to compare with the results by MERLIN-DASH. The comparisons showed excellent agreement between two programs. In this paper, the typical comparisons are presented and the typical comparisons of the plastic shear capacity, $V_{p}$, the ratio of the shear buckling resistance to the shear yield strength for unstiffened web, $C_{\text {unstiffened, }}$ and the nominal shear resistance of stiffened section, $V_{n}$, are discussed for brevity. The comparison of the plastic shear capacity, $V_{p}$, is presented in Figure 5.24. Figure 5.25 shows typical comparison of the ratio of the shear buckling resistance to the shear yield strength for unstiffened sections, $C_{\text {unstiffened, }}$ generated by two computer programs. Note that MERLIN-DASH calculates the ratio of the shear buckling resistance to the shear yield strength for unstiffened section only. Hence, the values for stiffened sections were not used in this comparison. The comparison of the nominal shear resistance, $V_{n}$, is shown in Figure 5.26. These figures show excellent agreement between the shear capacity and the associated variables calculated by MERLIN-DASH and PURDUE CSBD. The values completely overlap each other. The comparison for the other bridges in the test-bed is reported in the CD. 


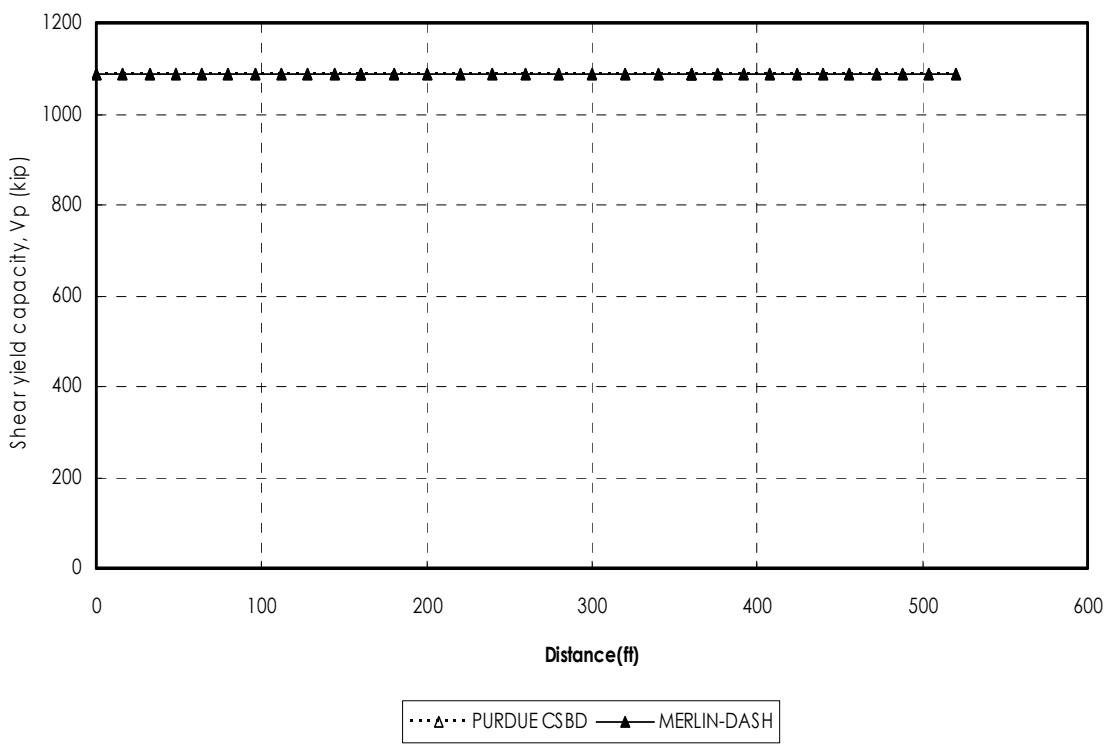

Figure 5.24 Comparison of the plastic shear capacity, $V_{p}($ BridgeID $=20)$

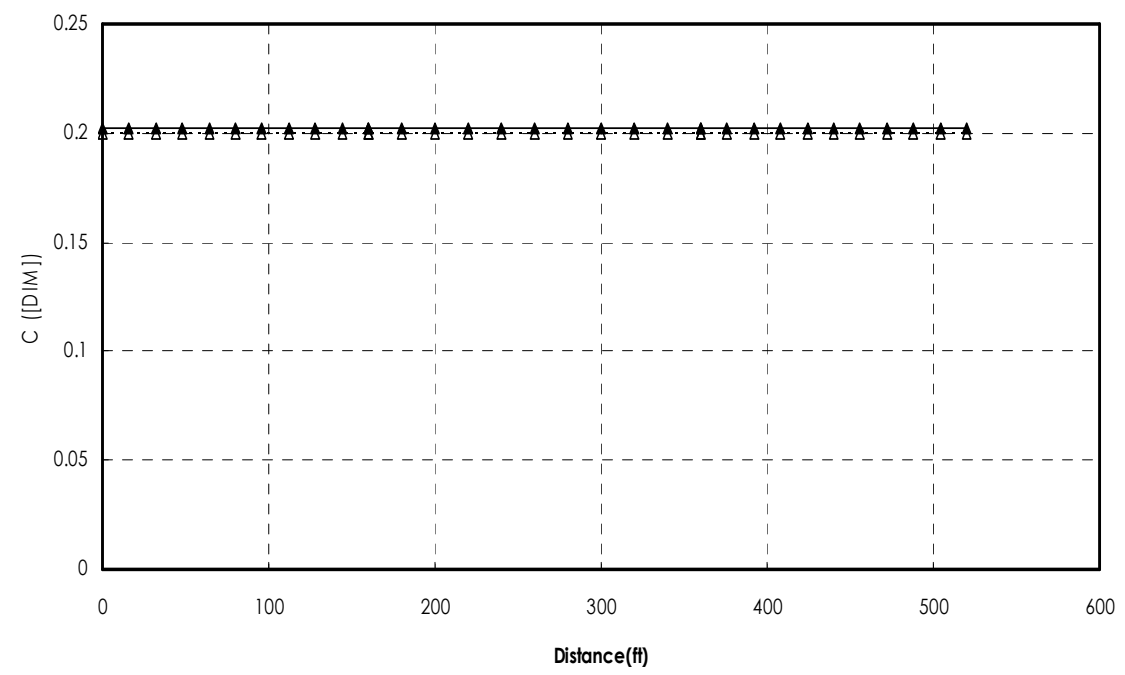

$\cdots \Delta \cdots$ PURDUE CSBD $\longrightarrow$ MERLIN-DASH

Figure 5.25 Comparison of the ratio of the shear buckling resistance to the shear yield strength for unstiffened web, $C_{\text {unstiffened }}($ BridgeID $=20$ ) 


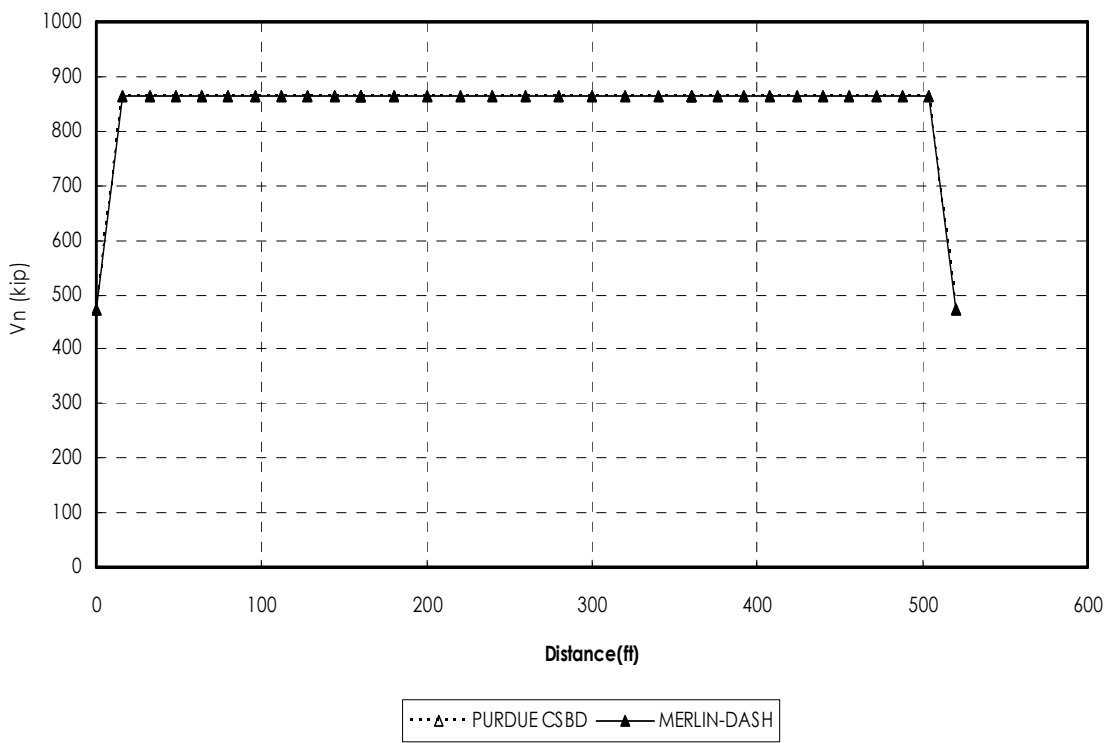

Figure 5.26 Comparison of the nominal shear resistance of stiffened section, $V_{n}($ BridgeID $=20)$ 


\section{$\underline{\text { Service limit state }}$}

Flange stresses in the top and bottom flange and compressive flange stresses due to Service II load were computed by both MERLIN-DASH and PURDUE CSBD to check the service limit state. The computation was performed without consideration of flange lateral bending. Two programs also computed three limiting stresses for the service limit sate and they are the limiting flange stress for the top flange, the limiting flange stress for the bottom flange, and the nominal bend buckling resistance for webs as given in Equation 4.40, 4.41, and 4.42 of Chapter 4.

These computed values described above are compared and they showed good agreement between two programs. The typical comparisons are presented in this report. The comparison of flange stresses at the top flange due to Service II load is shown in Figure 5.27 and the comparison of flange stresses at the bottom flange due to Service II load is presented in Figure 5.28. Figure 5.29 shows the comparison of compressive flange stresses due to Service II load. Figures 5.30 - 5.32 present the comparisons of three limiting stresses. Figure 5.30 presents the comparison of the limiting flange stress for the top flange. The comparison of the limiting flange stress for the bottom flange is shown in Figure 5.31 and Figure 5.32 presents the comparison of the nominal bend buckling resistance for webs for compression flange stress check. Each figure shows good agreement at all tenth points along the span length. Other results are compared and stored in the accompanying $\mathrm{CD}$ and can be reviewed separately. Note that absolute values are used for values of flange stresses and compression flange stress. 


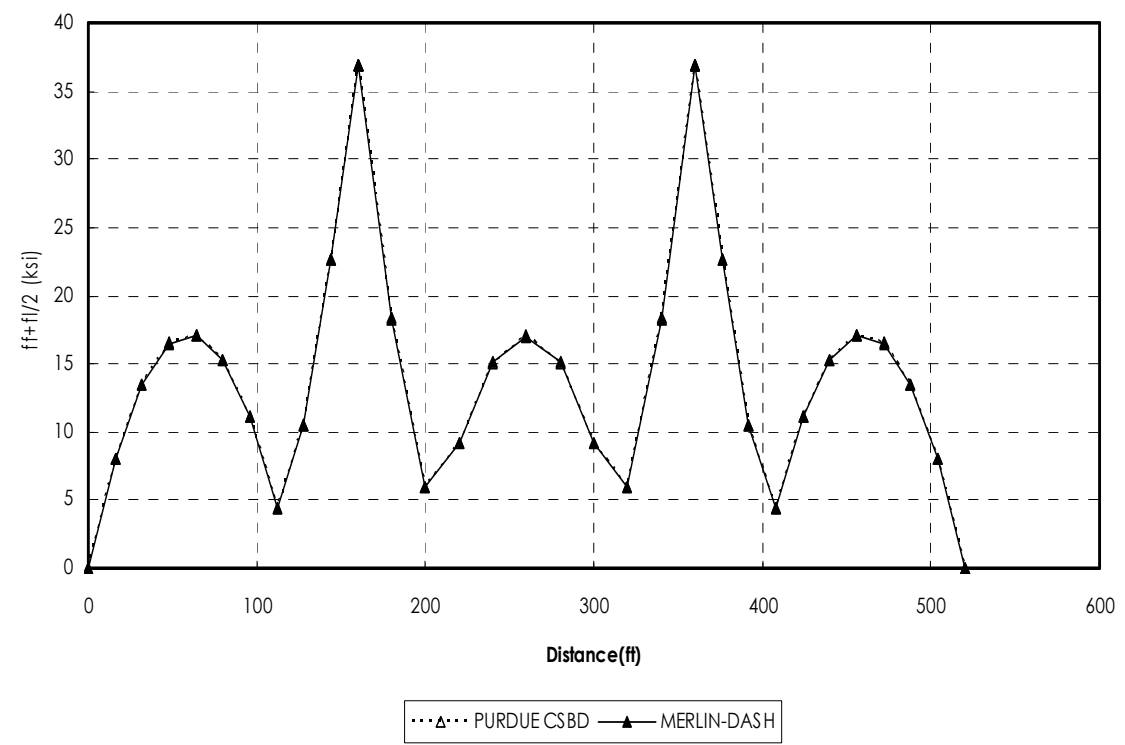

Figure 5.27 Comparison of flange at the top flange stress due to Service II load (BridgeID = 21)

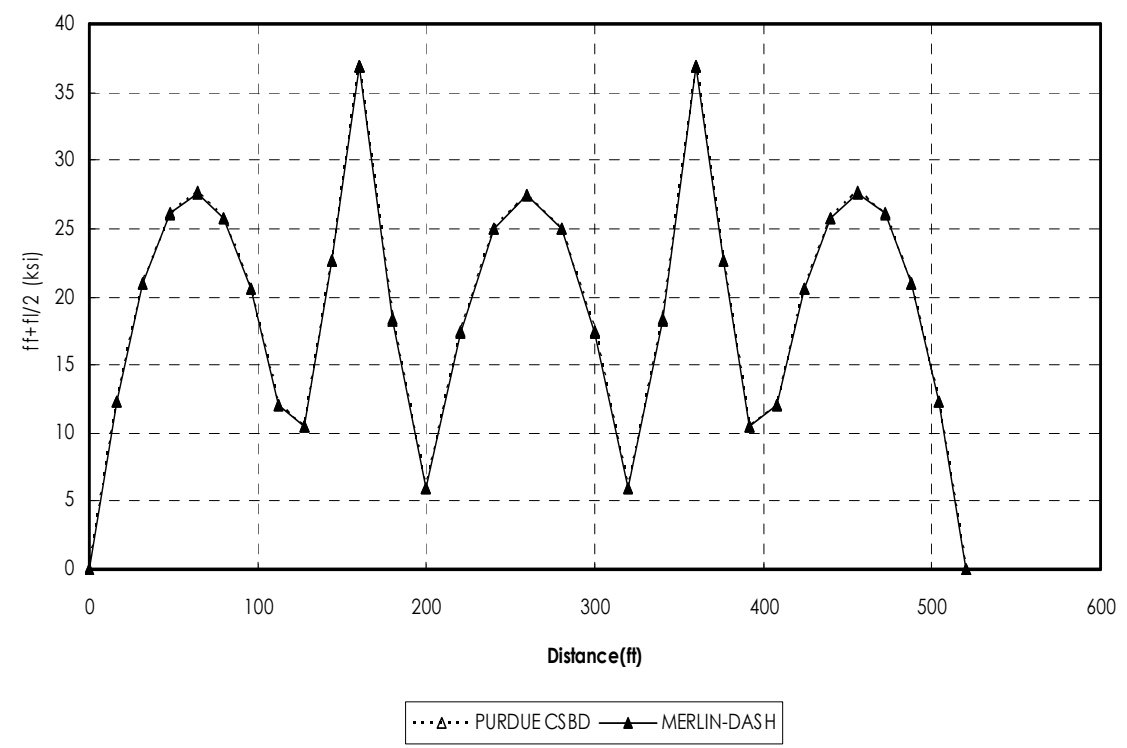

Figure 5.28 Comparison of flange stress at the bottom flange due to Service II load (BridgeID = 21) 


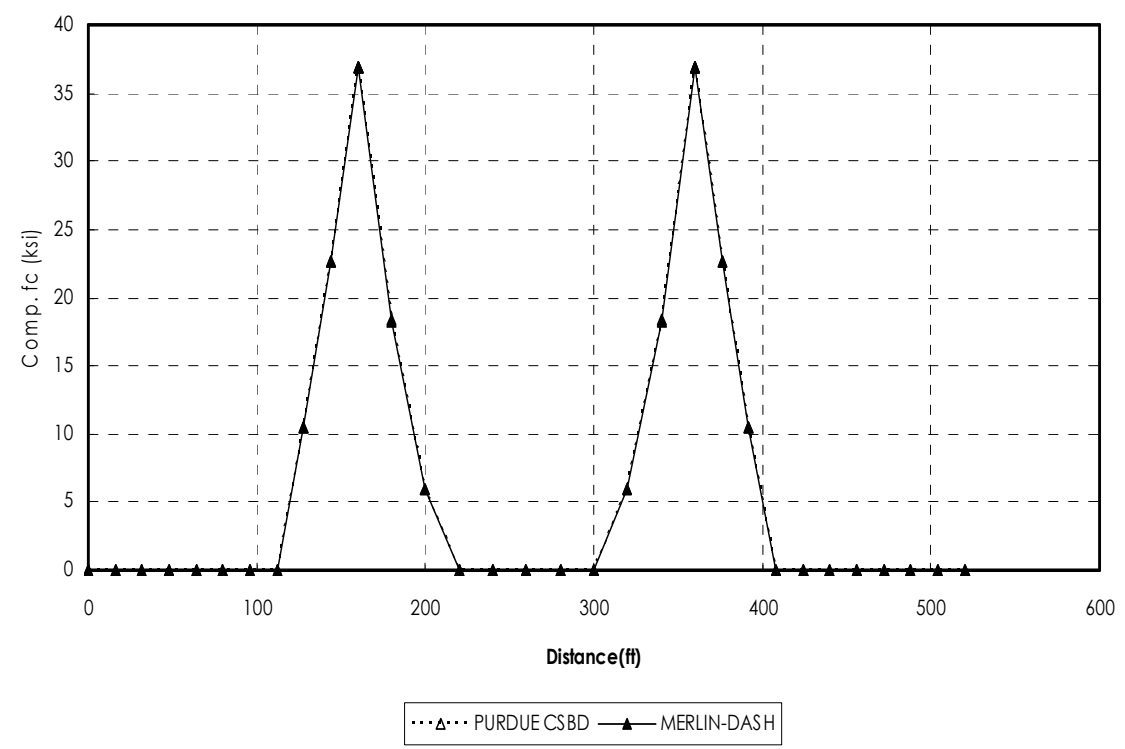

Figure 5.29 Comparison of compression flange stress due to Service II load (BridgeID = 21)

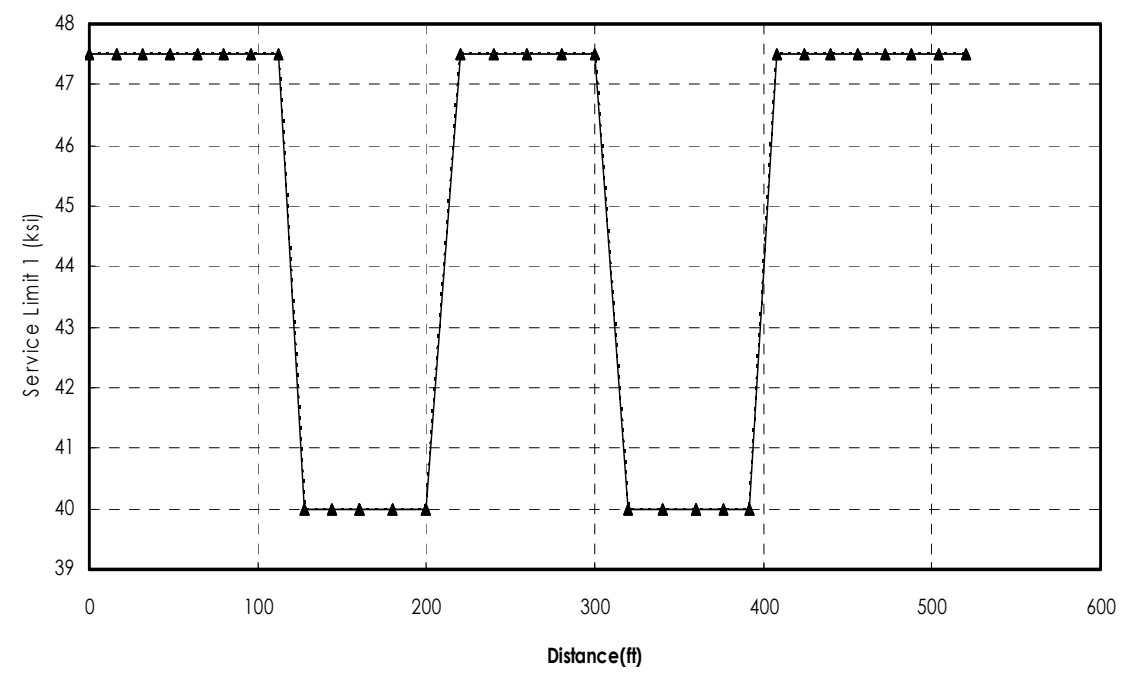

$\cdots \Delta \cdots$ PURDUE CSBD $\multimap$ MERLIN-DASH

Figure 5.30 Comparison of the limiting flange stress for the top flange $($ BridgeID $=21$ ) 


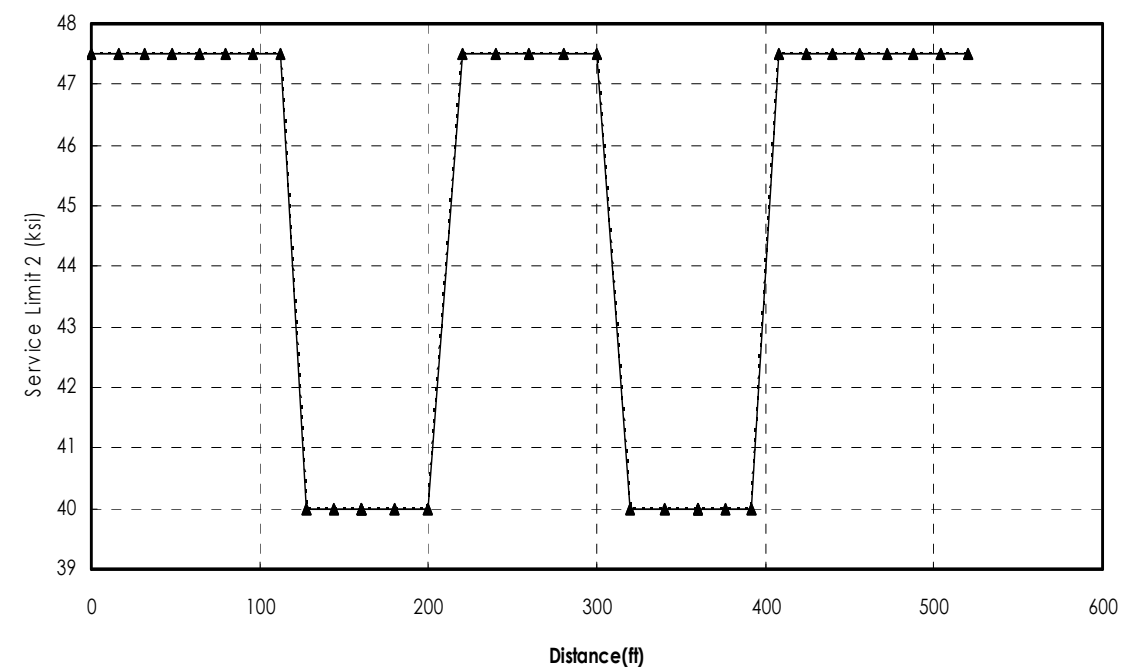

$\cdots \Delta \cdots$ PURDUE CSBD $\longrightarrow$ MERLIN-DASH

Figure 5.31 Comparison of the limiting flange stress for the bottom flange (BridgeID = 21)

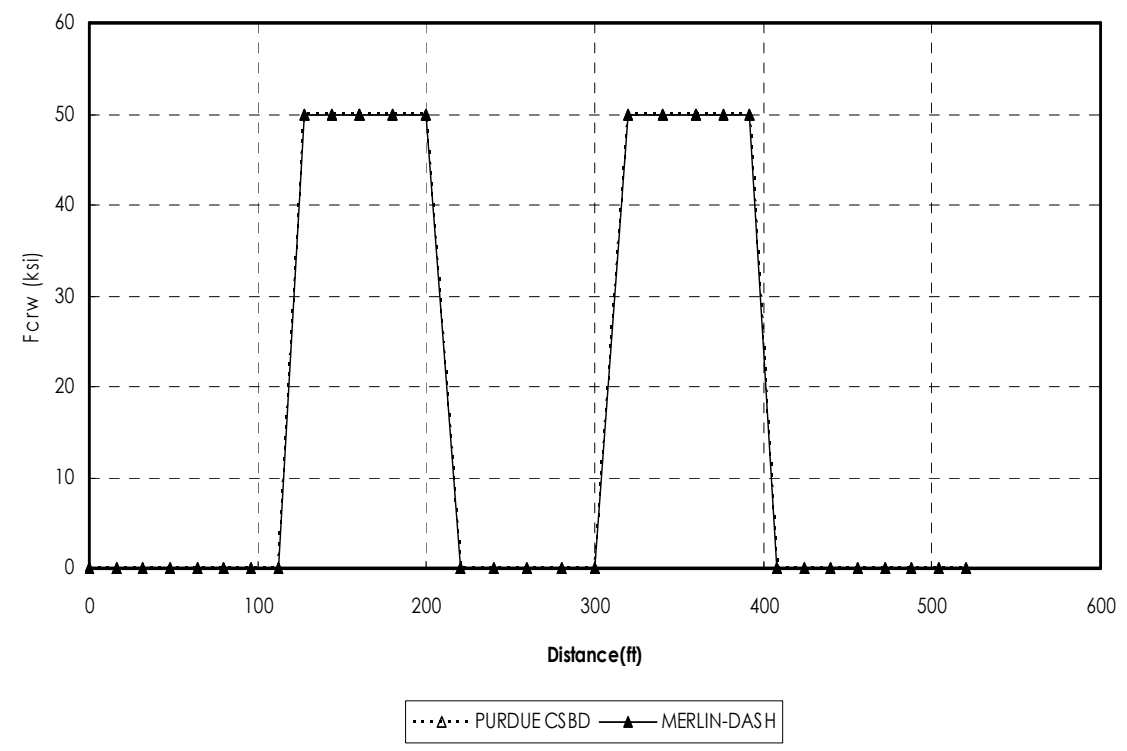

Figure 5.32 Comparison of the nominal bend buckling resistance for webs for compression flange stress check $($ BridgeID $=21)$ 


\section{Fatigue stress}

MERLIN-DASH and PURDUE CSBD compute fatigue stresses in the top and bottom flange as described in the Fatigue_fracture subroutine of Chapter 4. Only fatigue stresses were computed by this subroutine since MERLIN-DASH does not provide fatigue results. Two computed fatigue stress ranges were compared and they showed good agreement between two programs. In this report, the typical comparison of the fatigue stress in the top flange is presented in Figure 5.33 and the comparison of the fatigue bottom flange stress range is shown in Figure 5.34. These two figures show good agreement at all tenth points along the span length. The rest of results are also compared and stored in the accompanying $\mathrm{CD}$. 


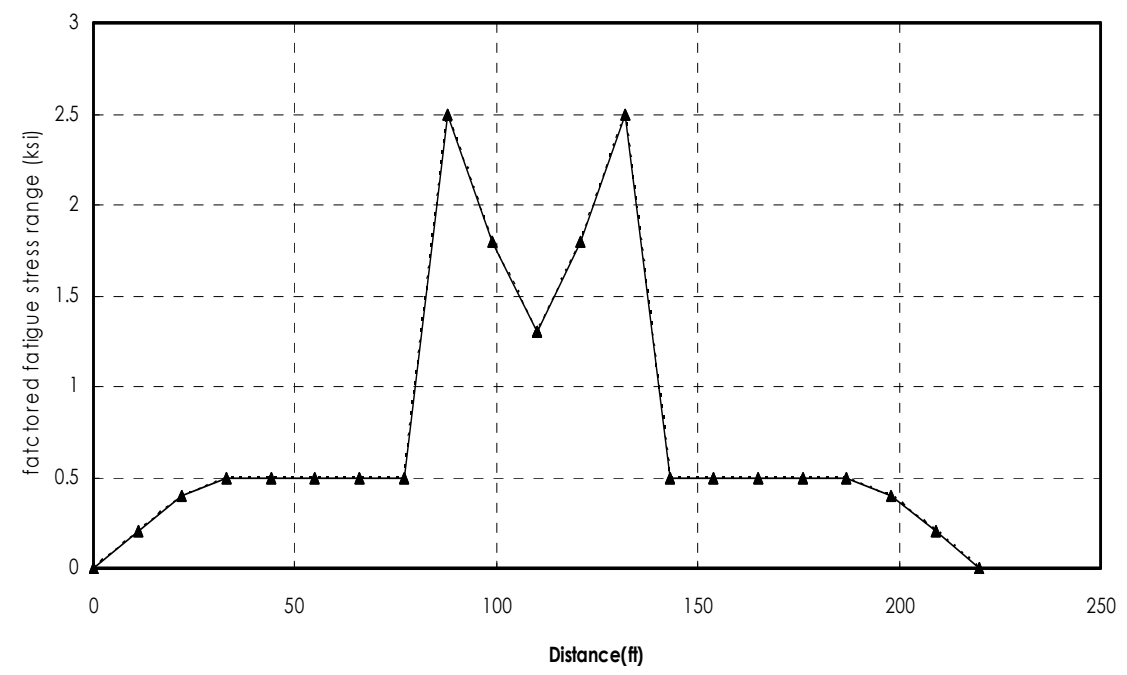

$\cdots \Delta \cdots$ PURDUE CSBD $\longleftarrow$ MERLIN-DASH

Figure 5.33 Comparison of the fatigue stress range of the top flange (BridgeID = 9)

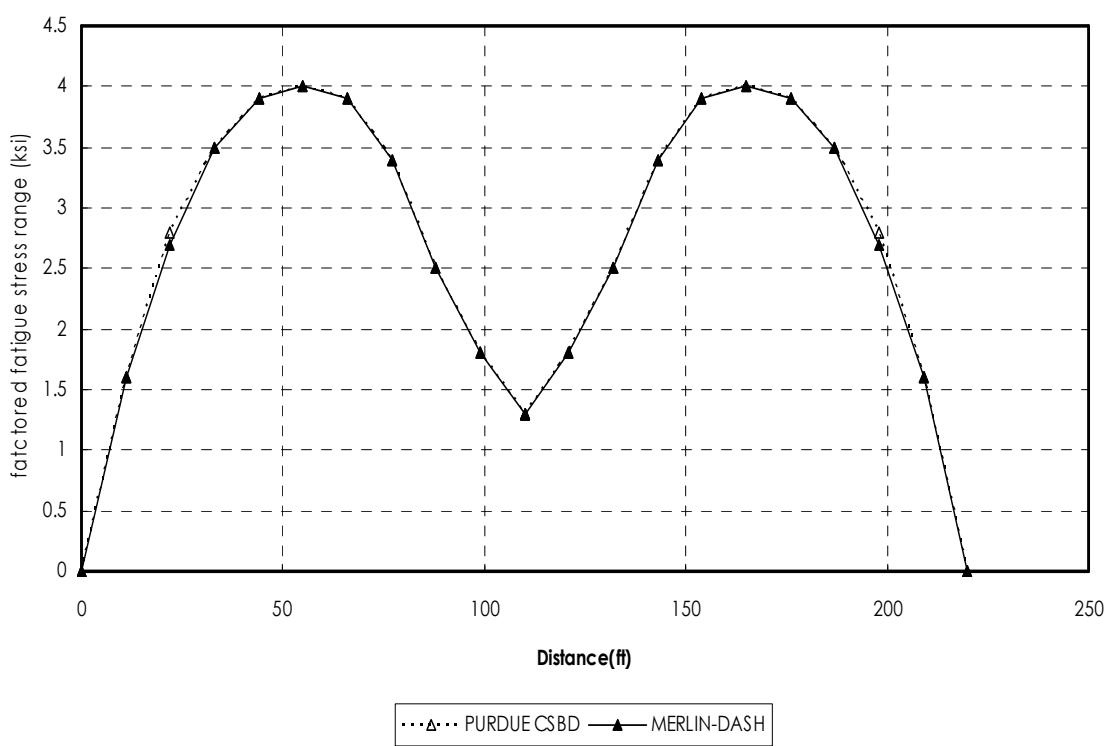

Figure 5.34 Comparison of the fatigue stress range of the bottom flange (BridgeID = 9) 


\section{Shear connector}

MERLIN-DASH and PURDUE CSBD computed design parameters related to shear connector as described in ShearConnector subroutine of Chapter 4. The design parameters included shear due to live loads, $V_{f}$, statical moment about the neutral axis of the composite section of the transformed compressive concrete area, $Q$, range of horizontal shear, $V_{s r}$, longitudinal fatigue range per unit length, $V_{f a t}$, allowable range of horizontal shear, $Z_{r}$, and maximum allowable pitch, $p_{\text {maxall }}$. However, only the range of horizontal shear, $V_{s r}$, and maximum allowable pitch, $p_{\text {maxall, }}$ are compared in this study due to the importance of two parameters. The comparisons of range of horizontal shear, $V_{s}$, and maximum allowable pitch, $p_{\text {maxall }}$, computed by two programs showed good agreement. Figure 5.35 presents the typical comparison of horizontal fatigue shear range per unit length computed by both programs. The typical comparison of maximum allowable pitch of shear connector is shown in Figure 5.36. It appears that two figures show minor discrepancies at some of tenth points along the span length. However, the discrepancies appear to be negligible as shown in Table 5.3. The rest of results are compared and they are stored in the accompanying CD. 


\begin{tabular}{|c|c|c|c|c|c|c|}
\hline \multirow{2}{*}{ BridgeID } & \multirow{2}{*}{ LoationID } & \multirow{2}{*}{ Location } & \multicolumn{2}{|c|}{$V_{\text {sr }}$} & \multicolumn{2}{c|}{$p_{\text {maxall }}$} \\
\cline { 4 - 7 } & & & $\begin{array}{c}\text { PURDUE } \\
\text { CSBD }\end{array}$ & $\begin{array}{c}\text { MERLIN- } \\
\text { DASH }\end{array}$ & $\begin{array}{c}\text { PURDUE } \\
\text { CSBD }\end{array}$ & $\begin{array}{c}\text { MERLIN- } \\
\text { DASH }\end{array}$ \\
\hline 18 & 1 & 0 & 0.6 & 0.6 & 9.31 & 9.22 \\
\hline 18 & 2 & 11 & 0.5 & 0.5 & 10.71 & 10.62 \\
\hline 18 & 3 & 22 & 0.5 & 0.5 & 11.89 & 11.83 \\
\hline 18 & 4 & 33 & 0.4 & 0.5 & 12.98 & 12.82 \\
\hline 18 & 5 & 44 & 0.4 & 0.5 & 12.98 & 12.84 \\
\hline 18 & 6 & 55 & 0.5 & 0.5 & 12.59 & 12.5 \\
\hline 18 & 7 & 66 & 0.5 & 0.5 & 12.23 & 12.06 \\
\hline 18 & 8 & 77 & 0.5 & 0.5 & 11.57 & 11.55 \\
\hline 18 & 9 & 88 & 0 & 0 & 0 & 0 \\
\hline 18 & 10 & 99 & 0 & 0 & 0 & 0 \\
\hline 18 & 11 & 110 & 0 & 0 & 0 & 0 \\
\hline 18 & 12 & 110 & 0 & 0 & 0 & 0 \\
\hline 18 & 13 & 123.75 & 0 & 0 & 0 & 0 \\
\hline 18 & 14 & 137.5 & 0 & 0 & 0 & 0 \\
\hline 18 & 15 & 151.25 & 0.5 & 0.5 & 11.1 & 11.15 \\
\hline 18 & 16 & 165 & 0.5 & 0.5 & 11.4 & 11.43 \\
\hline 18 & 17 & 178.75 & 0.5 & 0.5 & 11.72 & 11.51 \\
\hline
\end{tabular}

Table 5.3 Comparison of $V_{s r}$ and $p_{\text {maxall }}$ computed by MERLIN-DASH and PURDUE CSBD $($ BridgeID $=18)$ 


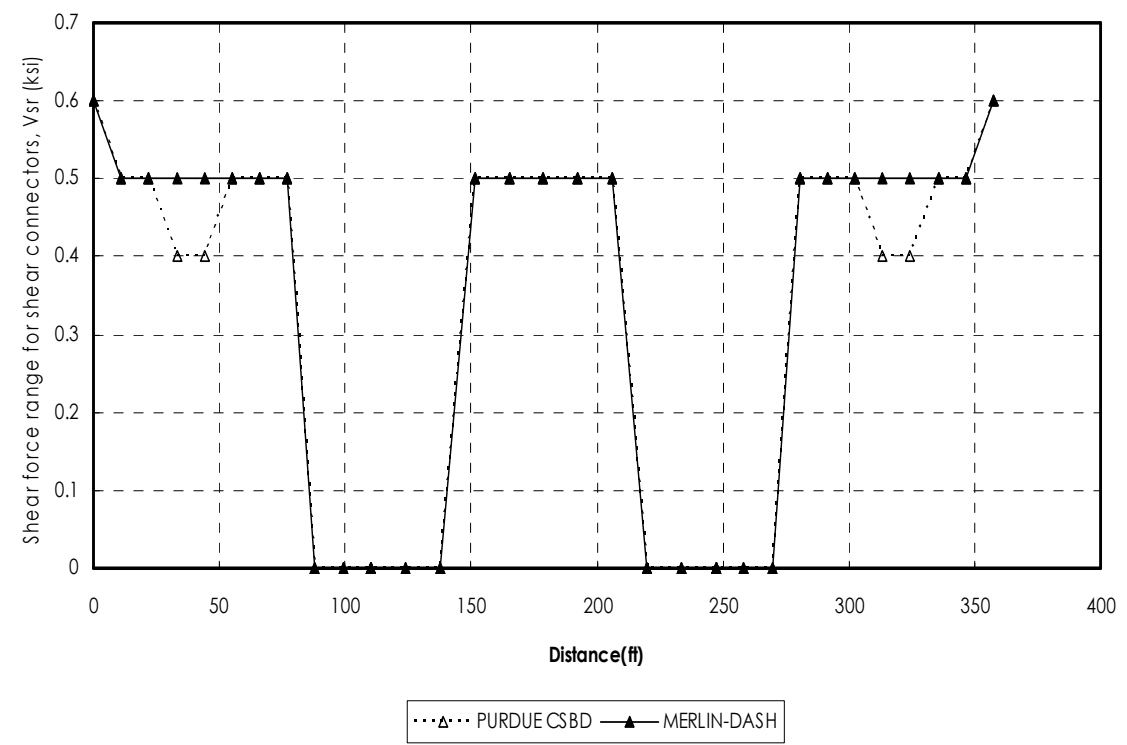

Figure 5.35 Comparison of horizontal fatigue shear range per unit length (BridgeID = 18)

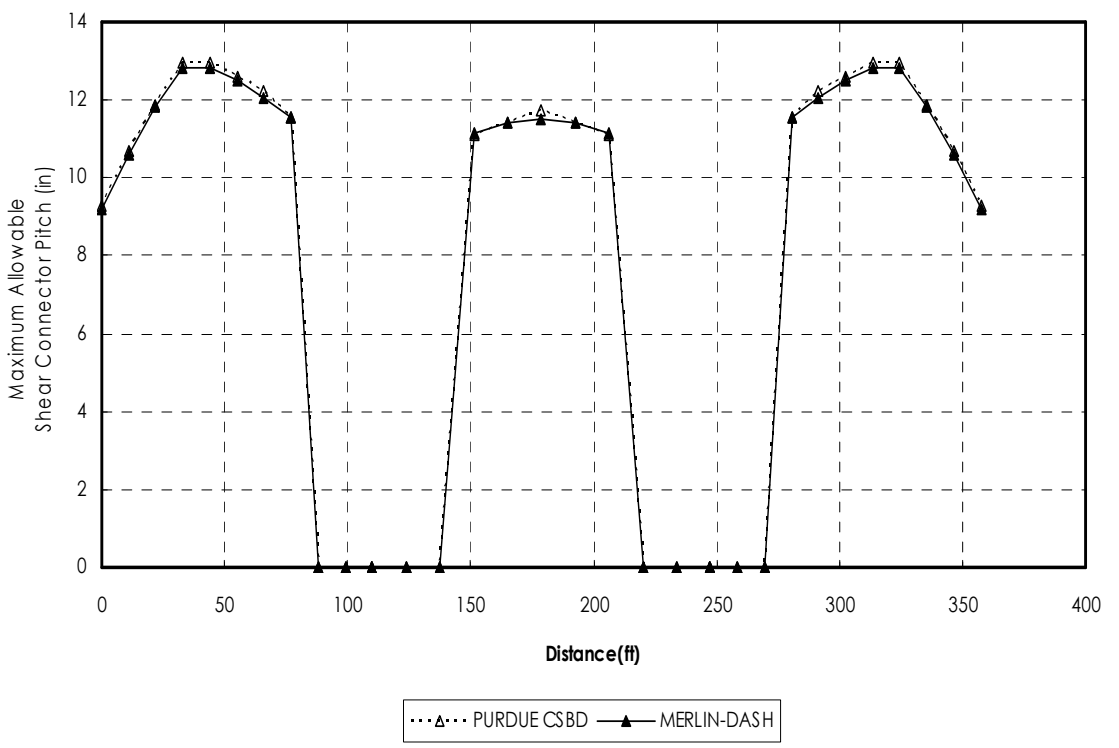

Figure 5.36 Comparison of maximum allowable pitch $($ BridgeID $=18)$ 


\section{CONCLUSION}

Process 12-50 was used to validate computational results generated by commercial software, MERLIN-DASH, for composite steel I-girder bridges. Five simple-span and sixteen multi-span bridges of the test-bed were developed with the guidance of practicing engineers and INDOT specialists. Girder sections recommended by local engineers were used to define complete set of bridges in the test-bed. An indigenous computer program, PURDUE CSBD, was developed using the AASHTO LRFD specifications and Visual Basic for Applications (VBA) to generate output for comparisons with output generated by MERLIN-DASH.

PURDUE CSBD computes section properties, moments, shears, stresses, deflections. The program also performs design calculations associated with flexural strength, shear strength, fatigue limit state, and shear connectors. The results included section properties, moments, shears, stresses, deflections. Design calculations associated with flexural strength, shear strength, fatigue limit state, and shear connector were also included in this study. Both MERLIN-DASH and PURDUE CSBD generated a set of output for all the simple and multi-span bridges in the testbed. The results from both computer programs were compared to identify graphical and numerical discrepancies between them. The results indicate that:

1. The comparison shows excellent agreement between moment and shear envelopes calculated by MERLIN-DASH and PURDUE CSBD.

2. The comparison shows excellent agreement between concrete and steel stresses computed by MERLIN-DASH and PURDUE CSBD.

3. The comparison shows excellent agreement between dead load deflections generated by two programs.

4. The comparison also shows good agreement between maximum live load deflections computed by MERLIN-DASH and PURDUE CSBD if the correct reduction factor for the force effect $\left(m_{r e d}\right)$ is utilized. The factor is determined based on the value of ADTT and it appears that MERLIN-DASH does not utilize ADTT properly.

5. The comparison shows excellent agreement between flexural strength and all relevant parameters required for the strength limit state check computed by MERLIN-DASH and PURDUE CSBD

6. The comparison shows excellent agreement between shear strength and all relevant parameters computed by MERLIN-DASH and PURDUE CSBD 
7. The comparison shows good agreement between fatigue stresses due to truck load computed by two programs. Only fatigue stresses were compared since MERLIN-DASH does not provide the result of the fatigue limit state as specified in AASHTO LRFD Article 6.6.1.2.2.

8. The comparison shows negligible discrepancies between horizontal fatigue shear range per unit length, $V_{s r}$, and maximum allowable pitch of shear connectors along the longitudinal axis, $p_{\text {maxall }}$, computed by two programs. 


\section{LIST OF REFERENCES}

American Association of State Highway Transportation Officials (AASHTO). (2008). LRFD Bridge Design Specifications. $4^{\text {rd }}$ Ed., Washington, D.C.

American Institute of Steel Construction (1986), "Moments Shears and Reactions for continuous highway bridges", New York, N.Y.

Baker et al. (2003). Bridge Software-Validation Guidelines and Examples (NCHRP Report 485). Transportation Research Board, Washington, D.C.

Barker, R. M. and Puckett, J. A. (1997). "Design of Highway Bridges.” John Wiley \& Sons, Inc., New York, NY.

Varma, Amit H. and Choe, Lisa (2009). "Evaluation of Prestressed Concrete I-Girder Bridge Design Software Using NCHRP Process 12-50." Transportation Research Board $88^{\text {th }}$ Annual Meeting, Washington DC

Indiana Department of Transportation (INDOT). (2005). The Indiana Design Manual. Indianapolis, IN. 


\section{$\underline{\text { Appendix A }}$}

This appendix presents the available Report IDs corresponding to the design of simply supported slab-on-girder composite steel I-girder bridges and their descriptions as established by Baker et al. (2003).

\section{Report ID Description}

$40000 \quad$ Point of interest, POI

40001 Effective slab width, be

40002 Web depth in Compression at Strength I: Composite

40003 Web depth in Compression at Strength III : Composite

40004 Web depth in Compression at Strength V : Composite

40005 Web depth in Compression at Service II : Composite

40006 Web depth in Compression at Construction : Non-Composite

40007 Yield moment of composite section at Strength I

40008 Yield moment of composite section at Strength III

40009 Yield moment of composite section at Strength V

40010 Yield moment of composite section at Service II

40011 Yield moment of non-composite section at Construction

40012 Compression-flange stress at Strength I : Composite

40013 Compression-flange stress at Strength III : Composite

40014 Compression-flange stress at Strength V : Composite

40015 Compression-flange stress at Service II : Composite

40016 Compression-flange stress at Construction : Non-Composite

40017 Tension-flange stress at Strength I : Composite

40018 Tension-flange stress at Strength III : Composite

40019 Tension-flange stress at Strength V : Composite

40020 Tension-flange stress at Service II : Composite

40021 Tension-flange stress at Construction : Non-Composite

40022 Distance from the top of the concrete deck to the neutral axis of the composite section at the plastic moment

40023 Depth of the web in compression at the plastic moment : Non-composite 


\section{Report ID Description}

40024 Depth of the web in compression at the plastic moment : Composite

40025 bf/tf : top flange

40026 Dc/tw : Strength I : Composite

40027 Dc/tw : Strength III : Composite

40028 Dc/tw : Strength V : Composite

40029 Dc/tw : Construction : Non-Composite

40030 Dcp/tw : Composite

40031 Dcp/tw : Non-Composite

40032 Compact web indicator : Strength I : Composite

40033 Compact web indicator: Strength III : Composite

40034 Compact web indicator: Strength V : Composite

40035 Compact compr. flange indicator : Construction : Non-Composite

40036 Compact LTB indicator : Construction : Non-Composite

40037 Compact indicator : Strength I : Composite

40038 Compact indicator : Strength III : Composite

40039 Compact indicator : Strength V : Composite

40040 Compact indicator : Construction : Non-Composite

40041 Moment gradient factor, $\mathrm{Cb}$ : Construction : Non-Composite

40042 Force in compr. flange at brace point : $\mathrm{Pl}$ : Construction

40043 Force in compr. flange at brace point : $\mathrm{Ph}$ : Construction

40044 Unbraced length, $\mathrm{Lb}$ : Construction

40045 Load shedding factor, $\mathrm{Rb}:$ Strength I

40046 Load shedding factor, $\mathrm{Rb}$ : Strength III

40047 Load shedding factor, $\mathrm{Rb}$ : Strength $\mathrm{V}$

40048 Load shedding factor, $\mathrm{Rb}:$ Construction

40049 Factored flexural resistance at Strength I : Composite

40050 Factored flexural resistance at Strength III : Composite

40051 Factored flexural resistance at Strength V : Composite

40052 Fr : Strength I : Composite

$40053 \quad$ Fr : Strength III : Composite 


\section{Report ID Description}

40054 Fr : Strength V : Composite

40055 Shear yield capacity, Vp

$40056 \quad$ Factored shear resistance : unstiffened web

40057 Max flexural stress in comp. flange for DL + fatigue, fcf

40058 Max shear stress in web for DL + fatigue, vcf

40059 Actual flexural stress in comp. flange for DL + fatigue

40060 Actual shear stress in web for DL + fatigue

40061 Shear force range for shear connectors, Vsr

40062 Shear connector fatigue resistance, $\mathrm{Zr}$

40063 Factor for shear connector fatigue resistance, a

40064 Shear connector strength, Qr

40065 Cross sectional area of shear connector, Asc

40066 Shear connectors fatigue controlls indicator

40067 Shear connectors, Vh

40068 Shear connectors, max pitch

40069 Bearing stiffener projecting element area, Apn

40070 Bearing stiffners, bt OK indictor

40071 Bearing stiffners, Area OK indictor

40072 Bearing stiffners, I OK indicator

40073 Bearing stiffeners, $\operatorname{Pr}$

$40074 \quad$ Fatctored fatigue stress range

40075 Fatigue resistance

40076 Wind load Mw : Strength III

40077 Wind load Mw : Strength V

40078 Wind load bw : Strength III

40079 Wind load bw : Strength V

$40080 \quad$ Wind load Mr : Strength III

40081 Wind load Mr: Strength V

40082 Moment due to the factored loads for the constructability check

40083 Factored flexural resistance for the constructability check 


\section{Report ID Description}

40084 Shear due to the factored loads for the constructability check

40085 Factored shear resistance for the constructability check

40086 Fr : Strength I : Composite : Top Flange

40087 Fr : Strength III : Composite : Top Flange

40088 Fr : Strength V : Composite : Top Flange

40089 Shear buckling factor, C

40090 Shear interaction coefficient, R : Strength I

40091 Shear interaction coefficient, R : Strength III

40092 Shear interaction coefficient, R : Strength V

$40093 \quad$ Factored Shear capacity, Vr : Strength I

$40094 \quad$ Factored Shear capacity, Vr : Strength III

40095 Factored Shear capacity, Vr : Strength V 


\section{$\underline{\text { Appendix B }}$}

This appendix presents the Report IDs corresponding to the effects of dead and live loads (moment, shear, and deflection), as established by Baker et al. (2003).

\section{Report ID Description}

30002 Dead load deflection due to girder weight

30014 Dead load deflection due to slab and haunch weight

30026 Superimposed dead load \#1

30035 Dead load deflection due to prestress loads

30044 Dead load deflection due to future wearing surface

30047 Dead load deflection due to barrier weight

32094 Live load deflection due to HL-93 positive moment envelope including impact

$34000 \quad$ Maximum moment due to Strength I load

34002 Maximum shear due to Strength I load 


\title{
$\underline{\text { Appendix C }}$
}

This appendix presents 92 Report IDs and their descriptions. They are added into the initial ReportID developed by Baker et al. (2003) for the better comparison.

\author{
Report ID Description \\ 40500 \\ 40501 \\ 40502 \\ 40503 \\ 40504 \\ 40505 \\ 40506 \\ 40507 \\ 40508 \\ 40509 \\ 40510 \\ 40511 \\ 40512 \\ 40513 \\ 40514 \\ 40515 \\ 40516 \\ 40517 \\ 40518 \\ 40519 \\ 40520 \\ 40521 \\ 40522 \\ 40523 \\ 40524 \\ 40525 \\ 40526 \\ 40527 \\ 40528 \\ 40529 \\ 40530 \\ 40531 \\ 40532 \\ Maixmum Live Load Deflection : Composite, $n$, Construction,unfactored : \\ Stress : Non-Composite, unfactored : Top Flange : DC1 \\ Stress : Non-Composite, unfactored : Bot Flange : DC1 \\ Stress : Composite, 3n, unfactored : Top Slab : DC2+DW \\ Stress : Composite, 3n, unfactored : Top Flange : DC2+DW \\ Stress : Composite, 3n, unfactored : Bot Flange : DC2+DW \\ Stress : Composite, $n$, unfactored : Top Slab : Max LL \\ Stress : Composite, $\mathrm{n}$, unfactored : Top Flange : Max LL \\ Stress : Composite, n, unfactored : Bot Flange : Max LL \\ Stress : Composite, n, unfactored : Top Slab : Min LL \\ Stress : Composite, $n$, unfactored : Top Flange : Min LL \\ Stress : Composite, n, unfactored : Bot Flange : Min LL \\ Stress : Service I : Top Slab : Total Positive \\ Stress : Service I : Top Flange : Total Positive \\ Stress : Service I : Bot Flange : Total Positive \\ Stress : Service I : Top slab : Total Negative \\ Stress : Service I : Top Flange : Total Negative \\ Stress : Service I : Bot Flange : Total Negative \\ Stress : Service II : Top Slab : Total Positive \\ Stress : Service II : Top Flange : Total Positive \\ Stress : Service II : Bot Flange : Total Positive \\ Stress : Service II : Top Slab : Total Negative \\ Stress : Service II : Top Flange : Total Negative \\ Stress : Service II : Bot Flange : Total Negative \\ Stress : Strength I : Top Slab : Total Positive, Maximum \\ Stress : Strength I : Top Flange : Total Positive, Maximum \\ Stress : Strength I : Bot Flange : Total Positive, Maximum \\ Stress : Strength I : Top Slab : Total Negative, Maximum \\ Stress : Strength I : Top Flange : Total Negative, Maximum \\ Stress : Strength I : Bot Flange : Total Negative, Maximum \\ Stress : Strength I : Top Slab : Total Positive, Minimum \\ Stress : Strength I : Top Flange : Total Positive, Minimum \\ Stress : Strength I : Bot Flange : Total Positive, Minimum
}




\section{Report ID Description}

40533

40534

40535

40536

40537

40538

40539

40540

40541

40542

40543

40544

40545

40546

40547

40548

40549

40550

40551

40552

40553

40554

40555

40556

40557

40558

40559

40560

40561

40562

40563

40564

40565

40566

40567

40568

40569

40570
Stress : Strength I : Top Slab : Total Negative, Minimum

Stress : Strength I : Top Flange : Total Negative, Minimum

Stress : Strength I : Bot Flange : Total Negative, Minimum

Stress : Strength II : Top Slab : Total Positive, Maximum

Stress : Strength II : Top Flange : Total Positive, Maximum

Stress : Strength II : Bot Flange : Total Positive, Maximum

Stress : Strength II : Top Slab : Total Negative, Maximum

Stress : Strength II : Top Flange : Total Negative, Maximum

Stress : Strength II : Bot Flange : Total Negative, Maximum

Stress : Strength II : Top Slab : Total Positive, Minimum

Stress : Strength II : Top Flange : Total Positive, Minimum

Stress : Strength II : Bot Flange : Total Positive, Minimum

Stress : Strength II : Top Slab : Total Negative, Minimum

Stress : Strength II : Top Flange : Total Negative, Minimum

Stress : Strength II : Bot Flange : Total Negative, Minimum

Moment gradient factor, $\mathrm{Cb}:$ Strength I

Hybrid Factor, Rh : Construction

Hybrid Factor, Rh : Strength I

2Dcp/tw : Construction : Composite, $\mathrm{n}$

2Dc/tw : Service II : Composite, $\mathrm{n}$

Webcategory : Composite, $\mathrm{n}$

2Dc/tw : Construction : Non-Composite

Webcategory : Non-Composite

Lamdaf : Non-Composite

Lamdapf : Non-Composite

Lamdarf : Non-Composite

FLB category : Non-Composite

Lp : Non-Composite

Lp : Composite, $\mathrm{n}$

Lr : Non-Composite

Lr : Composite, $\mathrm{n}$

LTB category : Non-Composite

FLB Fnc : Construction : Dead Load

FLB Fnc : Strength I : Dead Load + Live Load : Negative flexure

LTB Fnc : Construction : Dead Load

LTB Fnc: Strength I : Dead Load + Live Load : Negative flexure $\mathrm{Mu}+1 / 3 \mathrm{flSxt}:$ Strength I

fbu : flange stress : Top Flange 


$\begin{array}{ll}\text { Report ID } & \text { Description } \\ 40571 & \text { fbu : flange stress : Bot Flange } \\ 40572 & \text { fbu }+1 / 3 \text { fl : flange stress : Bot Flange } \\ 40573 & \text { Strength Limit } 1: \\ 40574 & \text { Strength Limit } 2: \text { (Phi)*Rh*Fyt - tension flange : Negative flexure } \\ 40575 & \text { Strength Limit } 3: \text { 0.6Fyt - Positive flexure } \\ 40576 & \text { Strength Limit } 4: \text { (Phi)Fnc : Negative flexure } \\ 40577 & \text { Strength limit state check } \\ 40578 & \text { C : shear bucklin resistance / shear min. yield strength : Unstiffened } \\ 40579 & \text { Vn : Nominal shear resistance } \\ 40580 & \text { fatctored fatigue stress range : Top Flange } \\ 40581 & \text { fatctored fatigue stress range : Bot Flange } \\ 40582 & \text { ff+fl/2 : Service II : Top Flange } \\ 40583 & \text { ff+fl/2 : Service II : Bot Flange } \\ 40584 & \text { Comp. fc : Service II } \\ 40585 & \text { Fcrw : nominal web bend buckling resistance } \\ 40586 & \text { Service Limit } 1: \text { 0.95RhFy - Composite } \\ 40587 & \text { Service Limit } 2: \text { 0.95RFy - Non Composite : Top Flange } \\ 40588 & \text { Service limit state check } \\ 40589 & \text { Deflection : Dead Load : DC1 + DC2 + DW } \\ 40590 & \text { Vn : Nominal shear resistance : Unstiffened } \\ 40591 & \text { Maximum Allowable Shear Connector Pitch } \\ & \end{array}$




\section{Appendix D}

Flowcharts for most of the subroutines and public functions in the VBA program are presented in this section. Some of the flowcharts continue over several pages, and are identified using the term continued (cont) in the figure title. 


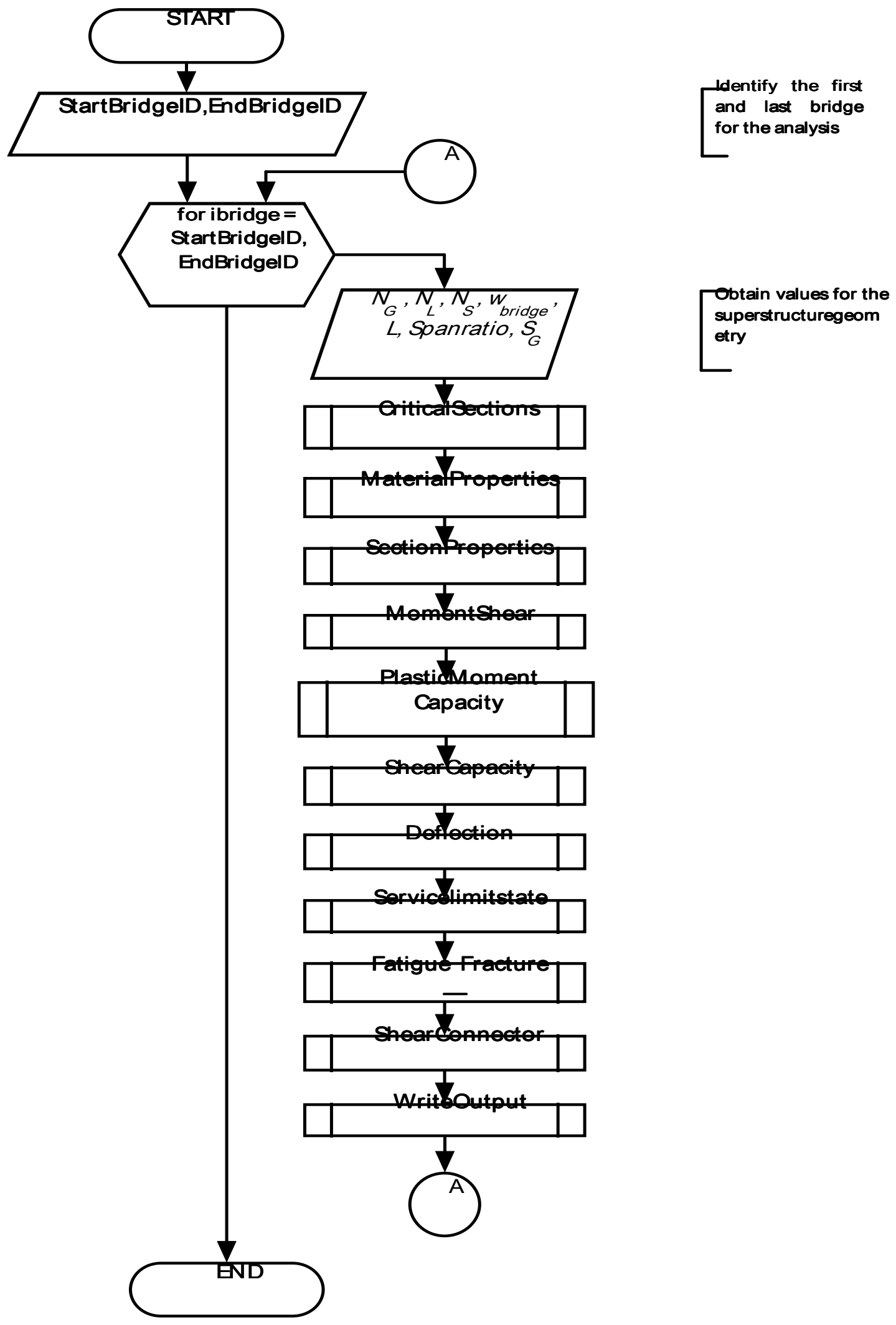

Flowchart D.1 BridgeAnalysis 


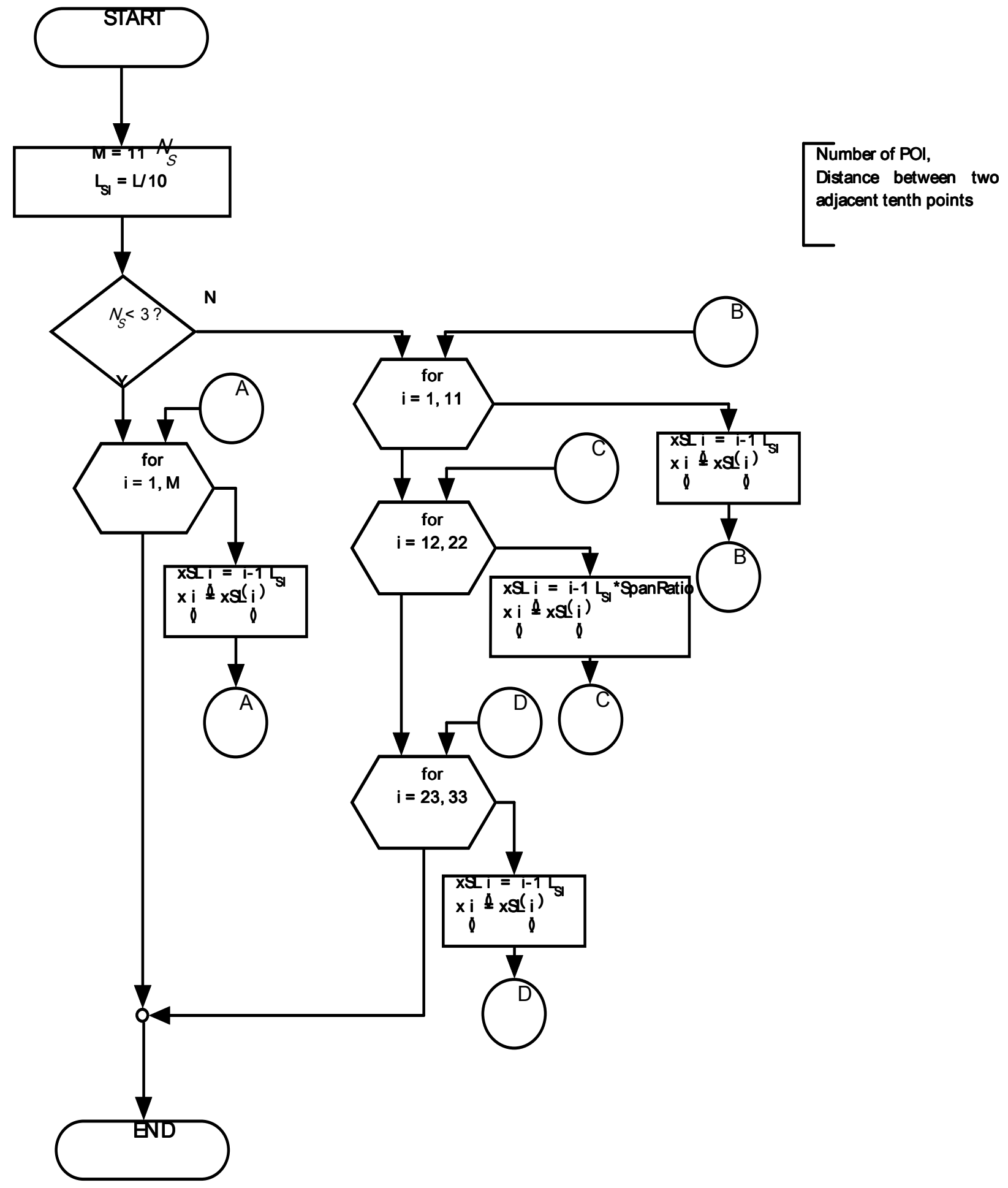

Flowchart D.2 CriticalSections 


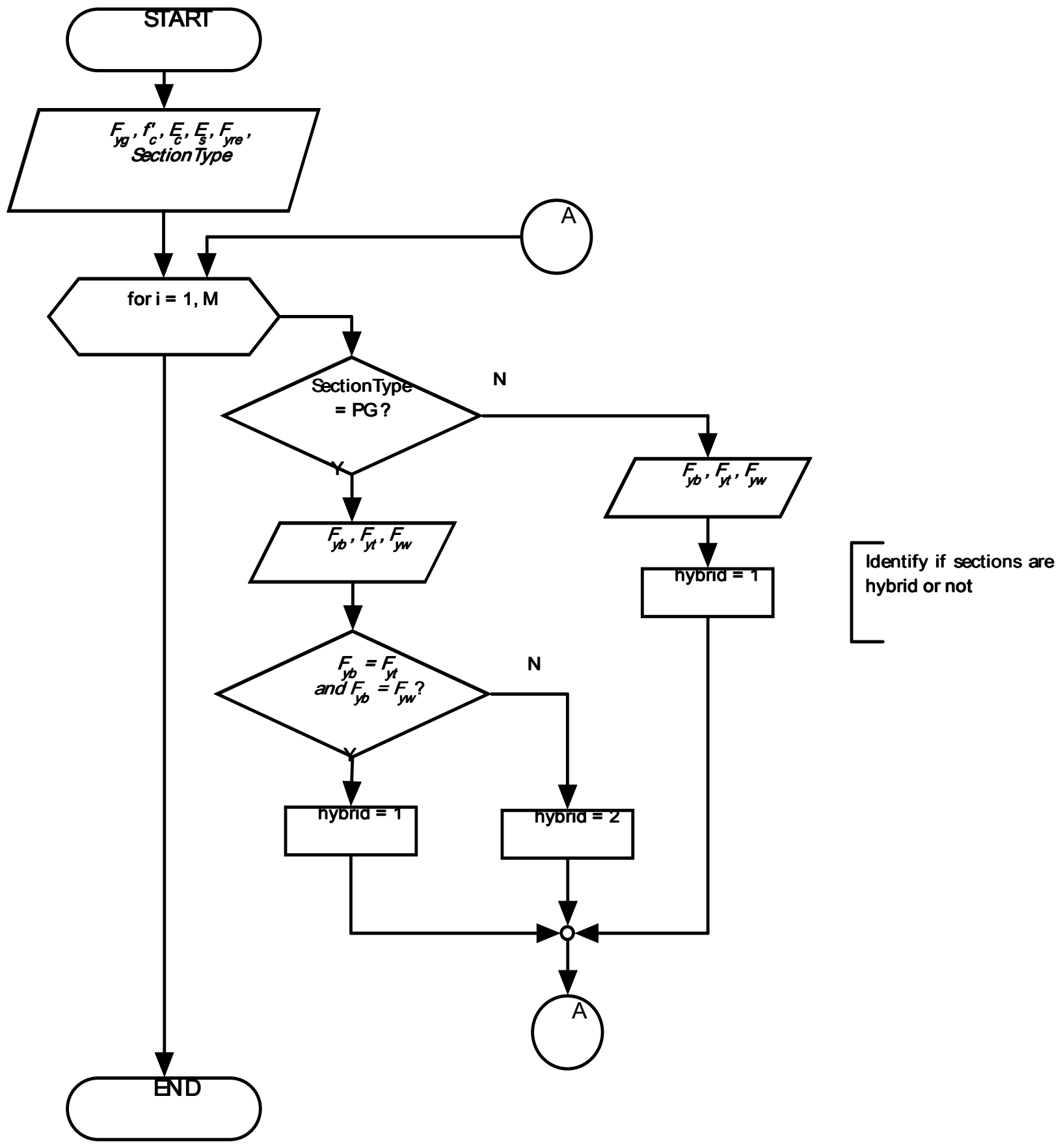

Flowchart D.3 MaterialProperites 


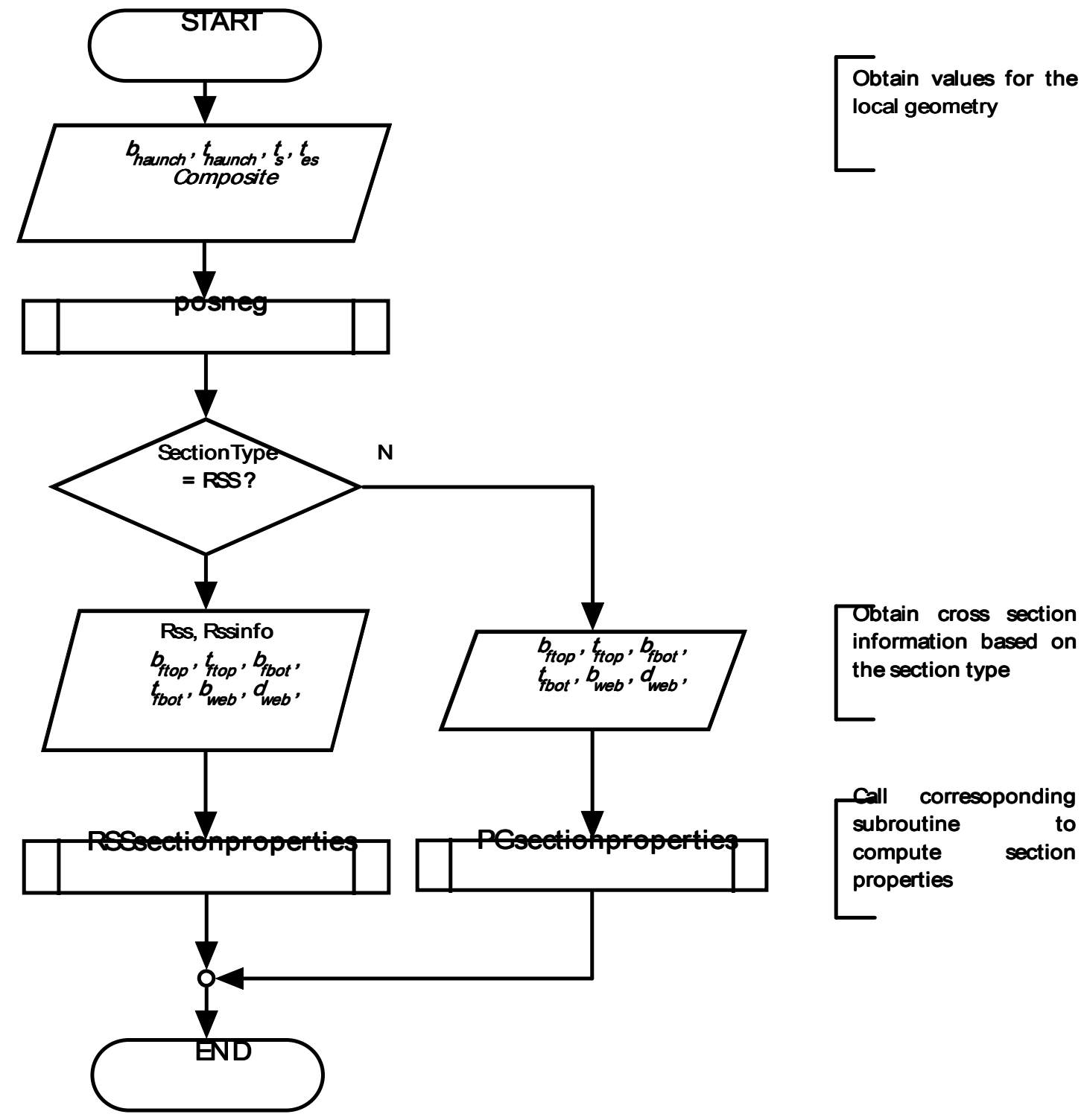

Flowchart D.4 SectionProperties 


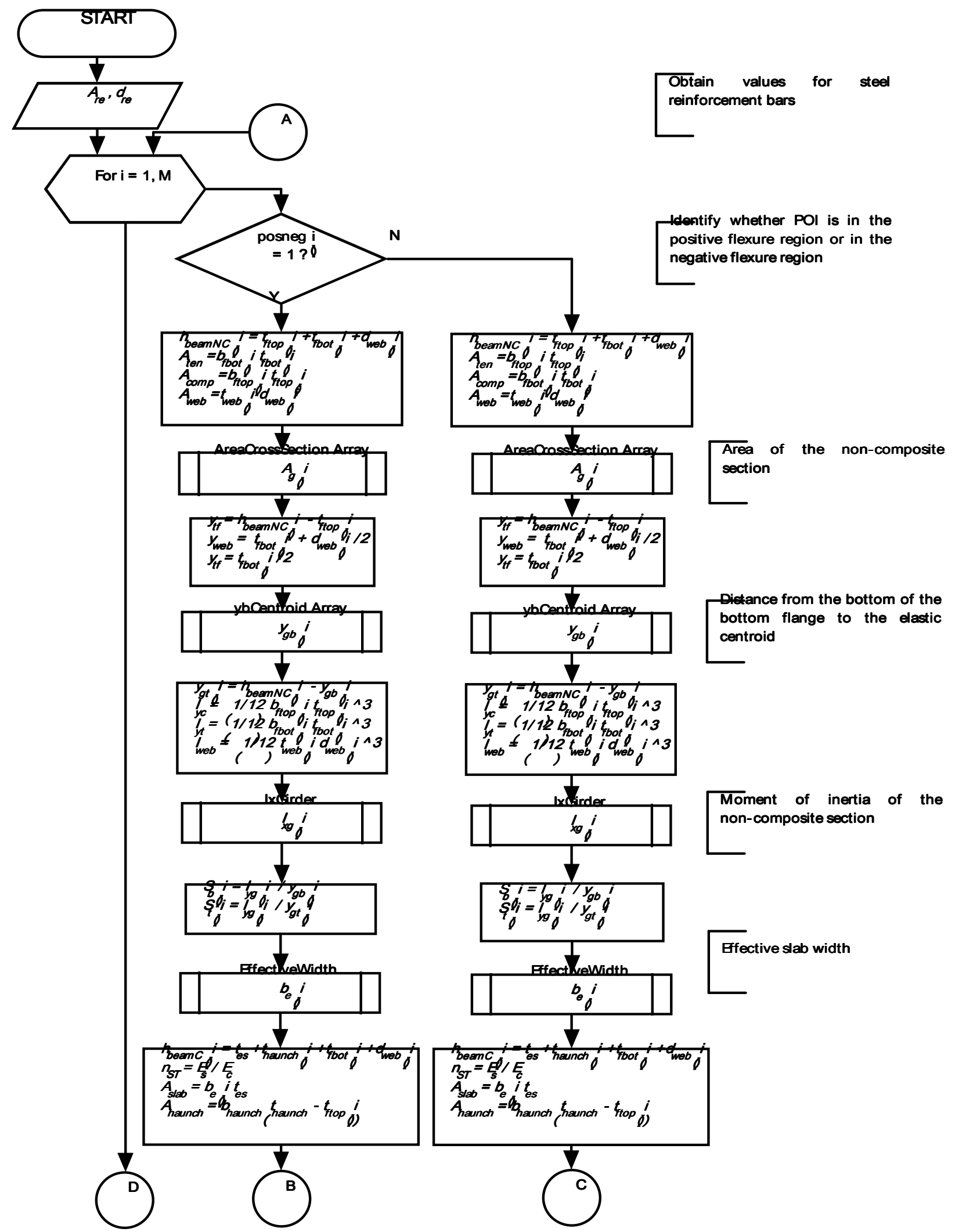

Flowchart D.5 SectionProperties - PGsectionProperties - 


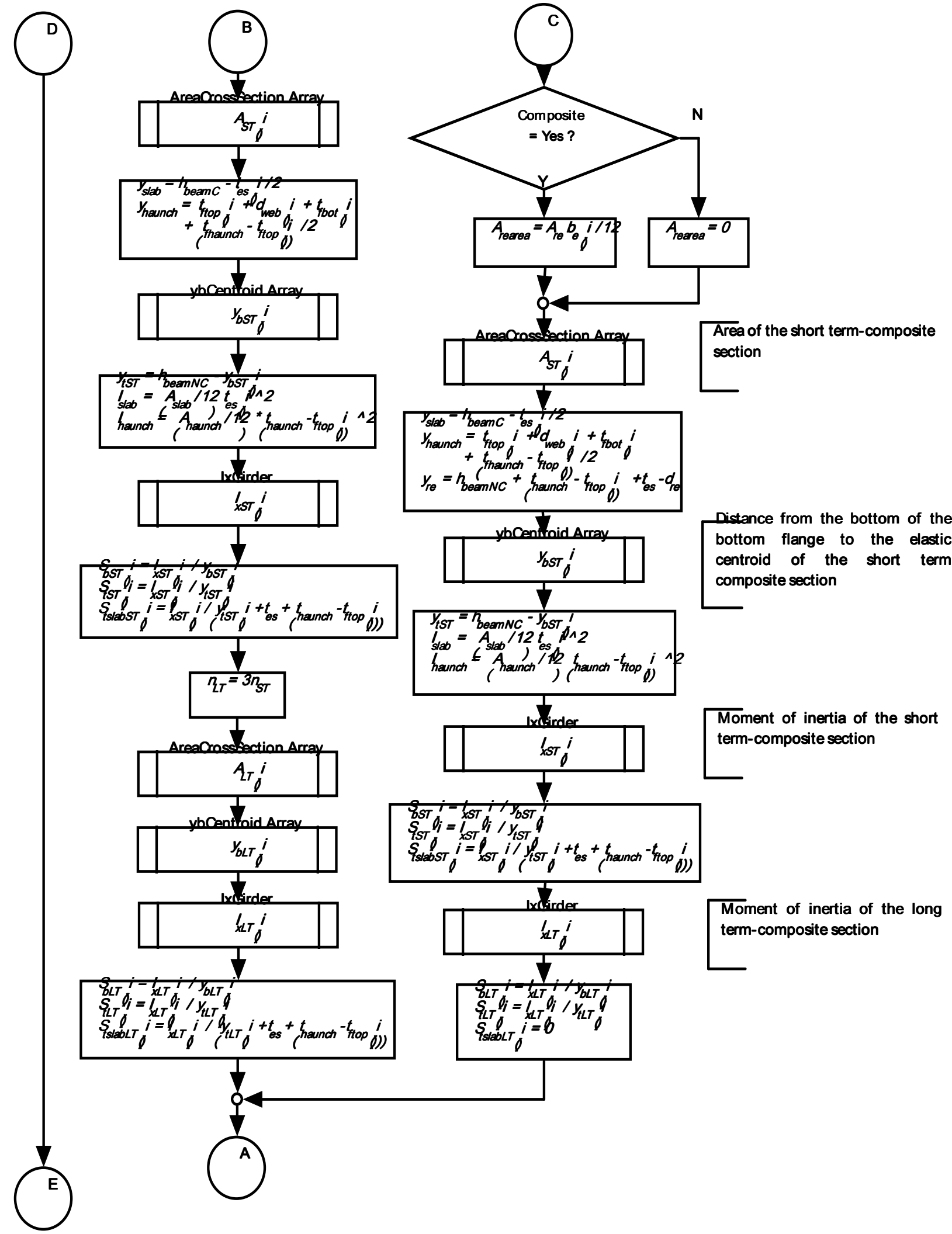

Flowchart D.5 (cont) SectionProperties - PGsectionProperties 


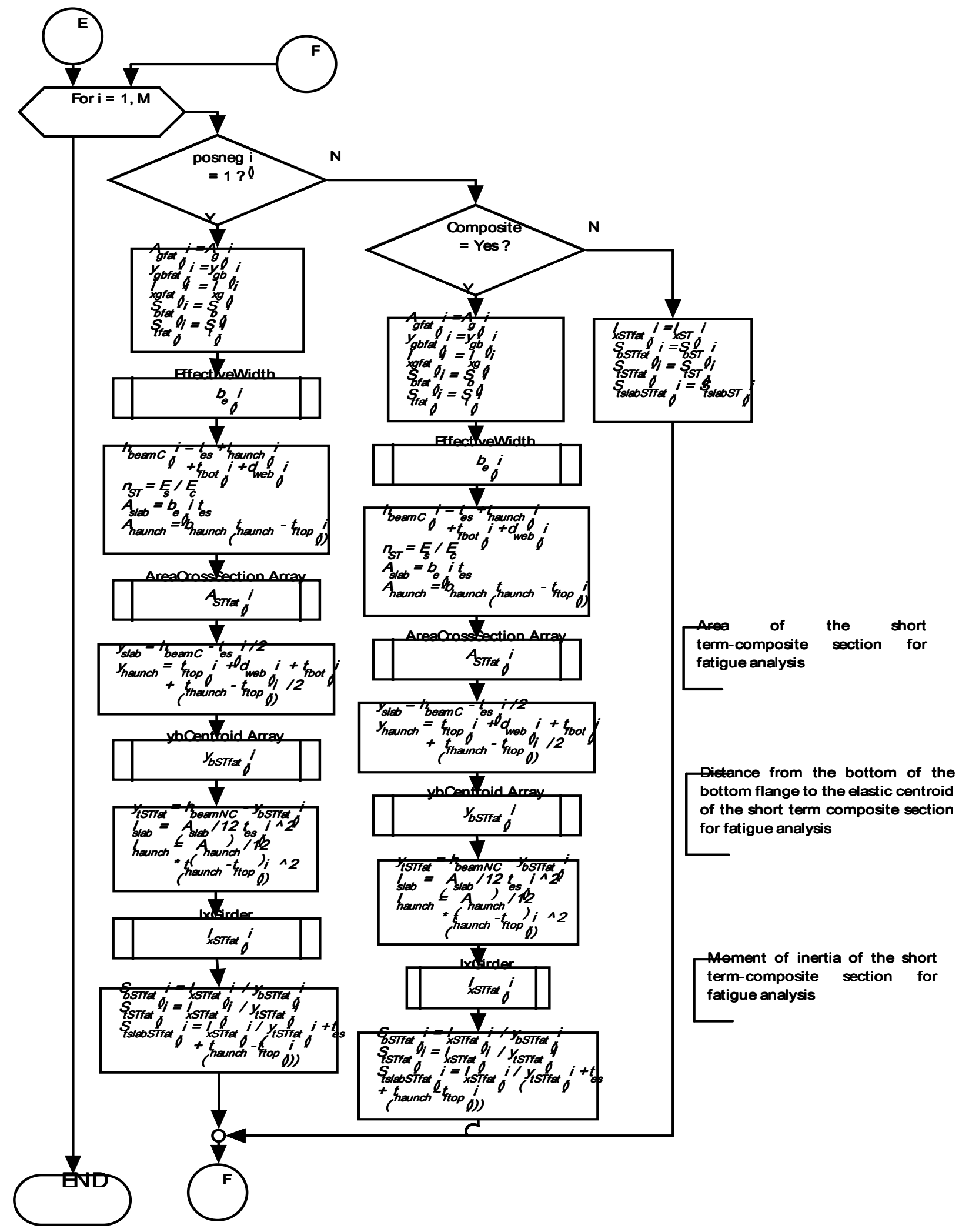

Flowchart D.5 (cont) SectionProperties - PGsectionProperties 


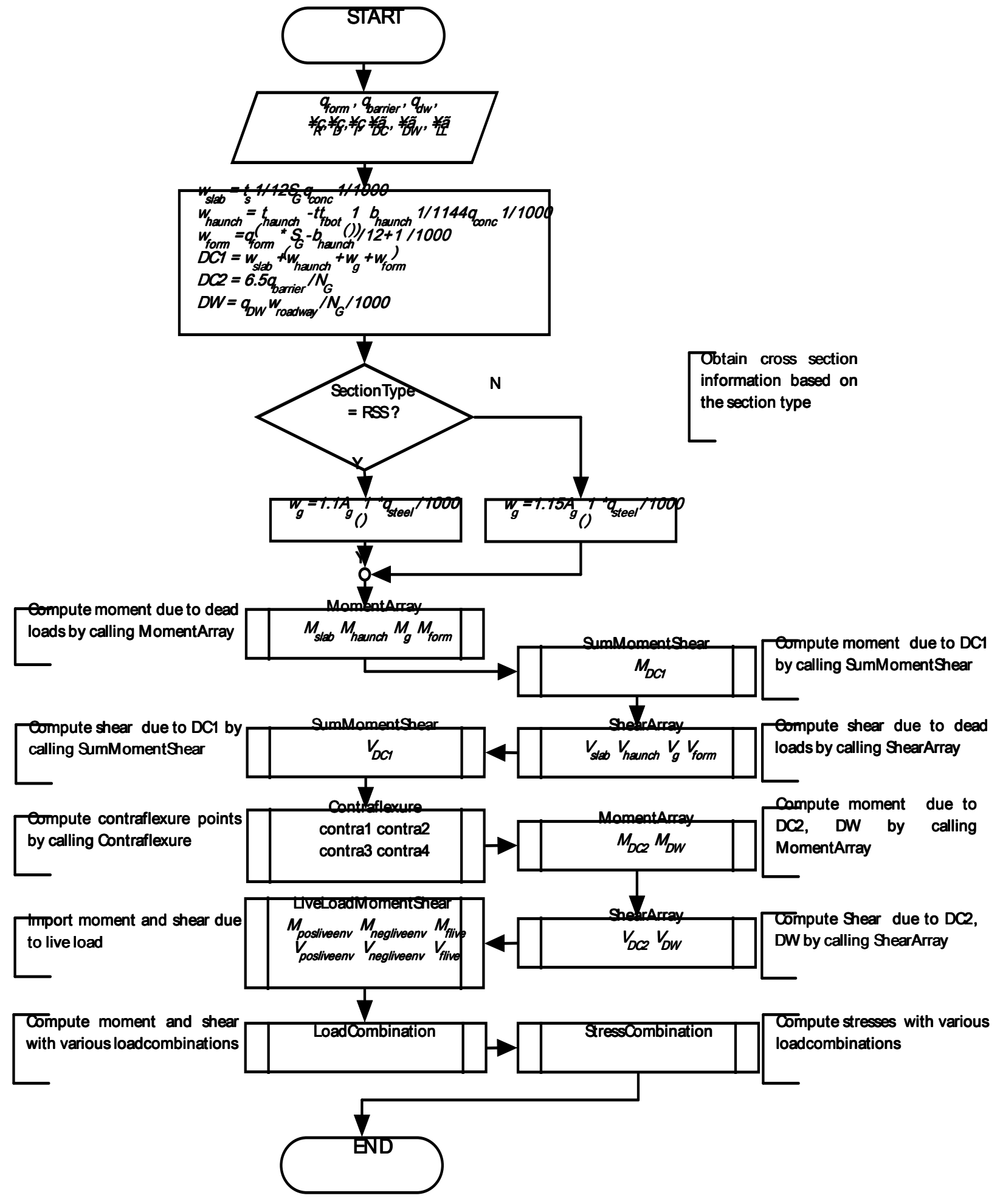

Flowchart D.6 MomentShear 


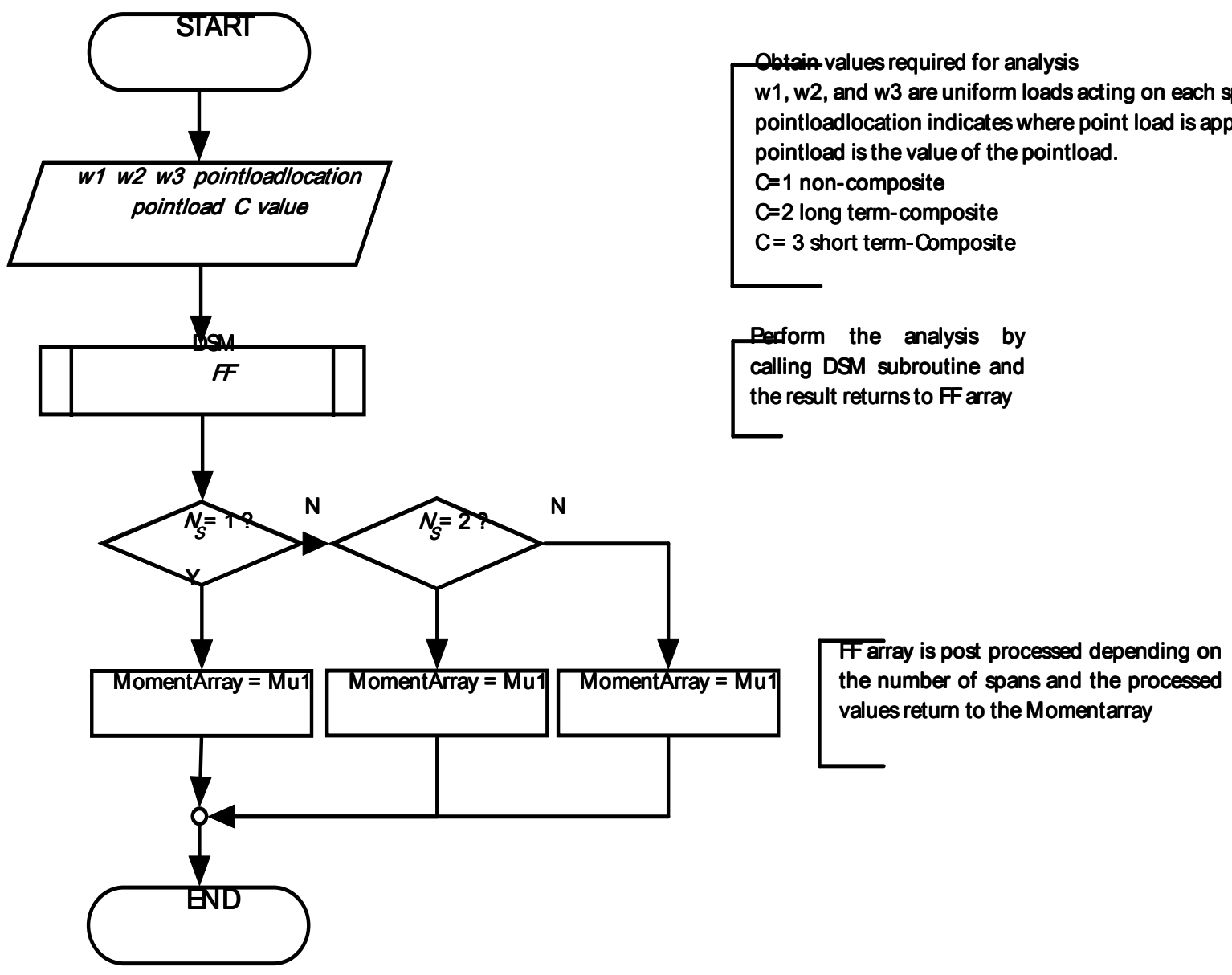

Flowchart D.7 MomentShear - MomentArray 

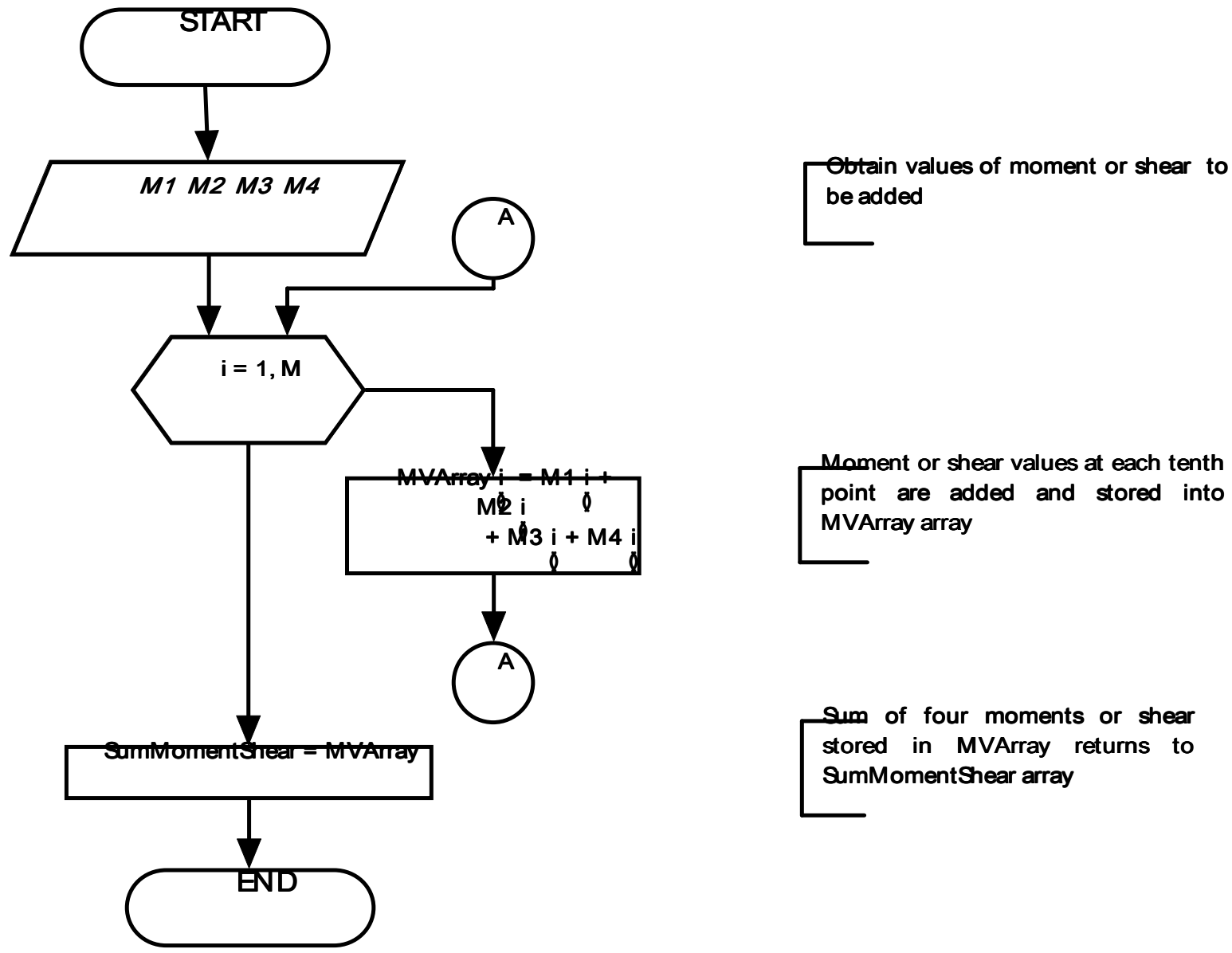

Flowchart D.8 MomentShear - SumMomentShear 


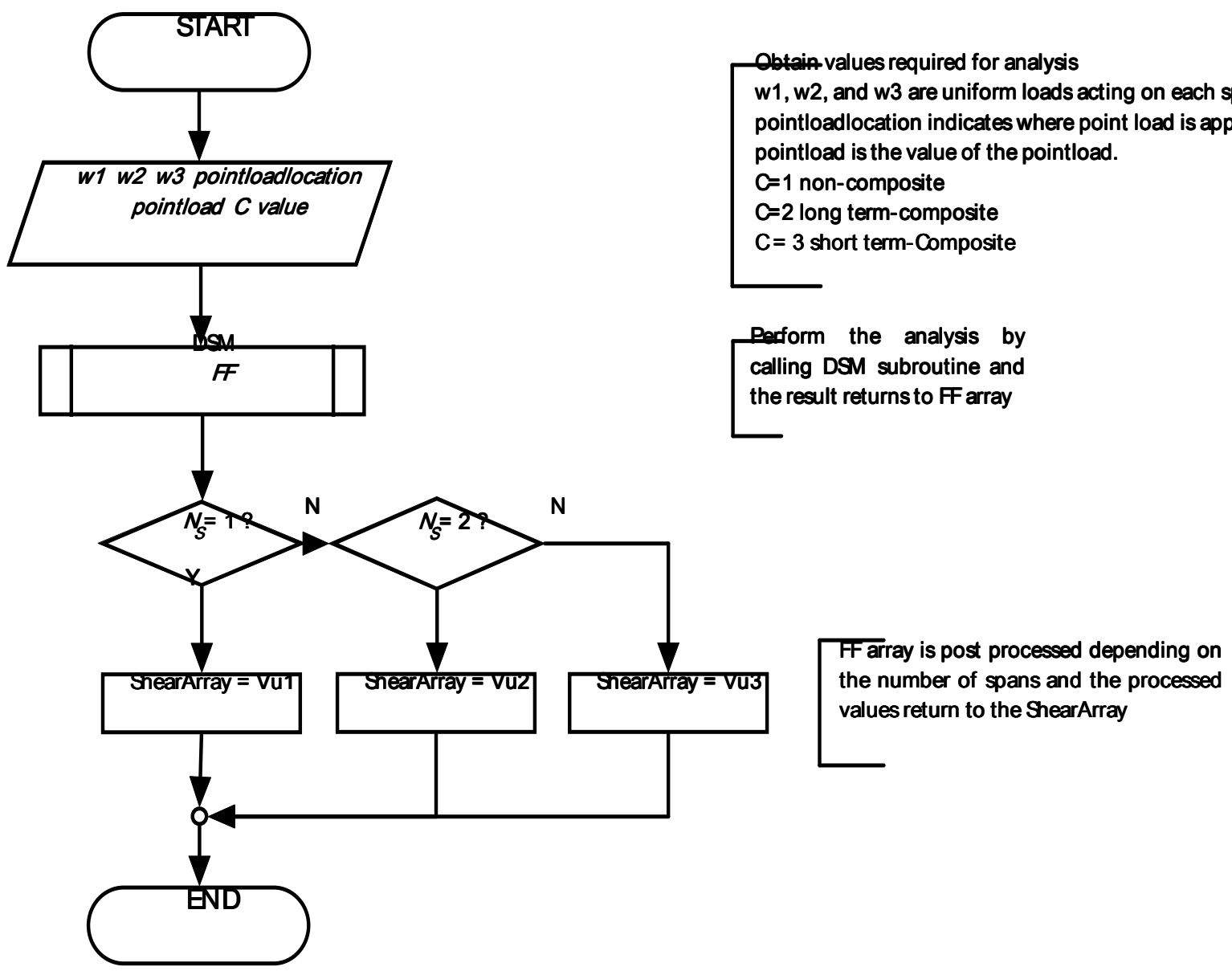

Flowchart D.9 MomentShear - ShearArray 


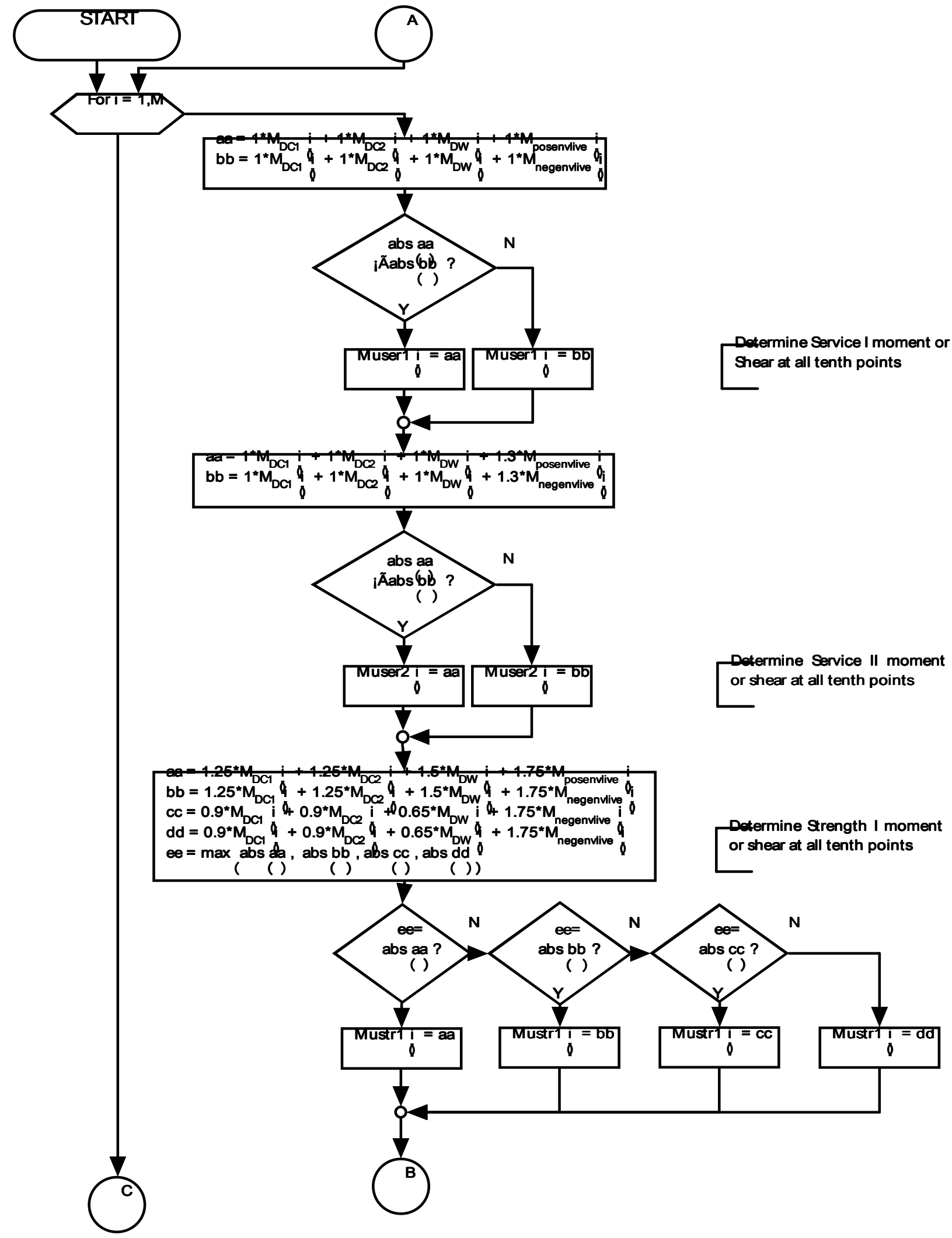

Flowchart D.10 MomentShear - Loadcombination 


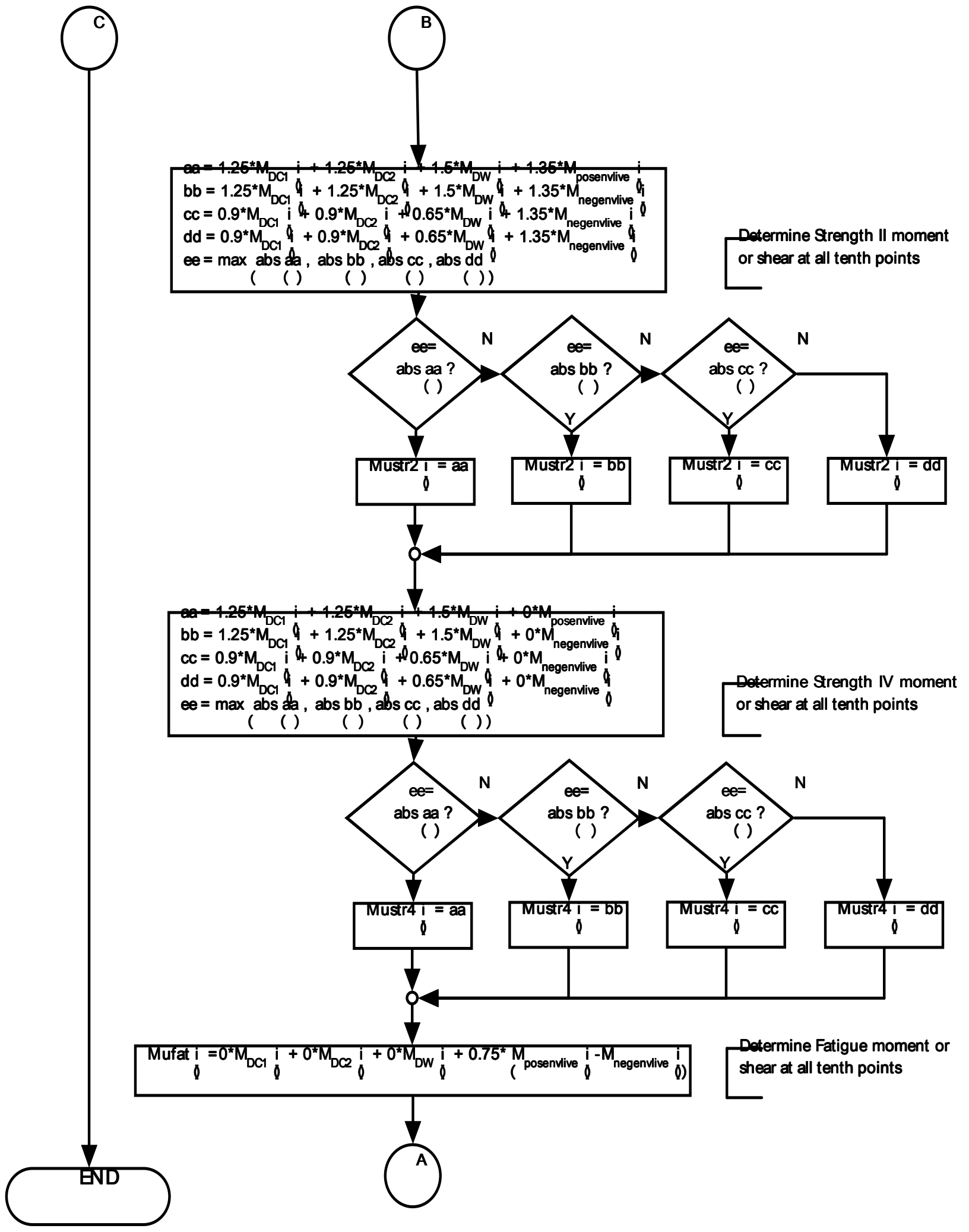

Flowchart D.10 (cont) MomentShear - Loadcombination 


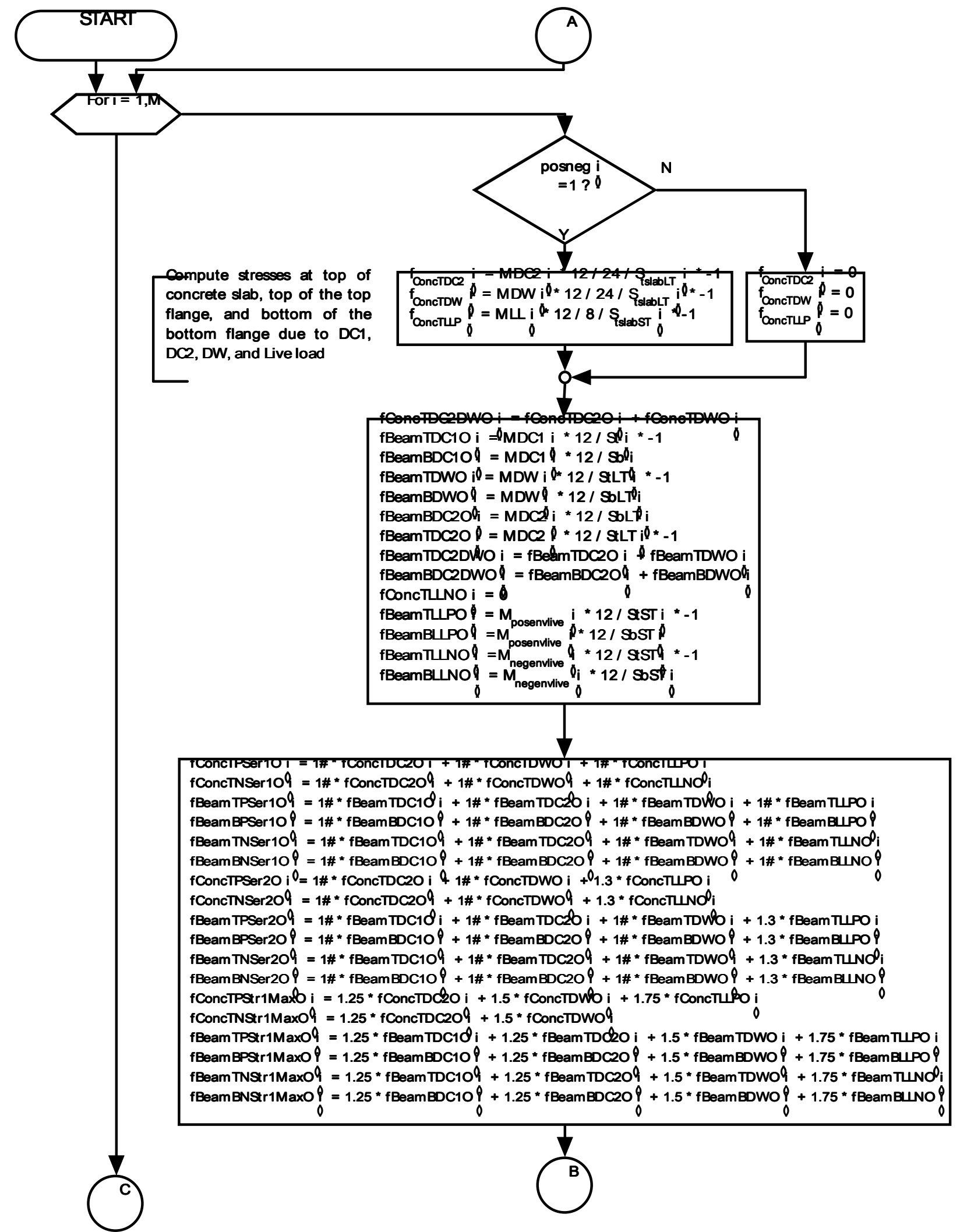

Flowchart D.11 MomentShear - Stresscombination 


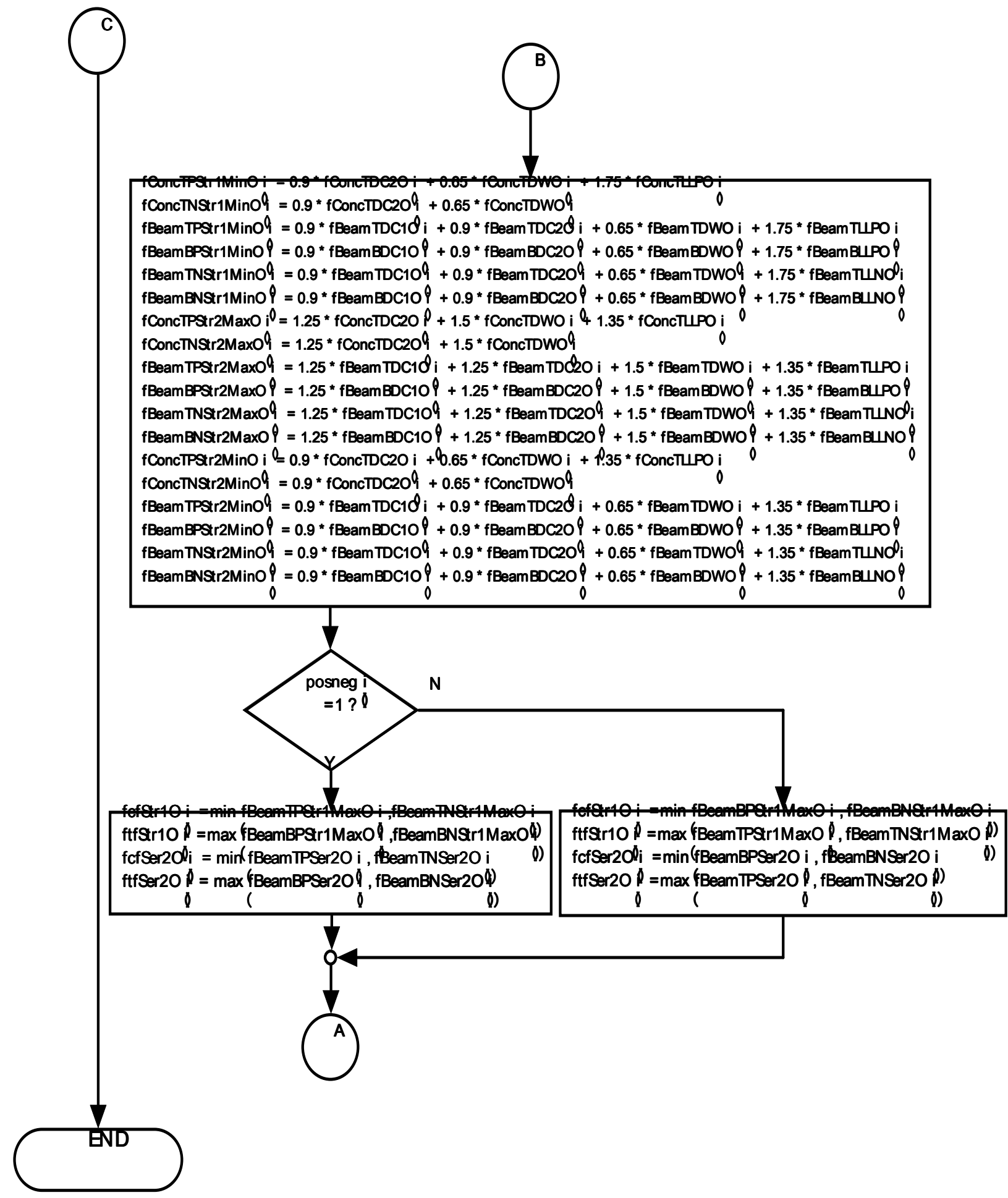

Flowchart D.11 (cont) MomentShear - Stresscombination 


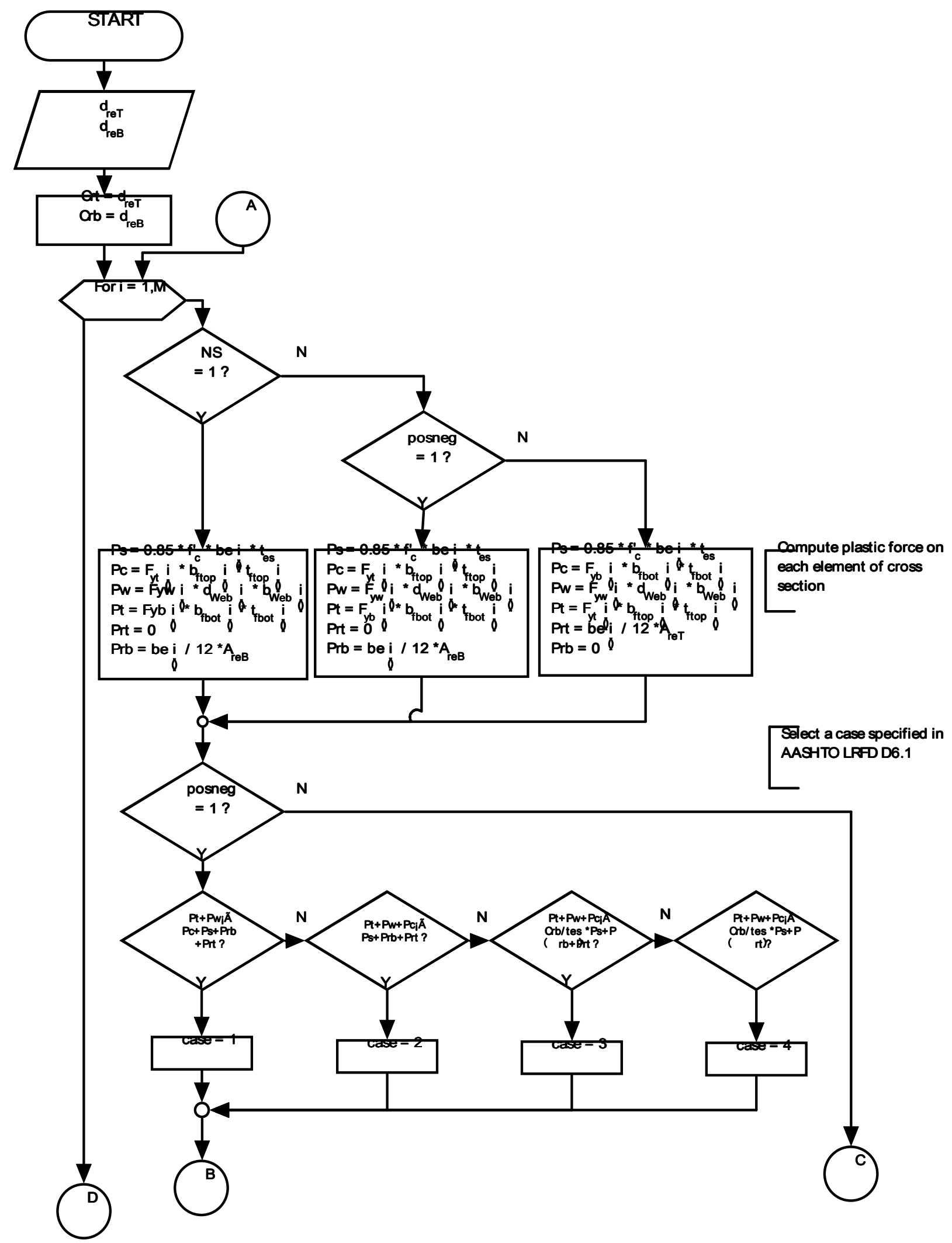

Flowchart D.12 PlasticMomentCapacity 


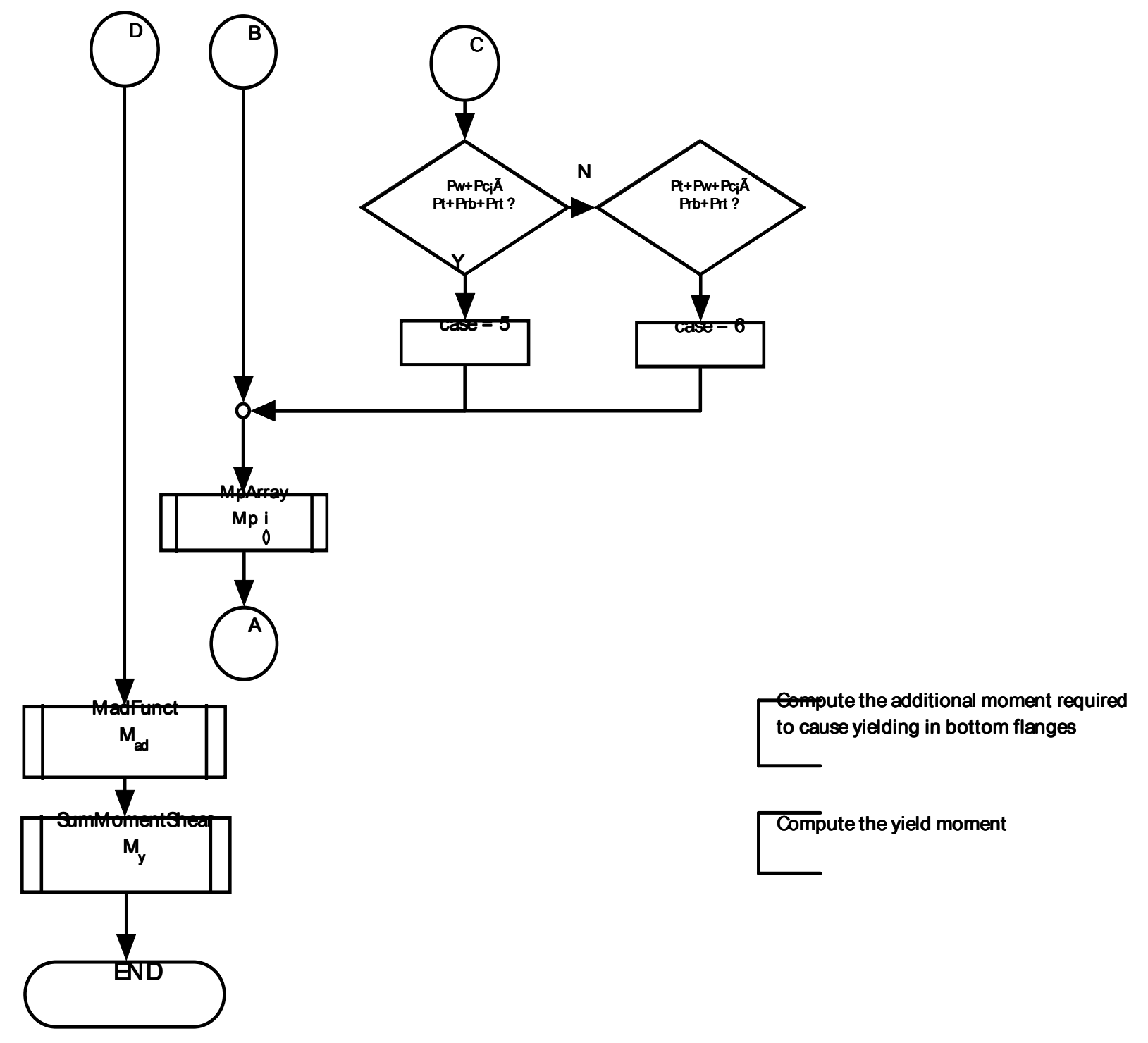

Flowchart D.12(cont) PlasticMomentCapacity 


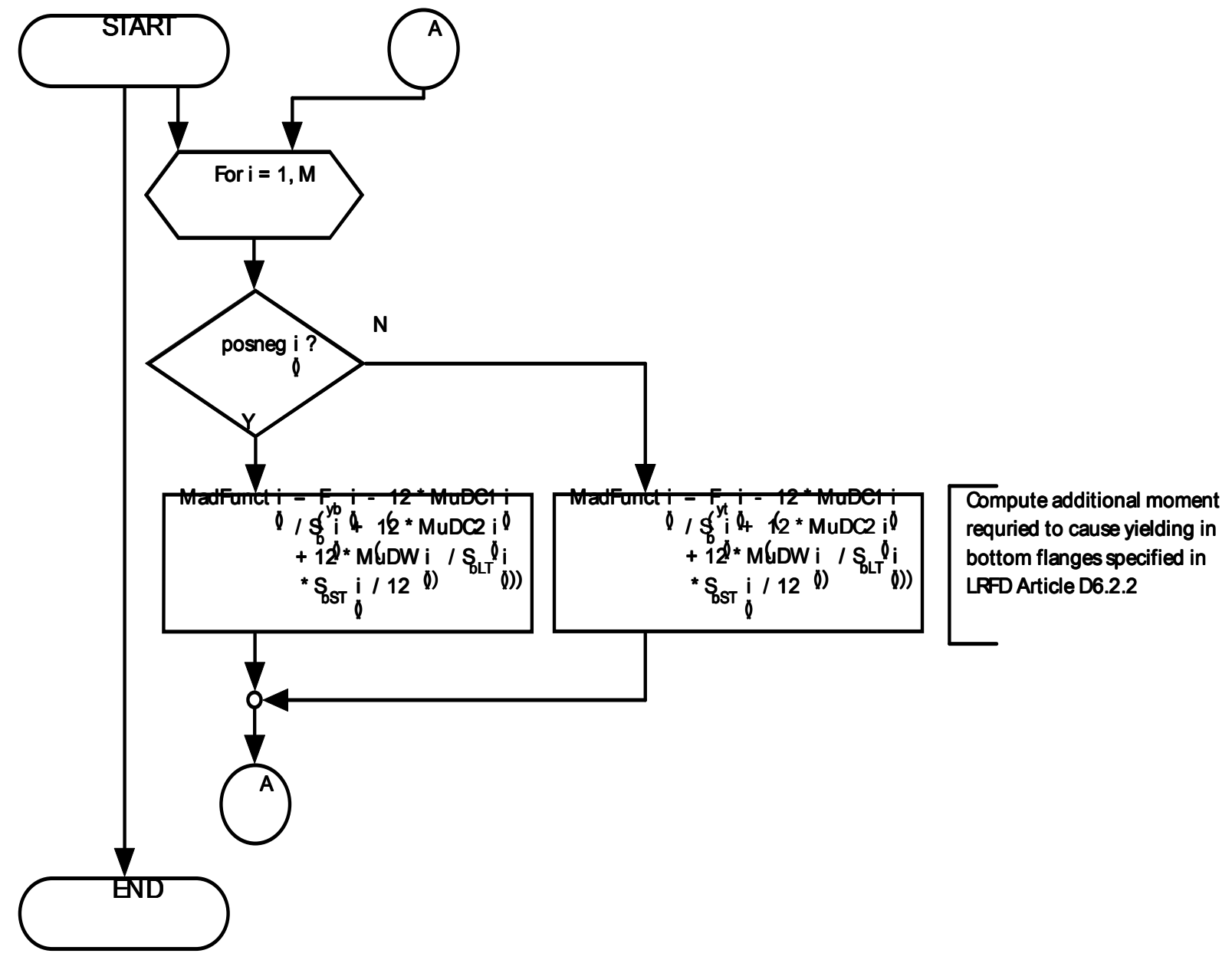

Flowchart D.13 PlasticMomentCapacity - Madfunct 


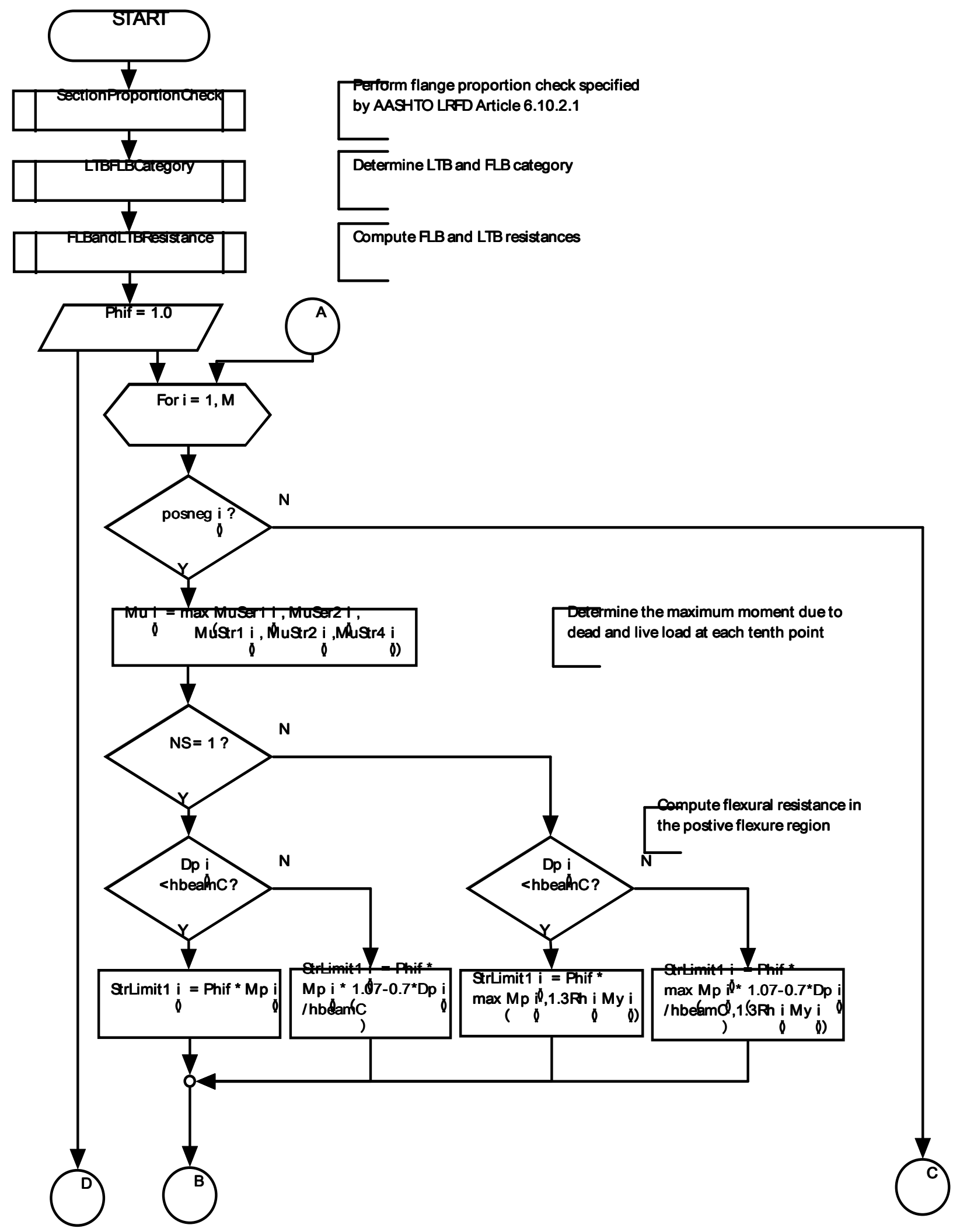

Flowchart D.14 StrengthLimitState 


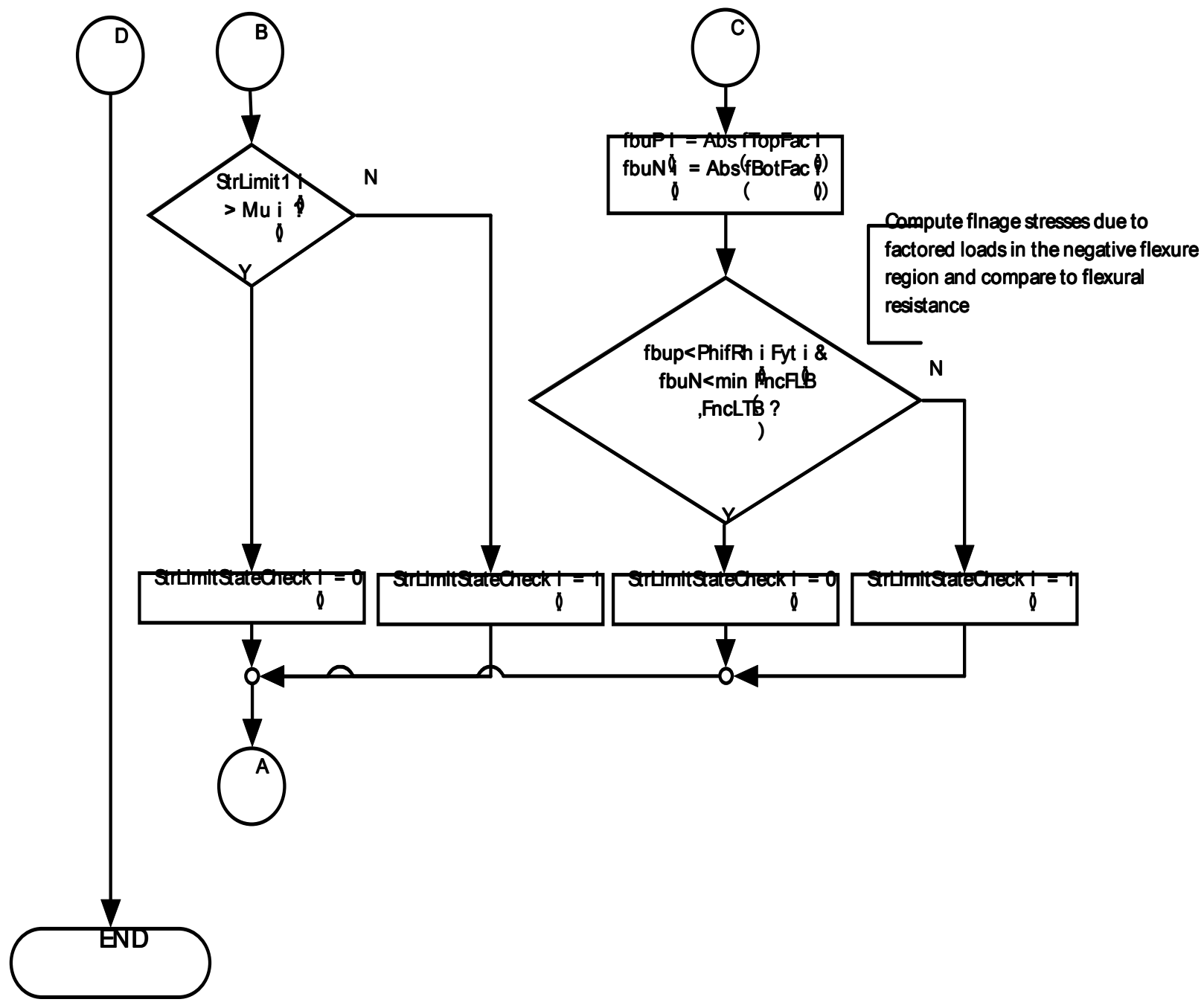

Flowchart D.14(cont) StrengthLimitState 


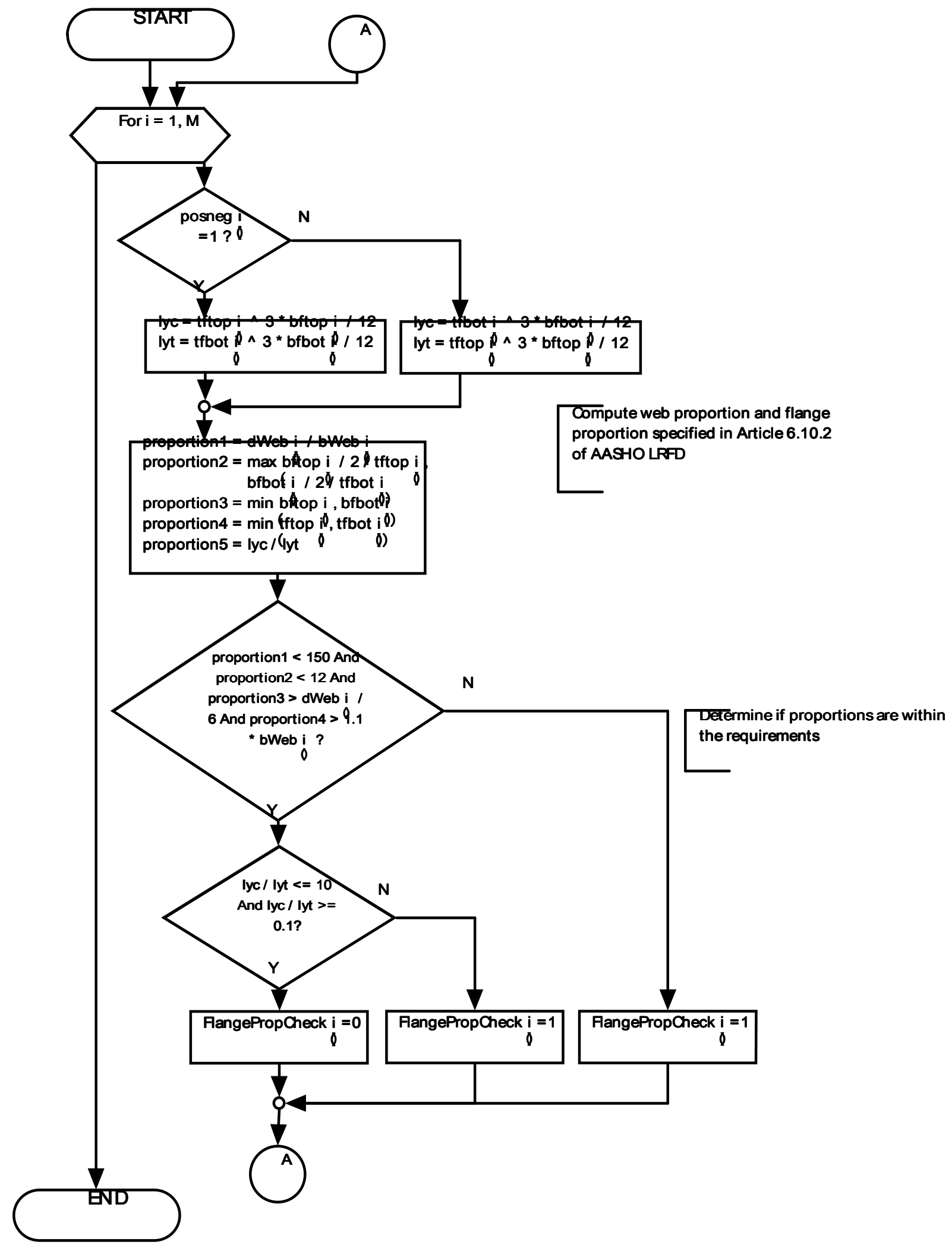

Flowchart D.15 StrengthLimitState - SectionProportionCheck 


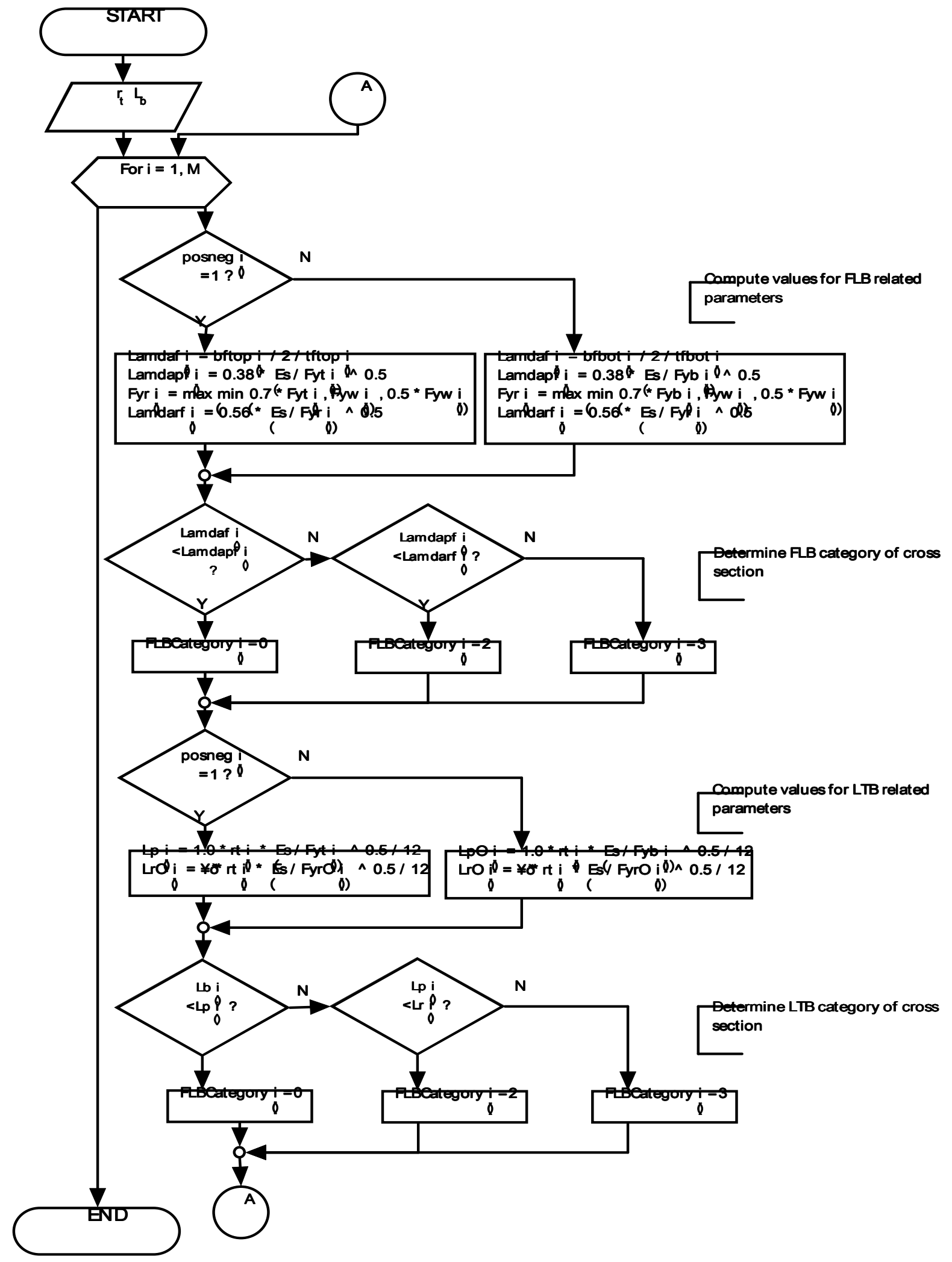

Flowchart D.16 StrengthLimitState - FLBLTBCategory 


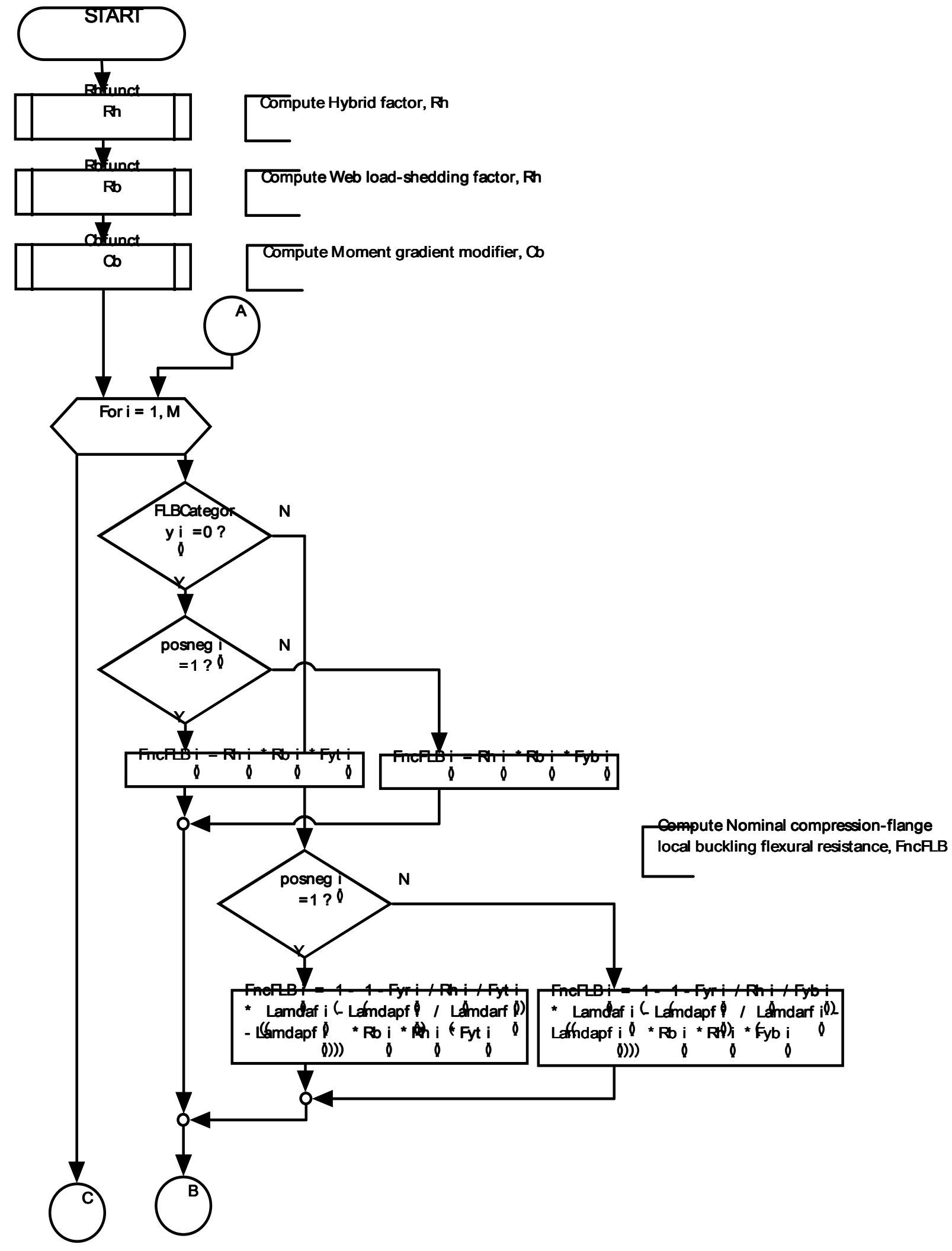

Flowchart D.17 StrengthLimitState - FLBandLTBResistance 


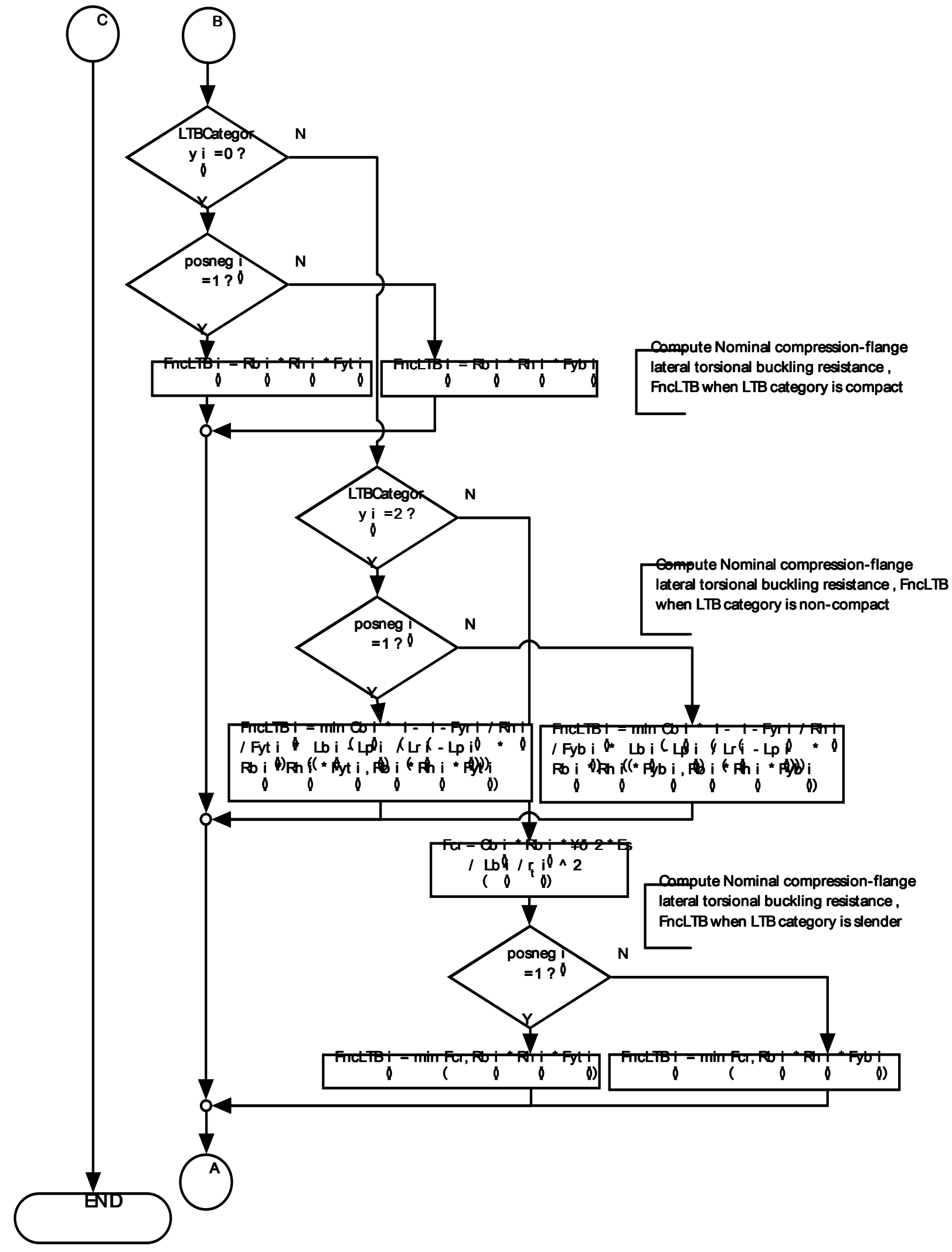

Flowchart D.17(cont) StrengthLimitState - FLBandLTBResistance 


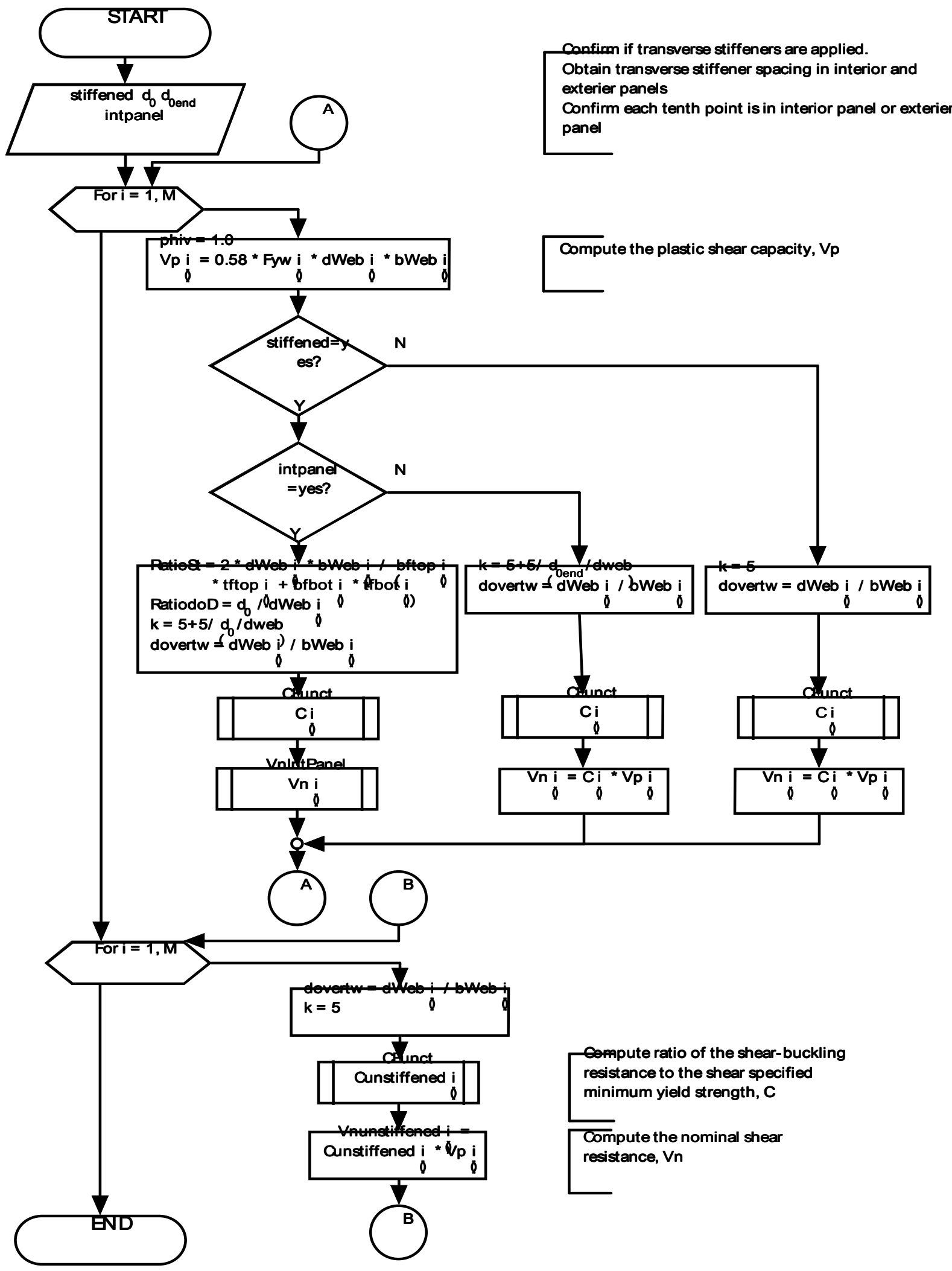

Flowchart D.18 ShearCapaicty 


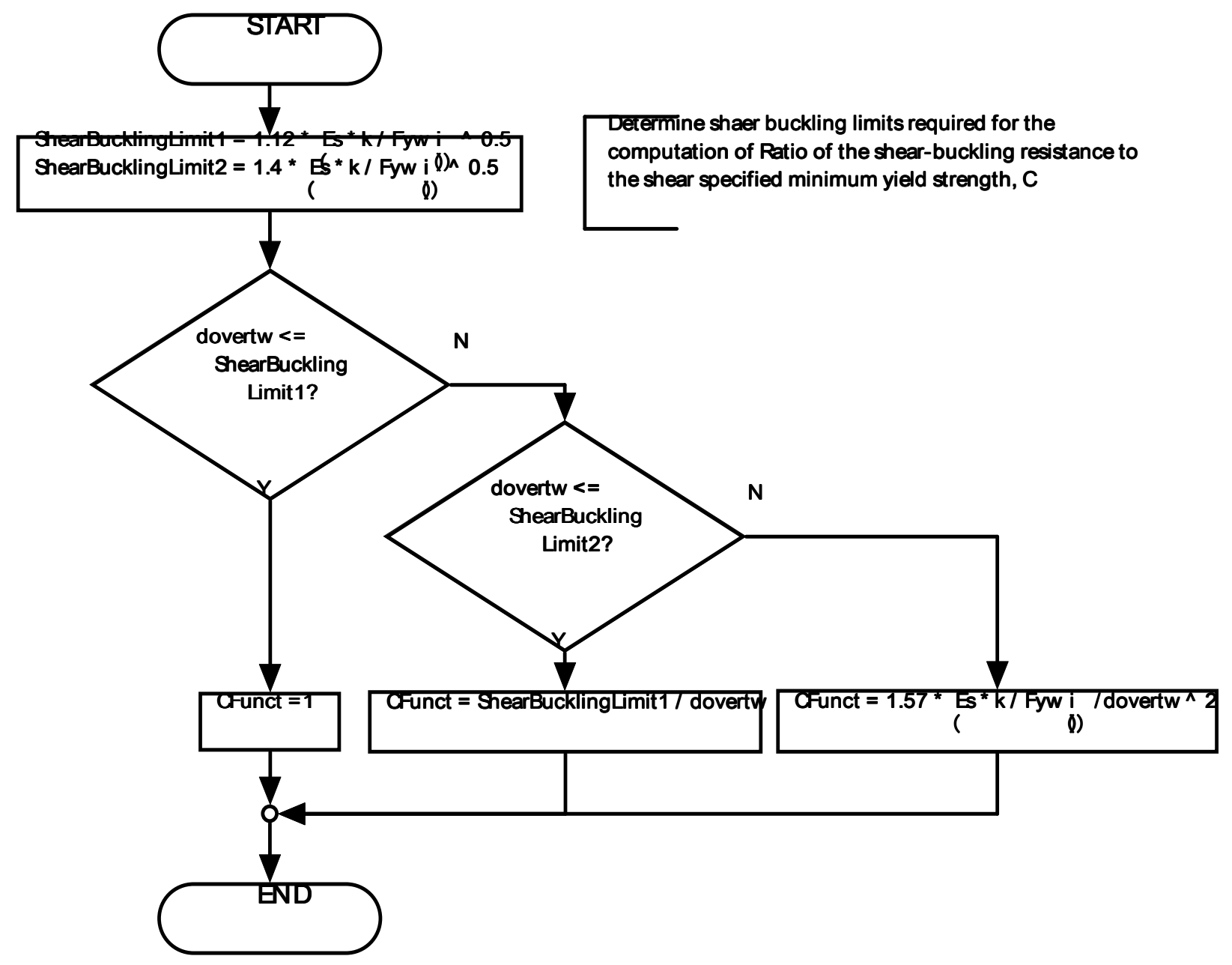

Flowchart D.19 ShearCapacity - CFunct 


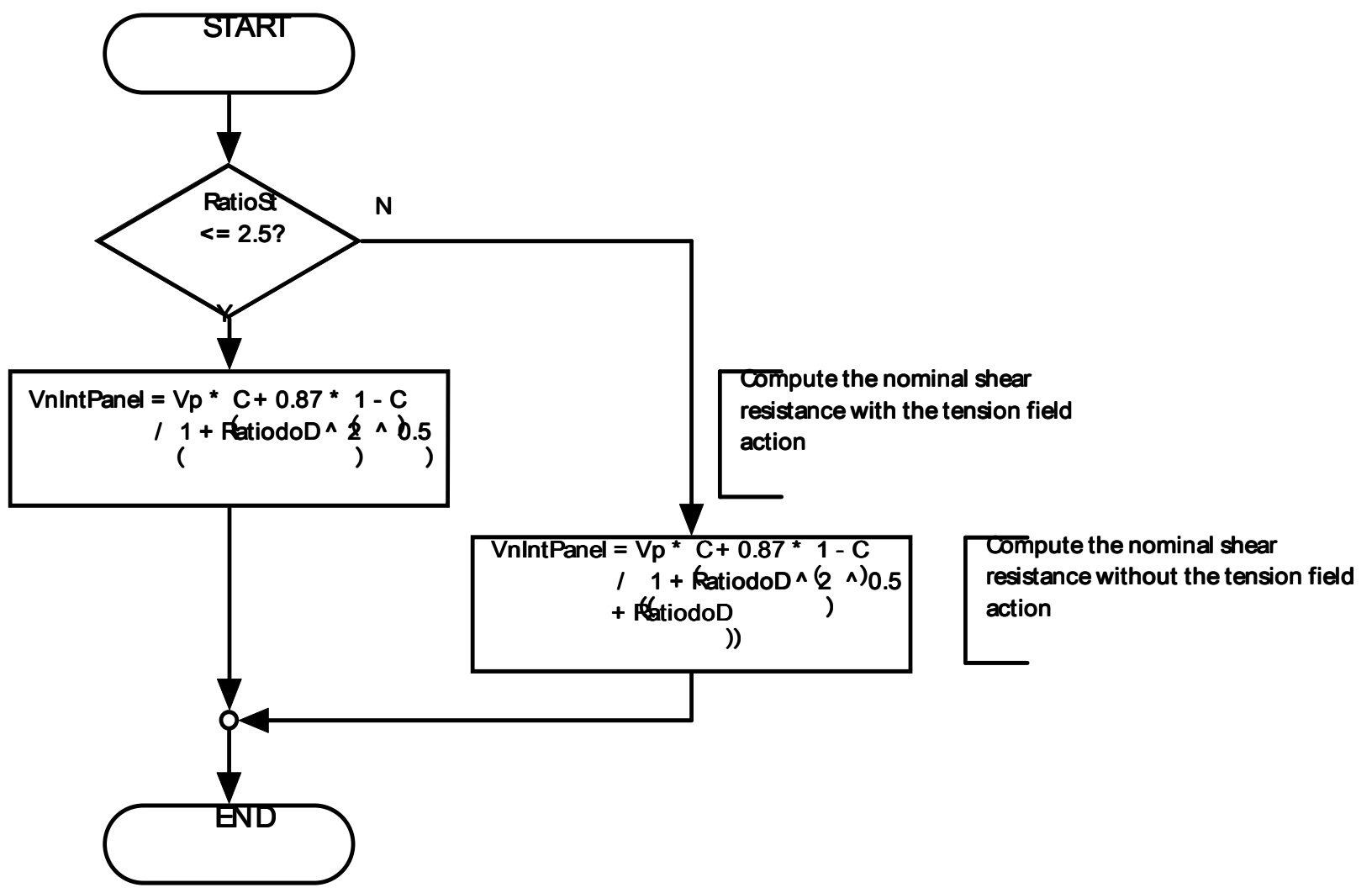

Flowchart D.20 ShearCapacity - VnIntPanel 


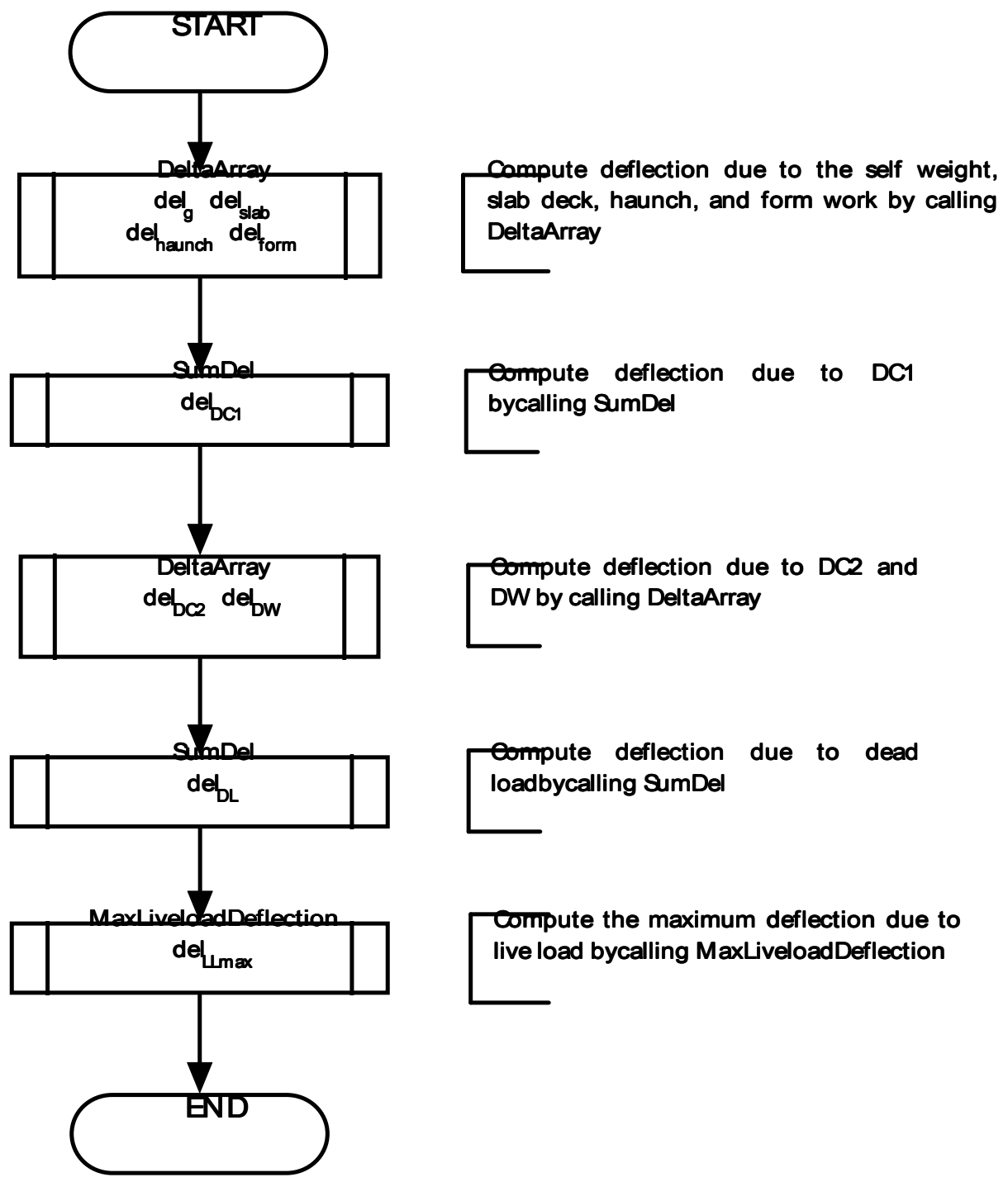

Flowchart D.21 Deflection 


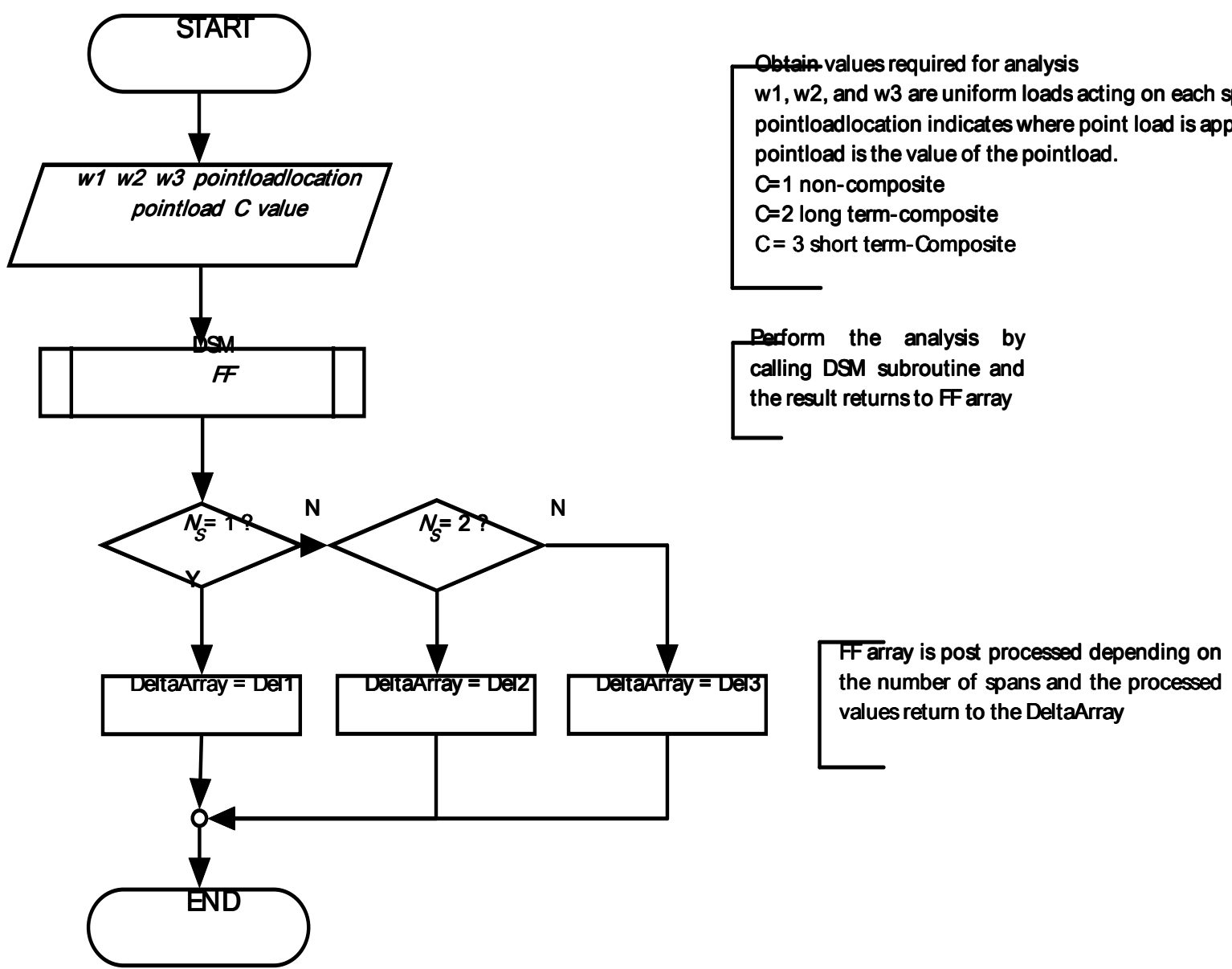

Flowchart D.22 Deflection - DeltaArray 


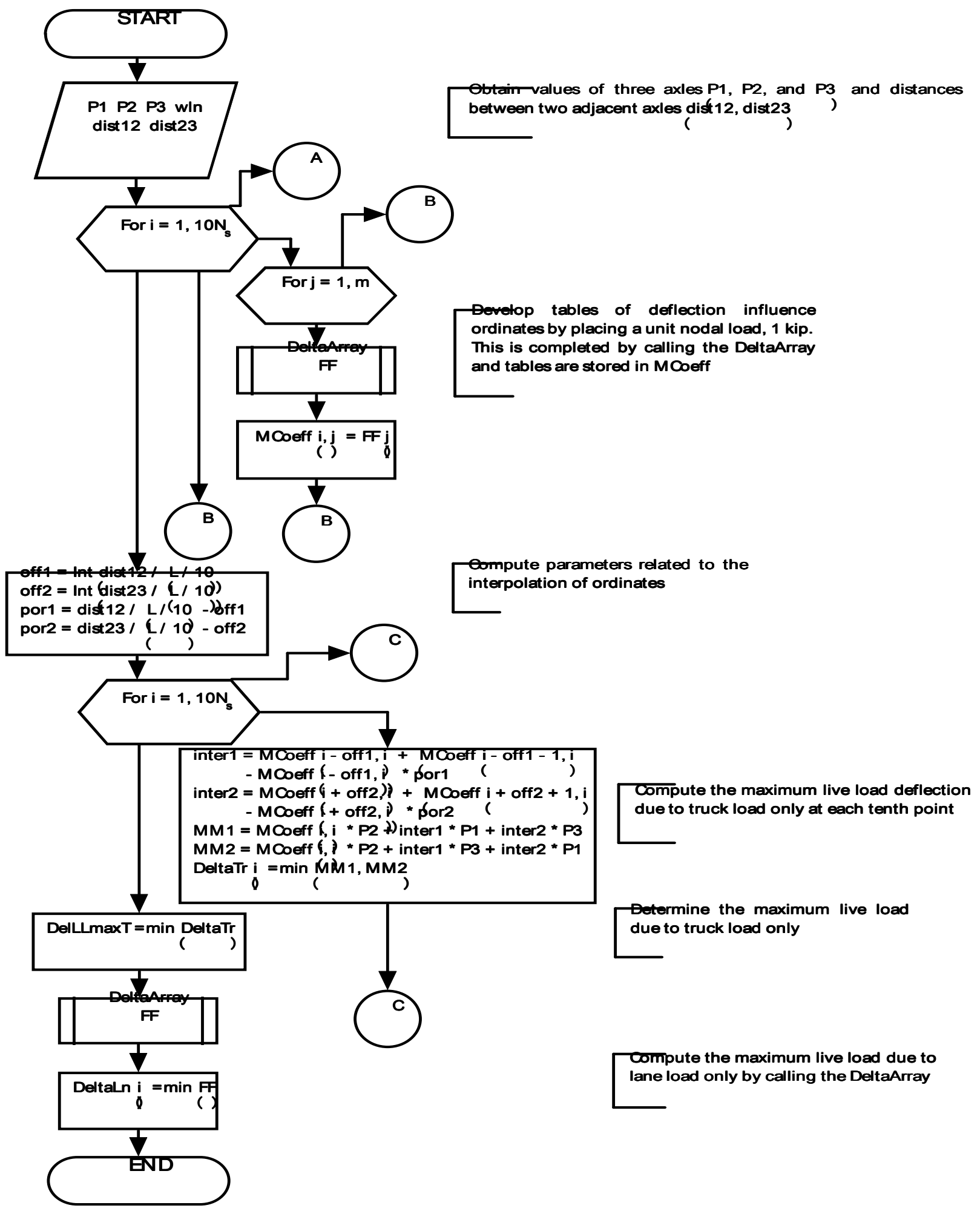

Flowchart D.23 MaxLiveloadDeflection 


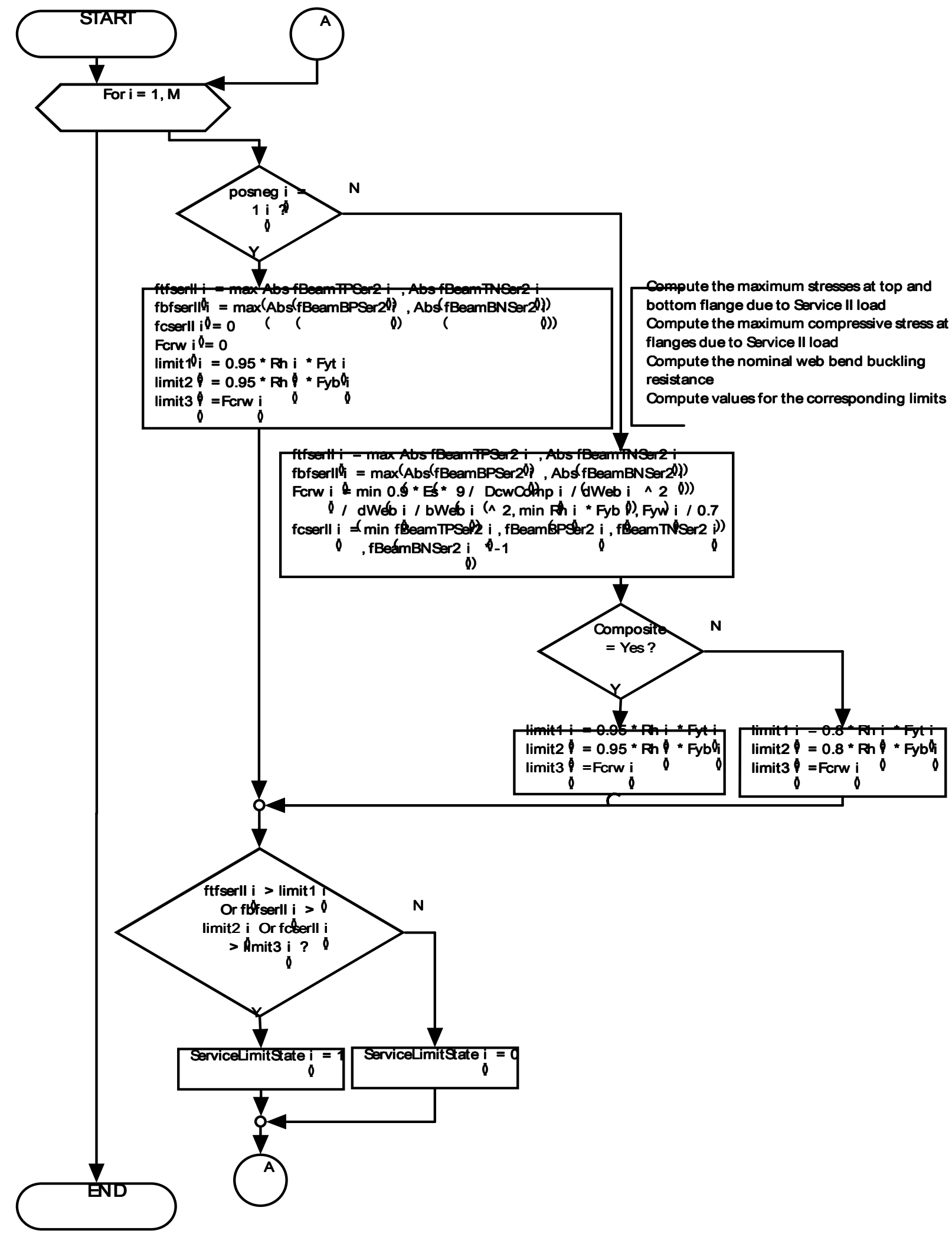

Flowchart D.24 ServiceLimitState 


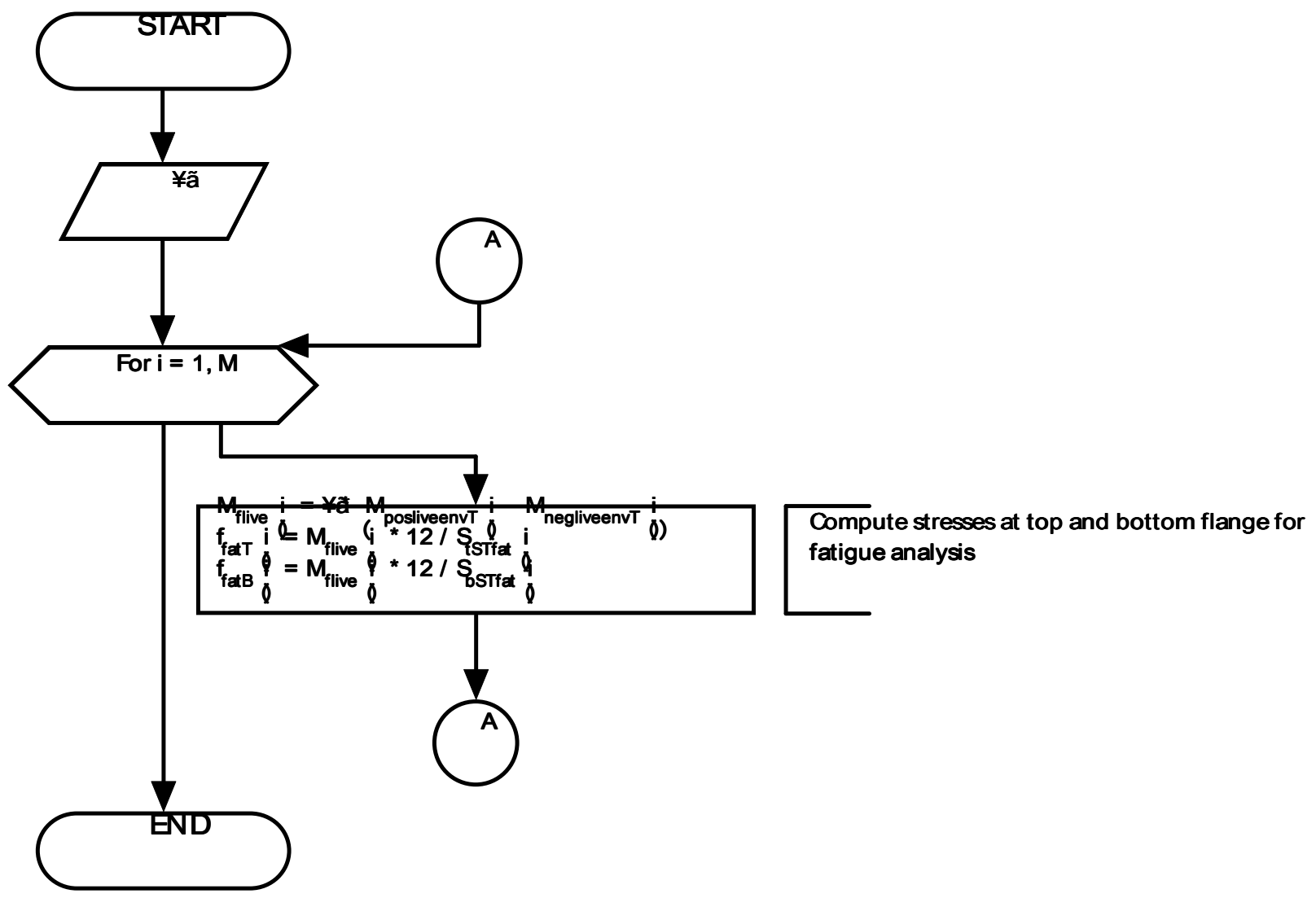

Flowchart D.25 Fatigue_Fracture 


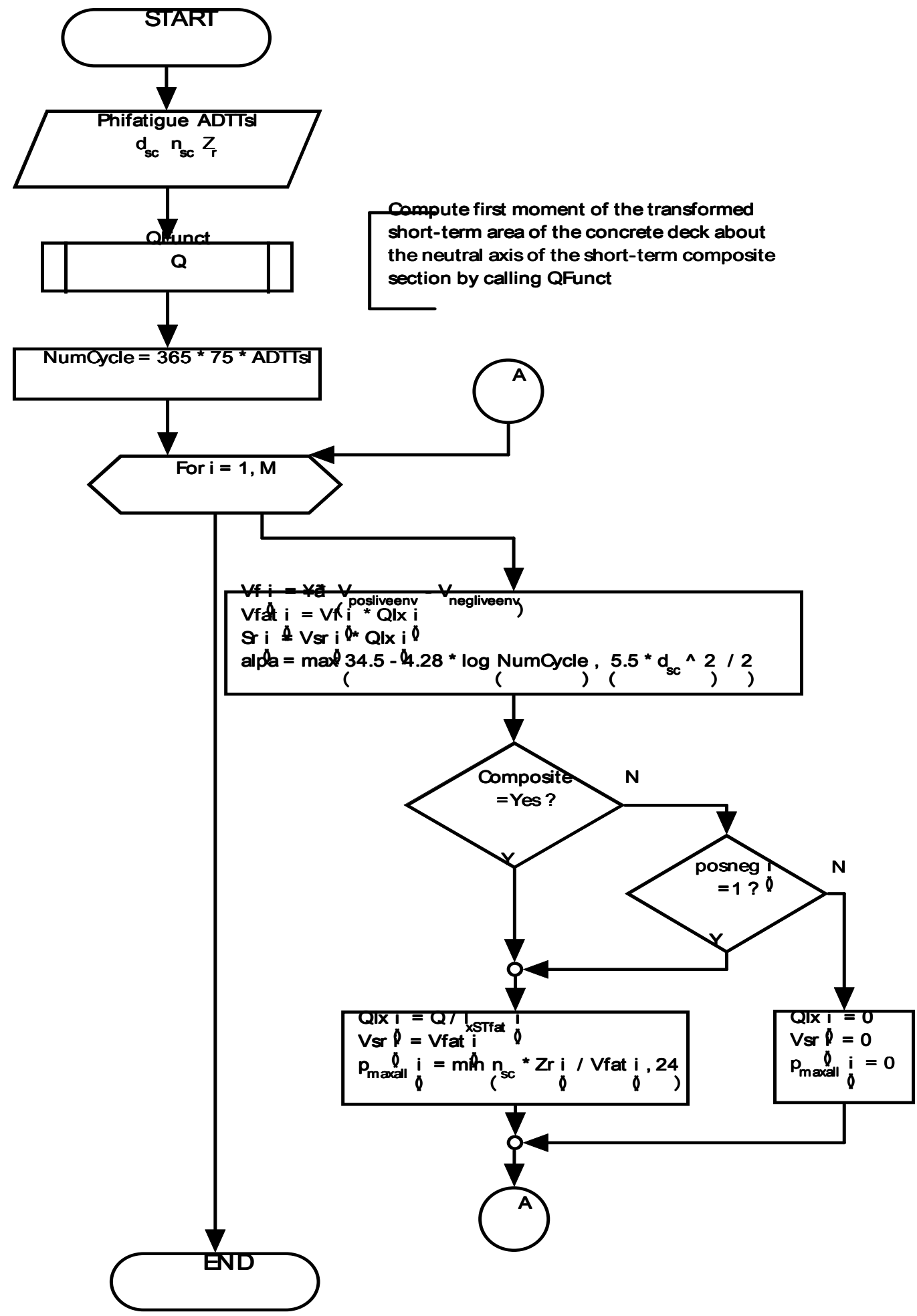

Flowchart D.26 ShearConnector 


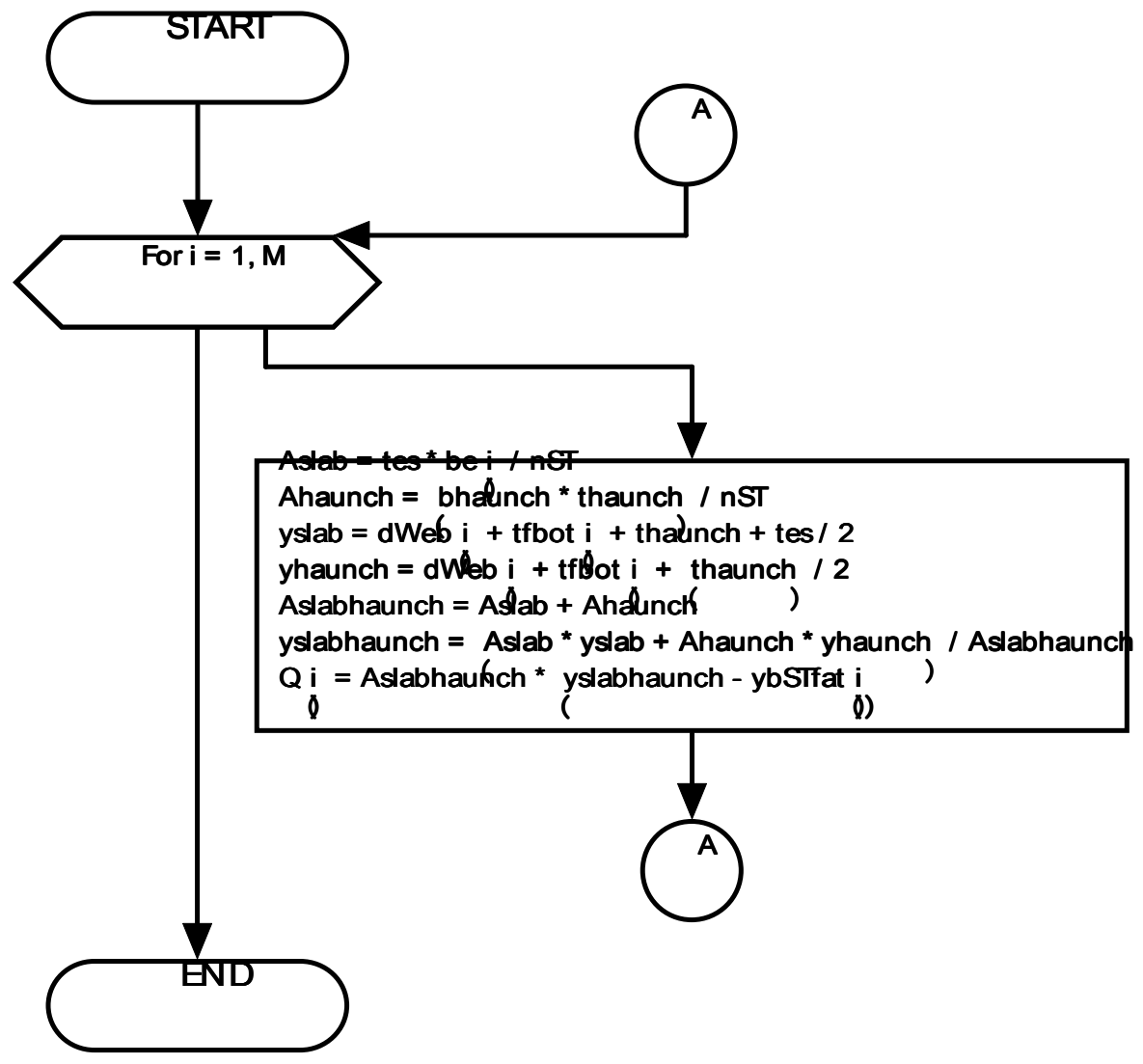

Flowchart D.27 ShearConnector_QFunct 


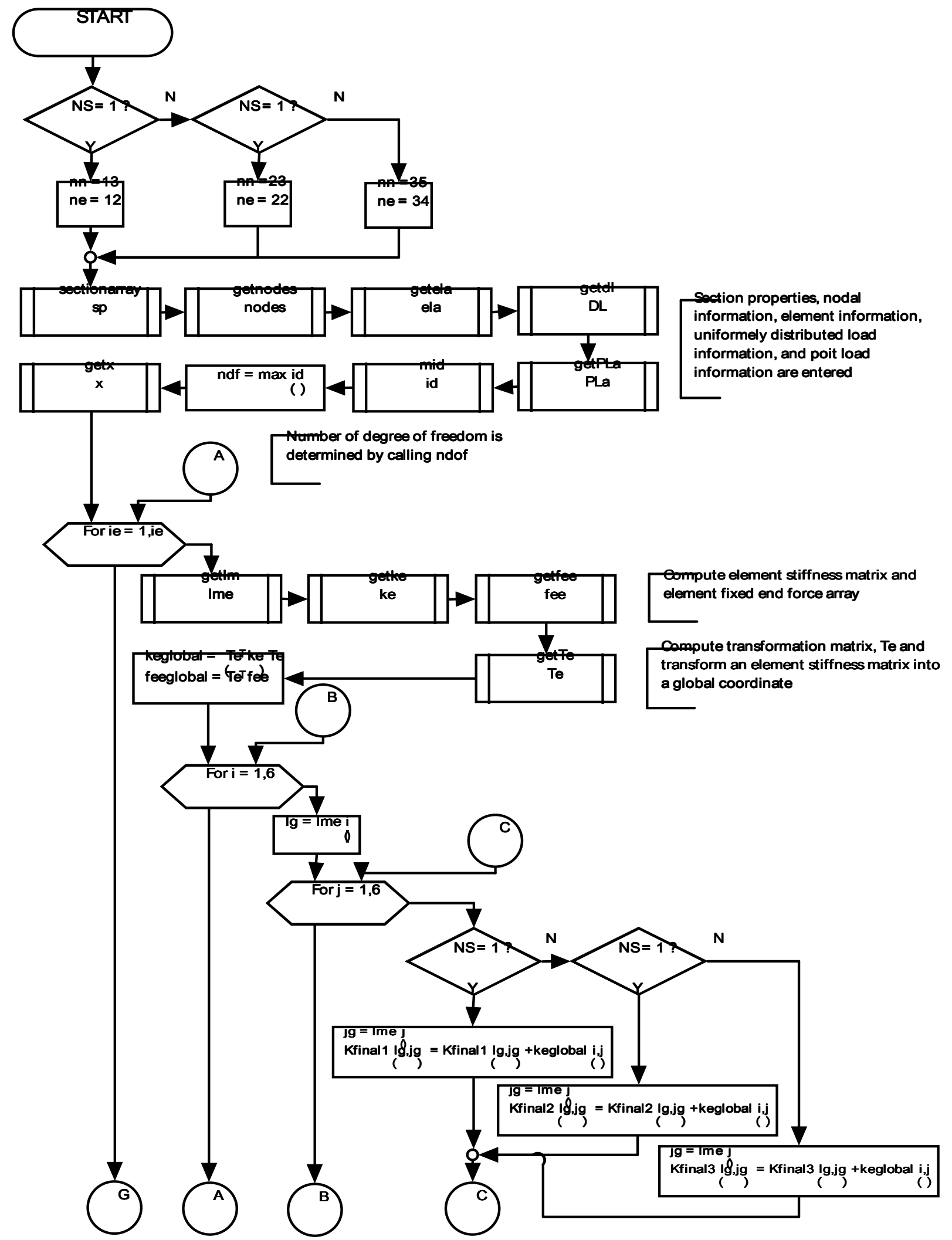

Flowchart D.28 DSM 


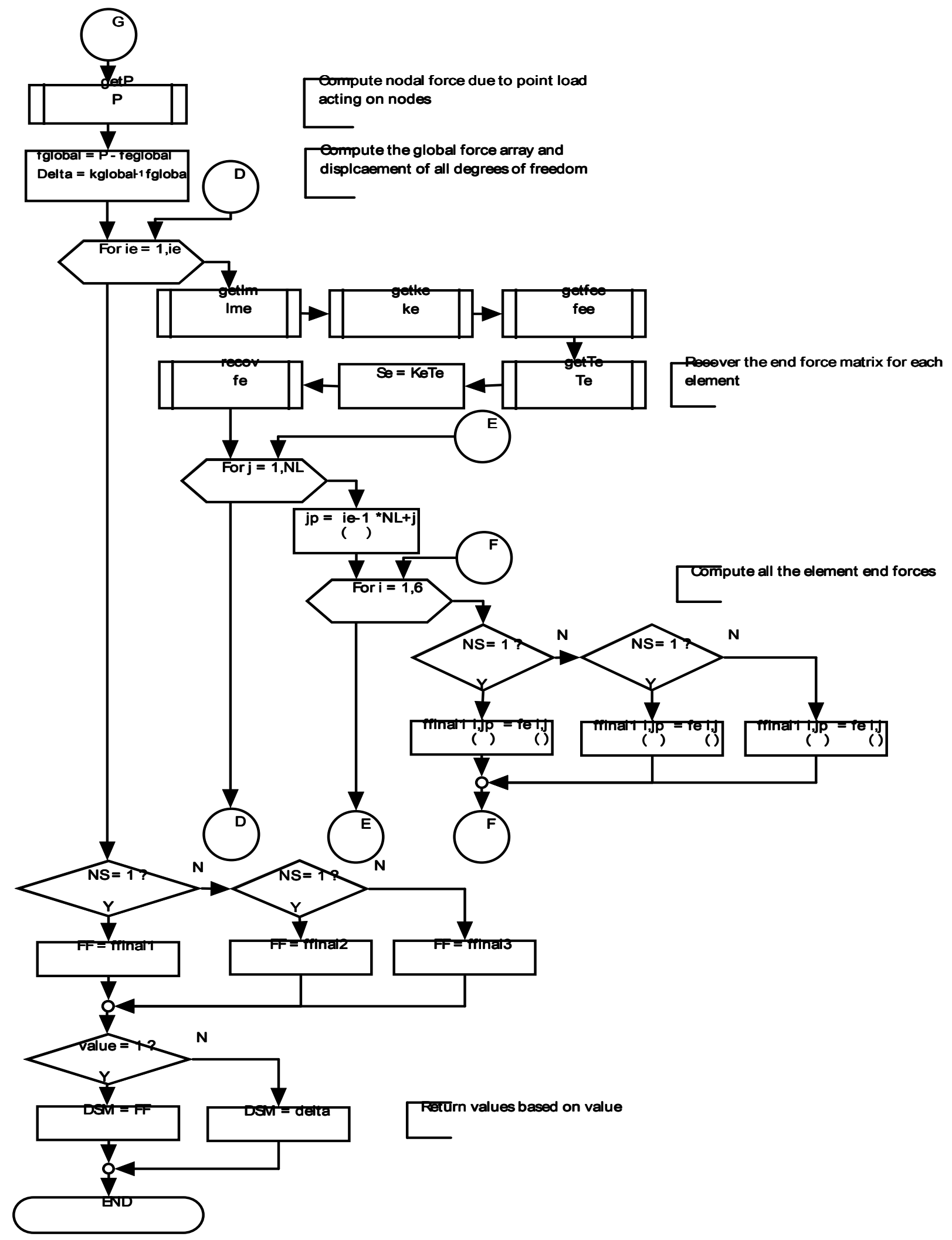

Flowchart D.28(cont) DSM 


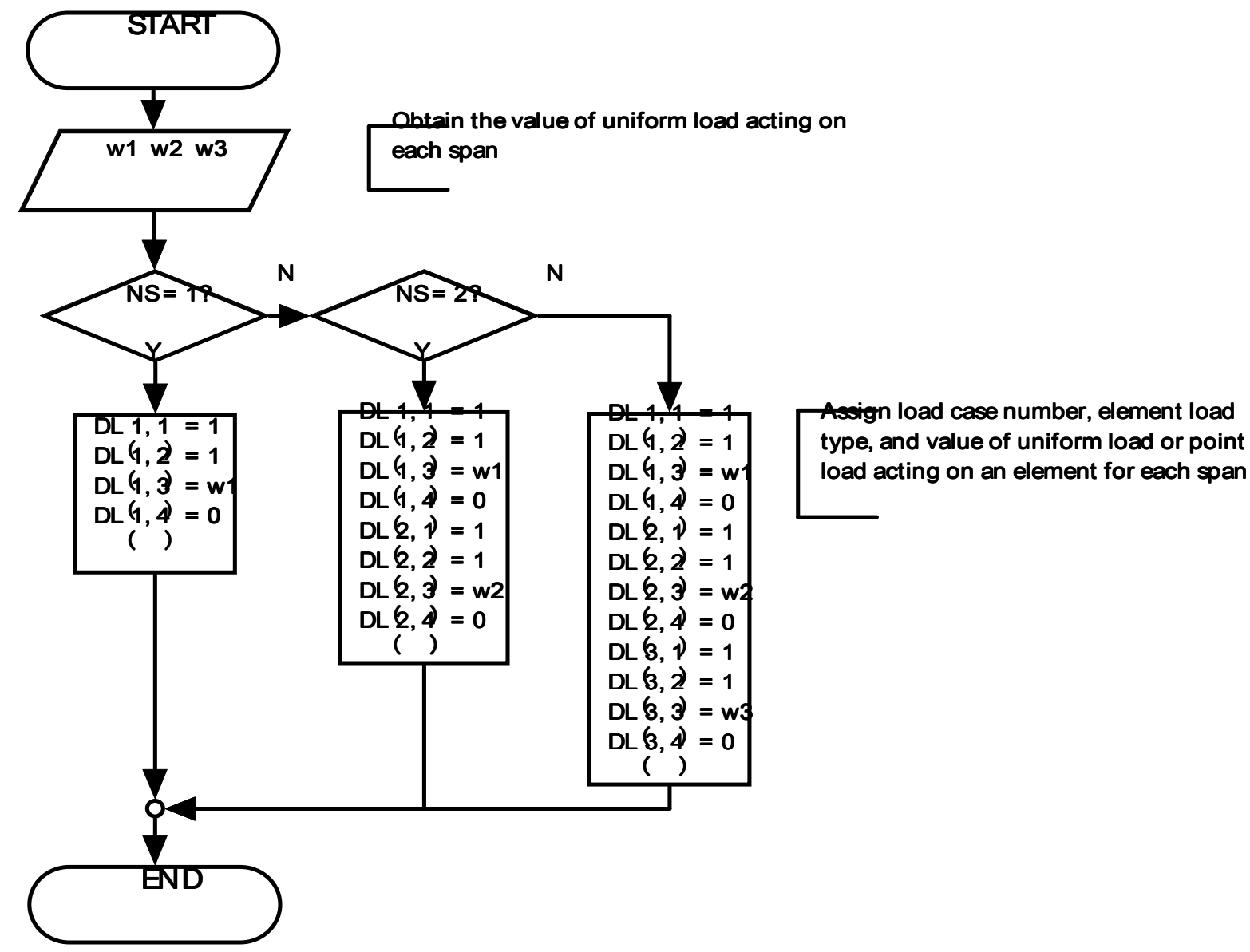

Flowchart D.29 DSM - getDL 


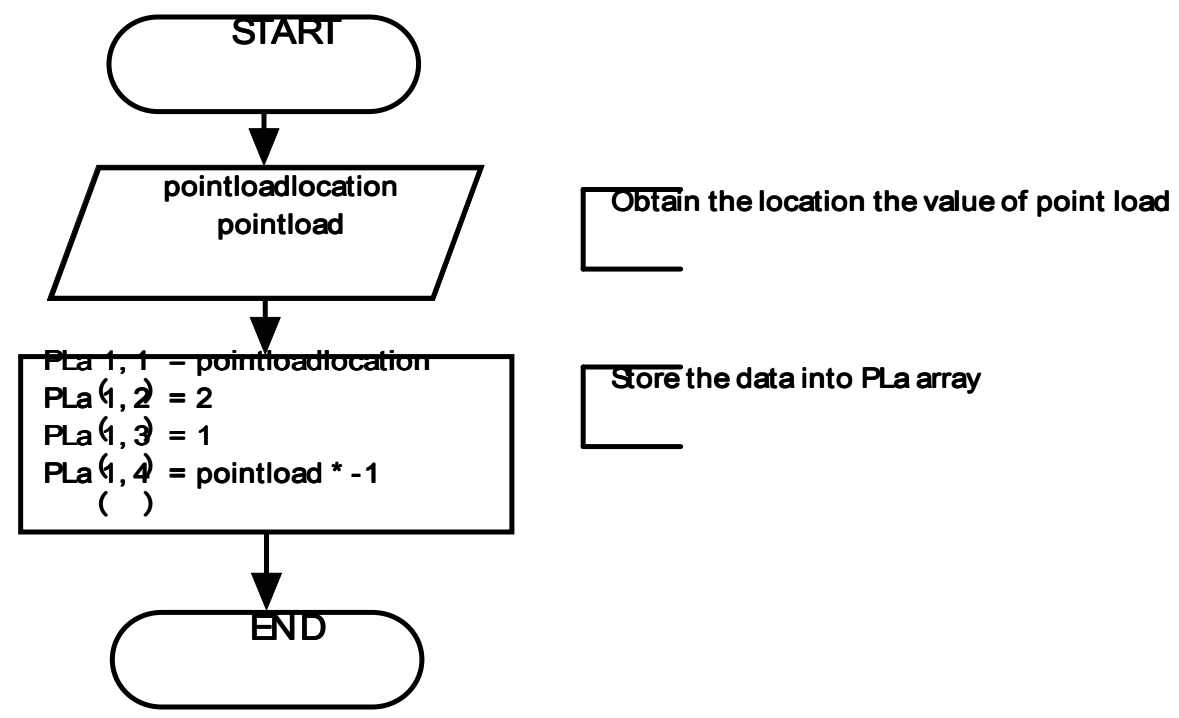

Flowchart D.30 DSM - getPLa 


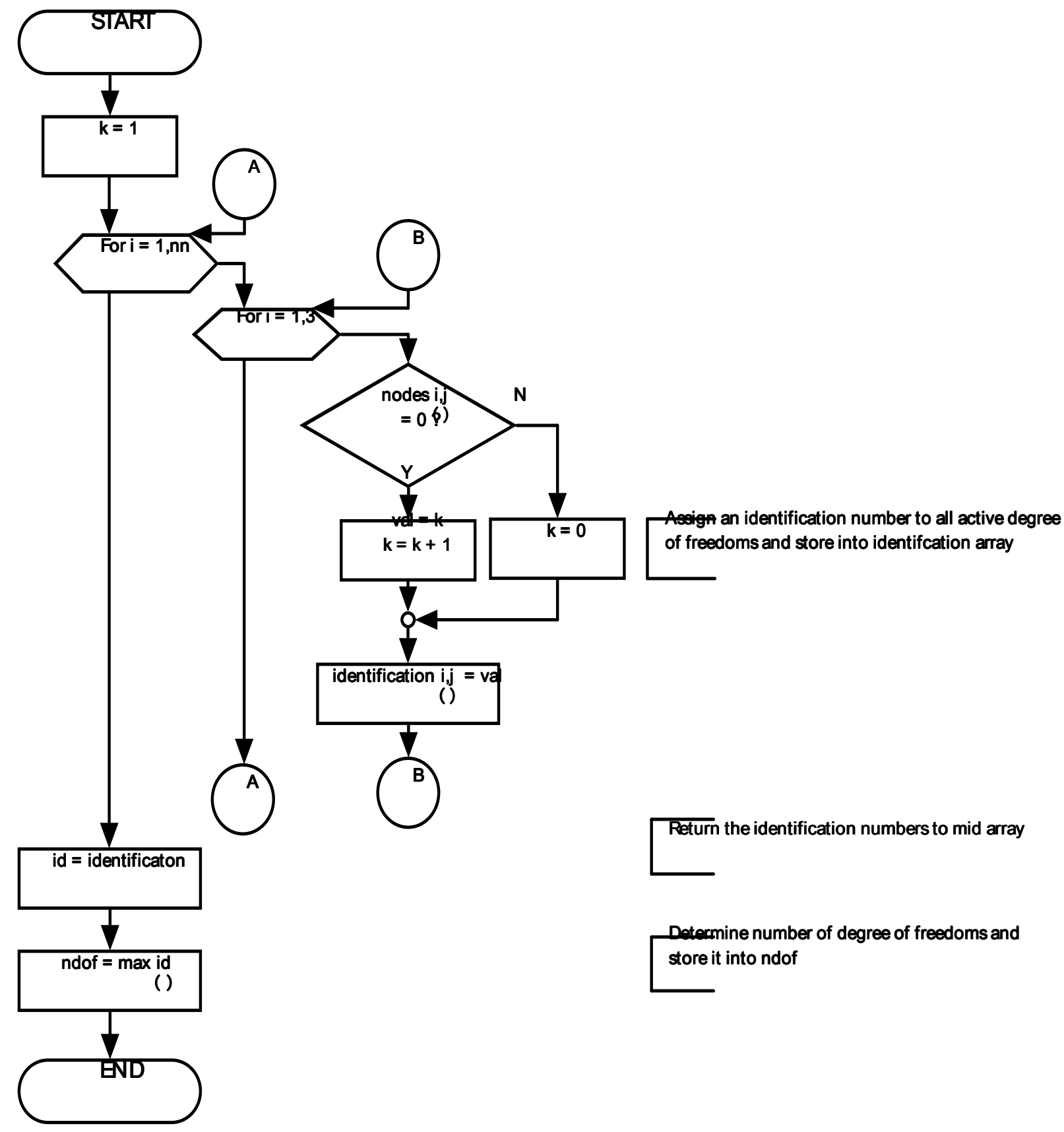

Flowchart D.31 DSM - mid 


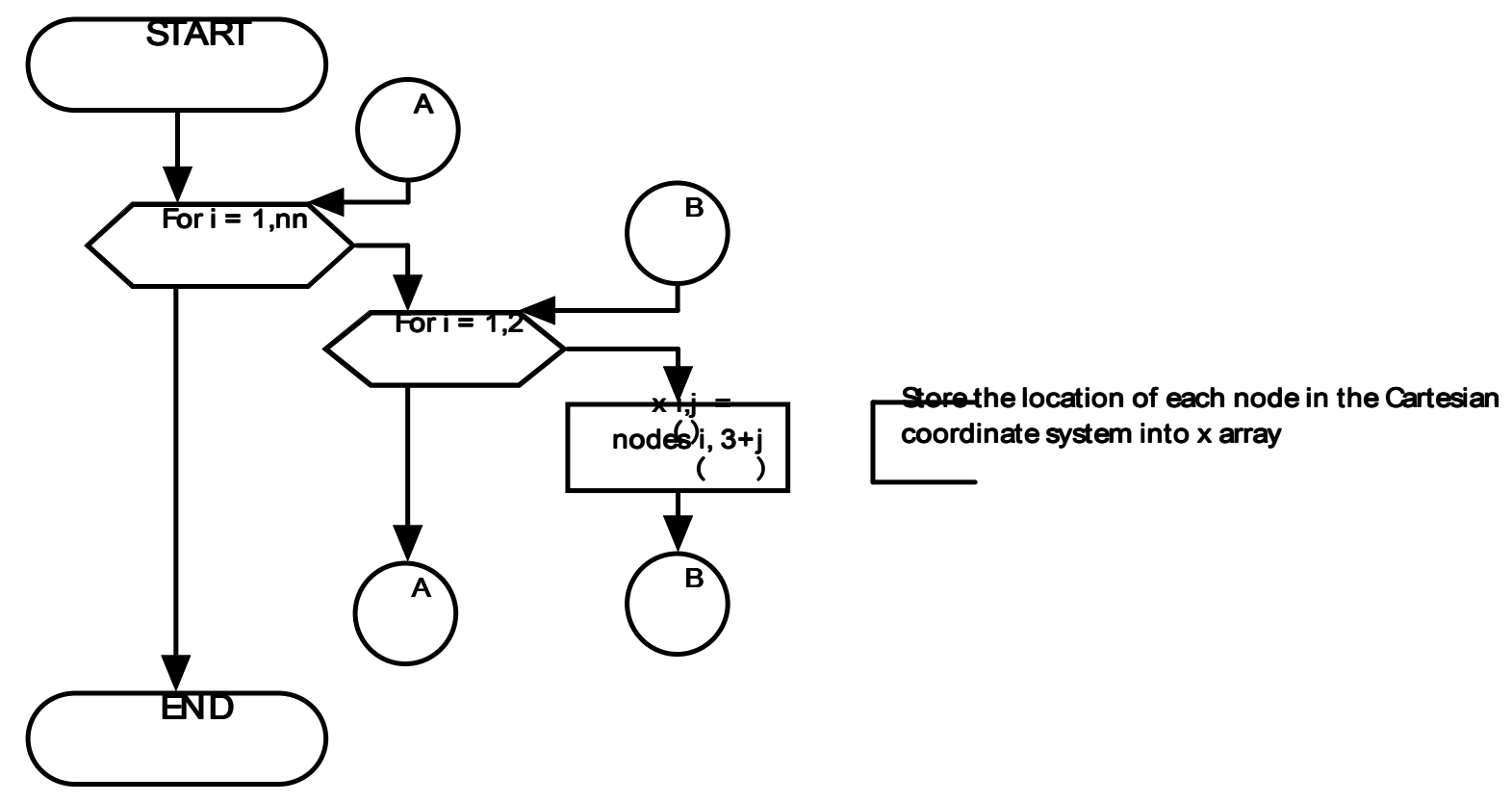

Flowchart D.32 DSM - getx 


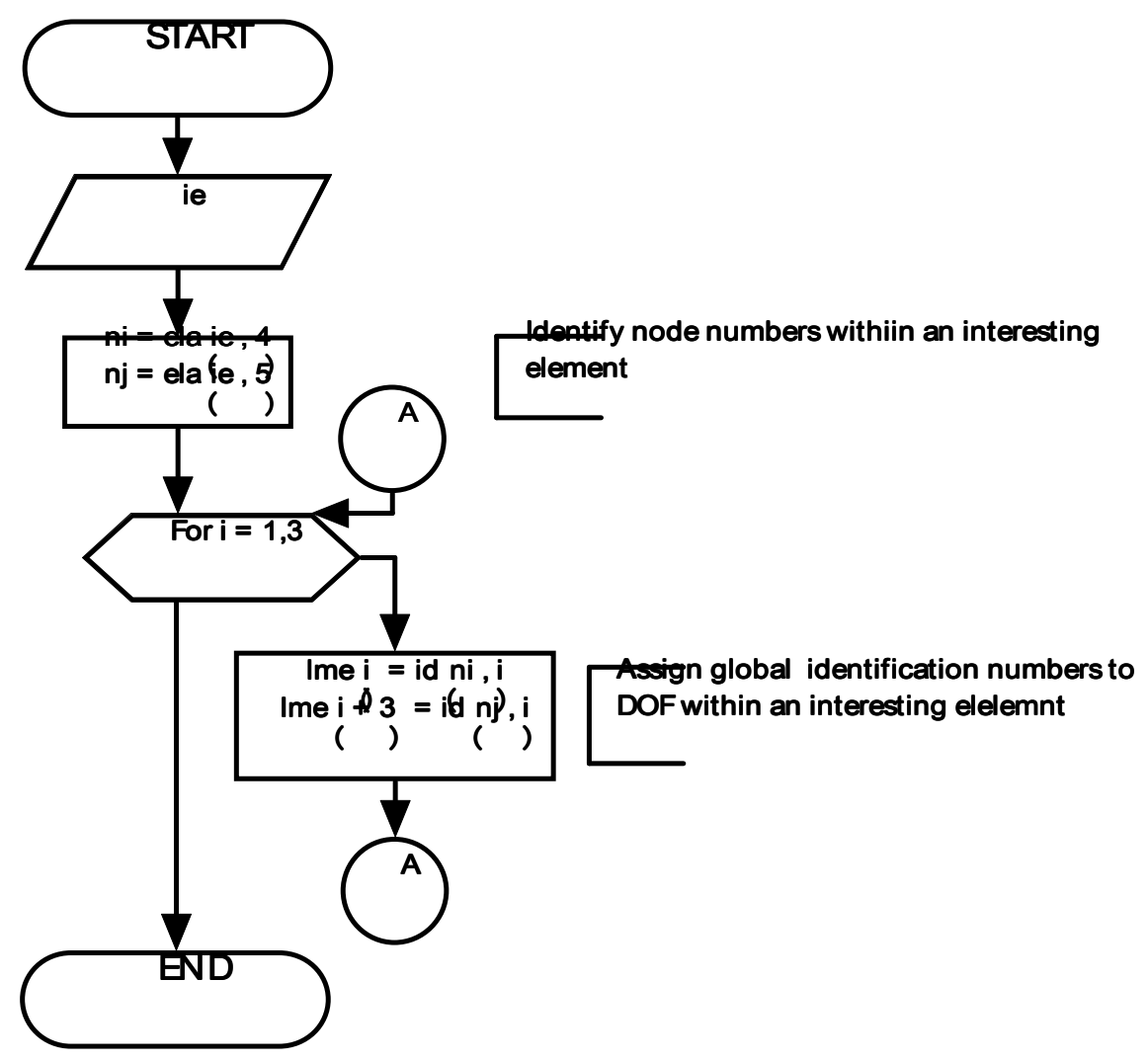

Flowchart D.33 DSM - getlm 


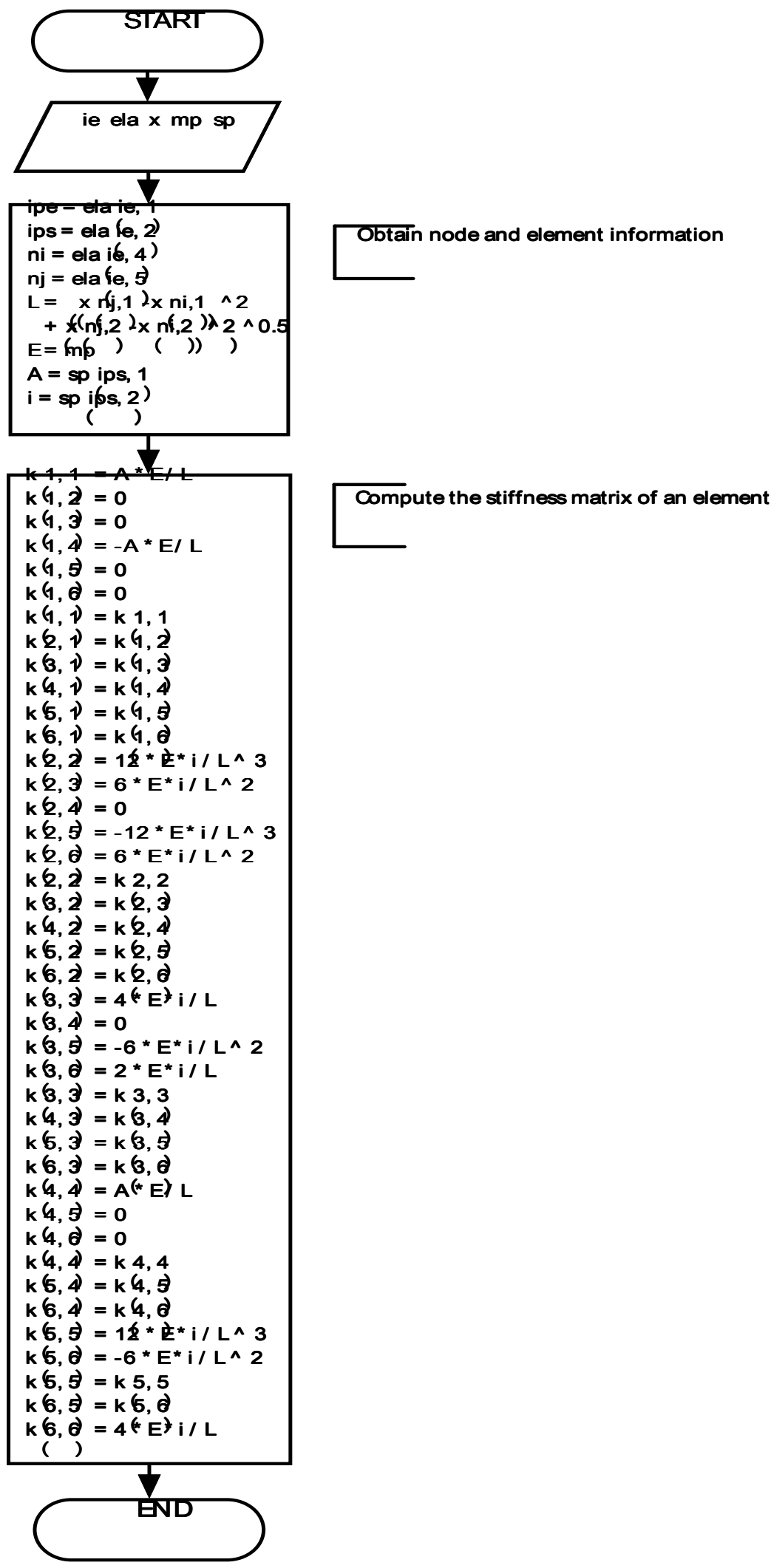

Flowchart D.34 DSM - getke 


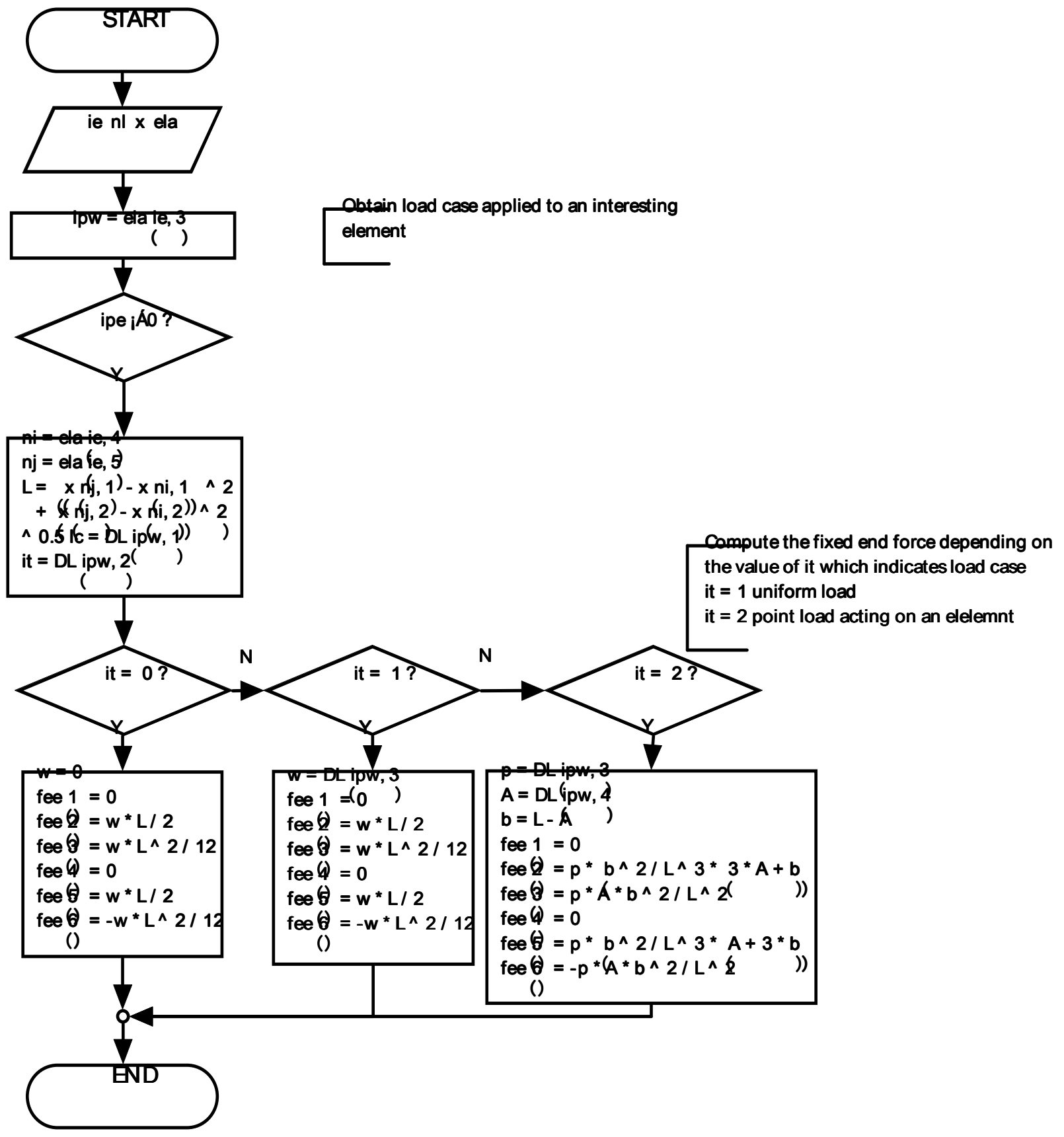

Flowchart D.35 DSM - getfee 


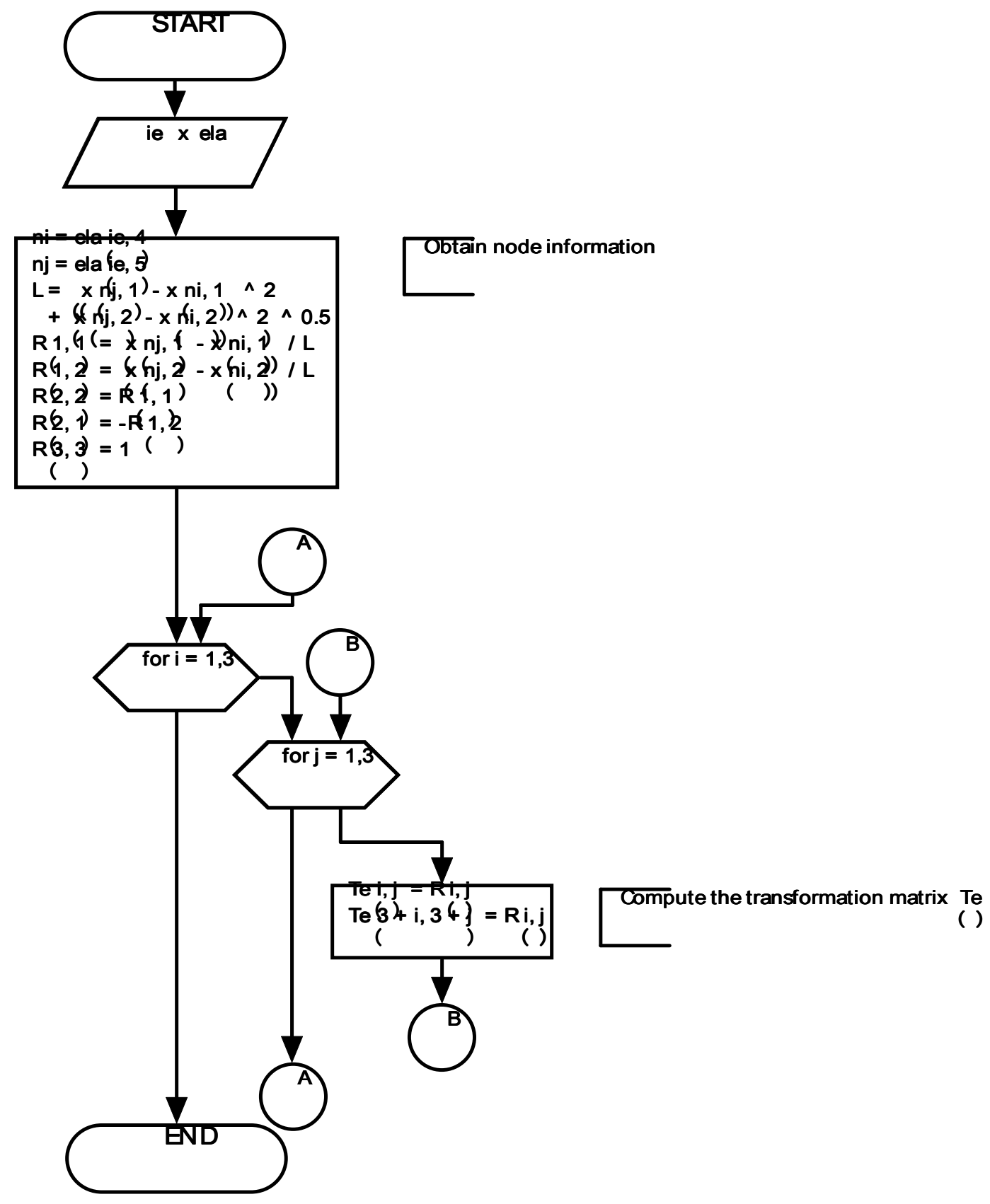

Flowchart D.36 DSM - getTe 


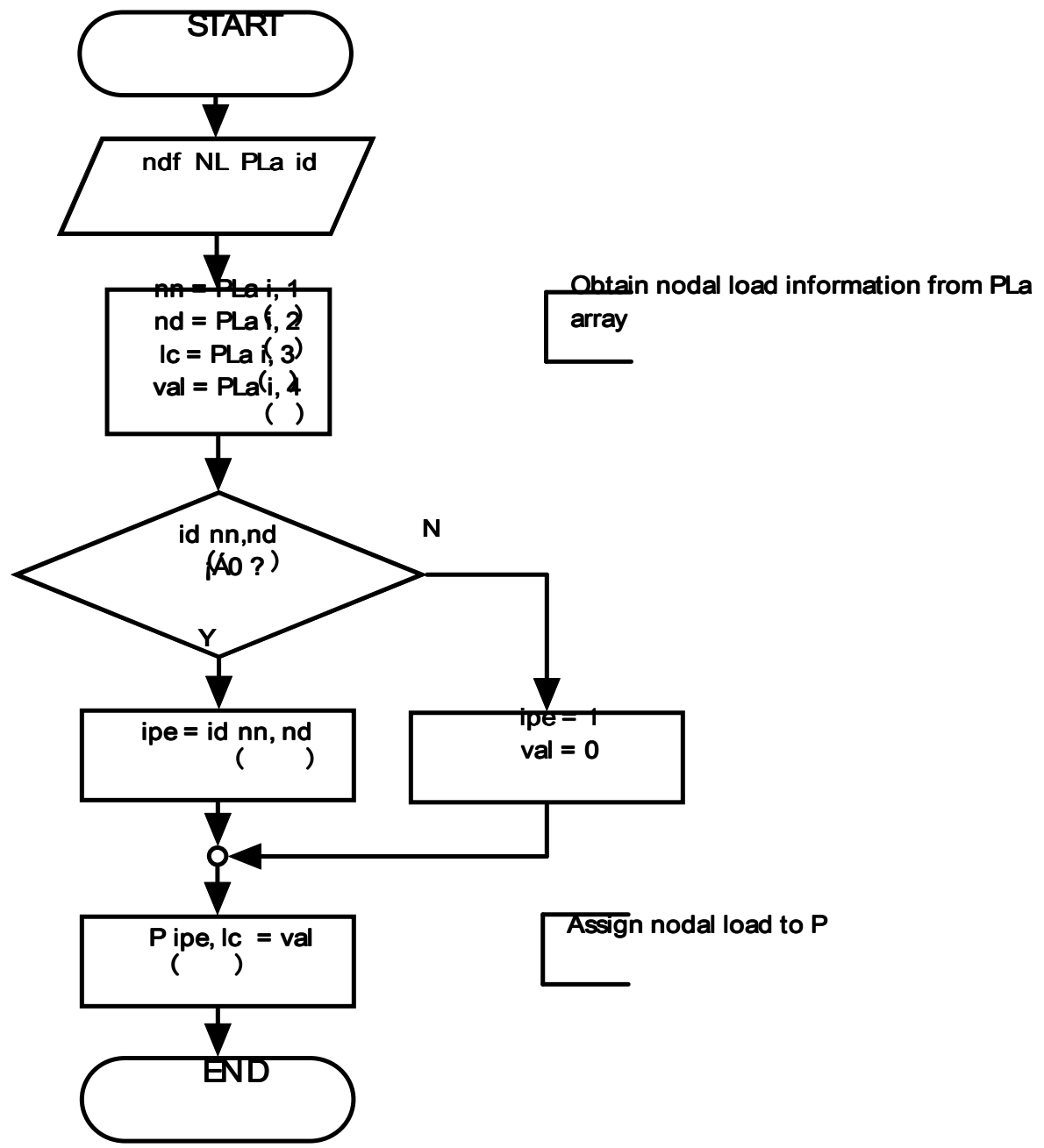

Flowchart D.37 DSM - getP 


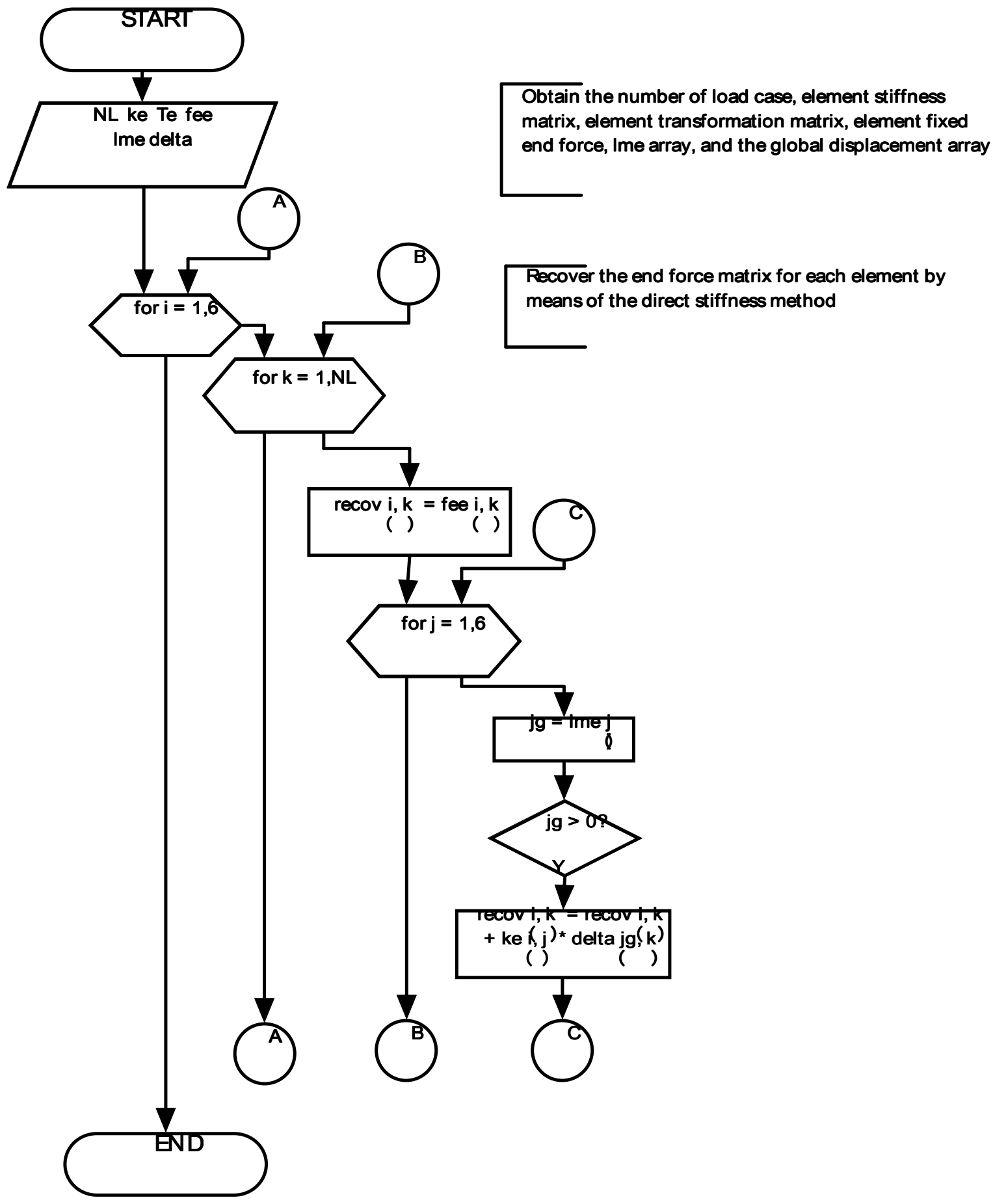

Flowchart D.38 DSM - recov 